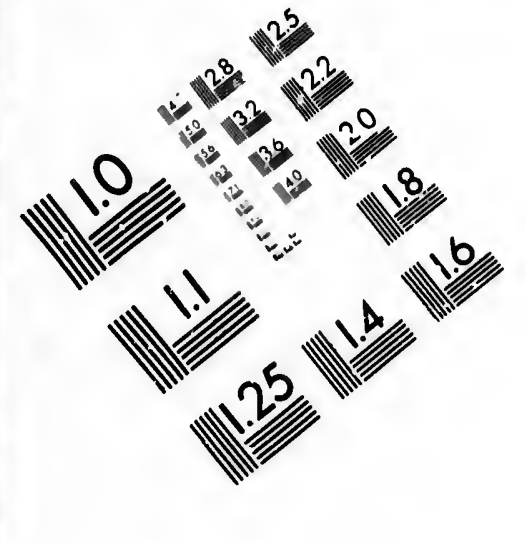

IMAGE EVALUAATION

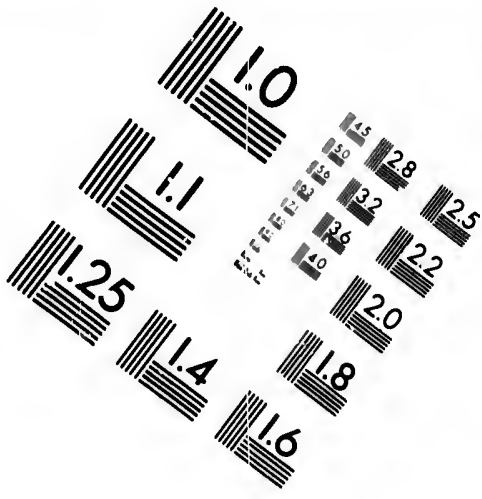

TEST TARGET (MT-3)
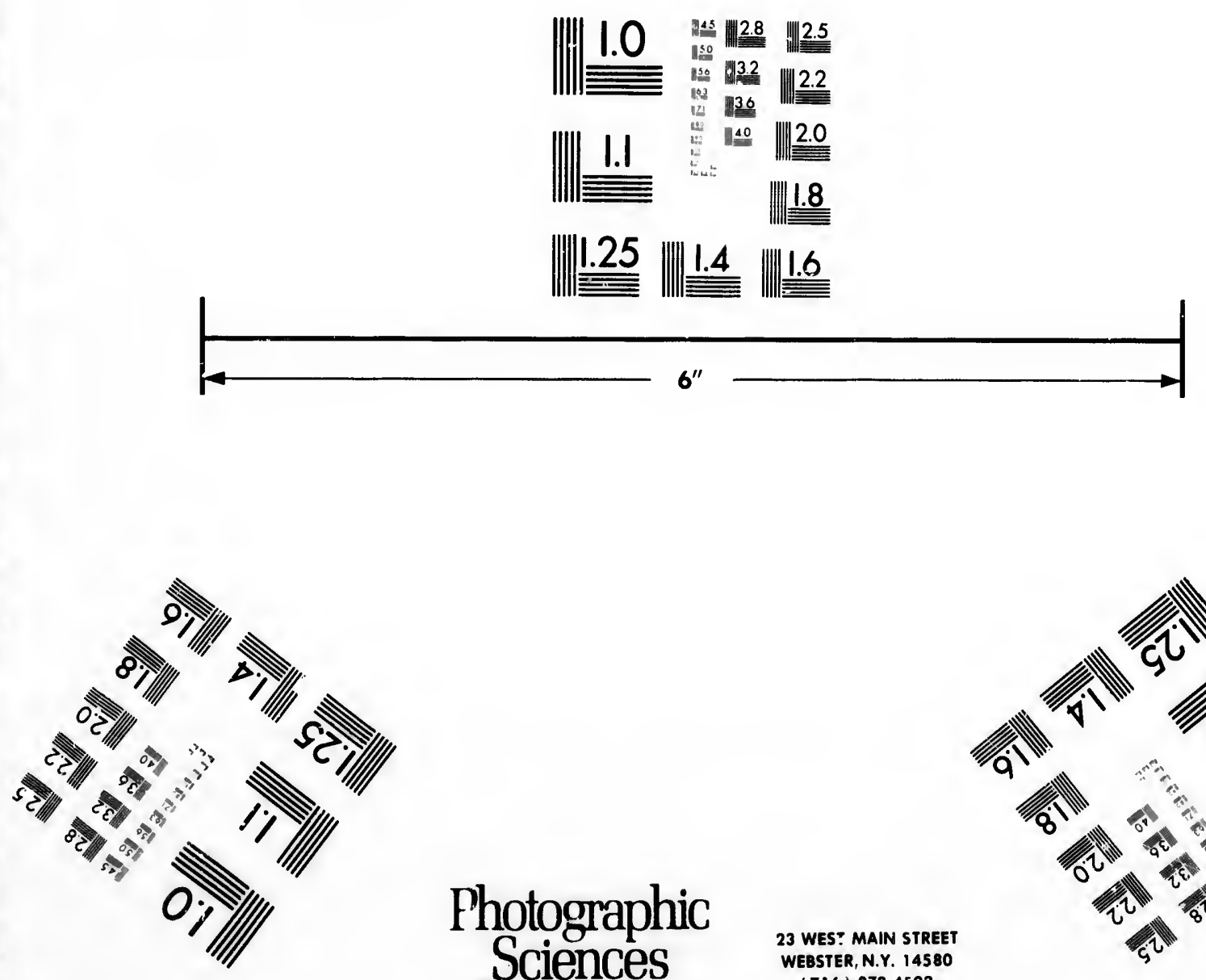

Photographic Sciences
Corporation

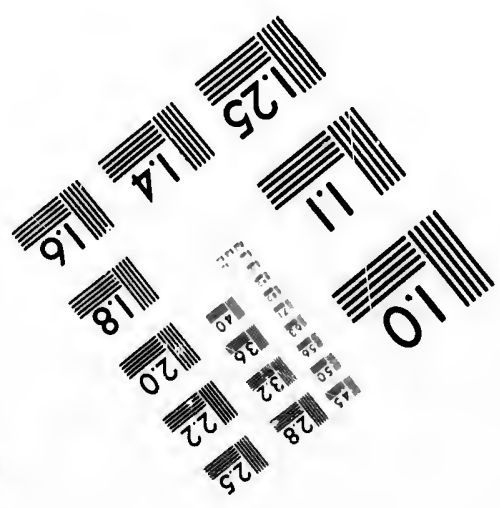




\section{CIHM/ICMH Microfiche Series.}

\section{CIHM/ICMH Collection de microfiches.}


The Institute has attempted to obtain the best original copy available for filming. Features of this copy which may be bibliographically unique. which may alter any of the images in the reproduction, or which may significantly change the usual method of filming, are checked below.

Coloured covers/

Couverture de couleur

Covers damaged/

Couverture endommagée

Covers restored and/or laminated/

Couverture restaurée et/ou pelliculée

Cover title missing/

Le titre de couverture manque

Coloured maps/

Cartes géographiques en couleur

Coloured ink (i.e. other than blue or black)/

Encre de couleur (i.e. autre que bleue ou noire)

Coloured plates and/or illustrations/

Planches et/ou illustrations en couleur

Bound with other material/

Relié avec d'autres documents

Tigh: binding may cause shadows or distortion along interior margin/

La reliure serrée peut causer de l'ombre ou de la distortion le long de la marge intérieure

Blank leaves added during restoration may appear within the text. Whenever possible, these have been omitted from filming/

II se peut que certaines pages blanches ajoutées lors d'une restauration apparaissent dans le texte, mais, lorsque cela était possible, ces pages n'ont pas été filmées.

\section{Additional comments:/}

Commentaires supplémentaires:
L'Institut a microfilmé le meilleur exemplaire qu'il lui a 6t'́ possible de se procurer. Les détails de cet exemplaire qui sont peut-être uniques du point de vue blbliographique, qui peuvent modifier une image reproduite, ou qul peuvent exiger une modification dans la méthode normale de filmage sont indiqués ci-dessous.

Coloured pages/

Pages de couleur

Pages damaged/

Pages endommagées

Pages restored and/or laminatedí

Pages restaurées et/ou pelliculées

Pages discoloured, stained or foxed/

Pages décolorées, tachetées ou piquées

Pages detached/

Pages détachées

Showthrough/

Transparence

Quality of print varies/

Qualité inégale de l'impression

Includes supplementary material/

Comprend du matériel supplémentaire

Only edition available/

Seule édition disponible

Pages wholly or partially obscured by errata slips, tissues, otc., have been refilmed to ensure the best possible image/

Les pages totalement ou partiellement obscurcies par un feuillet d'errata, une pelure. etc.. ont été filmées à nouveau de façon à obtenir la meilleure image possible. 
The copy filmed here has been reproduced thanks to the generosity of:

\section{National Library of Canada}

The images appearing here are the best quality possible considering the condition and legibility of the original copy and in keeping with the filming contract specifications.

Original copies in printed paper covers are filmed beginning with the front cover and ending on the last page with a printed or illustrated Impression, or the back cover when appropriate. All other uriginal copies are filmed beginning on the first page with a printed or illustrated impression, and ending on the lasi page with a printed or illustrated impression.

The last recorded frame on each microfiche shall contain the symbol $\rightarrow$ (meaning "CON. TINUED"), or the symbol $\nabla$ (meaning "END"), whichever applies.

Maps, plates, charts, etc., may be filmed at different reduction ratios. Those too large to be entirely included in one exposure are filmed beginning in the upper left hand corner, left to right and top to bottom, as many frames as required. The following diagrams illustrate the mothod:
L'exemplaire filmé fut reproduit grâce a la générosité de:

Bibliotheque nationale du Canada

Les images suiventes ont été reproduites avec le plus grand soin, compte tenu de la condition et de la netteté de l'exemplaire filmé, et en conformite avec les conditions du contrat de filmage.

Les exemplaires originaux dont la couverture en papier est imprimé sent filmés en commençant par le premier plat et en terminant soit par la derniere page qui comporte une empreinte d'impression ou d'illustration, soit par le second plat, selon le cas. Tous les autres exemplaires originaux sont filmés en commençant par la premiére page qui comporte une empreinte d'impression ou d'illustration et en terminant par la dernière page qui comporte une telle empreinte.

Un des symboles suivants apparaître sur la dernière image de chaque microfiche, selon le ces: le symbole $\rightarrow$ signifie "A SUIVRE", le symbole $\nabla$ signifie "FIN".

Les cartes, planches, tableaux, etc., peuvent ètre filmés à des taux de réduction différents. Lorsque le document est trop grand pour étre reproduit en un seul cliché, il est filmé à partir de l'angle supérieur gauche, de gauche à droite. et de haut en bas, en prenant le nombre d'images nécessaire. Les dia jrammes suivants illustrent la méthode.

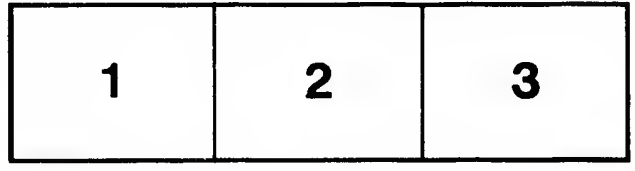

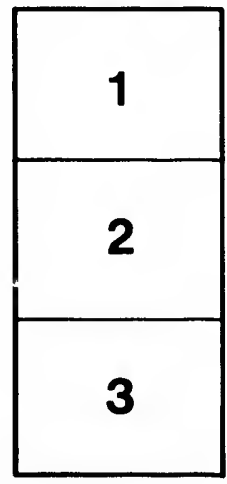

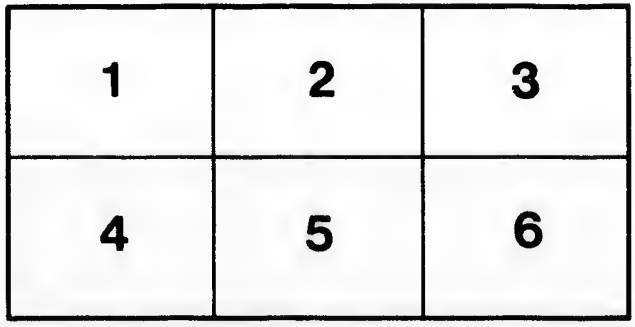




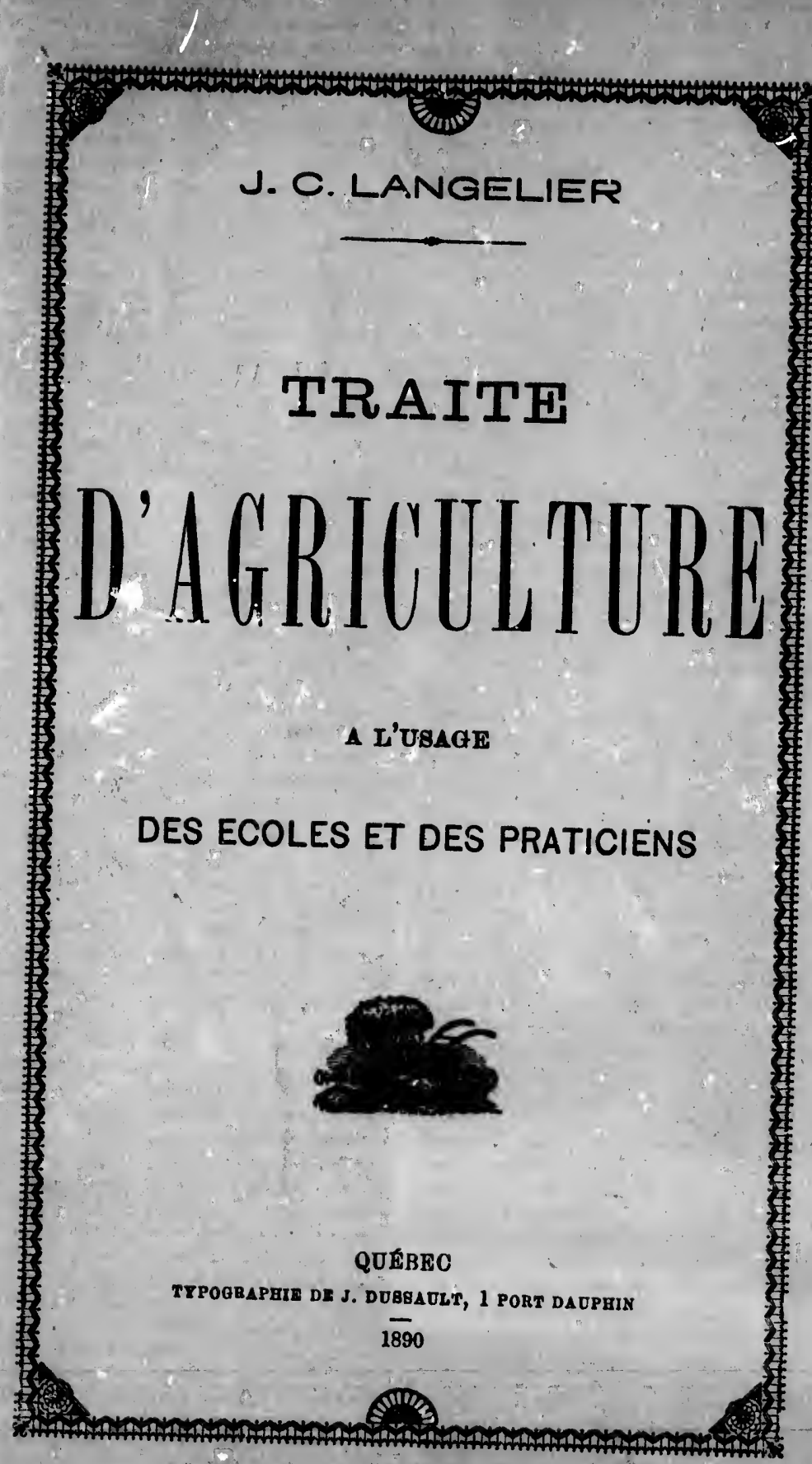




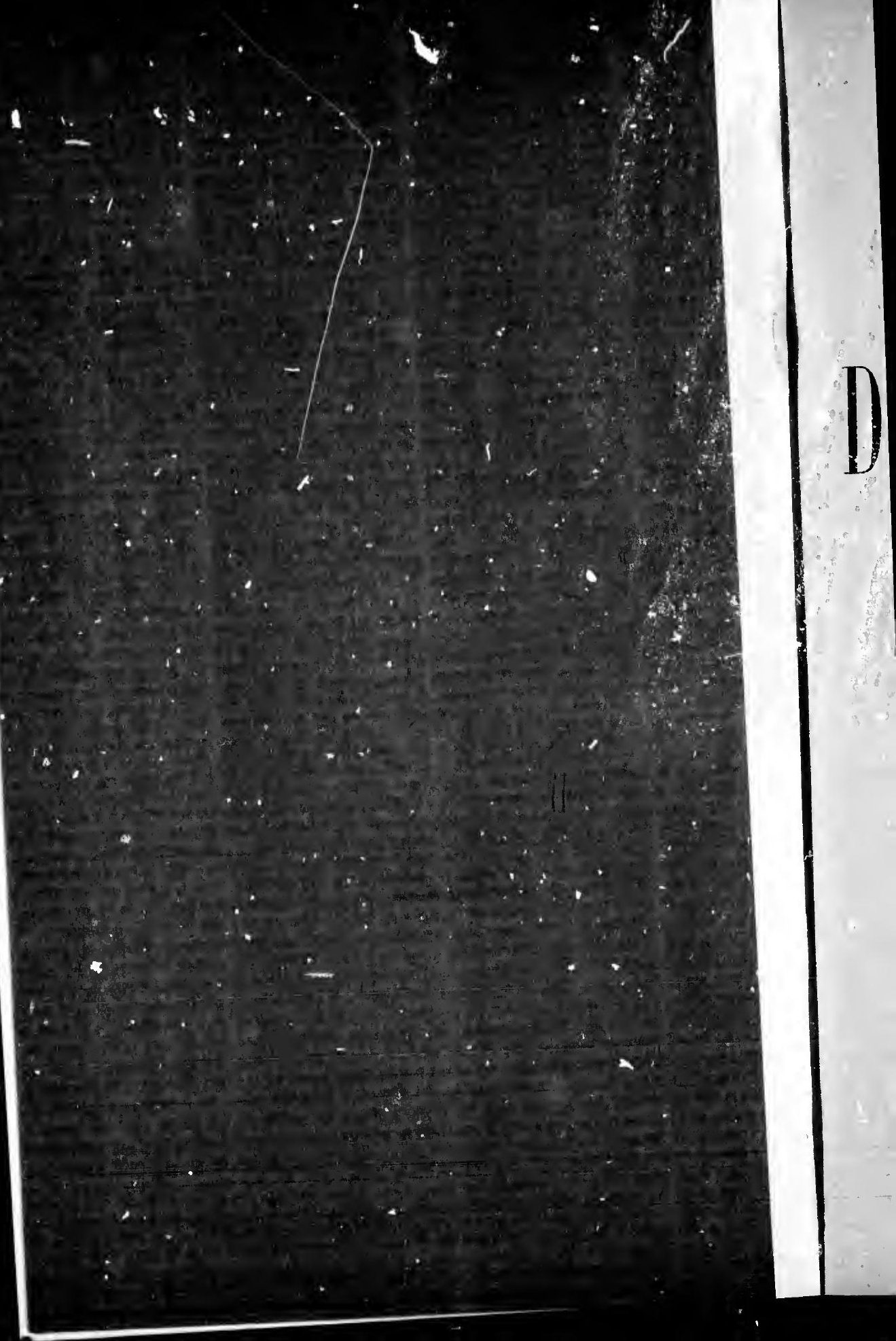




\title{
J. O. LANGELIER
}

TRAITÉ

JAGRGULTIRE

\author{
A L'USAGE
}

DES ECOLES ET DES PRATICIENS

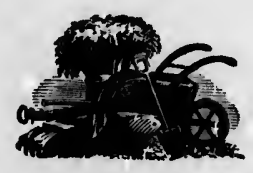

QUÉBEC

TYPOGRAPHIE DE J. DUSSAULT, 1 PORT DAUPHIN

$\overline{1890}$ 


\section{1 \\ $\angle 29$.}




\section{AVERTISSEMENT}

Les bons ouvrages sur l'agriculture-en langue française-ne manquent pas ; mais il en est perı qui soient en tous points adaptés à notre province. Le meilleur livre publié dans le pays est celui de M. Laandry, calqué en grande partie sur le Traité d'Agriculture de Girardin et Dubreuil ; malheureusement, ce livre n'est pas complet, ne dit rien du bétail et laisse de côté benucoup d'autres matières d'une utilité incontestahle. Le Traité théorique et pratique de l'Agriculture, publié en 1837, par William Evans, est plus complet et peut-être plus à la portée de la masse des cultivateurs; mais il est facile de comprendre que depuis la publication de cet ouvrage, l'art agricole a fait des progrès qu'il importe de signaler à l'attention de nos cultivateurs.

Dans le but de procurer à la classe agricole tous les renseignements les plus sûrs et les plus actuels, ]'auteur du présent livre a compilé les meilleurs ouvrages, dont il reproduit souvent le texte, sur toutes les parties de l'agriculture, en prenant bien soin de simplifier la partie 
purement scientifique, pour la mettre à la portée des cnltivateurs qui n'ont pas fait des Gtudes suffisantes pour comprendre une dissertation exclusivement scientifique.

En.fin, l'auteur a adopté la forme du questionnaire, $1^{\circ}$ parce que cela convient mieux a l'enseignement dans les écoles, $2^{\circ}$ parce que cette forme permet de répondro plus brièvement aux objections et de mieux donner l'explication ou la raison d'être d'une operation culturale. 


\section{CHAPITRE I}

\section{NOTIONS PRELIMINAIRES}

\section{Qu'est-ce que l'agriculture?}

L'agriculture est l'art de cultiver la terre.

Quel est le but de l'agriculture?

C'est de procurer, en aussi grande quantité que possible et de la manière la plus économique, le plantes et les substances alimentaires nécessaires à l'homme et aux animaux domestiques. .

Quel rang l'agriculture occupe-t-elle dans les arts?

Elle occupe le premier rang, à raison du caractère de son institulion, de son antiquité, de son utilité et de la nature de ses pratiques.

Qu'avez-vous d dire de son institution?

Elle est l'œuvre directe du Seigneur, puisque l'Ecricure Sainte nous apprend que "l'agriculture a été institué par le Très-Haut." De tous les arts, c'est le eul qui ait une origine aussi sainte et relevant aussi lirectement de la Divinite. 
Qu'avez-vous di dire de son antiquité?

L'agriculture est le plus ancien de tous les arts; elle remonte à l'origine même du monde, ainsi que nous l'apprennent ces autres paroles de l'bcriturs Sainte : "Dieu plaça l'homme dans le paradis terrestre afin qu'il le cultivat et le gardat."

\section{Qu'aves-vous d dire de son utilité?}

L'agriculture est le plus utile de tous les arts : c'est elle qui procure à l'homme la nourriture, le vetement ainsi que la plupart des matieres premières que l'industrie transforme pour notre bien-etre. Sans l'agriculture, la terre ne produirait pas assez pour suffire aux besoins du genre humain et les hommes civilisés seraient obligés de se nourrir et de se vêtir romme les Sauvages.

Qu'avez-vous d dire de la nature des pratiques de l'agriculture?

Les pratiques de l'agriculture constituent le travail le plus noble et le seul qui ait été directement imposé par Dieu a l'homme en le chassant du paradis terrestre. Puis le spectacle continuel des œuvres du Créateur, de l'action de la Providence, entretient le sentiment religieux chez le cultivateur, élève son âme vers Dieu et le porte à la pratique de la vertu, la plus précieuse de toutes les noblesses. Ayant toujours ouvert sous les yeux le grand livre de la nature où se révèlent la puissance et la bonté du C'-éateur, il trouve dans ce livre sublime des enseignements qui mettent son cœur au-dessus de tout ce qui est de nature à dérader l'humanité.

L'agriculture constitue-t-elle une carrière libre et indépen. dante?

Oui, plus que toutes les autres occupations industri- 
elles auxquelles l'homme est obligé de se livrer pour gagner sa vie. Le cultivateur est plus indépendant que l'ouvrier des villes, car il n'est pas soumis aux règles sévères des atsliers; il est plus tranquille sur l'avenir, car il n'est guère exposé à manquer du nécessaire. Si Dieu bénit ses travaux, si ses récoltes réussissent bien, il trou"e dans son travail tout ce qu'il lui faut pour vivre, en sorte qu'd proprement dire, le cultivateur ne dépend que de Dieu et de ses propres bras.

$s:$ c'est etement yue l'inis l'agriffire aux iseraient auvages. de l'agri-

travail le t imposé terrestre. ateur, de hent reli-

Dieu et cieuse de s les yeux puissance e sublime dessus de ité.

et indépen.

s industri-
L'agriculture est-elle une profession capable de procurer le bonheur?

Oui et peut-être plus que toutes les autres professions industrielles ou libérales. Outre qu'elle satisfuit avec abondance a leurs besoins, elle porte ceux qui la pratiquent a une heureuse simplicité. Elle détourne l'ennui par la variété de ses travaux; elle amorit les passions par les fatigues corporelles qui, contractées dans le travail en plein air, assurent au cultivateur la jouissance d'une santé robuste, le plus précieux de tous les biens temporels.

L'agriculture est-elle une profession en horneur?

Oui, elle l'a été dans tous les temps passés et elle l'est encore de nos jours; elle a été ainsi reconnue par les écrivains les plus célèbres et aujourd'hui encore elle compte parmi ses adeptes le plus grand nombre des nobles en Angleterre ainsi que dans les autres pays, ou la principale occupation des grands seigneurs est l'exploitation do leurs domaines.

Que faut-il pour bien réussir en agriculture?

La scionce et la pratique. 
Lx pratique seule ne suffit-elle pas pour atteindre le but de l'agriculture?

scie

des

Sans doute qu'avec la pratique, on peut faire une assez bonneculture; mais il est impossible d'atteindre le but de l'agriculture, qui est de produire le plus possible et de la manière la plus économique. Avec la pratique seule, c'est-à-dire la répetition de ce que l'on a vu faire à ses ancêtres, on peut derenir un bon manœuvrier agricole, mais jamais un véritable agriculteur.

A quoi sert la science en agriculture?

A faire connaître les causos qui influent sur les résultats de la pratique agricole, à perfectionner ses méthodes, a détruire les vices qui s'y sont introduits et a donner au cultivateur la raison de toutes ses opérations, en le faisant bénéficier de l'expérience des meilleurs praticiens. En agriculture, comme en toute autre chose, pour réussir il faut pouvoir se rendre compte de ce que l'on fait, et ce serait concevoir une bien frusse idée de l'art agricole que de vouloir le limiter à un certain nombre de pratiques irréfléchies, fruit de la routine et transmis ss de père en fils sans discernement.

La science, ou la théorie seule, suffirait-elle à faire un bon agriculteur?

Non, car on ne fait généralement bien que les choses que l'on a pratiquées. D'ailleurs, on acquiert dans la pratique un esprit de prudence qui ne supplée pas à la science, mais qui corrige ce que la science pourrait avoir de trop absolu.

$Y$ a-t-il opposition entre la pratique et la science?

Non, puisque la pratique n'est que l'application de la 
ire une indre le oossible atique vu faire euvrier

os résulméthoits et à irations, ceiileurs e chose, e ce que idée de certain utine et

re un bon

is choses dans la pas à la ait avoir tion de la

science, comme la science n'est que la mise en systems des choses observées dans la pratique.

Quel est le plus grand ennemi de l'amélioration de la pratique agricole?

C'est la routine, qui ne porte à faire que ce que l'on a vu faire, sans même songer à faire mieux; qui repousse aveuglement tous les changements utiles ot oppose à la science les préjugés les plus opiniâtres.

Qu'est l'agriculture your un homme sans aucune science de cet art?

Pour un homme sans aucune science de cet art, l'agriculture n'est qu'un métier pénible et peu lucratif; pour le cultivateur instruit et expérimenté, c'est le premier des arts, un des plus agréables et des plus avantageux. 



\section{CHAPITRE II}

NOTIONS GÉNÉRALES SUR LA VÉGÉTATION

Les plantes sont-elles des êtres vivants?

Sans avoir la sensibilité et la faculté de se déplacer, comme les animaux, les plantes sont des etres vivants qui naissent, croissent, se nourrissent et se reproduisent au moyen des substances qu'elles puisent dans la terre et dans l'air ou l'atmosphère.

Qu'appelez-vous végétation?

On appelle végetation l'ensemble des fonctions qui constituent la vie des plantes.

Comment les plantes exercent-elles ces fonctions viiales qui constituent la végétation?

Au moyen de 'eurs organes, qui sont la racine, la tige, les feuilles et les fleurs.

Qu'appelez-vous racine d'une plante?

La racine est la partie de la plante qui s'enfonce dans le sol.

A quoi sert la racine?

A fixer la plante et à tirer du sol la plus grande partie de sa nourriture. 


\section{Qu'appelez-vous tige?}

La jige est la partie de la plante qui croît en sens contraire de la racine, généralement dans la direction verticale, au-dessus du sol.

\section{A quoi sert la tige?}

A supporter les feuilles et les fruits, mais surtout à conduire de la racine aux feuilles et des feuilles à la racine les sucs et les autres substances nutritives puisées dans le sol et dans l'air.

Qu'appelez-vous feuilles et à quoi servent-elles?

Les feuilles sont des organes attachés à la tige ou a ses rameaux et qui servent à puiser dans l'air une partie de la nourriture de la plante.

$A$ quoi servent les fleurs?

A renfermer et à préparer les graines destinées à reproduire la plante.

De quoi se composent les plantes?

Les plantes se composent de certaines substances solides et gazeuses qui se trouvent dans la terre et dans l'air.

Quelles sont les principales de ces substances?

Ce sont la silice, le soufre, le phosphore, le chlore, la potasse, la soude, la chaux, la magnésie, l'alumine, les oxydes de fer et de manganèse, le carbone, l'azote, l'oxygène, l'hydrogène et l'eau.

Comment les plantes s'assimilent-elles ces différentes substances?

Par l'intermédiaire des quatre principaux agents de la végétation, qui sont l'air, l'eau, la chaleur et la lumière. 
De quoi se compose l'air?

L'air se compose d'oxygène, d'azote, d'acide carbonique et de vapeur d'eau.

\section{L'air renferme-t-il autre chose?}

Oui, il est le réceptacle de tous les gaz ainsi que de tous les corps solides assez légers pour flotter dans l'atmosphère et, en sus des gaz, on y trouve presque toutes les substances qui entrent dans la composition des plantes, notamment les sels de coude, de potasse, de magnésie, des composés azotés et plusieurs autres.

Comment l'air concourt-il à la végétation?

En fournissant aux plantes, pour leur croissance et leur nutrition, leis gaz et les autres substances qu'il renferms.

Comment la plante s'empare-t-elle des gaz et autres substances contenues dans l'air?

Au moyen de l'absorption opérée par les feuilles et les racines, qui sucent pour ainsi dire ces matières pour les introùuire dans la plante.

Comment augmente-t-on l'absorption opéréc par la racine?

En ameublissant la terre pour la rendre plus pénétrable par l'air, ce qui est une des principales raisons de la friabilité qu'on donne au sol en le labourant et le hersant.

L'oxygène et l'azote concourent-ils a la formation des plantes?

L'oxygène se trouve dans la composition de presque toutes les plantes-arbres, herbes et céréales. L'azote entre aussi dans la composition de certaines parties les 
plus importantes des plantes. C'est lui qui communique aux graines du blé, du seigle, des pois, de l'orge, de l'avoine, etc., les propriétés nutritives qui importent le plus à la nourriture de l'homme et des animaux.

Le carbone entre-t-il aussi dans la composition des plantes?

Oui, il forme à lui seul la plus grande partie du volume des plantes, qui le puisent dans l'air et dans le sol.

\section{Qu'est-ce que l'eau?}

L'eau est un composé de deux gaz-l'hydrogène et l'oxygène-qui entrent dans la composition de toutes les plantes.

L'eau remplit-elle un rôle important dans la végétation?

L'eau est un agent indispensable à la nutrition des plantes, qui ne peuvent pas vivre sans elle. Les diverses substances qui entrent dans leur composition ne peuvent être absorbées par les feuilles et les racines qu'en autant qu'elles sont dissoutes ou rendues liquides. C'est l'eau qui opère cette dissolution, de la même manière qu'elle dissout le sucre et le sel.

L'eau remplit-elle un autre rôle dans la végétation?

Oui, elle fournit aussi aux plantes les divers composés qui se trouvent dans l'atmosphère.

Quelle est l'eau qui remplit la plus grande partie de ces deux rôles?

C'est l'eau des pluies. Durant son séjour dans l'air et sa descente vers la terre, cette eau dissour une partie des gaz et autres matières contenues dans l'atmosphère, telles que l'oxygène, l'azote, l'acide carbonique, les sels 
munirge, de tent lo

lantes? tio du lans le

yène et toutes

ution?

on des iverses e peuqu'en 3. C'est aanière

?

compo-

e de ces

l'air et partie sphère, les sels

d'ammoniaque ou autres et les entraîne avec e:le. En arrivart à la terre, elle filtre à travers le sol et dissout encore les diverses substances qu'il renferme, telles que la potasse, la soude, la silice, la chaux ainsi que plusieurs autres et arrive chargée de toutes ces matières alimentaires à la racine, qui les absorbe. De la racine, l'eau monte avec toutes ces matières, par la force ascensionnelle de la sève, dans toutes les parties de la plante, à chacune desquelles elle cède les substances dont cette partie a besoin, puis finit par se décom poser pour céder son hydrogène et son oxygène, qui entrent pour une grande partie dans la composition des tissus, des feuilles et des graines des plantes.

Quel rôle remplit l'eau dans la germination?

Elle amollit les enveloppes de la graine semée, fait gonfler l'embryon et le nourrit des substances qu'elle renferme elle-même ou de celles qu'elle dissout dans les autres eléments nutritifs.

\section{Comment peut-on stimuler l'action de l'eau dans la végé- tation?}

En ameublissant la terre et la rendant plus friable, afin de permettre à l'eau de la pénétrer plus facilement, pour dissoudre les substances nutritives contenues dans le sol et pour atteindre plus aisément la racine.

Lc chaleur est-elle nécessnire à la végétation ?

La chaleur est absolument nécessaire à la végétation et c'est pourquoi celle-ci cesse quand arrivent les froids de l'automne et de l'hiver puis se réveille avec les chaudes journées du printemps.

Comment agit la chaleur dans la végétation?

Elle détermine la germination en stimulant le prin- 
cipe vital de la semence ou de l'embryon. Durant la période de croissance, elle stimule le mouvoment de la sève et de l'eau de végétation, qu'elle attire en desséchant les pores de la tige. Dans la fructification, elle opère une espèce de décoction des sucs précédemment accumules et qu'elle transforme en fruits.

Comment peut-on favoriser l'action de la chaleur dans la végétation?

En ameublissant la terre, pour permettre à la chaleur de la pénétrer mieux pour déterminer la germination, et ensuite pour rendre plus volatils et plus assimilables les gaz renfermés dans le sol et qui contribuent à la nutrition de la plante.

La lumière est-elle nécessaire à la végétation?

Oui, autant que l'air et la chaleur.

La lumière est-elle toujours également nécessaire à la végétation?

Non: la plante peut s'en dispenser à sa naissance; mais durant la période de croissance et de fructification la lumière lui est indispensable.

Qu'arrive-t-il lorsque les plantes manquent de lumière parce qu'elles ne sont pas suffisamment espacées?

Willes poussent en fuseau, ne forment souvent que des tiges grêles et faibles, se répandent en feuilles et ne donnent pas ou presque pas de fruit.

Les plantes cultivées dans un lieu obscur nous donnentelles une preuve du besoin qu'elles ont de la lumière?

Oui : celles qui croissent dans un lieu obscur n'ont 
rant la $\mathrm{t}$ de la dessén, elle mment

dans la

chaleur nation, ailables nt à la

la végé.

issance ; ification

lumiere que des ne don-

donnent? ar n'ont pas de vigueur, sont pales et jaunes et, pour se procurer la lumière dont elles ont besoin, se dirigent invariablement vers l'endroit ou elles peuvent trouver quelques rayons du jour. C'est le manque de lumière qui fait que les récoltes trop épaisses jaunissent en dessous.

Comment la lumière agit-elle sur les plantes?

En opérant la décomposition de l'scide carbonique qui se trouve dans l'air et renfermant le carbone, qui forme la plus grande partie des plantes. Sous l'influence de la lumière du soleil, les feuilles et les parties vertes des plantes s'emparent du carbone contenu dans l'acide carbonique et rejettent l'oxygène, l'autre gaz composant l'acide carbonique.

Comment peut-on faciliter l'action de la lumiere sur la végétation?

En laissant assez d'espace entre les plantes pour leur permettre de jouir en tous sens de la lumière du jour et en arrachant une partie de celles qui ont été semées trop dru.

Que faut-il pour que la végétation soit vigoureuse et produise les meilleurs résultats?

Il faut que la plante ait.assez d'eau et de chaleur, beaucoup d'air et de lumière.

Faut-il autre chose?

Oui, il fuut procurer au sol les gaz et les autres subsstances nutritives que ces quatre principaux agents de la végétation transforment pour permettre à la plante de s'en nourrir.

Conment cela se fait-il?

En donnant à la terre les engrais et ies façons néces. 2 
saires pour la rendre riche en principes nutritifs et assez friable pour se laisser pénétrer par l'eau, l'air et la chaleur, ce qui est toute la théorie de la bonne culture du sol et ce que Dieu demande à l'agriculteur pour récompenser amplemont son travail.

DU

Q

C

Q

C'

vége

$C$

E

Q

0

qui

$Q$

O

imn

$D$

Lt

tière

$D$

la co

$\mathrm{E}$ 


\section{CHAPITRE III}

DU SOL ET DES DIFFÉRENTES ESPÈCES DE TERRE

Quel est l'objet des principales opérations de l'agriculture? C'est lesol.

Qu'appelez-vous sol, en agriculture?

C'est la terre considérée dans ses rapports avec la végetation.

Comment se divise le sol?

En sol arable et en sous-sol.

Qu'appelez-vous sol arable?

On appelle sol arable la couche terrestre superficielle qui est propre a la culture des plantes.

Qu'appelez-vous sous.sol?

On appelle sous-sol la couche terrestre qui se trouve immédiatement au-dessous du sol arable.

De quoi se compose le sol?

Le sol se compose de substances mirérales et de matières organiques.

D'où proviennent les substances minérales qui entrent dans la composition $d u$ sol?

Elles proviennent de la décomposition des roches 
désagrégées et réduites en poussière par l'action de l'air et de l'eau.

Quelles sont les principales substances minérales qui entren.t dans la composition du sol?

Ce sont la silice, l'alumine et la chaux, ou, en d'autres termes, le sable, la glaise et le calcaire ou pierre d chaux.

D'ou proviennent les matieres organiques qui entrent dans la composition $d u$ sol?

Elles proviennent des débris de plantes et d'animuux qui se décomposent à la surface du sol et forment cette terre noiratre qu'on appelle terreau ou humus.

Quelles sont les principales de ces matières organiques qui entrent dans la composition du sol?

Ce sont l'humus, l'azote et l'acide carbonique.

Est-ce qu'une des substances minérales qui entrent dans la composition du sol pourrait constituer à elle seule une terre propre à la culture?

Non, aucune de ces substances minérales ne pourrait constituer à elle seule une terre propre à la culture; il faut pour cela que le sable, la glaise ou argile, le calcaire et l'humus soient mélangés dans certaines proportions.

D'ou la terre arable tire-t-elle les différents noms sous lesquels on la désigne généralement?

De la prédominance de l'un des quatre principaux éléments qui la composent, c'est-à-dire de la prédominance du sable, de l'argile, du calcaire ou de l'humus, qui donnent respectivement les terres sablonneuses, les terres argileuses, les terres calcaires et les terres humifères. 
Qu'appelez-vous terres sablonneuses et quelles sont leurs propriétés?

On appelle terres sablonneuses ou siliceuses celles qui sont principalement composees de sable ou de silice. Ce sont des sols légers, secs, perméables, c'est-d-dire se laissant traverser par l'enu et s'échauffant facilement sous les rayons du soleil, ce qui fait qu'on les classe parmi les terres chaudes.

Qu'appelez-vous terres argileuses ou glaiseuses et quelles sont leurs propriétés?

On appelle terres argileuses ou glaiseuses celles qui sont principalement composées d'argile ou de glaise. Ces sols sont très compactes, durcissent et se crevassent quand ils sèchent, retiennent 'eau et s'échauffent lentement sous les rayons du soleil, ce qui en fait des terres froides. Elles sont plus difficiles à travailler que les terres sablonneuses, mais elles sont aussi plus productives, quand elles sont débarrassées de leur excès d'humidité.

pourrait Iture; il calcaire portions. sous les-

ncipaux rédomi'humus, uses, les es humi-

Qu'appelez-vous terres calcaires et quelles sont leurs propriétés?

Cn appelle terres calcaires celles qui sont principalement composées de calcaire ou pierre à chaux. Ces terres sont ordinairement blanches, durcissent et se travaillent difficilement par la chaleur, retiennent peu l'eau et décomposent rapidement les engrais, ce qui les fait classer parmi les terres chaudes.

Qu'appelez-vous terres humifères et quelles sont leurs pro. priétes?

On appelle terres humifères ou humeuses celles qui sont principalement composées d'humus. Ce sont des 
terres légères, poreuses, qui absorbent beaucoun d'eau, se soulevent fortement à la gelée et ne contiennent pas assez de substances minérales pour donner la rigidité voulue au chaume des plantes cultivées.

Quiappelez-vous terres franckes et quelles sont leurs qua-
lités?

On appelle terres franches celles qui, renfermant dans de justes proportions toutes les matières qui dominent reapectivement dans les autres terres, ne sont ni trop consistantes ni trop friables et se laissent facilement pénétrcr par l'eau, l'air et la chaleur. Ces terres réunissent les meilleures conditions pour la culture : elles sont riches en humus, se travaillent facilement et ne consomment pas trop promptement les engrais.

Quelle est la composition de la terre franche?

Dans les meilleures conditions pour bien produire, sur cent parties la terre franche doit contenir quarantecing de sable, quarante-cinq d'argile ou glaise, unt a dix de chaux et trois à cinq d'humus ou terreau.

Le sous-sol a-t-il toujours la même composition que le sol?

Non, le sous-sol n'a pas toujours la même composition que le sol. Ainsi, il arrive souvent qu'un sol argileux a pour sous-sol du sable, de l'humus ou du calcaire, ou qu'un sol sablonneux a pour sous-sol de la terre forte, de même que les sols humifères ont presque toujours pour sous sol de la glaise ou du sable.

Est.il important de bien connaître la composition du soussol?

Oui, parce que dans la plupart des cas la valeur du terrain depend de la qualité du sous-sol. Des terres de 
1n d'eau, nent pas rigidité

eurs qua-

lant dans lominent $t$ ni trop cilement rres réuire : elles ent et ne s.

produire, yuaranteunt a dix

que le sol?

composiisol argicalcaire, la terre sque tou-

$n d u$ sousaleur du terres de même nature ont souvent une fécondité très différente, selon que leur sous-sol est compacte ou poreux, meuble ou dur, sableux, argileux ou calcaire. Enfin, des terres de la plus belle apparence peuvent n'avoir qu'une médiocre valeur, si leur sous-sol est d'une qualité peu appropriée à celle du sol.

Quelle est l'influeuce du sous-sol, selon qu'il est perméable ou imperméable?

Le sous-sol peut influer favorablement ou défavorablement sur la fertilité du sol, selon qu'il est perméable ou imperméable, c'est-à-dire qu'il laisse passer ou qu'il retient l'eau dont la terre est imprégnée. Ainsi, dans les terres sablonneuses, un sous-sol argileux est avantageux on retenant l'eau qui traverse trop rapidement le sable; dans les terres argileuses, qui conservent un excès d'humidité, un sous-sol sablonneux est préférable, parce qu'il laisse passer cet excès d'eau.

Quel est le plus mauvais de tous les sous-sols?

C'est celui qui se compose de gravier.

Le sous-sol d'humus offre-t.il quelque avantage?

Oui, car en le ramenant à la surface, il fait bénéficier le sol des substances fertilisantes qu'il renferme.

Quel est le meilleur sous-sol pour les terres légères?

C'est celui qui se compose de roches, de calcaire et d'argile, qui entretiennent un état de frấcheur très favorable à la végétation dans un sol léger. 


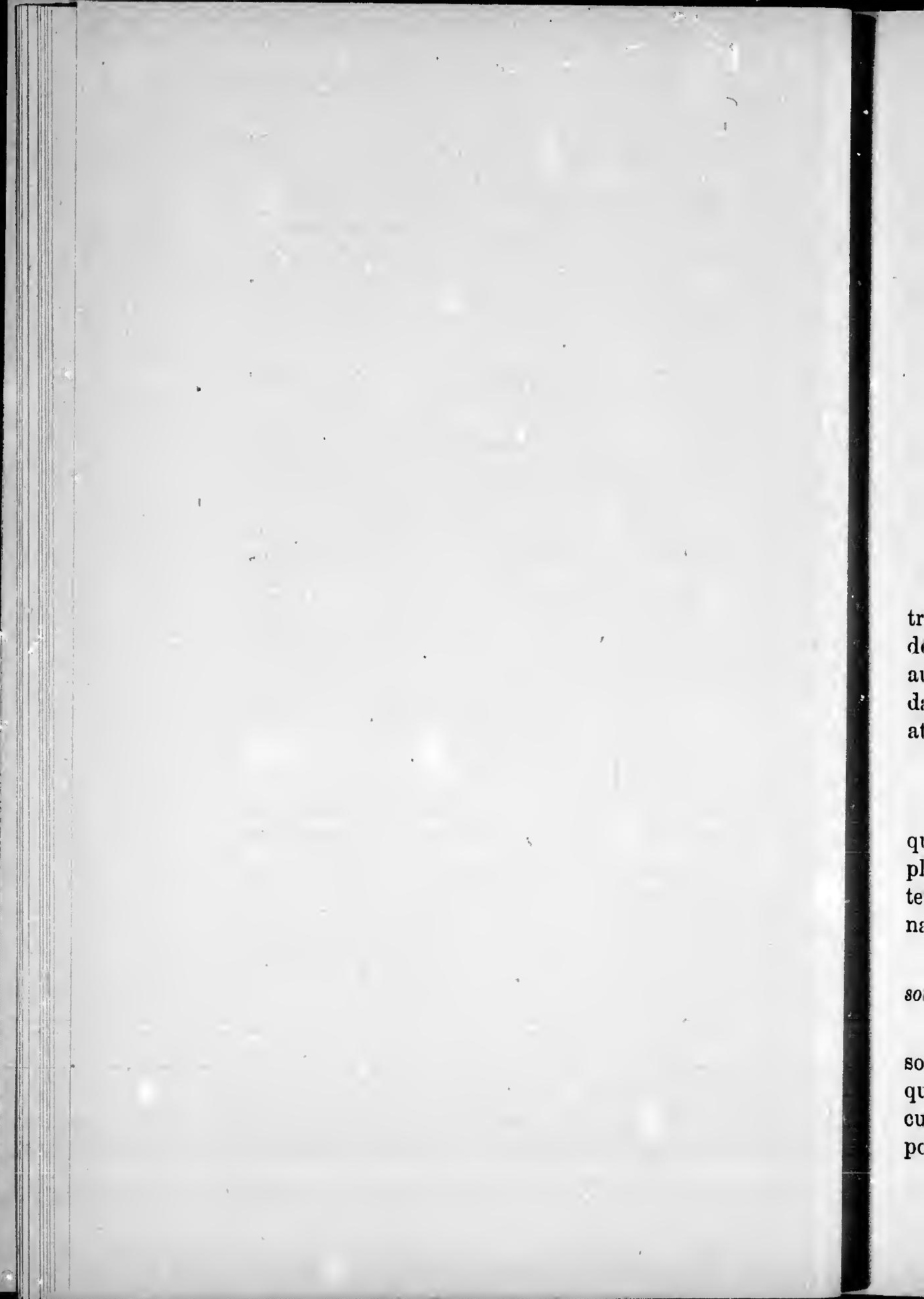




\section{CHAPITRE IV}

QUALITÉS ET DÉFAUTS DES DIFFÉRENTS SOLSPLANTES QUI ILEUR CONVIENNENT

Quels sont les traits caractéristiques des sols sablonneux?

Ces sols sont poreux ; ia chaleur et le froid les pénètrent facilement, ce qui fait que le dessèchement et le dégel s'y produisent plus promptement que dans lea autres terrains. La végétation commence plus tôt que dans les sols compactes, la gelée et les grandes chaleurs attaquent plus promptement les plantes.

Sont-ils faciles à cultiver?

Ils sont de facile culture, demandent moins de labours que les autres terres, la croissance des plantes s'y fait plus rapidement; mais, comme ils se dessèchent promptement, ils sont presque stériles quand ils ne sont pas naturellement frais.

Quelles sont les plantes qui réussissent le mieux dans les sols sablonneux?

Ces sols conviennent bien a la culture de l'orge et ils sont particulièrement propres à produire le seigle, ce qui fait qu'on les appelle souvent terres a seigle. On y cultive aussi, avec plus ou moins de succès, l'avoine, la pomme de terre, le lin, le trètle, les carottes et les navets. 
Les sols sablonneux tiennent-ils bien les engrais?

Non: leur porosité facilite trop l'action des $a_{i j}$ ents atmusphériques qui décomposent promptement le fumier, dont la partie gazeuse se perd dans l'air et les parties plus solides sont entrainées dans les couches inférieures du sol par les eaux pluviales.

Que faut-il faire pour éviter ces inconvénients?

Il faut fumer ces terres plus fréquemment, mais par plus petites doses à la fois.

Quels sont les engrais qui convie. nent le mieux aux sole sablonneux?

Ce sont les végétaux verts et les récoltes enfouies ou enterrés dans le sol par un labour avant leur maturité, vu que ces engrais se décomposent lentement.

Quels sont les traits caractéristiques des sols argileux?

Ces terres se crevassent facilement en temps de sécheresse. L'eau les pénètre difficilement, mais y séjournè longtemps quand elle s'y introduit. Quand elles perdent toute leur eau, elles deviennent tellement dures qu'elles pressent lcs racines des plantes et les empêchent de se développer. Leur aptitude à retenir l'eau les rend d'un accès difficile à la chaleur et les range dans la catégorie des terres froides.

Sont-elles faciles à culiver?

Non, elles ne sont pas faciles à cultiver. Pour les labours, il faut attendre le moment ou elles, sont ni trop sèches ni trop humides, de sorte que dans les temps trop secs ou trop humides il est presque impossible de les cultiver avantageusement. Il faut aussi les labourer 
l'automne, afin de les soumettre aux gelées d'hiver, qui les ameublissent mieux que le travail de l'homme, les rendent plus friables et bien plus faciles à herser. Il faut de plis les égoutter avec beaucoup de soin, pour neutraliser la propension qu'elles ont à retenir l'eau.

Quelles sont les plantes qui réussissent le mieux dans les sols argileux?

Les terres argileuses conviennent surtout au blé, qui y réussit particulièrement bien, ce qui fait qu'on les appelle terres à blé,-au lin, a l'avoine, au trèfle, aux fèves, aux choux et aux autres plantes qui ont des racines fortes, mais peu nombreuses.

Qucls sont les engrais qui conviennent le mieux aux terres argileuses?

Co sont les récoltes enfouies et les fumiers longs de litière, parce que tout en engraissant la terre ils la désagrègent, la rendent plus friable et plus pénétrable par l'eau, l'air et la chaleur. Quand ces terres sont très froides et très humides, il faut associer à ces engrais de la chaux ou d'autres engrais très chauds.

\section{Quels sont les traits caractéristiques des sols calcaires?}

Les terres calcaires, qui sont blanchatres, se gonflent par l'effet des pluies et de la gelée et sont très boueuses. Elles se réduisent en poussière après les dégels et forment parfois, en se desséchant, une croate qui empêche l'air et la chaleur de la pénétrer. Quand elles se dessèchent sans former de croute, par la chaleur ou la gelée, elles deviennent pulvérulentes, n'offrent plus d'appui convenable aux plantes et ne protègent pas leurs racines contre les atteintes du froid. 
Sont-elles faciles d cultiver?

Les terres calcaires, à raison de leur manque de ténacité, sont très faciles à cultiver et n'adhèrent que très faiblement aux instruments aratoires.

Quelles sont les plantes qui conviennent le mieux aux terres calcaires?

Ce sont le ble, İes fèves, les pois, le ble d'inde, les lentilles, les vesces, le trèfle, la pomme de terre et la betterave.

Les sols calcaires retiennent-ils bien les engrais?

Non: ils se décomposent promptement par l'excès de chaux que renferment ces sols et par leur porosité, qui permet à l'air d'enlever les gaz du fumier et à l'eau d'en laver les parties solides.

Que faut-il faire pour éviter ces inconvénients?

Il faut fumer ces terres fréquemment, mais par petites quantités à la fois.

Quels sont les engrais qui conviennent le mieux aux sols calcaires?

Ce sont les engrais verts ou les récoltes enfouies, les composts c'e terre, d'herbe et de purin, les cendres et les balayures des rues ou des chemins.

Quels sont les traits caractéristiques des terres humifères?

Les terres humifères, ou terres noires, sont légères, spongieuses, manquent de consistance, sont pour la plupart tourbeuses ou marécageuses, so gonflent à la gelée, se dessèchent beaucoup quand elles sont égouttées, sont souvent acides et manquent de substances 
minérales, ce qui fait que la paille des grains qu'on sème n'u pas de rigidité et verse presque toujours.

de ténaque très

aux terres inde, les irro et la

ir l'excès porosité, et à l'eau

ar petites

aux sols

ouies, les endres et

umiferes ? t légères, pour la lent à la nt égout. ubstances
Les terres humiferes sont-elles fuciles d cultiver?

Les sols de terreau sont particulièrement propres au jardinage et ont peu d'utilité pour la grando culture. Ils donnent d'excellertes récoltes de pommes de terre, de navets, de choux et de chanvre. Les sols tourbeux sont absolument impropres à la culture dans leur état naturel : pour les utiliser, il faut d'abord les égoutter, puis les amender au moven de la cendre, de la glaise, du sable et surtout de la chaux vive, qui est nécessaire pour détruire les acides que renferment ces terres. Quand elles sont ainsi préparées, elles sont très propres à la culture des plantes à fortes racines, de l'avoine, de l'orge, du sarrasin, du trèfle et surtout à être converties en prairies.

Quels sont les engrais qui conviennent le mieux aux sols humifères tourbeux?

Ce sont les composts de chaux, d'argile, de sable, d'immondices des rues, de vase d'étangs et de fumier en petite quantité. 


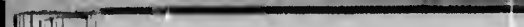

. 


\section{CHAPITRE V}

\section{AMENDEMENTS ET ENGRAIS}

Le sol, par sa composition naturelle, offre-til toujours les conditions les plus favorables d la culture?

Non, le sol n'offre pas toujours, par sa composition naturelle, les conditions les plus favorables à la culture. Il peut. par l'absence ou par l'excès de quelqu'une des principales substances qui le composent naturellement, c'est-à-dire l'argile, le sable ou le calcaire, être trop sec ou trop humide, trop consistant ou trop léger, trop froid ou trop chaud.

Un sol d'une bonne composition naturelle peut-il devenir impropre à une culture avantageuse?

Oui, par l'épuisement des matières organiques nécessaires à la nutrition des plantes. En semant tous les ans dans un même champ du blé, de l'orge, de l'avoine ou d'autres plantes, sans rendre au sol ce que ces plantes en ont tiré pour se former et se nourrir, la terre s'appauvrit nécessairement et devient impropre à une culture avantageuse.

Comment peut-on remédier aux défauts provenant de la composition du sol?

Par les amendements. 
Comment peut-on remédier aux défnuts du sol résultant de l'épuisement par la culture?

Par les engrais.

Qu'appelez vous amender une terre?

Amender une terre, c'est améliorer sa composition par des additions convenables de sable, d'argile ou de calcaire, de manière a la rendre plus ou moins accessible à l'action des principaux agents de la végétationl'eau, l'air et la chaleur - et de rétablir ainsi l'harmonie dans les proportions de ses éléments constituents.

Qu'appelez-vous engraisser une terre?

Engraisser une terre, c'est lui rendre, par l'addition des fumiers et autres matières fertilisantes, les substances qui lui ont été enlevées par la végétation, ou augmenter ses propriétés nutritives.

\section{Amendements}

Que faut-il connaître pour pratiquer avantageusement les amendements ?

Pour pratiquer avantageusement les amendements il faut connaitre :

1 - Lá nature du sol que l'on veut amender et l'espèce d'amendement qui convient à ce sol ;

$2^{\circ}$ Dans quelle proportion il faut employer l'amendement convenable. 
Quelles sont les principales matières que l'on emploie comme amendement?

Ce sont le sable, l'argile et le calcaire, ce qui fait qu'on divise les amendements en trois classes, qu'on appelle amendements siliceux, amendements argileux et amendements calcaires.

Quelles sont les matières qu'on emploie comme amendements siliceux?

Ce sont le sable et le gravier.

Comment agissent ces amendements?

Ils divisent le sol, atténuent sa oompaci!é, le rendent plus friab!e, plus meuble et plus pénétrable.

A quels sols conviennent les amendements siliceux?

Les amendements siliceux conviennent surtout aux terres argileuses ou glaiseuses, compactes et humides. Ils désagrégent ces terres, les ameublissent et les réchauffent en les rendant plus pénétrables par l'air et la chaleur. Quand ces terres sont humides, les amen. dements siliceux favorisent aussi l'écoulement des eaux surabondantes.

ement les

Comment emploie-t-on les amendements siliceux?

On répand le sable ou le gravier sur le sol avant les labours destinés à l'ensemencement. On les mélange d'abord avec une couche peu épaisse du sol, à l'aide de l'extirpateur ou de la herse, et on la laboure ensuite.

$Y$ a.t-il parfois un autre moyen plus facile d'arriver au même résultat?

Oui : quand un sol glaiseux a pour sous-sol du sable 8 
ou du gravier, il suffit de pratiquer un labour profond, ou de défoncement, pour amener a la surface le sable et le gravier, qui so melent ensuite d la glaise par le hersage.

Quelle est la quantité de sable requise pour amender un sol argileux?

Cette quantité dépend du dégré de compacité de la terre qu'on veut amender, mais ne doit jamais dépasser 45 pour 100 , ce qui est la proportion contenue dans la terre franche.

Les amendements siliceux conviennent-ils d d'autres terres?

Ces amendements conviennent aussi aux sols humifères et tourbeux; ils leur donnent plus de ténacité et leur procurent la silice qui leur manque, pour donner à la tige des céréales la rigidité voulue.

Quelle est la matière qu'on emploie comme amendement argileux?

C'est l'argile ou la terre glaise?

Comment agit cet amendement?

Il donne aux sols plus légers la tenacité et la compacité qui leur manquert, ce qui les rend plus propres à condenser et à réunir dans leurs pores l'engrais provenant de la décomposition des matières organiques ou introduites dans la terre par les eaux pluviales.

L'argile a-t-elle encore d'autres propriétés commъ amendement?

Oui, elle a encore la proprieté de fournir aux plantes la potasse et la soude provenant de la décomposition des roches alcalines"qui sont mêlées à sa substance. 
rofond, sable et $r$ le her-

ender un

ité de la dépasser dans la

"es terres?

ls huminacité et donner à

nendement

la compapropres à ais provehiques ou es.

lз amende-

1x plantes mposition stance.

\section{A quels sols conviennent les amendements argileux?}

I'umendement argileux convient surtout aux sols sableux et calcaires, qu'il rend plus tenaces, plus compactes, moins sujets aux gonflements produits par l'eau et la gelée.

\section{Comment pratique-t-on les amendements argileux?}

Par le défoncement et par l'épandage.

Comment procedde-t-on par le défoncement?

Quand un terrain sablonneux ou calcaire a l'argile pour snus.sol, on ramène cette argile d̀ la surface par un labour de défoncement en donnant un second trait de charrue dans les sillons. C'est le moyen lo plus facile et le nlus économique. La gelée et le hereage pulvérisent l'argile et achevent de la mélanger avec le sable ou le calcaire.

Comment procede-t-on par l'épandage?

On charroie de l'argile sur le sol sablonneux ou calcaire, pour que les pluies d'automne et les gelées la pulvérisent, et on achève le mélange par le labour et le hersage de la culture ordinaire.

Quelle est l'argile qui s'emploie le mieux comme apmendement?

C'est celle qui provient de la vase et des curures de fossés.

La quantité d'argile qu'il faut employer comme amendement est-elle toujours la même?

Non : elle varie d'un sol à l'autre et suivant les compositions des sols de même espèce. En général il faut 
faire en sorte que la terre amendée n'en renferme qu'environ 45 pour 100 , ce qui est la proportion contenue dans les terres franches.

Les amendements argileux conviennent-ils à d'autres terres?

Ils conviennent aux sols humifères, qu'ils rendent plus tenaces et plus propres à fixer les tiges des plantes. Par le defoncement, les sols humifères à sous -sol de glaise deviennent en peu d'années des terres de première qualite.

L'argile peut-elle devenir un amendement pour l'argile?

Oui : calcinée l'argile perd sa tenacité, sa propriété de retenir l'eau, et dans cet état elle devient un amendement très avantageux pour les terres argileuses, qu'elle rend plus meubles et plus perméables.

Quelles sont les principales matières employées comme amendements calcaires?

Ce sont la chaux, la marne et les plâtras de démolition.

Quelle est la meilleure de ces trois substances?

C'est la chaux; la mane et les platras n'ont de valeur comme amendements que parce qu'ils renferment de la chaux.

Quelles sont les principales propriétés de la chaux comme amendement?

Elle diminue la tenacité des terres fortes et compåctes, les ameuiviit et les réchauffe on les rendant plus pénétrables par l'air, la chaleur et l'eau.

Elle donne de la tenacité aux terres légères et peu compactes. 
me qu'encontenue

tres terres?

$s$ rendent es plantes. ol de glaise mière qua-

\section{r'argile?}

propriété un amenargileuses, is.

yées comme de démoli-

it de valeur cment de la

haux comme

compäctes, plus péné.

eres et peu
Elle neutralise, en les décomposant, les acides qui se trouvent dans le sol, principalement dans les sols humi fères et tourbeux.

Elle décompose l'argile, dégage par là même la potasse et la soude qui s'y trouvent et fait concourir ces minéraux à la nutrition des plantes.

\section{$A$ quels sols convient la chaux?}

La chaux convient à tous les sols, excepté les terres calcaires, qui en renferment déjà trop dans leur composition naturelle : mais elle convient d'une manière spéciale aux terres fortes et argileuses.

\section{La chaux constitue-t-elle un bon amendement?}

C'est le meilleur de tous les amendements. Quand il est bien employe, il augmente d'une manière prodigieuse le rendement de la terre.

\section{La chaux peut-elle être considérée comme un engrais?}

Bien qu'elle entre en une certaine proportion dans la composition des plantes, la chaux ne peut pas être con. siderée comme engrais ou comme une substance propre à rétablir les forces d'un terrain. Le chaulage ou l'emploi de la chaux sur le sol est un moyen d'amender la terre, de mettre en activité ses richesses inertes, mais il exige impérieusement le concours du fumier, lorsque la terre ne possède pas une surabondance de principes fertilisants.

Faut-il faire subir certaine préparation d la terre avant le chaulage?

Oui, il faut l'egoutter et l'assécher, car le chaulage ne produit sur les sols mouillés que des résultats à peine sensibles. 
: Emploie-ton la chaux vive ou la chaux éteinte?

“A raison de son action énergique et désorganisatrice, qui brale vite les matières organiques, on n'emploie la chaux vive que dans les sols acides ou contenant des matières végétales en abondance. Dans les autres sols, il faut employer la chaux éteinte.

Comment s'emploie la chaux?

- Elle s'emploie de plusieurs manières; mais la plus simple consiste à la déposer par petits tas sur le terrain qu'on veut amender. En absorbant l'humidité de l'air elle se gonfle, se pulvérise, et dès qu'elle est réduite en poussière fine, on l'épand à la pelle, puis on l'enterre au moyen d'in léger labour.

Quel temps faut-il choisir pour employer ainsi la chaux?

Il faut choisir un temps sec, car la pluie réduirait la chaux en bouillie et rendrait impossible son égale répartition sur le sol.

\section{$Y$ a-t-il une autre méthode?}

Oui: on dépose la chaux par petits tas, comme il vient d'être dit, mais au lieu de la laisser exposée à l'air, on la recouvre de terre pour la protéger contre ia pluie. Quand elle est bien ćteinte et réduite en poudre fine, on la mêle avec la terre qui la recouvre et on épand ce mélange sur le terrain.

\section{Peut-on l'éteindre directement dans l'eau?}

Oui : on met la chaux vive dans des paniers qu'on plonge dans l'eau et que l'on retire après quelques instants d'immersion. La chaux s'éteiut alors très promptement et on l'epand de suite sur le terrain, à la pelle. 


\section{Peut-on l'épandre a la volée?}

nisatrice, mploie la enant des utres sols,

is la plus r le terrain ité de l'air réduite en n l'enterre

ii la chaux? réduirait la son égale

hme il vient e à l'air, on re ia pluie. idre fine, on n épand ce

niers qu'on ès quelques $t$ alors très terrain, à la
On peut aussi épandre la chaux a la volée, de la même manière qu'on épand le grain pour le semer. Pour cela on la fait eteindre sous un abri, en l'arrosant ou en la laissant se déliter seule, et quand elle est bien pu'vérisée, on la sème par un temps calme, pour qu'elle ne soit pas emportée par le vent.

Peut-on épandre la chaux pure sur le hersage immédiatement après que le grain est semé?

Oui, mais cela présente quelque danger: la chaux peut attaquer et décomposer ia semence, et surtout les premières racines qui seraient en contact direct avec elle.

\section{$Y$ a-t-il encore une autre maniere de pratiquer le chaulage?}

Oui : on peut employer la chaux en composts. Pour cela, on fait un lit de terre avec des curures de fossés, des balayures de rues, des mauvaises herbes et autres matières semblables. Sur ce lit de terre, on met un lit de chaux, puis un autre lit de terre, et ainsi de suite. Quand la chaux est pulvérisée, on mélange la terre et la chaux, puis on épand ce mélange sur le sol.

Quelle est la meilleure époque pour operer le chaulage?

C'est l'ar:tomne, au temps des labourages.

Quelle est ia quantité de chaux qu'il faut employer pour amender un terrain?

En moyenne, il faut une quarantaine de minots a l'arpent. Ce sont les terres argileuses, absolument dépourvues de calcaire, qui exigent le plus fort chaulage et qui profitent le plus de cet amendement. 
Les effets du c'laulagé se fontils sentir longtemps?

Les effets du chaulage se font sentir de dix à quinze ans.

Peut-on reconnaître par les herbes qui poussent dans un terrain si ce terrain a besoin d'êtrs chaulé?

Oui : quand on voit certaines herbes, telles que les fougères, la prèle ou queue de renard, l'oseille, le chiendent ou la mousse croître dans un terrain, on peut dire de suite que ce terrain a besoin d'être chaulé.

Quel est, après la chaux, le meilleur amendement calcaire?

C'est la marne.

Qu'est-ce que la marne?

La marne est un mélange de carbonate de chaux avec du sable ou de l'argile.

A quoi la marne doit-elle ses propriétés comme amendement?

A la chaux qu'elle renferme. Elle agit de la même manière que la chaux, mais avec moins d'énergie.

Combien distingue-ton d'cspeces de marne?

On distingue trois especes de marne: la marne calcaire, la marne argileuse et la marne siliceuse, selon l'élement qui prédomine dans sa composition.

Quelle est la composition' de la marne calcaire et d quels sols convient-t-elle le mieux?

La marne calcaire est la plus riche et la plus active. Elle contient jusqu'à 60 à 70 pour 100 de chaux et on l'emploie de préférence dans les terres argileuses qu'on veut réchauffer, dessécher et rendre plus perméables. 
Quelle est la composition de la marne argileuse et d quels sols convientrelle le mieux?

La marne argileuse se compose de 20 a 50 pour 100 de carbonate de chaux et de 50 aे 70 pour 100 d'argile. Or l'emploie dans les terres sablonneuses pour en augmenter la consistance et l'humidite et pour les rendre moins perméables.

Quelle est la composition de la marne siliceuse et à quels sols convient-elle le mieux?

La marne siliceuse se compose de 20 a 50 pour 100 de carbonate de chaux et de 50 à 70 pour 100 de sable. On l'emploie dans les terres argileuses, pour les désagréger, les ameublir et les rendre plus perméables.

ou trouve-t.on la marne?

Dans les petits lacs peu profonds et dans les marais, où elle est ordinairement recouverte de tourbe.

\section{$Y$ a-t-il de la marne dans notre pays?}

la même gie.

Oui, er. beaucoup d'endroits. On a constaté son existence dans plusieurs localités du comté d'Argenteuil, dans celui de Terrebonne, dans l'île de Montréal, à Philippsburgh, à Saint-Pie, dans le comté de Bagot, à Lorette, sur les bords de la rivière Saint Charles, à Maria et New-Carlisle, dans le comté de Bonaventure et dans beaucoup d'autres localités.

et d quels

us active. ux et on ses qu'on néables.

Comment peut-on opérer le marnage?

On dépose la marne sur le sol en tas espacés d'une vingtaine de pieds. L'air et surtout la gelée font déliter la marne, c'est-à-dire la réduisent en poussière. Quand elle est ainsi délitée, on l'epand avec la pelle et on l'enterre ensuite par un labour ou a l'aide d'un scarificateur. 
Quelle est la meilleure époque pour mettre la marne sur la terre?

On peut la mettre en tous temps, mais les saisons les plus favorables sont l'automne et l'hiver. Les gelées délitent la marne, qui le printemps est prête à épandre.

Quelle quantité de marne faut-il employer?

Cela dépend de la composition de la marne et du sol auquel on l'applique; mais en moyenne on peut mettre une centaine de minots à l'arpent. La dose doit être d'autant plus grande que la terre à laquelle on l'applique renferme en moindre quantité l'élément qui prédomine dans la composition de la marne.

Est-il nécessaire de fumer les terrains marnés?

Oui, il faut fumer les terrains marnés. La marne, comme la chaux, stimule puissamment les propriétés productives du sol, et si on ne rendait pas à la terre par le fumier ce qu'elle perd par cette exubérance de végétation, le sol s'appauvrirait en peu d'années au point de devenir stérile.

Les effets du marnage se font-ils sentir longtemps?

Quand le marnage est abondant, ses effets peuvent se faire sentir durant une vingtaine d'années.

La marne épuise-t-elle la terre autant que la chaux?

Non, la marne n'épuise pas la terre autant que la chaux, puisque son action n'est pas aussi énergique; mais pour que le marnage produise des effets permanents, il faut toujours le combiner avec l'emploi du fumier. 
Qu'appelez-vous plalras de démolition?

On appelle platras les débris des constructions faites en platre ou en chaux.

Ces platras constituent-ils un bon amendement?

Ils constituent un des amendements les plus utiles et sont plus fécondants que la marne ou la chaux.

Pourquoi sont ils plus fécondants?

Parce que, en sus de la chaux et du carbonate de chaux, ils contiennent presque toujours des nitrates de potasse, de soude et de chaux qui contribuent à la nutrition et à la formation des plantes.

A quels sols conviennent les platras?

Ils conviennent de preférence aux sols non calcaires, principalement aux terres fortes et humides, qu'ils rendent plus sensibles à la sécheresse.

Comment emploie-t on les platras?

On les mêle avec du fumier, on épand le mélange sur la terre quand elle est sèche et on l'enterre par un labour.

Quelle est la quantité qu'il faut employer?

$L_{a}$ dose moyenne est de 200 minots à l'arpent. rgique; permaploi du 


\section{Des engrais}

\section{Qu'appelez-vous engrais ?}

On appelle engrais toutes les matières qui sont nécessaires à la vie des plantes et qui concourent à leur nutrition, soit par leur décomposition, soit par leur absorption immédiate.

Quel rôle les engrais remplissent-ils à l'égard des plantes?

Les engrais remplissent à l'égard des plantes le même rôle que les aliments remplissent à l'égard des animaux, c'est-à-dire qu'ils les nourrissent.

Quelle difference $y$ a-t-il entre les amendements et les engrais?

Les amendementa changent ou modifient la nature du sol par le mélange de matières organiques qui l'améliorent en l'ameublissant ou en la rendant plus compacte; les engrais, au contraire, fournissent aux plantes des matières favorables à leur nutrition et à leur croissance.

Distingue-t.on plusieurs classes d'engrais?

On distingue quatre classes d'engrais : $1^{\circ}$ les engrais animaux; $2^{\circ}$ les engrais végétaux; $3^{\circ}$ les engrais minéraux; $4^{\circ}$ les engrais mixtes ou composés.

\section{ENGRAIS ANIMAUX}

Quels engrais désigne-t-on sous le nom d'engraic animaux?

On désigne sous ce nom les engruis qui sont les plus riches en matières azotées. 
Quels sont les principaux engrais animaux?

Les principaux engrais animaux sont les débris d'animaux, les engrais liquides, les matières fécales et la colombine.

Que désignez-vous par l'expression débris d'animaux?

On désigne par cette expression la chair, le sang, les os, les cornes, les poils, les plumes, enfin toutes les parties des animaux morts, qui constituent des engrais d'une trè̀ grande richesse.

Comment prépare-t-on cet engrais?

On dépose la chair, le sang, les boyaux, le foie et les poumons dans une fosse; on les recouvre d'une couche de chaux, sur laquelle on met une couche de terre. En peu de temps la chaux décompose les matières animales; le mélange de ces matières avec la chaux et la terre qui les recouvrent, forme un des meilleurs engrais et qui a l'avantage de convenir à tous les sols.

Comment fait-on avec les animaux qui meurent de maladie et qu'on enterre tout ronds?

On les dépose dans une fosse après les avoir coupés par morceaux et l'on recouvre la fosse de chaux vive pour activer la putréfaction, puis on remplit la fosse de terre. Au bout de trois ou quatre semaines, on ouvre la fosse, on enlève les os, qui se sont séparés de la chair; on mélange celle-ci et le chaux avec trois ou quatre fois autant de terre sèche. On laisse consommer ce mélange pendant un mois, en le brassant de temps à autre à la pelle, et alors il est prêt à être employé.

Comment s'emploie le sang?

On le dessèche, on le pulvérise et on répand cette 
poudre sur les plantes, ou encore on la sème aveo les graines. On peut aussi le faire absorber par de la chaux éteinte et épandre ce mélange sur les cultures vertes.

Comment s'emploient le poil, le cuir et la plume?

On les fait décomposer dans une bouillie de chaux vive, puis on ajoute une partie de sable ou de terre de jardin. On epand ce mélange sur le sol.

Comment s'emploient les os?

En poussière ou sous forme liquide.

Comment les pulvérise.t-on?

Auprès des grandes villes, il y a souvent des industriels qui pratiquent cette opération au moyen d'appareils speciaux. A la campagne, on peut broyer les os autrement. On les lait bouillir pour les débarrasser des matières grasses ; on les dessèche autant que possible, puis on les écrase avec un caillou, avec une masse ou tout autre instrument. Cette poudre est ensuite répandue sur lo sol : elle est d'autant meilleure et plus active qu'elle est broyée plus fine.

Quelles sont les plantes qui profitent le plus des os pulvérisés?

Ce sont les betteraves et les navets.

Comment prépare-t-on les os pour les employer sous forme liquide?

On les broie, puis on les mélange avec un égal poids d'huile de vitriol ou acide sulfurique, étendue de deux fois son poids d'eau. On laisse macérer pendant deux jours, en ayant soin de brasser de temps à autre. Au bout de deux jours, il s'est formé une pate liquide qu'on

lan

les

tro
$\mathrm{da}$

to

da

li

e 
c les haux es.

haux re de

indus'appales os rasser te posmasse nsuite et plus oulvéri-

s forme

1 poids e deux t deux e. $\mathrm{Au}$ equ'on

dilue dans trente fois son volume d'eau. On répand cette dilution sur les plantes avec un arrosoir ou un tonneau d'arrosage.

Les vieux paturages se trouvent-ils bien de ce liquide?

Ce liquide leur donne un regain de vigueur qui se traduit par l'amélioration dans la quantite, et surtout dans la qualité du lait des vaches laitières.

Est-il un autre moyen d'employer celte pate liquide?

Oui : au lieu de la mélanger avec de l'eau on la mélange avec de la terre sèche et on sème cette poudre sur le sol, avant lè hersage.

Les os constituent-ils un bon engrais?

C'est un des meilleurs engrais qu'on puisse employer.

Pourquoi les os sont-ils favorables aux plantes?

Parce que les plantes ont toutes besoin de l'acide phosphorique coitienu dans le phosphate qui se trouve dans la composition des os.

Les poissons sont-ils de bons engrais?

ILes poissons, leurs vidanges, les moules, les étoiles de mer sont des engrais animaux et puissants qu'il est très avantageux d'employer quand on peut se les procurer facilement. Cet engrais convient également aux grains et aux légumes.

Pour quelle culture et de quelle façon les cultivateurs du bns du fleuve et de la baie des Chaleurs emploient-ils le poisson?

Principalement pour la culture de la pomme de terie. Ils déposent le hareng et le caplan crus et tout ronds avec les germes de pommas de terres, comme le fumier. 
Ce.mode d'emploi présente-til un inconvénient, et que suffirait.il de faire pour y obver ?

En se décomposant, ces poissons produisent de l'huila qui masse la terre et nuit a la végétation. Pour obvier à cela, il suffirait de faire bouillir le poiss $\theta$ qui le débarrasserait de l'huile sans affecter se. propriétes comme engrais.

Les chiffons de laine peuvent-ils être employés comme engrais?

Les chiffons de laine constituent le plus riche en azote de tous les engrais. Une voiture de ces chiffons vaudrait quarante voitures de fumier; mais il est trop dif. ficile de se les procurer pour en faire l'emploi en grand.

Comment prépare-t-on ces chiffons quand on peut se les procurer?

On les mélange dans la proportion d' zartie de chiffon pour deux parties de fumier, qui décompose less chiffons très vite. Ce mélange est peut-être le meilleur engrais qu'on puisse donner aux pommes de terre et aux navets.

\section{ENGRAIS LIQUIDES}

Qu'appelez-vous engrais liquides?

On appelle engrais liquides les urines des. animaux.

Quelle est la meilleure manière d'employer ces engrais?

C'est de les employer avec le fumier et la litière qui servent à les recueillir. 
Quand on n'a pas de paille pour faire de la litière, comment peut-on recueillir l'urine'?

Dans ce cas on remplace la paille par des feuilles, de la sciure de bois, de la terre de savane et des curures de fossés, qui absorbent l'urine et fixent ses. principes fertilisants.

\section{Peut-on recueillir autrement les urines?}

Dans certaines fermes bien organisées, les étables et les écuries sont installées de façon qu'en tombant, les urines, ou le purin, s'écoulent dans des conduits qui aboutissent à un réservoir où elles sont conservées. On les prend dans ces réservoirs pour les verser sur le fumier, quand il s'échauffe, ou les répandre directement sur la terre à fertiliser.

\section{Emploie-t.on les urines pures?}

Non: il faut y ajouter trois ou quatre fois son volume d'eau, sans quoi son action sur les plantes serait trop Energique et les bralerait.

Quel temps faut il choisir pour employer le purin?

Il faut choisir, autant que possible, un temps couvert et humide, afin de donner à la terre le temps d'absorber le purin avant que ses éléments fertilisants ne soient evaporés par le soleil.

Quand faut-il employer le purin?

$\mathrm{Au}$ printemps, sur les prairies; après la plantation et avant le buttage, sur les choux et les pommes de terre, auxquels il fait souvent produire des récoltes prodigieuses, principalement dans les sols sablonneux. 
A quels sols et d̀ quelles plantes convient le purin?

Il convient a tous les sols; mais il convient de préférence aux plantes qui se nourrissent beaucoup par les fenilles, ce qui fait qu'il ne produit pas beaucoup d'effet sur.lés céréales, qu'il porto à verser.

Comment se répand le purin?

On le répand avec un arrosoir dans les jardins ; mais dans la grande culture on se sert du tonneau d'arrosage.

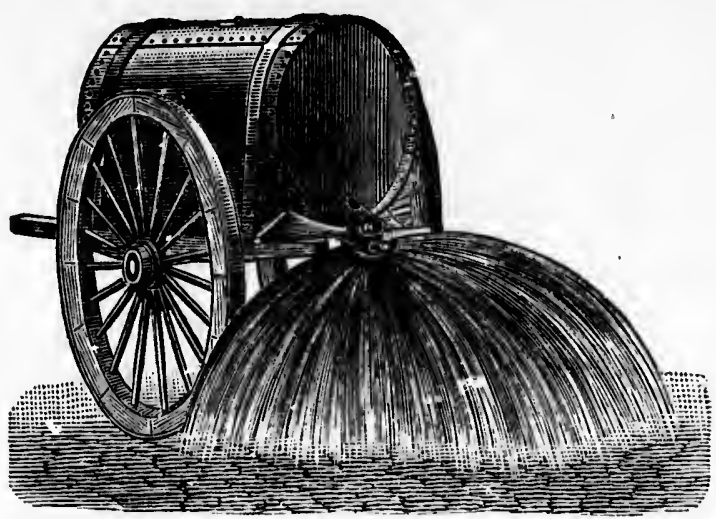

Fra. 1,-Tonneau d'arrosage

III MATIÈRES FÉCALES

Qu'appelez vous matières fécales?

On appelle matières récales ou engrais humain les excréments solides et liquides de l'homme.

Cet engrais a-t-il beaucoup de valeur?

C'est un des engrais les plus énergiques. Il renferme toutes les substances organiques et salines nécessaires

$\mathrm{au}$

$\operatorname{dix}$

à vi

$S$

$\mathrm{L}$

mél

grai

pouc

a

O।

tière

lum

plus

autr.

Co

On

dans

avec

coup

surto

mêm

véris

A

L'e

convi

Qu

Por dre 8 
au développement des plantes, $\epsilon$ t'on considère que dix voitures d'engrais humain employé frais, équivalent à vingt-cinq voitures dis fumier.

Sous quelles formes s'emploie l'engrais humain :

Les Flamands l'emploient avec l'eau et' forment un mélange liquide qu'on appelle engrais flamand, courtegraisse ou gadoue. En France, on en fait surtout de la poudrette. Ailleurs, on en fait du noir animalisé.

Comment ¿e prépare l'engrais flamand?

On le prépare en mettant dans une citerne les matières fécales, qu'on délaye de plusieurs fois leur volume d'eau et en laissant fermenter ce mélange durant plusieurs jours, en ayant soin de le brasser de temps à autre.

Comment fait-on pour prévenir la mauvaise odeur?

On fait dissoudre cinq ou six livres de couperose dans un gallon d'eau et l'on arrose les matières fécales avec cette solution, qui suffit pour désinfecter une couple de cents livres d'engrais. Ise sulfate de zinc et surtout le plâtre, ou sulfate de chaux, produisent le même résultat. Enfin, on peut se servir de terre pulvérisée, que l'on répand à la surface.

A quels sols et a quelles plantes convient cet engrais?

L'engrais flamand, comme toutes matières fécales, convient à tous les solp et à toutes les plantes.

Quand faut-il employer l'engrais flamand?

renferme écessaires

Pour le lin, le chanvre ou le tabac, on peut le répandre sur la terre avant ou après l'ensemencement; pour 
les plantes-racines et les céréales, il faut le répandre avant le semis; pour les prairies, il faut le répandre dès le printemps, afin de partir la végétation.

Les effets de l'engrais flamand se font-ils sentir longtemps?

Ils ne se font guère sentir plus d'une année, et si précieux que soit cet engrais, on se tromperait en le considérant autrement que comme un puissant auxiliaire $\mathrm{du}$ fumier ordinaire.

\section{Qu'est-ce que la poudrette?}

C'est tout simplement de la matière fécale séchée à l'air sur un plan incline, puis battue, réduite en une poudre noire, qu'on sème à la main, à raisor d'une vingtaine de minots à l'arpent.

Comment s'emploie la poudrette?

On la répand sur le labour au moment de l'ensemencement et on l'enterre avec le grain par le hersage.

Quel est le sol qui lui convient le miaux?

Ce sont les terres argilieuses.

Qu'est-ce que le noir animalisé ?

On appelle noir animalisé un mélange de matières fécales avec de la vase, des boues de marais, des curures de fossés, de la sciure de bois et autres matières semblables, calcinées en vase clos. Ces matières calcinées ou charbonneuses détruisent la mauvaise odeur des matières fécales et le mélange constitue un excellent engrais, qui convient à toutes les plantes et à tous les sols. 
pandre pandre

temps?

t si prée consixiliaire

séchée à en une is d'une

nsemenage.

matières curures res semcalcinées leur des xcellent tous les
Comment s'emploie le noir animalisé ?

On sème cette poussière à la main, comrse la poudrette, et aussi à la dose de vingt minots à l'arpent.

Est.il un moyen plus facile de se procurer du noir animalisé ?

Oui, en employant dans les maisons ou au dehors les cabinets d'aisance à terre sèche (earth closets), qui constituent autant de fabriques de cet engrais.

\section{COLOMBINE}

Qu'est-ce que la colombine?

On appelle colombine los déjections de tous les oiseaux de basse-cour.

La colombine est.elle un bon engrais ?

C'est un engrais des plus énergiques, vingt fois plus puissant que le fumier ordinaire, et qu'il faut employer avec prudence.

\section{La colombine s'emploie-t-elle seule?}

Non : elle ne doit être employée qu'en mélange avec d'autres matières qui temperent sa trop grande énergie et sa chaleur excessive, capable de détruire la végétation.

Quelle est la manière de la recueillir et de l'employer?

On la ramasse dans le poulailler, tous les mois, puis on l'entasse dans un lieu abrité. Quand arrive le temps de l'employer, lors des semences, on la pulvérise à coups de masse, on la mélange avec de la terre et l'on 
sème ce mélange avec la semaille, à la volée, à la dose de vingt minots de colombine par arpent.

Est-il une autre manière de la recueillir?

Oui : on met sous les perchoirs de la paille, de la terre ou aútres débris, qui se mêlent à la colombine et l'empêchent de s'évaporer. On met ce mélange dans une fosse, et à chaque fois on jette huil ou dix parties de terre pulvérisée pour une partie de colombine. On brasse le mellange pour l'employer et on l'epand à la volée. Cette méthode a l'avantage de conserver toutes les substances fécondantes de la colnmbine.

\section{Qu'est-ce que le guano?}

C'est un engrais analogue à la colombine. Il est formé par les déjections des oiseaux sauvages, déposées et accumiulées sur des îles rocheuses en face du Chili et du Pérou. Cet engrais est trop dispendieux pour être employé avantageusement dans notre pays.

\section{ENGRAIS VÉGÉTAUX}

\section{Qu'appelez-vous engrais végétaux?}

On appelle ergrais végétaux les débris de plantes ou les plantes qu'on enfouit dans lé sol pour le rendre plus productif.

Quelle aifjérence existe-t-il entre les engrais végétaux et les engrais animaux?

Les engrais végétaux contiennent beaucoup moins d'azote que les engrais animaux; ils se décomposent moins vite et constituent un engrais moins énergique, 
mais qui se fait sentir plus longtemps que l'engrais animal.

Quels sont les principaux engrais végétaux?

de la bine et ge dans parties 1e. On nd à la $r$ toutes

est forosées et Chili et our être

antes ou rendre

aux et les

moins mposent ergique,
Ce sont les débris de plantes et les engrais verts.

Qu'entendez-vous par débris de plantes?

On désigne sous ce nom la paillo, les balles des céréales, la fanes ou cotons de pommes de terre, les feuilles des arbres, la mousse, les mauvaises herbes coupées avant la formation de la graine, le varech, la tourbe, etc.

Comment agissent les débris de plantes?

En se décomposant dans le sol, ils lui rendent les principes fertilisants qu'ils lui ont enlevés pour se former.

Comment s'emploie la tourbe?

On l'expose à l'air pour la faire sécher et la décomposer ; on la mélange avec quelques centièmes de chaux, ce qui lui cummunique un principe stimulant, et on l'emploie alors en couverture sur des plantes déjà développées.

D'ou provient le principe fertilisant de la tourbe?

Des débris de feuilles, de bois et d'autres matières végétales qui la composent.

Peut-on utiliser la tourbe autrement?

On peut aussi l'utiliser en la mêlant à la litière des animaux. Elle absorbe ainsi le purin, l'empêche de s'écouler ou de s'évaporer, fixe ses principes fertilisants et devient de cette maniere un excellent engrais $\epsilon \pm$ un bon moyen d'amélic er les fumiers. 
$A$ quels sols convient la tourbe?

Elle convient de preférence aux terres glaiseuses, qu'elle engraisse et amende en les rendant plus friables et plus meubles.

\section{Qu'est-ce que le varech?}

C'est une plante marine qui s'emploie beaucoup comme engrais par les cultivateurs qui habitent les bords de la mer.

\section{$A$ quelles cultures convient le varech?}

Le varech augmente la quantité et la qualité du lin ; on l'applique avantageusement à la culture de l'orge ; il fertilise les paturages et le salin qu'il renferme fait rechercher par les animaux l'herbe ainsi engraissee. Cet engrais se décompose promptement.

\section{Qu'appelez-vous engrais verts ou récoltes enfouies?}

On appelle engrais verts des plantes qu'on cultive exprès pour les enfouir dans le sol avant leur maturité.

Pourquoi les enfouit-on avant leur maturité ?

Parce que jusqu'à leur maturité, et mieux encore jusqu'à leur floraison, les plantes se nourrissent en grande partie des substances qu'elles absorbent dans l'air et ne prennent presque rien à la terre, à laquelle elles rendent bien plus qu'elles ne lui ont pris, au moment où on les enfouit.

Quelle espèçe d'engrais donnent les plantes enfouies?

Un engrais froid et humide, qui convient particulièrement aux terrains sableux et calcaires. 
Quelles propriétés doivent avoir les plantes semées pour l'enfouissement?

Elles doivent être des plantes non épuisantes, qui empruntent leur nourriture plutôt à l'atmosphère qu'a la terre, c'est-à-dire des plantes qui ont peu de racines et beaucoup de feuilles. Il faut ausei choisir des plantes qui poussent très vite, pour ne pas occuper le sol longtemps, et dont la semence ne coute pas cher.

Quelle est la plante qui réunit le mieux ces qualités?

C'est le sarrasin : aussi c'est toujours lui qu'on emploie de préférence pour l'enfouissement, et il produit de bons résultats. On peut aussi employer la vescie, les lentiles et même le trèfle, dans les terres fortes, impropres au sarrasin.

Comment faut-il semer les plantes destinées à l'enfouissement?

Il est bon de les semer très fort, afin qu'elles produisent le plus de feuilles possibles.

Quel avantage le, sol retire-t-il de cet enfouissement?

D'abord, le sul reprend tout ce que la plante lui a enlevé par sa racine; il bénéficie en sus de tous les principes fertilisants que cette plante a puisés dans l'air par ses feuilles, ce qui constitue le surplus gagné.

Comment se pratique l'enfouissement?

Quand les plantes à enfouir commencent à fleurir, on les enterre par un labour, en ayant soin d'attacher à l'avant de la charrue une chaîne trainante qui les renverse, afin qu'elles soient étendues par terre quand le versoir ou l'oreille de la charrue roule la terre pardessus. 


\section{ENGRAIS MINGRAUX}

Qu'appelez-vous engrais minéraux?

On appelle engrais minéraux des substances inorganiques ou minerales susceptibles de contribuer à la nutrition des plantes.

Quels sont les principaux engrais minéraux?

Ce sont le phosphate de chaux, le platre, la cenćre, le sel marin et la suie.

D'où provient le phosphate de chaux employé en agriculture?

Des os et des mines de phosphate, qui abondent en certaines parties de notre province.

Quel est le principe ou l'élément fertilisant du phosphate de chaux?

C'est principalement l'acide phosphorique, qui entre dans la composition des plantes.

Quelle est la meilleure préparative de phosphate provenant des os?

C'est le noir animal ou noir des raffineries.

Qu'appelez-vous noir des rafineries?

Ce sont des os calcinés qui ont été employés dans les raffineries pour décolorer le sirop, précédemment chauffé. avec du sang de bœuf.

Ce noir des raffineries constitue-t-il un bon engrais?

C'est un engrais riche : en sus du carbonate de chaux 
et du phosphore que contiennent les os, il renferme aussi les restes de sang provenant de la clarification $d u$ sucre.

\section{$A$ quelles plantes convient cet engrais?}

Il convient à presque toutes les plantes, céréales et racines, mais surtout a la pomme de terre, dunt il ameliore la qualité en lui donnant une chair plus dense et plus riche en fécule.

\section{$A$ quels sols convient cet engrais ?}

Il peut être employé dans tous les sols; mais son efficacité est particulièrement remarquable dans les terres légères, meubles, surtout dans les sols sablonneux ou sablo-argileux.

Le noir animal convient-il aussi aux prairies?

Oui; mais pour cela on le mélange avec beaucoup de terre pour faire un compost riche, auquel on incorpore de la chuux, des cendres, des débris organiques et animaux, que l'on répand sur l'herbe à raison de cinq ou six certs livres de noir par arpent.

A quelle époque se fait l'épandage du noir animal?

Il est préférable de le faire à l'automne. On peut a ussi le faire au printemps, par un temps chaud et humide, qui favorise sa décomposition dans le sol. Quand on l'emploie au printemps pour la pomme de terre, il est indispensable de mélanger le noir à une certaine quantité de terre fine et de déposer ce mélange à la main, au fond de la fosse ou du sillon creusé pour recevoir les plants. 
Comment prépare-t-on le phosphate minéral pour le livrer à l'agriculture?

En le broyant et le traitant par l'acide sulfurique, ou huile de vitriol, ce qui le rend plus assimilable.

A quels sols convient le phosphate minéral, ou superphosphate de chaux?

Il convient de préference aux terres sablo-argileuses et surtout aux terres fortes et argileuses, pour lesquelles il constitue le meilleur fournisseur d'acide phosphorique.

Quel inconvénient rencontre-t-il dans les terres calcaires?

L'excès de chaux que renferment ces terres a pour effet de rendre l'acide phosphorique insoluble.

Comment faut-il l'employer dans les sols légers et peu absorbants?

Il ne faut l'employer qu'en petite quantite. Dan: les terres sablonneuses, l'acide phosphorique se répand trop et il est entraîné par l'eau : c'est pourquoi il est mieux, pour ces terrains, que le phosphate ne soit pas broyé bien fin.

Qu'est-il bon de faire pour assurer une égale répartition du phosphate?

On mêle le phosphate en poudre, tel que livré par le commerce, avec de la terre pulvérisée ou de la sciure de bois; mais il faut bien éviter dans se mélange la cendre ou la chaux, qui diminuerait la solubilité de l'acide phosphorique et pourraient neutraliser l'action du phosphate. 
- Dans les terres fortes et argileuses, est-il bon d'employer le superphosphate en petite quantité?

Non: dans ces terres, le superphosphate employé d̀ petite dose ne produit pas d'effet.

A quelle dose faut-il employer le phosphate minéral ou superphosphate de cíaux?

La dose moyenne est d'environ 50 livres d'acide phosphorique a l'arpent; mais pour la culture intensive, ou à laquelle on veut faire produire les plus gros résultats, on peut aller jusqu'd 100 livres.

Quel poids de phosphate représentent 50 ou 100 livres d'acide phosphorique?

Cela dépend de la richesse du phosphate en acide phosphorique; mais en prenant la proportion de 14 livres d'acide par 100 livres de phosphate, ce qui est la proportion moyenne, pour procurer à un arpent de terre 50 livres d'acide phosplorique, il fuudrait $35 \mathrm{C}$ livres de phosphate, et 700 livres pour la dose maximum de 100 livres d'acide phosphorique.

Comment s'emploie le superphosphate de chaux?

On peut l'épandre au moment de la semaille; mais il est préférable de l'appliquer quelques semaines plus tôt. Le superphosphate ne donne pas de bons résultats en couverture, ni iorsqu'on le dépose dans les lignes de plantes. Il faut le semer sur le sol, puis l'enterrer par un labourage ou de profonds hersages. Sur les guérets d'automne, le meilleur moyen est de l'enterrer avec le scarificateur et ensuite la herse, ce qui se fait au printemps. 
A quelles plantes convient le superphosphate?

Il est efficace dans la culture des céréales et des plantes-racines. Il est l'engrais spécifique pour certaines piantes $d$ racine charnue, notamment la betterave.

Le superphosphate peut.il étre employé seul?

Oui, dans les sols qui ont reçu une abondante fumure d'engrais de ferme, ou dans les terrains riches ou ren. fermant un humus fertile; mais ses effets sont bien plus considérables lorsqu'on l'emploie simultanément avec des engrais'azotés, c'est-à-dire des engrais animaux ou des fumiers riches.

Quels effets l'emploi du superphosphate produit-il sur la qualité des récoltes?

Les engrais phosphatés modifient d'une façon avan. tageuse la qualité des récoltes. Le grain est plus parfait: l'orge vaut mieux pour le maltage; la paille est plus nourrissante; la pomme de terre contient plus de fécule et de matière sèche; la betterave est plus riche en sucre, et en général les plantes mûrissent plus tôt. Enfin, les superphosphates améliorent sensiblement la qualité de la pomme de terre, même quand le sol est peu favorable à cette culture.

\section{Qu'est-ce que le platre?}

Le platre, gypse ou sulfate de chaux, est un minfiral qui se trouve à l'état naturel dans la terr

Qu'appelez-vous platre cru?

C'est tout simplement la roche we plâtie pulvérisée mécaniquement. 


\section{Qu'appelez-vous platre cuit ?}

des

O'est le plâtre que l'on a calciné ou cuit pour le dé. barrasser de l'eau qu'il renferme a l'état cru.

Quelle est celle de ces deux espèces de platre qui s'emploie généralement en agriculture?

C'est généralement le platre cru, parce qu'il coâte moins cher.

A quelles plantes se limite l'action du platre?

L'action du platre comme engrais paraít limitée au trèfle, à la vesce, aux pois, aux choux, au tabac, au lin et au sarrasin. Il agit peu sur les prairics naturelles et point sur les céréales.

Quand et comment emploie.t-on le platre?

C'est au printemps qu'on sème le plâtre ì la main, sur la végétation déjà commencée. On le répand le soir ou le matin, à la rosée, par un temps calme et couvert, avant ou après une petite pluie. On le répand sur les plantes déjà levées, au moment où elles sont baignées de rosée, pour qu'il s'attache aux feuilles.

Quel est l'effet de la gelée sur le platre?

La gelée, si légère qu'elle soit, arrête l'action du plâtre et l'empêche de se produire, alors même que la temperature redevient favorable.

Faut-il plâtrer souvent?

Le plâtrage ne doit être employé sur un même terrain que tous les cinq ou six ans.

A quels terrains convient le plâtre?

Le plâtre produit ses meilleurs effets sur les terrains 
argileux, calcaires, sablonneux et sur les terres jaunes : 'il ne produit aucun effet sur les sols marécageux, humides ou mal égouttés.

A quelle dose s'emploie le platre?

A la dose d'un à trois minots à l'arpent.

Est-il avantageux d'employer le platre sur un sol pauvre?

Pour obtenir du plâtre des avantages réels, il faut ne l'employer que zur un sol riche en éléments nutritifs, c'est-à-dire que l'emploi du platre doit être accompagné de celui du fumier.

Les cendres s'emploient-elles comme engrais?

Elles constituent un engrais d'autant plus précieux qu'elles contiennent tous les principes minéraux des plantes qui les ont produites par la comburation. Elles rendent au sol une partie des substances que les plantes lui avaient enlevées pour croître et se nourrir.

Distingue-t-on plusieurs espèces de cendres?

On distingue les cendres de bois, les cendres de tourbe et les cendres de houille, ou charbon de terre.

Guelle est la plus riche de toutes ces cendres?

C'est la cendre de bois; et celle de bois franc est plus riche que celle de bois mou.

Quels sont les principaux éléments constitutifs de la cendre de bois?

Outre une grande quantité de carbonates de chaux et de magnésie, la cendre de bois renferme souveni 6 à 10 pour 100 de potasse et 2 à 5 pour 100 d'acide phosphorique. 
A quels sols et a quelles cultures convient la cendre?

Les bons effets de la cendre se font surtout sentir sur les sols argileux, compactes, humides et froids, et c'est principalement sur les trèfles, le tabac et les prairies naturelles que son action est plus puissante. Elle s'emploie aussi avec succès dans les sols marécageux et sur les prés, pour détruire les mauvaises herbes.

Qu'appelez-vous charrée?

On donne ce nom à la cendre éteinte, qui a servi aux lessives ou à la préparation de la potasse. Cette cendre est moins riche que la cendre vive; mais son emploi n'expose pas à brûler les plantes, comme cela arrive souvent avec la cendre vive.

Quels sont les principaux éléments constitutifs de la charrée?

La charrée contient lu carbonate de chaux, environ 10 pour 100 de phosphates, des silicates de potasse, qui lui donnent la propriété de faire sentir pendant longtemps ses bons effets sur la végétation.

$A$ quels sols convient la charrée?

Elle convient à tous les sols, mais surtout aux terres argileuses et compactes, qu'elle ameublit en même temps qu'elle les engraisse.

\section{A quelles récoltes convient la charrée?}

Elle est ́́galament profitable à toutes les récoltes et peut être employée au printemps sur les prés, les pâturages, pour la semaille de l'orge, de l'avoine et du blé d'Inde, et en été sur le sarrasin. 
La charrée agit-elle bien sur les prairies?

Elle est l'engrais par excellence des prairies, dont elle maintient longtemps la fertilité. Elle redonne au sol les principes minéraux dont il a été appauvri par la récolte du foin et communique à l'herbe la faculter de puiser dans l'air du carbone et de l'azote, qui ne coútent rien au cultivateur.

Combien de temps dure l'effet de la charrée?

De cinq à huit ans.

Comment s'épand la charrée?

A la main ou avec une pelle, lorsqu'elle est bien sèche et que le sol est peu humide. On peut l'enterrer par un léger hersage ou la laisser à nu sur le champ. Il est bon qu'elle reçoive un peu de pluie après avoir été semée, vu que la sécheresse l'empêche d'agir.

A quelle dose s'emploie la charrée?

A la dose de 50 à 150 minots à l'arpent. Il faut augmenter ou diminuer la dose, selon l'humidité et la nature du sol. Plus le sol est humide, comparte et pauvre en calcaire, plus il faut augmenter la dose; plus il est sec et léger, plus il faut aussi l'augmenter.

Quels sont, dans notre pays, les cultivateurs qui doivent le plus s'adonner à l'emploi de la cendre comme engrais?

Ce sont les colons qui défrichent de nouvelles terres, vu que les bois qu'ils brûlent pour débarrasser la terre leur procurent d'immenses quantités de ce précieux engrais, qu'ils n'ont qu'à ramasser. 
Les cendres de tourbe sont-elles aussi riches que les cendres de bois?

Non : elles renferment moins de soude, de potasse et pas de phosphate, mais joliment de plâtre, ce qui fait que ces cendres exercent sur le trèfle une action vraiment surprenarte.

A quelles récoltes convient la cendre de tourbe?

$\mathrm{Au}$ lin, aux prairies, mais surtout au trèfle, sur lequel elle produit des effets prodigieux.

A quelle dose l'emploie-t.on?

A la dose de 50 à 100 minots, au plus, à l'arpent.

Quelles sont les meilleures cendres de tourbe?

Ce sont celles qui sont blanchâtres et proviennent de tourbières situées à peu de distance de la mer et qui ont été autrefois submergées par les eaux.

A quoi servent principalement les cendres de houille?

On les emploie pour amender les terres froides, humides et argileuses, pour noircir les terres blanches et les rendre ainsi plus accessibles à la chaleur, pour améliorer les terres marécageuses.

$A$ quelles récoltes conviennent ces cendres?

Comme engrais, on les donne aux pommes de terre, au trèfle et au seigle, à raison de 50 à 100 minots à l'arpent.

Comment les emploie-t-on et quelle est leur durée?

On les emploie comme couverture ou comme engrais à enfouir. Leur effet ne se fait pas sentir plus d'un an. 
La suie donne-t-elle un bon engrais ?

A raison de sa composition, qui renferme de l'acide ulmique, beaucoup d'azote, de la potasse et de la soude, la suie constitue un engrais d'une grande valeur, principalement la suie de charbon de terre, qui est plus riche que celle de charbon de bois.

A quels sols convient la suie?

A tous les sols, mais principalement aux terres calcaires et graveleuses.

$A$ quelles récoltes convient-elle?

A toutes les récoltes, mais principalement aux prairies naturelles, sur lesquelles elle agit avec beaucoup d'énergie.

\section{Comment l'emploie-t-on?}

Au printemps, on l'emploie en couverture pour les trèfles et avćc la semence pour les céréales. On augmente ses effets en la mélangeant à parties égales avec de la charrée.

La suie a-t-elle d'autres qualités que ses propriétés comme engrais?

Oui : par son gout âcre et son odeur forte, elle chasse les insectes, qui sans cela s'attaqueraient aux plantes.

A quelle dose s'emploie la suie?

A la dose de 20 à 30 minots à l'arpent.

Le sel marin renferme-t-il quelques principes fertilisants?

Oui : il nferme du chlore et de la soude, qui se trouvent dans la composition des plantes, ce qui explique son emploi comme engrais. 
Quelle est la manière d'employer le sel ?

Comme il pourrait brâler les plantes à l'etat solide, on l'emploie généralement en solution ou en saumure, dont on arrose la terre par un temps humide, afin que le soleil ne le dessèche pas trop promptement.

Peut-on l'employer autrement?

Oui, et c'est la méthode la plus recommandable. On mélange une partie de sel avec deux parties de chaux. On met pendant trois mois ce mélange sous un abri ou une couverture de terre; on brasse alors le tout et on l'applique à la dose de mille livres à l'arpent, en le semant à la main comme le plâtre, au printemps.

Quel est l'effet du sel ?

Il augmente la qualité et la quantité du grain, mais surtout du foin et des pâturages, qui sont plus recherchés des animaux.

$A$ quels sols convient le sel?

Il convient principalement aux terres calcaires; mais beaucoup de cultivateurs prétendent l'employer avec succès dans les terrains sableux, surtout pour la sulture de l'avoine.

\section{ENGRAIS MIXTES}

Qu'appelez-vous engrais mixte ou complet?

C'est un engrais qui renferme toutes les substances minérales et organiques dont les plantes ont besoin pour croitre et produire, ou un engrais qui rend au sol autant d'éléments de fertilité que les récoltes lui en enlèvent. 
Quel est l'engrais qui réunit ces qualités?

C'est le fumier de ferme.

De quoi se compose le fumier?

Le fumier se compose des déjections solides et liquides des animaux ainsi que de la litière qu'on leur donne.

Quelle est la valeur du fumier de ferme?

C'est le plus important de tous les engrais et la base de la production agricole.

Quelles sont les causes qui influent d'une manière générale sur la qualité du fumier?

La qualité de la nourriture donnée aux animaux influe d'une manière sensible sur la qualité du fumier produit. Plus cette nourriture est bonne et abondante, meilleur et plus abondant est le fumier.

$Y$ a t-il une autre cause qui influe sur la qualité du fumier?

L'état des animaux influe aussi sur la qualité du fumier. Les animaux en santé et surtout les animaux gras donnent un bien meilleur fumier que les animaux malades et maigres. Les bêtes adultes donnent aussi un meilleur fumier que les jeunes, et le fumier des bœufs de travail est plus riche que celui des vaches laitières.

Comment divise-t-on les fumiers au point de vue de leurs propriétés physiques?

En fumiers froids et en fumiers chauds.

Quelles sont les propriétés caractéristiques des fumiers froids?

Ils sont moins actifs, moins prompts à fermenter, plus 
aptes à retenir l'humidité et la fraîcheur; ils agissent plus lentement, mais leur effet se fait sentir plus longtemps dans le sol.

liquilonne.

a base

'énérale

imaux fumier idante,

umier?

ité du imaux imaux aussi er des vaches

de leurs

fumiers

$r$, plus

Quelles sont les propriétés caractéristiques des fumiers chauds?

Les fumiers chauds sont spongieux, secs, peu consistants, perméables à l'air; ils fermentent avec une grande énergie et sont difficiles à conserver; ils se décumposent promptement et agissent rapidement sur le sol.

Quels sont les animaux qui produisent respectivement les fumiers froids et les fumiers chauds?

Les fumiers froids sont produits par les bêtes à cornes et les porcs; les fumiers chauds, par les chevaux et les moutons.

A quels sols conviennent ces deux espèces de fumier?

Les fumiers froids, ou ceux de cochons et de bêtes à cornes, s'emploient de préférence dans les sols secs, sableux et chauds; les fumiers chaux, de cheval et de mouton, s'emploient plus avantageusement dans les sols froids et humides, où les causes de décomposition sont moins actives.

Comment expliquez-vous les propriétés du fumier des bêtes a cornes?

Les bêtes à cornes mâchent beaucoup plus le fourrage que les autres animaux de ferme, ce qui fait que leurs déjections se composent de parties beaucoup plus divisées et sont moins poreuses. Nilles boivent et urinent plus que les autres animaux, ce qui rend leur fumier plus aqueux et plus frais. 
Le fumier de cochon a-t-il les mêmes propriétés?

Bien que classé dans les fumiers froids, parce qu'il est aqueux, le fumier de cochon se dessèche plus facilement et devient alors bien plus friable que celui des bêtes à cornes, auquel il est bien inférieur.

Quel inconvénient présente l'emploi de ce fumier?

Appliqué seul à la culture des plantes-racines, le fumier de porc leur communique une saveur désagréable. Pour cette raison et à cause de sa fluidité, il convient de préférence aux prairies, et le meilleur moyen d'en tirer partie, c'est de le mêler aux autres fumiers.

Comment s'expliquent les propriétés du fumier de cheval?

Les chevaux boivent et urinent bien moins que les bêtes à cornes, se nourrissent à l'écurie de fourrages secs et d'avoine, ce qui rend leur fumier moins aqueux, plus riche en azote et en phosphate, plus énergique que celui des bêtes à cornes, mais aussi plus susceptible de s'echauffer, de se dessécher au contact de l'air, et de perdre ainsi une grande partie de ses éléments fertilisants.

Comment s'explique la prompte décomposition du fumier de cheval?

Le défaut de consistance de ce fumier favorise l'évaporation de l'humidité, la pénétration de l'air, et accélère la decomposition de la matière organique. Cette décomposition est encore favorisée par la concentration et la richesse en azote de l'urine du cheval, qui se décompose rapidement et agit comrse ferment.

Le fumier de cheval exige t-il beaucoup de soin ?

Oui, beaucoup plus que celui des bêtes à cornes. 
Pour en obtenir de bons résultats, il faut lui donner plus d'humidite que ne lui en procurent les urines du cheval et l'entretenir au moins égal en poids au fumier de vache.

A quels sols convient le fumier de cheval?

A l'état ordinaire ce fumier, qui est le fumier chaud par excellence, convient aux terrains froids, c'est-à-dire aux sols argileux, profonds et humides, et pas du tout aux terres sablonneuses et calcaires.

Le fumier de mouton est-il aussi chaud que celui de cheval?

Il est moins chaud et son action est plus durable, parce qu'il est plus pailleux et renferme moins d'urine, attendu que les moutons boivent moins que les autres animaux.

$A$ quels sols et à quelles récoltes convient le fumier de mouton?

A tous les sols, excepté aux terres calcaires; mais il convient de préférence aux terres fortes, argileuses, compactes et humides. Les plantes qui s'en trouvent le mieux sont le tabac et les choux. Il donne une saveur désagréable aux plantes délicates, fait verser le blé et affecte sa qualité ainsi que celle de l'orge, qui fournit moins d'amidon.

Qu'appelez-vous fumiers longs et fumiers courts?

On appelle fumiers longs, frais ou pailleux, les fumiers qu'on sort des étables pour les employer aussitôt, sans les laisser fermenter. Les fumiers courts ou gras sont ceux qu'on a laissé tomber en une décomposition profonde, qui les convertit en une espèce de terreau qu'on appelle fumier pourri ou beurre noir. 
Quelles sont les propriétés particulières des fumiers longs?

Ils ont une action bien plus longue et plus durable sur la végétation que les fumiers courts: c'est pourquoi on les applique de préférence aux plantes qui restent longtemps en terre, aux sols forts, compactes et argileux, qu'ils ameublissent tout en les engraissant.

Quelles sont les propriétés particulières des fumiers courts?

Ils sont lourds, compactes, agissent instantanément sur les plantes; mais leur effet a peu de durée, ce qui fait qu'on les applique de préférence aux plantes qui ne restent pas longtemps dans le sol et aux terres légères.

Quelle est la partie la plus riche du fumier?

C'est la partie liquide, ou l'urine, qui contient en moyenne presque la moitié de l'azote et un peu plus du tiers des matières minérales renfermées dans le fourrage.

Est-il important de ne pas laisser perdre les urines des animaux?

Le cultivateur soucieux de ses plus chers intérêts doit consacrer tous ses soins à la conservation des urines des animaux, puisqu'elles sont de toutes les parties du fumier la plus riche en éléments fécondants.

Quels rapports existe-t-il entre les déjections solides et les déjections liquides des animaux?

Les déjections solides et les déjections liquides se complètent réciproquement par les éléments nutritifs végétaux qu'elles renferment. Il faut donc, autant que possible, les réunir pour les rendre au sol ; ce n'est qu'à cette condition que le fumier d'étable forme un fumier complet. 
Quel est l'intermédiaire le plus efficace pour opérer cette réunion des déjections liquides aux déjections solides?

C'est la litière.

\section{Qu'appelez-vous litière?}

Ce sont des pailles, des balles, des fanes, des feuilles ou des matières terreuses que l'on répand sous les animaux en stabulation pour rendre leur couche plus douce et plus sèche, en même temps que pour absorber l'urine et l'incorporer à la partie solide du fumier.

\section{Quelle est la litière la plus généralement employée?}

C'est la litière de paille. La conformation creuse et tubuleuse de la paille lui permet de mieux absorber les urines, de mieux retenir les déjections molles, sans compter qu'elle augmente le volume du fumier et 'e rend plus propre à ameublir la terre et à iui donner plus de perméabilité.

La paille est-elle elle-même un engrais?

Oui, puisqu'elle se compose de matières provenant de l'action de la végétation. Sous ce rapport, les pailles les plus riches sont celles des plantes légumineuses, notamment la paille de sarrasin, qui renferme le plus d'azote et d'acide phosphoriqne.

$A$ défaut de paille, que peut-on employer pour litière?

des se utritifs nt que st qu'à fumier

On peut employer une foule de plantes et de débris végétaux, tels que les fougères, la sciure de bois, les feuilles, la mousse et la tourbe. La plupart de ces matières sont plus riches en azote et en principes saling que la paille. 
Quelle est la meilleure de toutes ces matieres

C'est la poussière de tourbe, qui possede au plus haut dégré la faculté d'absorber l'ammoniaque, principalement quand elle renferme beaucoup de mouss Grace à cette qualité, elle agit aussi comme désinfectant et son emploi a pour effet de purifier l'air des étables, surtout des écuries, et d'y maintenir une atmosphère presque entièrement dépourvue d'ammoniaque.

L'emploi de la tourbe, pour absorber les urines, exige-t-il beaucoup de frais?

Non, pas beaucoup : on fait sécher la tourbe sur champ, ce qui la rend très friable, et les manipulations du transport et de l'emploi la réduisent en poudre. On met cette poudre dans un endroit commode, et, matin et soir, on en répand un peu dans l'allée en arrière des animaux et on l'enlève avec le fumier quand elle est saturée d'urine.

Peut-on employer autre chose au même effet, quand on n'a pas de tourbe?

On peut employer de la même manière de la terre noire, de la terre à jardin et même de la terre ordinaire, bien pulvérisée.

Comment dispose-t-on les allées pour employer la tourbe ou la terre sèche comme absorbants du purin?

On les dispose de façon à ce que la partie contiguë au bout du pavage forme une espèce de rigole de trois pouces' de profondeur et d'une dizaine de pouces de largeur, en ayant soin de laisser la partie médiane de l'allée au niveau du pavage. On met dans cette rigole, qui reçoit naturellement toute l'urine, la tourbe ou la 
terre destinée à l'absorber, et on enleve le tout avec le reste $d u$ fumier.

haut palenche. ctant ables, ohère

$g e \cdot t-i l$

sur tions On uatin $e$ des e est

$n n^{\prime} a$

terre aire,

be ou iguë trois $\mathrm{s}$ de e de role, a la

Existe.t.il un autre moyen de recueillir la partie liquide du fumier?

Oui, c'est le système du drainage des étables et des citernes à purin. Mais ce système nécessite des frais de construction, des fosses à purin, des tonneaux-arrosoirs et autres dépenses qui ne peuvent être avantagcusement encourues que dans les grandes exploitations.

Quanc le fumier, solide et liquide, a été bien recueilli dans les étables, exiget-il encore d'autres soins?

Oui, ce sont les plus importants et malheureusement les plus négligés.

En quoi consiste ordinairement la négligence dans le traitement du fumier à sa sortie de l'étable?

Les fumiers généralement accumulés à la porte des étables sont enneigés l'hiver et lors du dégel et des pluies, le printemps, le purin s'en échappe, transforme souvent les cours en bourbiers malpropres et malsains et se mêle à l'eau des neiges et des pluies pour être entraîné dans les cours d'eau. Après avoir subi ce lavage, le fumier qui reste en tas durant l'été s'échauffe en se desséchant, et perd par l'évaporation l'ammoniaque et les autres substances gazeuses qui en forment la partie la plus fertilisante, de sorte que, à l'automne, il ne reste pour ainsi dire que de la paille desséchée.

Quelles sont les substances qui sont ainsi perdues par le lavage et l'évaporation?

Ce sont l'ammoniaque, ou l'azote transformé, l'acide 
phosphorique, lés sels de potasse et autres, c'est-à-dire les substances qui contribuent le plus à la nutrition et à la formation des plantes et des graines.

Que dit-on de celui qui laisse ainsi perdre son funier?

On dit avec raison qu'il fait manger son bien par le soleil.

Quels sont les soins généraux à dorner au fumier à la sortie de l'étable?

Il faut le déposer sur un fonds imperméable afin d'empêcher le purin de s'infilirer dans la terre. Ii faui que ce fonds soit un peu élevé, afin que leßs couches inférieures du fumier ne soielit ras atteintes par les eaux de neige et de pluie. Enfin, il est, bon que l'emplacement du tas de fumier soit couvert, afin de protéger le fumier contre la neige et la pluie, qui le laveraient sans cela, ainsi que contre l'ardeur du soleil, qui le ferait trop chəuffer et le porterait à s'évaporer.

Quel fonds est le plus facile à faire pour l'emplacement d'un tas de fumier?

C'est tout simplement une couche de terı' glaise, qu'il est bon d'éle"er un peu an bord, pour empêcher l'écoulemen` du purin.

Quelle couverture faut-il donner au tas de funier?

Les bons cultivateurs ont souvent un bon hangard à fumier; mais on peut arriver au même but avec une construction moins dispendieuse et peut-être plus commode. Il suffit de monter sur quelques poteaux une 
couverture en planches, à joints couverts, qui arrête la neige, la pluie et les rayons du soleil. aient ui le

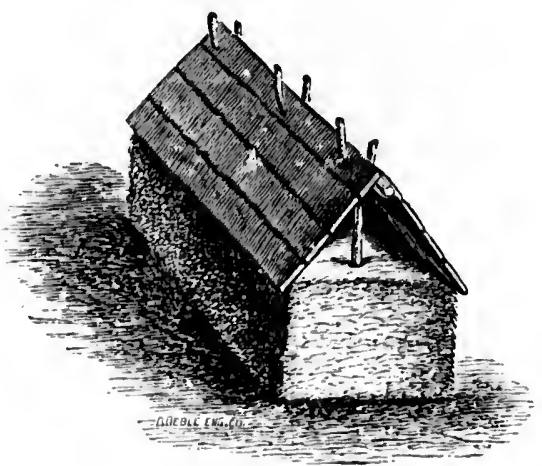

Fig. 2

Est-il un procédé encore plus simple?

Dans certaines fermes bien tenues, on se contente pour toute couverture de mettre un lit de paille sur le tas de fumier, dès qu'on a fini de le monter et après l'avo': bien foulé. On pourrait mettre un lit de terre sèche, ce qui'serait encore mieux.

Quelle hauteur et queli: de fumier?

On peut le faire circulaire ou carré; mais il faut que le bord soit perpendiculaire au sol et bien droit. Ia ha uteur du tas ne devrait pas excéder cinq ou six pieds. 


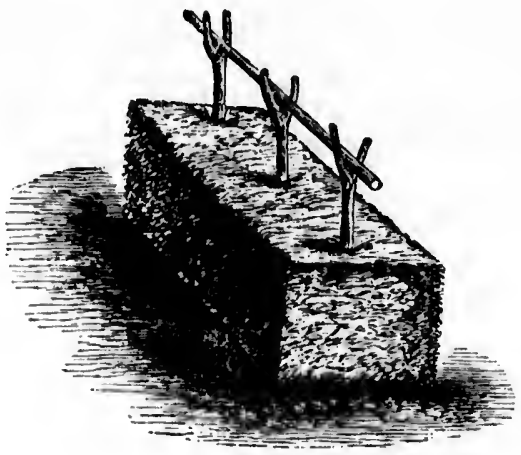

Fig. 3

Comment faut-il disposer le fumier dans le tas?

Commo les fumiers des divếrses espèces d'animaux n'ont pas tous la même valeur ni les mêmes propriétés physiques, il est mieux de les mélanger, afin qu'ils s'améliorent les uns les autres. De cette façon, les fumiers froids tempèrent l'énergie des fumiers chauds, qui sont trop portés à fermenter, de même que les fumiers chauds favorisent la décomposition des fumiers froids, qui s'échauffent plus difficilement.

Est-il bon d'Entremêler des couches de terre ávec les couches do fumier?

C'est ine excellente pratique, recommandée et suivie par les hommes les plus compétents. Outre qu'elles régularisent la fermentation, ces couches de terre absorbent le purin et les substances gazeuses qui, sans cela, s'écouleraient au dehors. 
Comment régularise-t.on encore la fermentation?

En tassant le fumier. Plus il est foule, moins il s'échauffe. Enfin, le tas fini, il faut le recouvrir d'une couche de terre, de tourbe autant que possible, qui absorbe les gaz réussissant à s'échapper et devien` ellemême un excellent fumier.

Emploie-t-on aussi le platre pour prévenir la fermentation du fumier et fixer les gaz ammoniacaux?

Oui, on emploie le plâtre à cette fin; mais des expériences scientifiques et pratiques constatent qu'il produit ¿'ès peu ou point d'effet, et que la terre sèche, principalement la terre sablo-argileuse, lui est infiniment préterable.

Est-il encore un autre moyen d'arrêter la fermentation excessive du fumier?

Oui : on l'arrose avec du purin ou de l'eau.

Que faut-il faire quand on veut se procurer du purin pour arroser le fumier ou les plantes?

O $\approx$ pratique autour du fonds de glaise sur lequel doit reposur le fumier, avec des ramifications atteignant le centre, un rigolet qui amène le purin dans un réservoir organisé à cette fin.

Quelle forme doivent avoir ces réservoirs?

On les fait profonds, mais de peu de diamètre, pour qu'ils offrent peu de surface à l'évaporation, et on les tient constamment couverts. 
Comment fait.on pour arrêter la fermentation du purin dans les réservoirs?

On jette dans le purin de la couperose dissoute dans de l'eau, ou, ce qui est encore bien mieux, de l'huile de vitriol dilué dans sept ou huit fois son volume d'eau, et J'on brasse le purin, afin que le réactif pénètre partout.

Peut-on employer le platre pour arrêter cette fermentation?

On l'emploie généralement; mais c'est à tort, car outrf qu'il ne possède pas les propriétés voulues pour prévenir la production et l'action de l'ammoniaque, il se dépose au fonds du réservoir et n'agit plus sur le reste de la masse.

Est-il avantageux de laisser décomposer le fumier au point de le transformer en fumier pourri ou beurre noir?

Non, cette décomposition excessive lui fait perdre plus de la moitié de ses principes fertilisants, sans compter que le fumier pourri est compacte et n'ameublit pas les terres fortes, ce qui fait qu'il convient de préférence aux terres sableuses et graveleuses.

Quand le furiier est-il dans le meilleur état pour être employé avantageusement?

Quand la fermentation a amolli et aplati les pailles, que celles-ci ont pris une couleur brune, un aspect gras et que toute la masse est parfaitement homogène.

Est-il quelquefois utile d'employer le fumier frais?

L'emploi du fumier frais est parfois très avantageux. Lorsque le sol est argileux, le climat froid et humide, le fumier frais a pour effet de l'smeublir, de le dessécher et de l'échaufier rapidement. 
Quelle est ordinairement la maniere de mettre le fumier sur la terre?

On le transporte dans le champ à l'avance, on le dépose en tas qu'on laisse séjourner longtemps sur la terre a vant de les épandre.

Quels sont les mauvais effets de cette pratique?

Le fumier ainsi exposé à l'air, surtout dans les temps chauds, perd par l'évaporation une bonne partie de ses substances gazeusee les plus riches en matières fortilisantes. Les matières salines sont dissoutes par les pluies et se concentrent sur l'espace occupé par le tas de fumier, qui se trouve ainsi plus engraissé que le ies endroits et fait verser le grain, qui pousse $e^{r}$. ..ffes. Ce qui reste à épandre ne renferme que des suatières lavées, desséchées, n'ayant pas plus de valeur que de la paille.

Quelle est la meilleure manière d'épandre et d'enterrer le fumier?

On le dépose dans le champ en tas espacés d'une vingtaine de pieds, et l'on épard imizédiatement ces tas de la manière la plus uniforme possible. On enterre ensuite le fumier par un labour.

\section{Quelle doit être la profondeur de ce labour?}

Dans les terres fortes, environ six pouces, et même moins, quand la terre est compacte et très humide. Dans les terres sableuses et legères, il est bon d'enterrer le fumier un peu plus que dans les terres fortes. Enfin, le fumier destiné aux plantes pivotantes doit être enterré à une plus grande profondeur que celui ćestiné aux céréales ou autres plantes à racines superficielles. 
Quel est le meilleur moyen de bien enfouir le fumier?

C'est de faire suivre la charrue par des enfants ou des hommes qui, avec des rateaux, ramènent le fumier dans le sillon, à mesure qu'il est ouvert. Le fumier ainsi ramené dans un premier sillon est complètement enterré par le sillon suivant.

\section{Qu'appelez-vous fumure en couverture?}

Cette fumure consiste à distribuer à la surface du sol le fumier qui n'est enfoui que plus tard, après la récolte.

Pour quelles cultures s'emploie la fumure en couverture?

Pour les prairies, surtout les prés de trèfle, et les récoltes sarclées, notamment les pommes de terre. Ce mode de fumure convient de préférence aux terres légères et sableuses, auxquelles le fumier ainsi employé conserve un peu d'humidité.

Quels sont les inconvénients de la fumure en couverture?

C'est la méthode qui expose aux plus grandes pertes en azote, sans cómpter qu'elle favorise la croissance des mauvaises herbes. C'est pourquoi il faut l'appliquer de préférence aux cultures sarclées, dont les binages combattent la propagation des mauvaises herbes.

A quelle dose faut-il employer le fumier?

Cela dépend de la nature des terres et des plantes à récolter; mais la dose varie de quarante à soixante et dix voitures de fumier à l'arpent.

Comment s'emploie le purin?

Quand on emploie le purin séparément, il faut d'abord l'additionner de cinq ou six fois son volume d'eau, sans quoi il brûlerait les plantes. On le répand ensuite sur le champ avec le tonneau-arrosoir. 
mier?

unts ou des imier dans mier ainsi ent enterré

ace du sol la récolte.

ouverture?

fle, et les terre. Ce erres légèemployé

ouverture? des pertes ssance des appliquer s binages bes.

plantes à ixante et

faut d'ane d'eau, li ensuite
A quelles cultures convient le purin?

Le purin, employé seul, convient admirablement aux prairies, dont il augmente beaucoup le rendement. On peut aussi l'appliquer aux plantes sarclees, sur lesquelles il produit souvent des effets prodigieux.

Quel temps faut-il choisir pous cpandre le purin?

Il faut choisir un temps couvert et humide, afin que le purin ne soit pas immédiatement évaporé par le soleil et perdu pour la végétation.

\section{Qu'appelez-vous compost?}

Le compost est un engrais mixte, ou mélange de débris minéraux, végétaux et animaux.

Que fait-on entrer dans les compost3?

On fait entrer dans les composts une foule de déchets et de résidus qui sans cela seraient perdus-balayures, criblures, suie, chiffors, sciure de bois, feuilles, mauvaises herbes, fanes, épluchures de légumes, cadavres d'animaux, poils, plumes, eaux de cuisine et de lavages, charrée, curures de fossés, platras, curures de jardins, ainsi que de la terre et de la chaux.

Pourquoi emploie-t-on de la terre et de la chaux?

On emploie la chaux pour provoquer et consommer la décomposition des matières animales et végétales; la terre, pour absorber les gaz fertilisants provenant de cette décomposition.

\section{Quelle est l'utilité du compost?}

Outre qu'il transforme en un bon engrais une foule de matières qui sans cela seraient perdues, le compost a encore l'avantage d'introduire dans l'exploitation des habitudes d'ordre et de propreté. 


\section{Comment se fait le compost?}

On donne au tas une forme carrée or rectangulaire et une hauteur n'excédant pas cinq ou six pieds, et on l'installe dans un en lroit ombragé, afin que la dessication soit ralentie. Il est bon d'incliner légèrement l'emplacement du tas, pour que les eaux d'arrosage puissent s'écouler dans une fosse qui les retient. Pour faciliter la pénétration des arrosages, on pratique avec un pieu des trous dans le tas. On place les matières les plus dures à décomposer au milieu du tas, où la fermentation est plus forte. Quand c'est possible, on alterne les couches do résidus avec les couches de chaux, et quand la décomposition est opérée, on recoupe, c'est-à-dire on brasse le tas à la pelle, pour effectuer le mélange complet de toutes les matières; et si l'on n'est pas prêt à employer le compost de suite, on couvre le tas d'une couche de terre ou de paille, comme le fumier, pour empêcher les peites par le lavage des pluies ou l'évapo. ration.

Emplcie-t-on la chaux vive ou la chaux éteinte?

On peut employer i'une ou l'autre; mais il est préférable de se servir de la chaux en pierre, qui a une bien plus grande force de décomposition.

\section{Comment s'emploient les composts?}

On les emploie généralement en couverture et on les applique de préférence aux prairies, sur lesquelles l'effet de cet engrais se fait souvent sentir deux ou trois ans. Quand la proportion de chaux est un peu considerable, l'enfouissement du compost équivaut à un chaulage. 


\section{CHAPITRE VI}

\section{MISE F.N CULTURE DU SOL}

Quels sont les travaux requis pour mettre le sol en cullure?

Ce sont les travaux de déboisement, d'épierrement, d'assainissement et les travaux de culture proprement dits, qui comprennent le labourage, le hersage, le roulage et les autres façons que l'on donne à la terre pour fuvoriser la végétation.

\section{\& 1-Déboisement}

préfée bien

\section{Quel est le but du déboisement?}

C'est de débarrasser lé sol vierge des bois qui le recouvrent.

on les l'effet is ans. Erable, age.
Quels sont les travaux que nécessite le déboisement?

On commence d'abord par essarter, c'est-à-dire arracher ou couper les arbustes et les petits arbres qui poussent au pied des grands arbres. On abat ensuite les arbres de haute futaie et on les fait braler sur le champ. Pour mieux nettoyer le terrain, on coupe les branches des arbres abattus et l'on amasse ces branches en tas séparés ou sur les piles de troncs d'arbres. 
Abat-on de la même façon les bois mous et les bois francs?

Nnn : les bois mous, qui bralent plus facilement, s'abattent d'ordinaire en javelles, c'est-à-dire qu'on les abat de façon à ce qu'ils s'entrecroisent et forment des javelles ou des faisceaux qui s'enflamment et se consomment aisément. Comme les bois francs sont plus difficiles a brûler, on les coupe par tronçons d'une douzaine de pieds de longueur, qu'on empile avec soin, pour favoriser l'action $d u$ feu.

Que fait-on de la cendre provenant des brûlages?

Les colons soigneux ramassent la meilleure, principalement celle de bois franc, et en font de la perlasse ou de la potasse. Les charrées provenant des lessives de potasse et les cendres de qualité inférieure sont répan. dues sur le sol nouvellement défriché, pour en corriger l'acidité et empêcher ainsi les plantes de rougir.

Comment cultive-t-on les terres nouvellement déboisées?

On sème à la herse, vu que les souches et les grosses racines rendent le labourage impraticable, c'est-à-dire qu'on se contente de répandre la semence sur le sol et de l'enterrer par un hersage aussi énergique que possible. Quand on n'a pas d'atelages, on laboure d la pioche, on sème sur ce labourage, puis on enterre la semence au rateau.

Quelles sont les plantes ordinairement cultivées dans les terres neuves?

Ce sont l'orge, l'avoine, le sarrasin, quelquefois le blé, et surtout les pommes de terre, que l'on sème en rangs ou à la butte.

Que seme-t-on avec les céréales?

On sème de la graine de foin, afin de convertir le plus 
tot possible la terre neuve en prairie et en paturage, ce qui est le meilleur moyen de préparer la terre, d'empêcher la pousse des broussailles et de faile pourrir les racines et les souches.

Que fait-on des souches?

On les laisse quelques années sans leur toucher et, sous l'action des agents atmosphériques, elles se décomposent, les racines pourrissent et leur enlèvement devient facile. Cette décomposition ajoute au sol de nouveaux éléments de nutrition pour les plantes.

Comment se fait l'essouchage?

rlasse ves de répanrriger

rosses à-dire sol et possibioche, aence

ns les

e blé, rangs

Quand on les suppose assez pourries, on déterre les

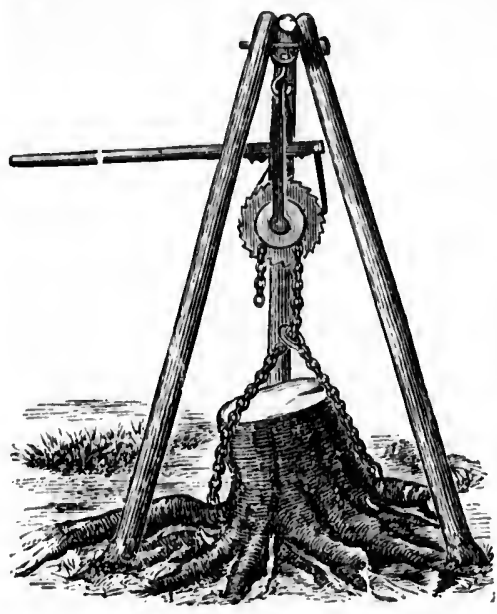
racines à la pioche, on les coupe aussi loin que possible dans la terre, dont on les extrait, puis on arrache les souches à bras ou avec les attelages, surtout les bœufs, quand elles ne sont pas trop grosses, et avec des appareils spéciaux, quand elles sont trop pesantes ou trop prises dans la terre.

Fig. 4.-Arrache-souches.

Quels sont les principavx appareils mécaniques ordinairement employés?

Le cabestan, la chèvre et les arrache-souches. 

Que fait-on des souches arrès les avoir arrachées?

On les ramasse en tas et on les fait braler, puis on épand la cendre sur la terre.

Comment se fait le défrichement des savanes?

On commence par les égoutter autart que possible, au moyen de fossés; on arrache ensuite les talles de broussailles ou d'arbustes, qu'on amasse en tas, et quand la couche superficielle est assez sèche, on la fait braler avec les tas d'arbustes.

Quel instrument peut-on employer pour arracher les broussailles?

La grippe, ou arrache-broussailles, qui est tirée par un cheval et fait beaucoup d'ouvrage en peu de temps.

Comment fait-on pour activer le desséchement des terres savaneuses?

On passe la charrue de deux pieds en deux pieds, ce qui ramène des billons à la surface et donne de l'écoulement à l'eau renfermée dans les espaces non attaqués par la charrue.

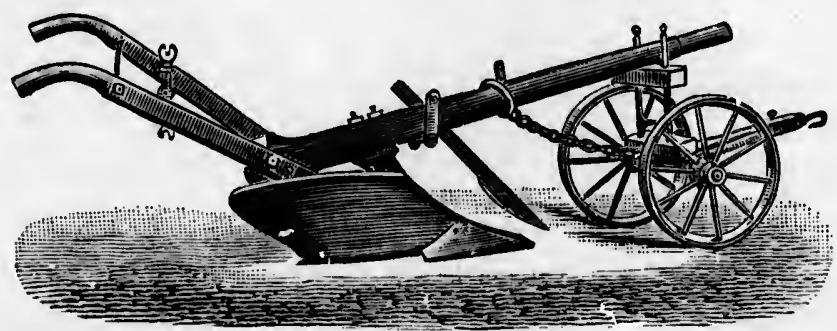

Fig. 5.-Charrue à rouelles.

Quelles charrues emploiet-on d̀ cette fin?

Des charrues fortes, munies de coutres capables de 
couper les branches et les bois qui se trouvent dans la terre. L'ancienne charrue à rouelles, ou avant-train, en bois et solidement ferrée, est celle qui convient par excellence à cet usage. En France, on emploie la charrue Trochu, munie de trois coutres dentés, qui agissent comme une scie pour couper les racines.

ossible, lles de ;quand braler

$s$ brous-

par un 1 ps.

is terres ieds, ce l'écouttaqués

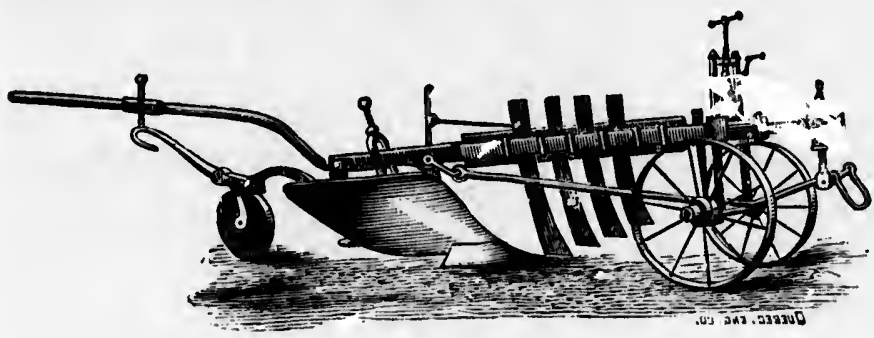

Fig. 6.-Charrue déboiseuse.

\section{\& 2-Epierrement}

En quoi consiste l'épierrement?

A enlever du sol toutes les pierres susceptibles de nuire à l'action des instruments aratoires.

Comment s'enlevent les pierres?

On enlève à bras d'hommé, celles qui ne sont pas trop grcsses et on les amasse en tas dans les endroits où eiles seront le moins nuisibles.

Comment se débarrasse-t-on des gros cailloux?

On creuse tout près un trou assez profond, on roule le caillou dedans et on le recouvre d'une couple de pieds de terre, afin que la charrue ne puisse pas l'atteindre. 
Que fait-on des cailloux qui sont trop gros pour être enterrés?

On les fait éclater en les minant. Quand on n'a pas ce qu'il faut pour miner, on les fait rougir en faisant un grand feu dessus; quand ils sont bien rouges, on y jett. de l'eau froide et la contraction qui s'opère fait éclater le caillou en morceaux qu'on peut transporter.

$Y$ a.t-il moyen de tirer parti des pierres et des cailloux? :

$\mathrm{Au}$ lieu d'amasser les pierres et les cailloux en tas, qui sont toujours nuisibles et font perdre la terre qu'ils recouvrent, les cultivateurs soigneux les emploient pour faire des clôtures.

Quel autre parti peut-on tirer des petites pierres?

On peut les employer pour faire des drains ou macadamiser les chemins bourbeux.

Quel est l'appareil qu'on emploie pour enlever les gros cailloux?

On se sert à crtte fin de l'arrache-pierres, qui peut enlever et transporter des cailloux pesant une couple de mille livres.

Quel est le but des travaux d'assainissement?

C'est de faire disparaître l'excès d'eau qui se produit à la surface ou dans l'intérieur du sol. 
enter-

'a pas ant un y jettr éclater

loux? : en tas, o qu'ils it pour

macates gros i peut couple

roduit

Quels travaux fait-on pour débarrasser le sol des eaux superficielles?

Des fossés et des rigoles.

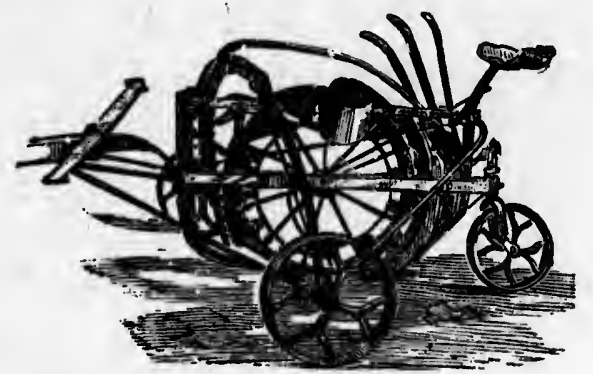

Fig. 7-Machine a fosses

Qu'appelez-vous fossés?

Ce sont des tranchées ouvertes, destinées à recevoir et écouler l'eau provenant des rigoles et des raies.

Quelles précautions faut-il observer dans la confection des fossés?

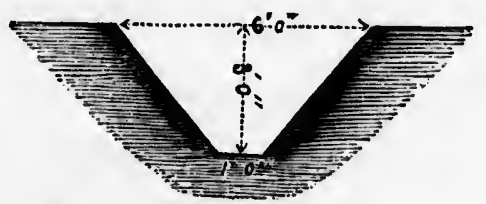

Fig. 8-Coupe d'un bon fossé

Il faut avoir soin de leur donner la pente ou l'inclinaison voulue pour leur permettre d'entraîner I'eau dans les cours d'eau plus considérables, notamment les ruisseaux et les rivières. Dans les terrains légers, il faut donner plus de talus aux bords, pour que les éboulis ne les remplissent pas. 
Quels soins faut-il donner aux fossés?

Il faut les curer ou les repiquer souvent, afin de toujours donner à l'eau un écoulement facile.

Que faut-il faire des cur'ures?

Les curures, c'est-à-dire la boue ou la terre qu'on enlève des fossés pour les entretenir en bon ordre, constituent un engrais d'une valeur incontestable. Les cultivateurs soigneux les enlèvent au tombereau ou à la pelle à cheval, pour les transporter sur les parties les plus pauvres de la terre ou les faire entrer dans les composts.

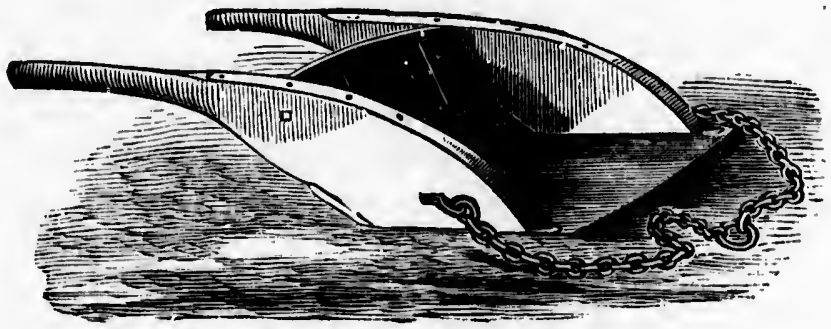

Fig. 9-Pelle d cheval

Qu'appelez-vous rigoles?

Ce sont de petites tranchées que l'on pratique à travers des planches ou des pièces de terre, pour recevoir l'eau des raies et la conduire dans les fossés.

Comment doit être faite une rigole, pour constituer un bon égoût?

Dans les terrains plans, elle doit être droite et, si elle aboutit à des fossés à ses deux extrémités, elle sera plus creuse à ses bouts qu'au milieu, afin d'avoir un peu de pente pour faire prendre le cours à l'eau. Si elle est 
pratiquée dans un bas-fond, elle doit être au centre et suivre autant que possible les sinuosités qu'il décrit. Dans tous les cas, elle doit être plus profonde que les raies, afin d'entraîner l'eau de ces dernières.

Comment fait-on les rigoles?

qu'on , consis cultiu à la ties les ans les

à traecevoir un bon , si elle ra plus peu de elle est

A la pelle ou avec un appareil spécial. Quand on les fait a la pelle, on dim:inue considérablement l'ouvrage en les ébauchant à le charrue, principalement avec une charrue à double veisoir ou un bratoir.

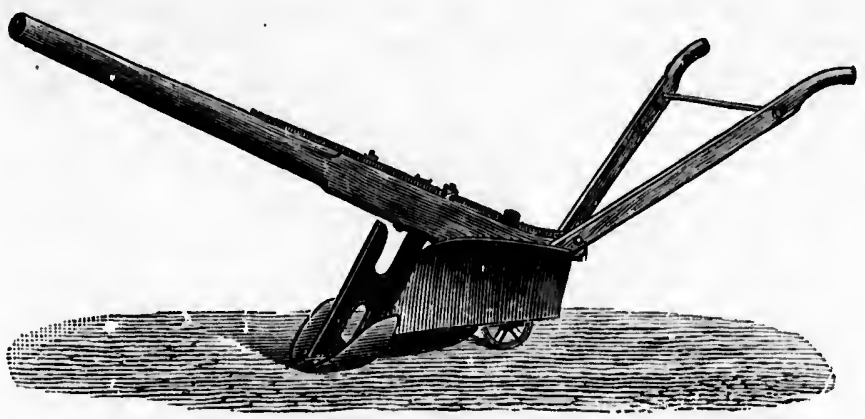

Fig. 10-Charrue rigolière

Quels soins faut-il donner aux rigoles?

Il faut les tenir constamment nettes, afin que l'eau ne s'y accumule pas. Pour cela, on les fait à neuf à l'automne, après le labourage, et on les nettoie au printemps, dès qu'on a hersé. Quant aux rigoles des prairies et des pâturages, on les retouche quand elles se bouchent par l'accumulation de l'herbe ou le piétinement des animaux.

Qu'appelez-vous drains?

Ce sont des rigoles et des fossés couverts. 
Dans quels terrains convient-il d'employer les drains?

On peut les employer avantageusement dans tous les terrains ; mais ils sont particulièrement utiles dans les terres planes, difficiles à égoutter, et surtout dans les terres dont l'humidité provient de sources et de filtrations souterraines ou à l'intérieur.

\section{Comment peuvent se produire ces filtrations?}

Dans les terres sitúes au pied des côteaux et des hauteurs, il arrive souvent que les eaux provenant des endroits les plus élevés s'écoulent par les couches per. méables du sous-sol vers les terrains plus bas, ce qui tient constamment dans le sorss-sol de l'eau qui ne peut traverser la couche superficieile pour s'écouler. Cette eau souterraine ne peut pas s'écouler par les rigoles, mais s'écoule parfaitement par les drains.

\section{Comment se font les drains?}

On pratique une tranchée parfaitement droite, dont l'ouverture s'evase de bas en haut. Au fond, on forme un conuuit avec du bois, de la pierre (figures 11, 12 et 13) ou des tuyaux de terre cuite (fig. 14), puis on recouvre le tout de petits cailloux, de paille, de jonc ou de branches et on achève de remplir la tranchée avec de la terre.

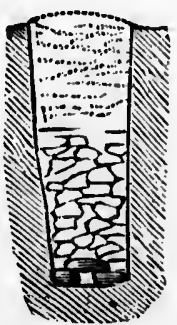

Fig. 11

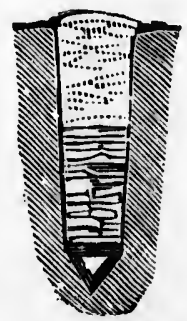

Fig. 12

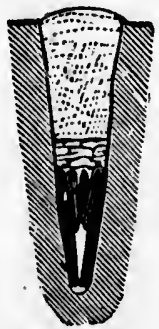

Fig. 13

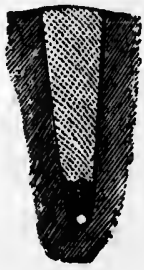

Fig. 14 


\section{Comment forme t on ces conduits?}

Il y a plusieurs manières de former ces conduits. Quelques-uns se contentent de mettre au fond de la tranchée des perches rondes, éloignées de deux ou trois pouces et de couvrir le joint avec une autre perche ou une croate. D'autres emplissent le fond de la tranchée avec de petites pierres, qu'ils recouvrent de gazon renversé, c'est-à-dire l'herbe en bas, sur lecyuel ils jettent ensuite la terre qui doit remplir la tranchée. Aux Etats-Unis, on emploie avec beaucoup de succès de planches de cèdre fendu, de six à huit pouces de largeur, que l'on dispose en triangle $\boldsymbol{\Delta}$ en les fixant avec quelques clous. Enfin, on forme ces conduits avec des tuyaux en tuile ou terre cuite, ce qui fait les meilleurs drains.

Que faut-il observer dans la confection des drains, quelles que soient les matières employées pour les former?

Il faut leur donner une inclinaison d'au moins six pouces par cent pieds, leur faire suivre la pentf: du terrain et les enfoncer à deux pieds et demi à trois pieds sous terre, afin qu'ils ne soient pas atteints par la gelée non plus que par les instruments aratoires, dans les travaux de culture.

\section{De quoi dépend la quantité les drains à établir?}

Du degré d'humidité du sol, c'est-à-dire de la quantité d'eau à recevoir et à écouler. Dans les terres les plus fortes, des drains à quatre pieds de profordeur et espacés de quarante pieds assurent un égouttement parfait. Dans les terres plus lègères, mais dont le sous-sol est mouillé, on peut les espacer de soixante à quatre-vingtdix pieds. 
Quels avantages ont les drains sur les rigoles ouvertes?

Dans les terrains dont l'humidité provient des eaux stagrantes dans les couches inférieures, les drains agissent très bien, au lieu que les rigo'es ouvertes n'ont aucun effet. Dans les cerrains ou il n'y a que des eaux de surface d̀ écouler, les drains n'agissent pas beaucoup mieux que les rigoles ouvertes, mais ils ont l'avantage de ne pas faire perdre de terre, comme les rigoles, et de ne pas gêner l'action des instruments aratoires, notamment celle des faucheuses, des moiszonneuses et des rateaux mécuniques.

Quels sont, en résumé, les avantages particuliers au drainage, ou à l'emploi des rigoles couvertes?

Les avantages particuliers au drainage peuvent se résumer ainsi :

$1 \circ$ Dans une terre drainée, on fait les planches infiniment plus larges et moins de raies d'écoulement, ce qui augmente d'autant la surface consacrée aux plantes;

$2^{\circ}$ Le drainage permet de travailler la terre de quinze à vingt jours plus tôt le printemps et une dizaine de jours plus tard l'automne, ce qui allonge d'un mois la saison agricole et avance d'au moins quinze jours la maturité des plantes;

$3^{\circ}$ Le sol drainé, s'asséchant à plusieurs pieds de profondeur, gèle beaucoup moins, se réchauffe plus vite, se travaille plus facilement et favorise beaucoup plus le développement des racines ;

$4^{\circ}$ Dans les terres drainées, les engrais produisent beaucoup plus d'effet, parce qu'ils ne sont pas entrainés par les eaux, comme cela a lieu dans les terres égoutlees au moyen des raies et des rigoles ouvertes;

$5^{\circ}$ Dans les terres drainées, l'air établit sa circulation 
libre et constante a l'aide des fissures qui s'y pratiquent, ce qui rend le sol plus léger, plus friable, plus facile a pénétrer par les racines, qui se développent plus facilement et puisent sans entrave les sucs nutritifs nécessaires à une bonne végétation;

$6^{\circ}$ Les sols drainés peuvent être travaillés plus pro fondément et s'usent moins sous l'influence des récoltes successives.

\section{Quel peui être l'effet d'un bon drainage?}

Un bon drainage peut augmenter du quart, de la moití et même plus, la production d'un terrain.

.N'estil pas vrai que la confection des drains est plus dispendieuse que celle des rigoles ouvertes?

Oui, il faut plus de temps et d'argēnt pour faire des drains que des rigoles ordinaires ; mais les rigoles sont à refaire tous les ans, au lieu que les drains peuvent durer vingt-cinq, trente et même quarante ans, selon leur confection, sans qu'il soit nécessaire d'y toucher, ce qui fait qu'en définitive ils coatent bien moins cher et produisent des résultats bien plus avantageux que les rigoles ouvertes.

Comment expliquez-vous les mauvais effets du mauvais égouttement ou du manque d'égouttement d'une terre?

Dans les terres labourées, l'excès d'eau provenant du manque d'égout empêche l'air de pénétrer dans le sol, s'oppose à la décomposition des engrais, nuit à la nutrition comme au développement des plantes et fait souvent pourrir leurs racines.

Le manque d'égouttement occasionne-t.il d'autres inconvénients?

Oui : les terres mal égouttées gèlent à une grande pro 
fondeur, ne peuvent être cultivées que tard le printemps ; la moindre pluie force a suspendre les travaux de culture, et quand vient la sécheresse, elles se durcissent beaucoup plus que les autres. Comme on ne peut les semer que tard, elles ne donnent que de pauvres produits, quand les semences ne pourrissent pas complètement. Les semences se faisant tard, les récoltes sont aussi plus tardives et se font dans la saison la plus exposée allx mauvais temps, ce qui occasionne souvent la perte d'une partie du peu qu'on récolte dans ces terres.

\section{\& 4-Des labours}

Quel est l'objet du labourage?

C'est d'ameublir le sol, pour le rendre plus friable et plus pénétrable, de mélanger la couche superficielle de la terre avec le sous-sol, d'enfouir les amendements ou les engrais, et enfin de détruire les mauvaises herbes.

Quels instruments emploie-t-on pour faire le labourage?

On peut employer la bêche, la fourche ou la houe, ainsi que cela se pratique pour le jardinage; mais, dans la grande culture, c'est la charrue seule qui est en usage.

Distingue-t-on plusieurs sortes de labours?

Oui, on distingue plusieurs sortes de labours, selon la forme de guérets, selon la profondeur du labourage et selon la saison à laquelle il a lieu.

Quelles sont les sortes de labours, selon la forme des guérets?

Ce sont les labours à plat, les labours en planches et les labours en billons. 
ntemps ; $x$ de culurcissent peut les vres proomplèteltes sont 1 la plus o souvent dans ces

friable et ficielle de ments ou herbes. purage? la houe, hais, dans en usage.

urs, selon labourage

es guérets? anches et
Qu'appelez vous labour d plat?

C'est celui qui se fait sans planches ni raies d'écoulement et en tournant tous les sillons du meme coté.

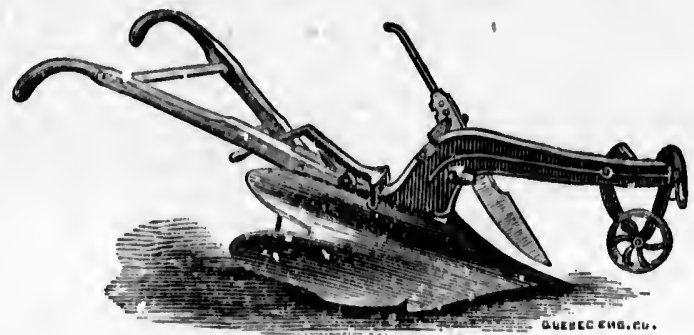

Fig. 15-Charrue tourne-oreille

\section{Quelle charrue faut-il employer piour le labour d̀ plat?}

La charrue tourne-versoir ou tourne-oreille. Il y a de ces charrues qui sont munies de deux versoirs fonctionnant alternativement, telle que la charrue Brabant, employée surtout en France et en Belgique; d'autres n'ont qu'un seul versoir, qui se tourne tantôt d'un côté, tantôt de l'autre, à chaque tour.

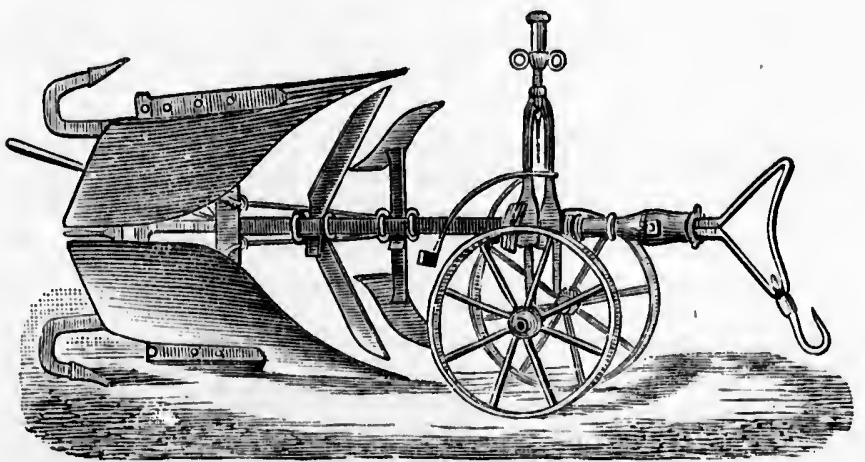

Fig. 16-Charrue Brabant-double, avec fouilleur 
Dans quels terrains pratique-t-on les labours d plat?

Dans les terrains drainés ou bien égouttés et les terres sablonneuses, où l'eau de surface ne peut pas s'accumuler, et surtout dans les terrainis en pente et les déclivités des côtes, auxquels ce labourage convient spécialement. C'est aussi le labour qui se fait exclusivement en grande culture dans les prairies du Nord-Ouest, ou l'on emploie beaucoup les charrues polysocs.

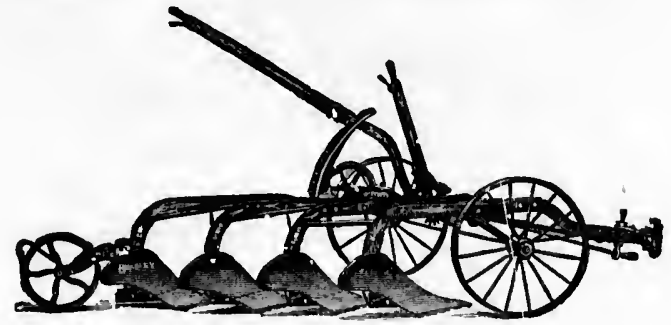

Fig. 17-Polysoc de Bradley

Quels avantages présente le labour à plat?

Comme la surface de la pièce de terre est parfaitement uniforme, les travaux de la récolte, le fauchage et le ratelage, sur tout à la machine, sont bien plus faciles, sans compter qu'il n'y a pas d'espace perdu par les raies d'écoulement.

Qu'oppelez-vous labour en plunches?

C'est celui dans lequel le terrain est partagé, à égales distances, par des raies d'écoulement destinées à conduire l'eau dans les rigoles.

Quel avantage présente ce labour?

Il facilite beaucoup l'ecoulement des eaux superficielles $\epsilon$ te desséchement de la terre, ce qui fait qu'on l'adopte invariablement dans les terrains exposès à. des eaux provenant de la pluie et de la neige. 


\section{Comment se fait le labour on planches?}

Il se fait en adossant ou en fendant. Pour adosser, on tire un premier sillon, puis rendu au bout de la piece, on vire à droite et l'on tire un autre sillon, qui se renverse ou s'adosse contre le premier. C'est ce qu'on

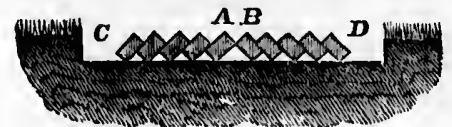

Fig. 18-Jabour a hue

appelle vulgairement labourer à hue (fig. 18). Pour labourer en fendant, on tire un premier sillon, puis rendu au bout de la pièce de terre, on vire à gauche et l'on tire un autre sillon assez éloigné pour donner à la planche la largeur désirée. C'est ce qu'on appelle

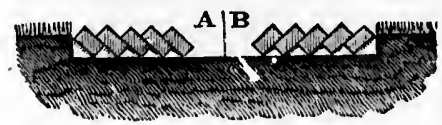

Fig. 19-Labour d dia labourer à dia (fig. 19). En continuant ainsi, on finit par former la raie d'eccoulement en rejetant dans les deux sens opposés les dernières bandes de terre attaquées par la charrue.

parfaitechage et s faciles, les raies

à égales $s$ à con-

superfiit qu'on posés à.
Comment finit-on la raie d'écoulement?

On tire au fond un trait de charrue, afin de diminuer sa largeur et d'augmenter sa profondeur. Cela facilite l'écoulement de l'eau et diminue la surface improductive de cette raie.

\section{Le labour en planches est-il bien employé ?}

Il est employé d'une manière presque exclusive, vu qu'il convient à toutes les terres et à toutes les cultures.

\section{Qu'appelez-vous labourer en billors?}

Labourer en billons, c'est partager le terrain en planches plus ou moins bombées, divisées par de profondes rigoles d'écoulement. 
Conment se font les billons?

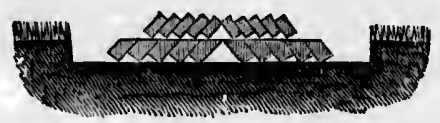

Fig. 20

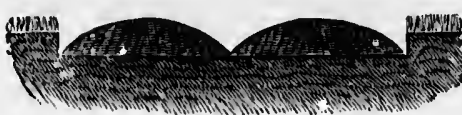

Fig. 21-Billons finis

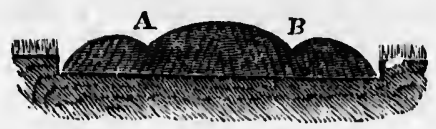

Fig. 22-Billon composé

Il fau; au moins trois labours superposés pour faire un billcn. On forme d'abord une planche par un premier labour en en ados (fig. 18); on fait un second labour sur cette planche (fig. 20), puis un troisıème labour sur le second, ce qui achève de donner au billon sa forme bombée (fig. 21)

A quels terrains convient le labour en billons?

Ce labour convient aux terres fortes, extrêmement mouillées, très difficiles à égoutter et qui ne sont pas drainées.

\section{Quels sont les avantages du labour en billons?}

Les avantages du labour en billons sont d'cungmenter artificiellement l'épaisseur de la terre végétale des sols peu profonds, ce qui permet d'y introduire la culture des plantes-racines. Dans les temps de pluie, les labours en billons s'egouttent promptement. Dans les temps ordinaires, l'humidité n'y est jamais trop grande ni la sécheresse redoutable, parce que la terre meuble du dessous conserve et communique longtemps sa frấcheur aux racines.

Quels sont les inconvénients des labours en billons?

Jes principaux inconvénients des labours en billons sont : 
$1^{\circ}$ D'offrir de chaque côté des pentes, dégarnies d'une couche suffisante pour alimenter la végétation autant que sur le milieu de la planche, ce qui rend la récolte inégale et peu homogène quant à la qualite;

$2^{\circ}$ De faire écouler une grande partie des engrais dans les raies, où ils sont noyés ou entraînés par l'eau;

$3^{\circ}$ De rendre presque impossible une égale répartition de la semence, qui s'accumule sur les côtés et dans les raies;

$4^{\circ}$ De rendre très incommode l'usage des instruments aratoires, pour le hersage, le fauchage et le ratelage;

$5^{\circ}$ D'occasioner une perte de terrain considérable, a raison de la grandeur et de la multiplicité des raies d'écoulement.

\section{Qu'appelez-vous labour de défoncement?}

On désigne sous ce nom des labours profonds, destinés à agir sur le sous-sol.

\section{Quel est l'objet des labours de défoncement?}

C'est ou de ramener à la surface une partie du soussol, pour la soumettre à l'action tes agents atmosphériques, ou d'ameublir le sous-sol, sans le ramener à la surface, afin de permettre aux plantes de développer plus facilement leurs racines.

Comment se pratique le défonsement pour ramener à la surface?

Comme le labour ordinaire : seulement, il faut donner à la charrue l'entrure nécessaire pour atteindre la profondeur désirée. Comme c'est toujours le dessous de la tranche de terre que la charrue ordinaire amène à la surface, en pénétrant plus dans le sous-sol, on ramène naturellement ce dernier à la surface du guéret. 
$Y$ a-t.il une autre manière de pratiquer les labours de défoncement?

Généralement, on fait suivre la charrue ordinaire d'une charrue spéciale, entrant plus dans la terre, faisant un second sillon dans le premier, et munie d'un versoir qui monte la terre jusques sur le guéret.

Emploie-t-on aussi des charrues qui font d'un seul coup deux sillons superposés?

Oui, on emploie aussi ces charrues, quand le sol n'est pas trop dur. En Angleterre, il y a la charrue Morton;

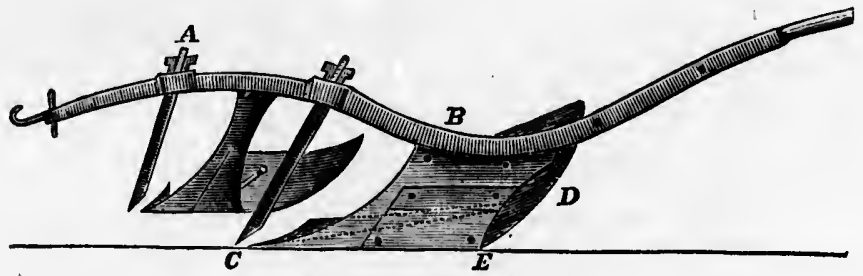

Fig. 23-Charrue Morton

en Belgique et en France, la charrue Brabant et plusieurs autres semblables.

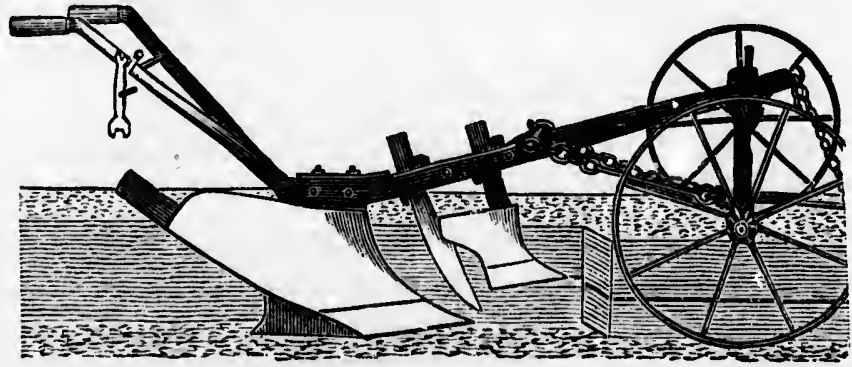

Fig. 24-Oharrue défonceuse 
Est-il a propos de s'assurer de la nature du sous-sol avant de faire un défoncement pour ramener d̀ la surface?

Non seulement il est à propos, mais encore il est bien nécessaire de s'assurer de la nature du sous-sol avant d'effectuer un defoncement pour ramener une couche de ce sous-sol à la surface. Si le sous-sol se compose d'une mauvaise terre, en le ramenant à la surface du sol arable, on steriliserait celui-ci ou l'on affecterait sa fertilité. On comprend que, dans ce cas, il ne faut pas ramener le sous-sol à la surface, mais se contenter de l'ameublir sans le déplacer.

Quand le sous-sol se compose de bonne terre, est-il prudent de le défoncer et de le ramener à la surface d'un seul coup et en grande quantite?

Non, cela pourrait encore avoir pour effet d'affecter sensiblement la fertilité du sol superficiel au lieu de l'augmenter. Ayant été jusque là privé de l'influence de l'atmosphère, le sous-sol ramené à la surface, quelle que soit sa composition élémentaire, est presque toujours stérile et ne s'améliore qu'au contact de l'air. C'est pourquoi il ne faut le ramener à la surface qu'à petite dose et en ayant soin, autant que possible, de lui appliquer des ergrais en plus ou moins grande quantité.

Quelle progression faut-il suivre pour opérer ces défoncements?

Pour la première fois, on ne ramène à la surface qu'un pouce d'épaisseur du sol, qui s'amóliore par les façons données à la couche arable. Au bout de trois ou quatre ans, on pénètrera encore d'un pouce dans le sous-sol, et ainsi de suite, jusqu'à ce qu'on ait donné au sol cultivé la profondeur convenable, c'est-à-dire de douze à dixhuit pouces. 
Comment se pratiquent les défoncernents qui n'ont pour but que d'ameublir le sous-sol?

En remuant ce sous-sol sans le déplacer ni l'amoner à la surface, ce qui se fait en passant la fouilleuse ou charrue sous-sol dans. Je sillon ouvert par la charrue ordinaire.

\section{Qu'appelez-vous labours ordinaires?}

On appelle labours ordinaires ceux qui ne dépassent pas la couche de terre cultivée et qui varie entre cinq et huit pouces.

De quoi dépend la profondeur des labours ordinaires?

Du but qu'on recherche en les opérant. La profondeur du labour doit être plus ou moins grande, selon que les racines des planteis à semer s'enfoncent plus ou moins dans la terre. Quand on laboure pour enterrer des engrais, il ne faut pas que le labour ait une profondeur telle, qu'elle mette l'engrais hors de la portée de la racine des plantes. Quard on se propose de donner deux labours à une pièce de terre, il faut que le premier soit plus profond que le dernier, afin de rendre la couche superficielle plus meuble et plus propre au premier dévelop pement des plantes.

Quelles sont les principales qualités que doit réunir un bon labour ordinaire?

Un bon labour ordinaire doit réunir les qualités suivantes :

$1^{\circ}$ Les tranches de terre soulevées par la charrue doivent être droites, d'une épaisseur et d'une largeur uniformes ;

$2^{\circ}$ Ces tranches de terre doivent être toutes également renversées à un angle de 45 dégrés et bien tassées 
les unes contre les autres, afin de ne laisser aucun trou ni espace découvert;

$3^{\circ}$ Les planches doivent avoir une largeur uniforme et être aussi unies que possible;

$4^{\circ}$ Les raies d'écoulement doivent avoir assez de profondeur, n'être pas larges, être nettes et droites, afin de n'offrir aucun obstacle à l'écoulement de l'eau ;

assent sinq et

$5^{\circ}$ Le labour doit avoir la profondeur requise pour la culture des plantes qu'on se propose de semer.

De quoi dépend la largeur du sillon ou de la tranche de terre enlevée par chaque trait de charrue?

Cette largeur dépend des deux conditions suivartes, absolument indispensables à un bon labour: $1^{\circ}$ que la tranche de terre soit renverste de manière à offrir le plus de prise possible à la herse qui doit la pulvériser; $2^{\circ}$ que les plantes nuieibles de la surface soient assez enterrées pour être détruites.

Pour remplir ces deux conditions, quelle profondeur faut-il établir entre la largeur et l'épaisseur de la tranche de terre?

Il faut que la largeur soit ì l'épaisseur dans la proportion de 3 à 2 , ou que la tranche de terre soit d'un tiers plus large qu'épaisse, c'est-à-dire que si le sillon a 6 pouces de profondeur, il doit en avoir 9 de largeur.

$Y a-t-i l$ des exceptions à cette règle?

Oui, pour les labours de défoncement, dont la largeur des sillons n'excède ordinairement la profondeur que d'un quart.

Qu'arrive-t-il quand la tranche de terre est plus épaisse que large?

Elle n'est pas retournée par la charrue et l'herbe, bonne ou mauvaise, reste à la surface (C fig. 26), ce qui 
expose moins de terre a l'action de l'air, favorise la croissance des mauvaises herbes et neutralise l'action de la herse.

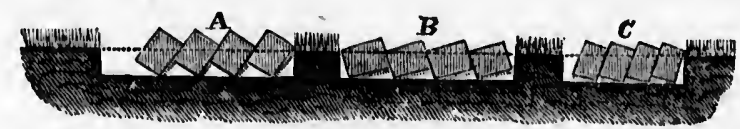

Fig. 25-Inclinaison des tranches

Qu'arrive-t-il quand la tranche de terre est trop large?

Elle est complètement retournée par la charrue, tombe ì plat dans le sillon (B fig. 26), ce qui diminue considérablement l'action ameublissante de l'air et de la herse, en diminuant la surface exposée à cette action.

Qu'arrive-t-il quand la largeur et l'épaisseur' de la tranche de terre sont bien proportionnées?

La tranche de terre fait un angle de $45^{\circ}$ (A fig. 26); elle offre une surface double d'un labour renversé (B) ou d'un labour étroit (C), l'acuité de l'angle favorise l'action de la herse et le tassement des tranches étouffe plus efficacement les herbes de la surface ainsi renversée.

Quels avantages présentent les labours profonds?

Ils augmentent la quantité des récoltes, en permettant aux racines de pénétrer plus avant dans le sol et d'en tirer plus de substances alimentaires pour l'accroissement de la plante. Dans ces labours, les plantes souffrent moins de la sécheresse, vu que la couche meuble renferme plus d'humidite; elles souffrent moins de l'humidite, parce que la terre étant ameublie à une grande profondeur, l'excès d'humidité descend au-dessous de la couche occupéo par les racines. 
Pourquoi faut-il régler la profondeur du labour sur la nature des plantes a cultiver?

Parce qu'il y a des plantes dont les racines s'enioncent beaucoup plus que d'autres dans la terre.

Qu'appelez-vous labours superflciels et d quoi servent-ils?

On appelle labours superficiels ceux qui n'ont qu'une profondeur de trois ou quaire pouces. On en fait usage pour detruire et enterrer les mauvaises herbes, pour enfouir les engrais pulvérulents, pour donner la dernière préparation à la terre avant l'ensemencement et pour recouvrir les semences sous raies, notamment les pois, les lentilles et les pommes de terre.

Quelles charrues emploie-t-on pour faire ces labours super. ficiels?

On peut employer les charrues ordinaires; mais il

ermetsol et ir l'aclantes o meubins de à une u-des-

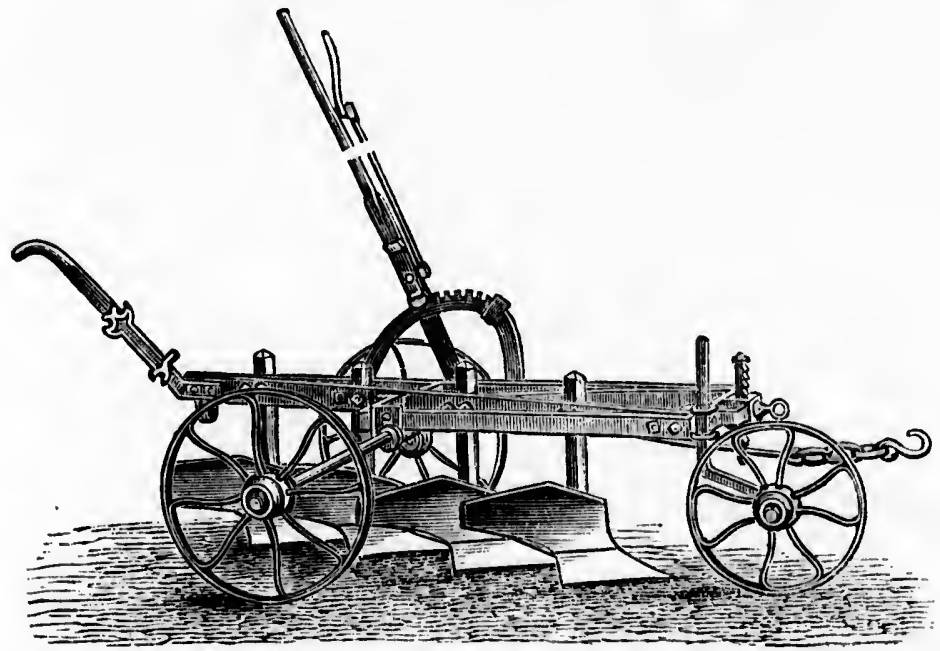

Fig. 26-Déchaumeuse de Bajac 
est plus avantageux d'employer les polysocs, ou charrues faisant plusieurs sillons à la fois.

Comment appelez-vous les labours, selon la saison da laquelle on les pratique?

On les appelle labours de printemps, labours d'été et labours d'automne.

Qu'appelez-vous labours de printemps et à quelles terres conviennent-ils?

On appelle ainsi les labours qui sont pratiqués au printemps. Ils conviennent aux terres sableuses, légères ou très meubles, qui se tasseraient par la gelée et se laveraient par l'eau provenant de la fonte des neiges et dos grosses pluies de l'automne et du printemps.

Qu'appelez-vous labours d'été et d̀ quoi servent-ils?

Ce sont des labours superficiels que l'on pratique en été, généralement pour détruire les mauvaises herbes qui se multiplient surtout par leurs racines. On pratique ces labours par un temps de sécheresse et on les fait suivre d'un hersage, quand les racines des mauvaises herbes sont bien desséchées.

Emploie-t-on aussi ces labours pour détruire les mauvaises herbes qui se reproduisent par leurs graines?

Non: pour détruire ces herbes, on donne après la récolte du grain un hersage, qui favorise la germination des mauvaises graines, et quand celles-ci sont en pleine végétation, on les enterre par le labour d'automne, qui les détruit.

Qu'appelez-vous labours d'automne et quels avantages présentent-ils?

On désigne sous ce nom les labours qui se font à l'au- 
tomne. Ils conviennent mieux que tous les autres labours aux terres fortes, compactes et tenaces, qui, après ce labour, sont pulvérisées par la gelée et rendues parfaitement meubles pour les semailles. Ces labours ont en sus l'avantage de donner une grande avance pour les autres travaux de culture, le printemps.

Ces labours conviennent-ils aux terres légères?

Non, parce qu'ils ameublissent trop ces terres en les exposant à l'action de la gelée, et qu'ils les font trop laver par les grosses pluies de l'automne et du prin. temps, lesquelles entraînent la glaise et la meilleure terre dans les rigoles et les fossés.

Quel temps faut-il choisir pour opérer le labourage?

Dans les terrains légers et sableux, même dans les "terres jaunes," on peut faire facilement un bon labour à peu près en tout temps, quand la terre n'est pas gelée; mais dans les terres fortes ou argileuses, il faut choisir le temps où le sol n'est ni trop sec ni trop humide,trop sec, il bourre sous le soc, adhère au versoir, s'accumule en masses inégales et ne forme qu'un guéret irrégulier ; trop humide, surtout dans les labours du printemps, il forme des bandes irrégulières, que la chaleur durcit comme des briques et transforme en grosses mottes que ìa herse ne peut pas pulvériser. Dans ces tranches humides, les mauvaises herbes se conservent intactes, poussent promptement et font périr le grain.

De quoi dépend la largeur qu'il faut donner aux planches?

De la nature du sol et de son égouttement. Dans les terres fortes oi franches bien égouttées, les planches peuvent avoir de douze à dix-huit pieds de largeur, plus 
dans les terrains drainés ainsi quo dans les terres sableuses et sèches.

\section{$Y$ a-t-il plusieurs espèces de charrues?}

Oui, il y en a plusieurs espèces : chaque pays a la sienne, qui se subdivise suivant les types divers adoptés par les fabricants; mais les charrues des différentes

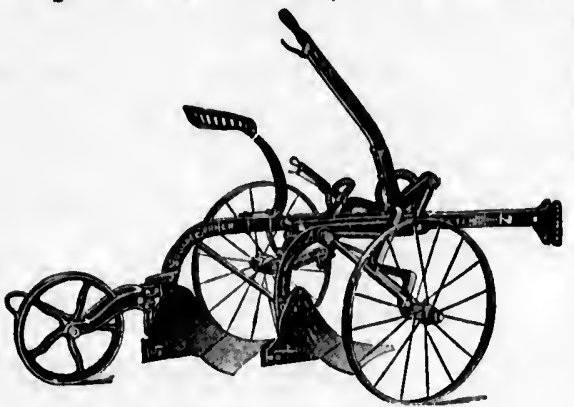

espèces ont à peu près les mêmes pieces principales et ne se distinguent que par les variati on s introduites dans la forme et la disposition de ces pièces.

Fig. 27-Bisoc ì siège de Bradley

Quels sont les trois principaux genves de charrues?

Ce sont la charrue simple, ou araire, la charrue composée, ou à avant-train et la charrue polysoc.

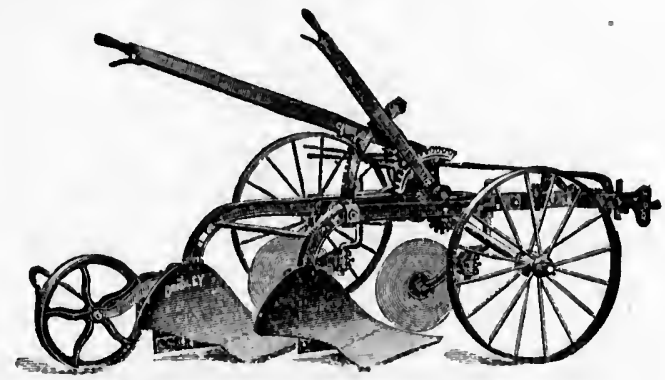

Fig. 28-Cliarne bisoc de Bradley

Qu'appelez-vous araire?

C'est la charrue sans point d'appui antérieur, géné- 
ralement employée dans notre pays. Le type le plus parfait est la charrue écossaise, toute en fer.

Quels sont les avantages et les désavantages de l'araire?

pays a la rs adopifférentes nt ì peu mémes incipales stinguent les variatroduites rme et la in de ces

es?

rue com-

Cette charrue est plus légère et coate généralement moins cher que les autres. Elle fait mieux les labours profonds, obeit mieux a la main qui sait la diriger, laboure plus près des arbres, des pierres et autres obstacles, se manœuvre plus facilement; mais elle exige de l'habitude, de l'habileté et une aittention coutinue de la part du laboureur ; dans les labours superficiels, la moindre pression latérale la fait dévier, et quand la terre bourre, elle cherche constamment à sortir de la raie.

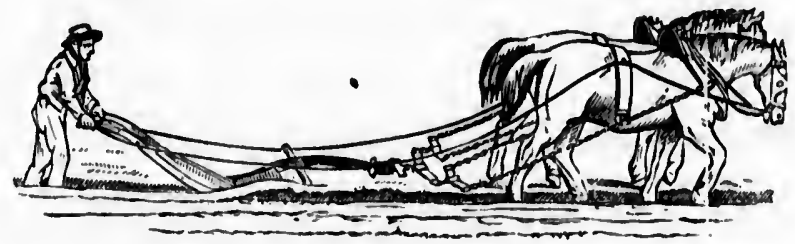

Fig. 29-Charrue écossaise en marche

Qu'appelez-vous charrue d̀ avant-train ?

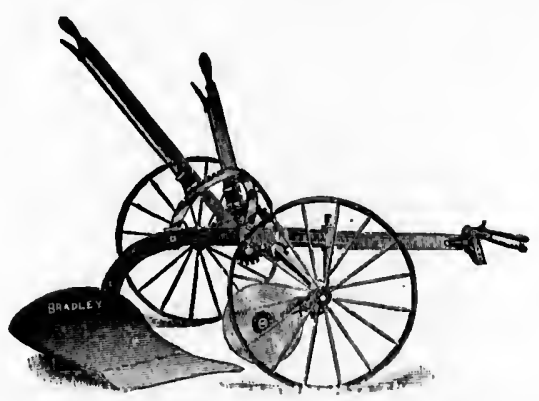

Fig. 30-Chırrue i roues de Bradley

C'est celle dont l'âge ou la perche repose sur un point d'appui antérieur, formé par l'avant. train et dont notre charrue à rouelles (fig. 5) est le type primitif.

ur, géné. 
$Y$ a-t-il plusieurs sortes de charrues d avant-train?

Oui : les principales sont la charrue de Brie, la charrue Garnicr, semblables à notre charrue à rouelles, la charrue Brabant et la charrue à siége.

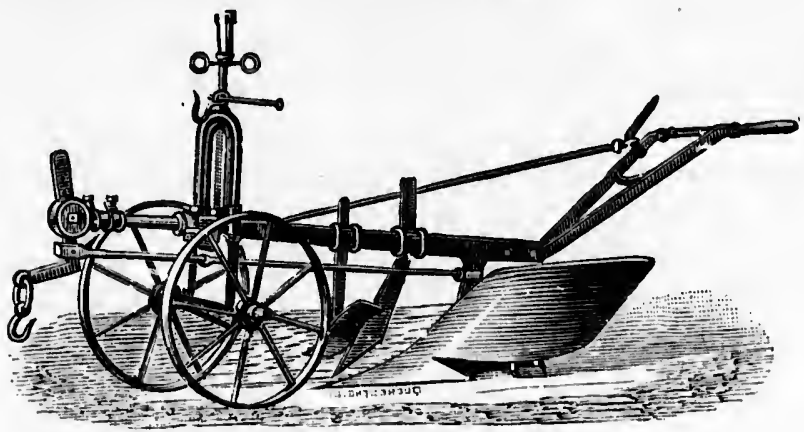

Fig. 31-Charrue Bäabant, simple

Quels sont les avantages et les äésavantages des charrues à avant-train?

Ces charrues tiennent mieux leur raie, font un guéret d'épaisseur uniforme et plus régulier, dans les labours superficiels, sont plus faciles et beaucour moins fatigantes à conauire; inais on prétend que l'avant-train ajoute au tirage, complique l'atelage et la manœuvre de la charrue, pour tourner dans les endroits difficiles.

Qu'appelez-vous charrue polysoc?

C'est un bâti auquel sont adaptés plusieurs corps de charrues.

Les polysocs sont-ils en grand usage dans notre pays?

Dans notre province, il n'y a que le bisoc anglais qui soit un peu employé; mais dans les grendes prairies 
du Nord-Ouest, on se sert beaucoup des polysocs pour la grande culture.

\section{Qu'appelez-vous fouilleuse ou sous-solleuse?}

La fouilleuse est une charrue qui s'emploie dans les labours de défoncement qui n'ont pour but que d'ameublir le sous-sol, sans l'amener à la surface. La soussolleuse est une charrue employée pour les labours de défoncement qui ont pour objet de ramener le sous-sol à la surface.

\section{Existe-t-il d'autres sortes de charrues?}

Oui, il $\mathrm{y}$ a plusieurs autres sortes de charrues, adaptées à des fins spéciales, notamment :

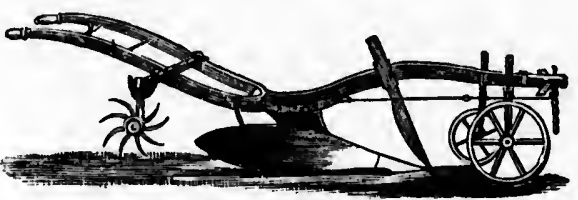

Fig. 32-Charrue Corbett

Les charrues

arrues à

guéret abours as fatit-train avre de les.

rps de

y3?

ais qui rairies tourne-oreille, pour labourer les terrains en déclivité et faire les labours plats. En France, on emploie principalement le Brabant double, qui se compose de deux corps de charrues superposées, jetant la terre l'une à droite, l'autre à gauche; de sorte que pour labourer sans changer de sillon, il suffit, à chaque extrémité de la pièce, de mettre l'instrument sens dessus dessous;

Les déchaumeuses, polysocs qu'on emploie pour labourer. les terres légères, ou dans les terres fortes, pour les labours superficiels destinés à enterrer les engrais et les amendements, ou pour faire un deuxième labour; 


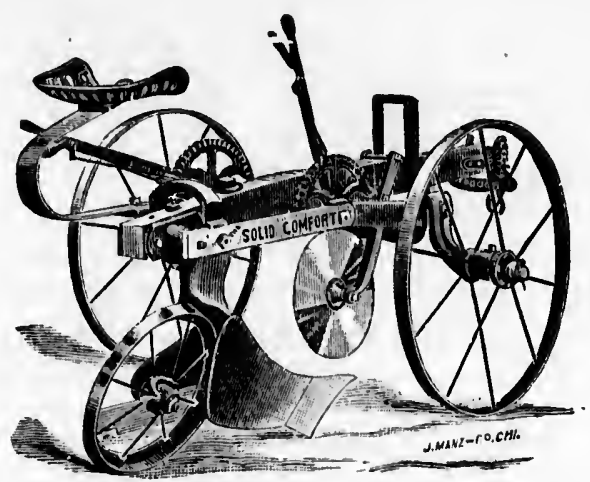

Fig. 33-Charrue à siège "Solid Comfort" "

La charrue déboiseuse, armée de plusieurs coutres dentelés, qui tranchent les racines, employée pour labourer les terres nouvellement défrichées et les terrains savaneux, où il y a des touffes de branches, des racines et des bois morts enfouis.

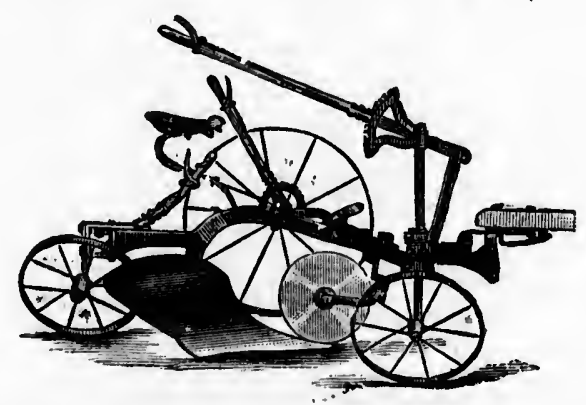

Fig. 34-Charrue à siège "Little Yankee"

la 
Quelle espèce de charrue emploie-t-on pour labourer un pré ou une prairie?

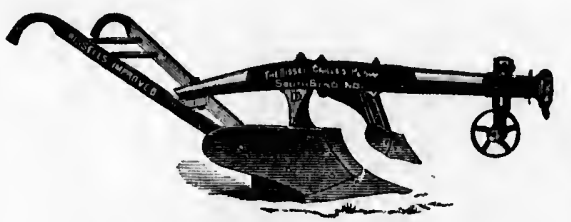

La charrue à pelloir, munie d'un avant-soc qui soulève une bande mince de terre en-

Fig. 35-Charrue a pelloir de Bissell gazonnée puis la verse au fond de la raie, où elle est recouverte par la tranche renversée par la grande charrue.

Quelles qualités doit réunir une bonne cñarrue?

Quel que soit son mode de construction, une bonne charrue doit réunir les qualités suivantes : $1^{\circ}$ être facile à conduire; $2^{\circ}$ occasionner le moins de traction possible; $3^{\circ}$ avoir un soc plat et tranchant; $4^{\circ}$ être munie d'une oreille qui nettoie la raie parfaitement et renverse bien la tranche de terre.

\section{\& 5--Du dechaumage}

Qu'est-ce que le déchaumage?

C'est un labour superficiel qui se donne immédiatement après la récolte, pour empêcher le durcissement du sol et détruire les mauvaises herbes, principalement le chiendent.

Quels sont les instruments qu'on emploie à cette fin?

Ce sont le scarificateur, l'extirpateur, le polysoc et la herse, principalement la herse à disques. 


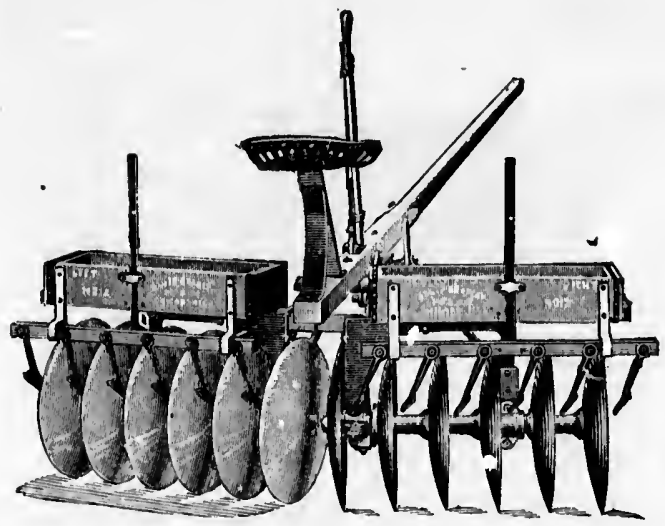

Fig. 36-Herse à disques de Bradley

Y a t-il plusieurs types de herses à disques?

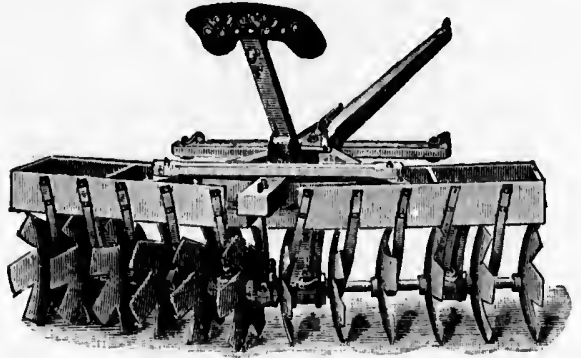

Oui : outre la herse à disques unis, il y a la herse à disques dentés, qui est un instrument très énergique.

Fig. 37-Herse à disques dentés de Clarke

Qu'appelez-vous scarificateur?

C'est un instrument destiné à scarifier la terre, c'està-dire à la rechausser en l'aérant, ou une espèce de herse montée sur des roues, pour en r'égler l'entrure, et armée de fortes dents courbées en avant, terminées par une lame en fer de lance. 


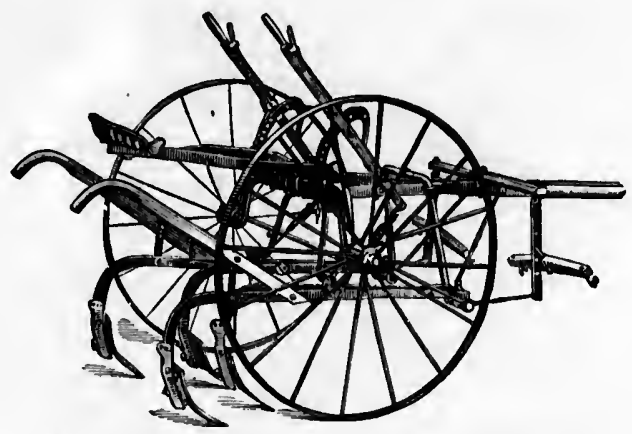

Fig. 38-Scarificateur "Vulcan" de Bradley

outre la disques y a la disques qui est rument rgique.

e, c'estle herse t armée ar une

\section{Qu'appelez-vous extirpateur ?}

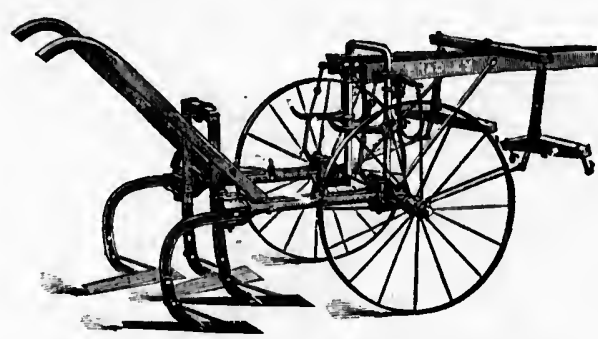

Fig. 39-Extirpateur à lames de Bradley

C'est un instrument employé pour extirper, c'est-à-dire pour couper entre deux terres les racines des mauvaises herbes, ou u ne espèce de herse qui, au lieu de dents, est armée de petites lames.

Le scarificateur et l'extirpateur servent-ils à autre chose qu'au déchaumage?

Oui : on les emplois aussi pour enterrer les engrais pulvérulents ainsi que les semailles sous raie, telles que les pois, les vesces et autres.

\section{Qu'appelez-vous cultivateur ?}

C'est un instrument semblable au scarificateur et a l'extirpateur. 


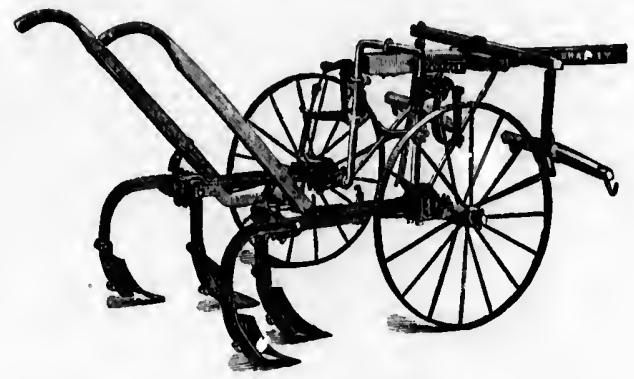

Fig. 40-Cultivateur a haies mobiles de Bradley

Comment transforme-t-on le culttvateur en scarificateur ou extirpateur?

Tout simplement en changeant les pieds ou socs, qui se fixent par des boulons.

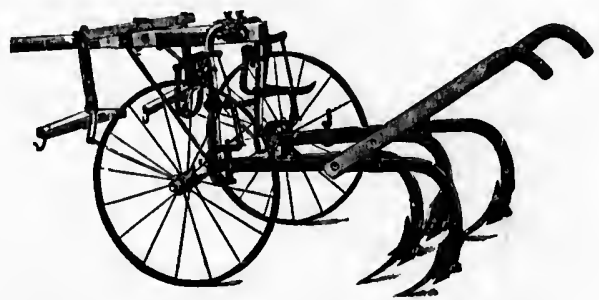

Fig. 41 -Oultivateur le "Magic" de Bradley

\section{\& 6-Du hersage}

Quiest-ce que le hersage?

C'est une opération qui a pour but de briser les mottes, d'unir la surface du sol, de recouvrir les semences. les engrais pulvérulents, ou de détruire les mauvaises herbes. 


\section{Y a-t-il plusieurs manières de herser?}

Oui, il y a plusieurs manières de herser. Quand il s'agit tout simplement d'enterrer la semence dans une terre bien préparée, on se contente de herser en long, c'est-à-dire dans le sens longitudinal des planches. Pour briser les mottes ou pulvériser une terre forte durcie

Fig. 42-Herse flexible de Vaughn par la chaleur, on herse aussi en travers, c'est-à-dire perpendiculairement à la longueur des planches. L'instrument le mieux adapté à cette fin est la herse flexible de Vaughn. Pour détruire les mauvaises herbes ou ramasser celles qui ont été déracinées par l'extirpateur, on herse en tournant.

De quoi dépend le nombre de hersages à àonner?

ottes, s. les vaises
De la nature du sol et des récoltes. Dans les terres compactes, qui se durcissent beaucoup en séchant, il faut plusieurs coups de herse, au lieu que dans les sols légers et sablonneux, deux coups de herse suffisent. Il y a aussi des semences qui exigent d'être plus recouvertes et, par conséquent, plus de her-

Fig. 43-Herse en zigzag sage les unes que les autres. 
Compte-t-on plusieurs sortes de herses?

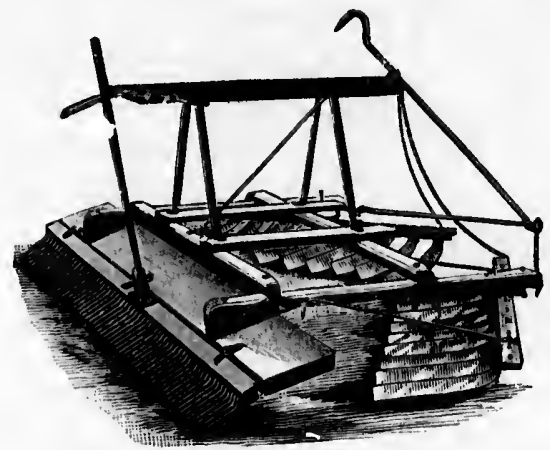

Fig. 44-Pulvérisateur de Tower

santes et les herses-scarificateurs.

Oui : il y a les herses triangulaires, les herses parallélogrammiques, qui se divisent en herses articulees, herses en zigzag, herses à chaînons ou herses couleuvres ; enfin, il y a les herses circulaires et tournantes, les herses pulvéri-

Quels sont les avantages de la herse à levier?

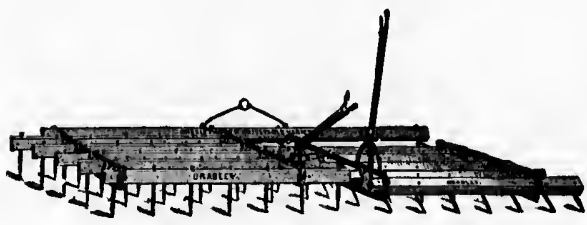

Fig. 45-Herse à levier de Bradley

Cette herse, munie d'un levier arrêté par un cliquet sur un demi-cercle, permet de donner aux dents l'inclinaison voulue pour faire un hersage énergique, ou en accrochant, un hersage ordinaire ou un hersage leger, en décrochant.

Quelles sont les principales conditions que doit réunir une bonne herse?

Quel que soit le mode d'après lequel elle est construite, une bonne herse doit réunir les conditions suivantes : $1^{\circ}$ les dents doivent être assez éloignées pour 
que la terre ne s'amasse pas entre elles ; $2^{\circ}$ elles doivent être placées à égale distance les unes des autres; $3^{\circ}$ chaque dent doit faire sa raie partieulière.

Est-il avantageux d'employer les herses doubles?

Oui : par ce moyen on économise le temps d'un homme pour l'ouvrage que peuvent faire deux chevaux.

Est-il important de faire le hersage avec soin?

Cela est très important : si la herse ne passe pas également partout, il reste des espaces où la semence ne germe pas et qui se couvrent de mauvaises herbes.

Dans quel état doit être la terre pour subir le hersage?

Il faut herser la terre au moment où, n'étant ni trop humide ni trop sèche, elle s'émiette et s'abat facilement sous l'action de la herse.

\section{\& 7-Du roulage}

\section{Qu'entendez-vous par roulage?}

C'est une opération ayant pour but d'achever de pulvériser les mottes qui ont résisté à l'action de la herse, de tasser les sols légers pour leur faire conserver plus de fraîcheur, ou de comprimer sur les racines la terre soulevée par les gelées. 


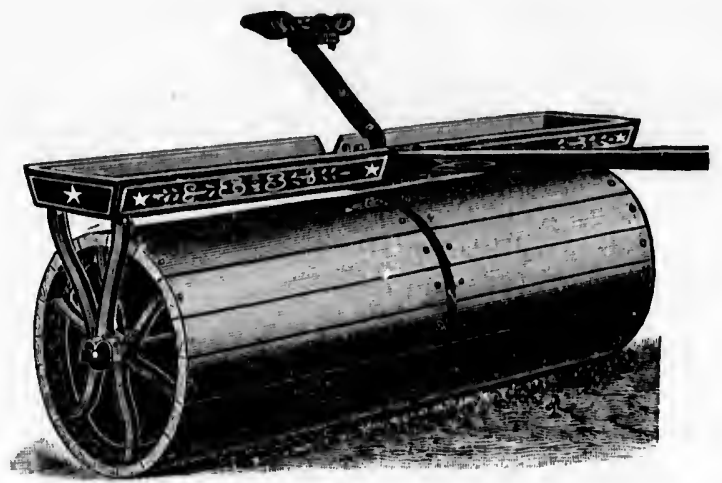

Fig, 46 - Touleau "Star"

Dans quel état doit être la terre pour subir le roulage?

Elle doit être assez sèche pour ne pas s'attacher au rouleau, car alors les mottes ne feraient que s'aplatir sans se pulvériser et le rouleau ferait une surface lisse qui, en se desséchant, deviendrait trop dure pour être traversée par les germes de la senıence.

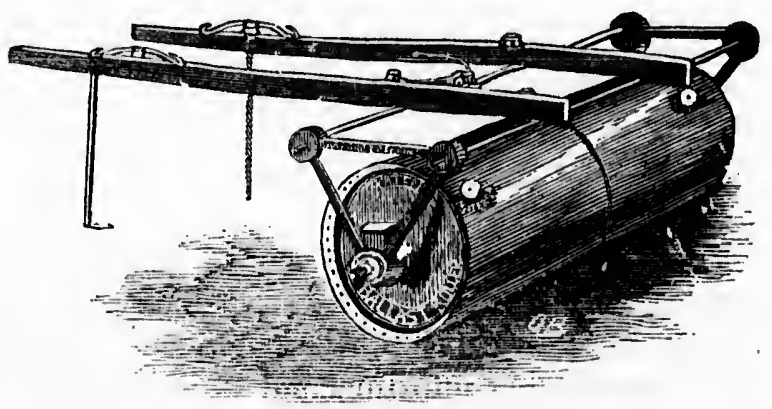

Fig. 47-Rouleau lesté d̀ l'eau 
Distingue-t-on plusieurs sortes de rouleanx?

Oui : il y a le rouleau plombeur ou ordinaire, le rouleau d̀ disques mobiles, le rouleau squelette et le rouleau brise-mottes, le plus énergidue de tous.

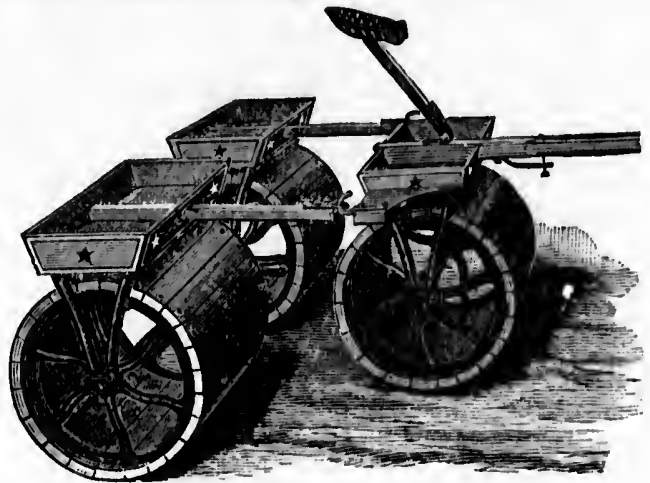

Fig. 48-Rouleau articulé de Castree

En quoi consiste le rouleau à disques et quel avantage présente $t$-il?

Ce rouleau se compose d'une série de disques, ou roulettes, indépendantes les unes des autres, munies d'une grande lumière qui leur permet de jouer sur un axe commun, c'est-à-dire de s'élever ou de s'abaisser chacune séparément et d'atteindre ainsi toutes les parties de la surface du sol, si inégale qu'elle soit.

Qu'est-ce que le rouleau brise-mottes?

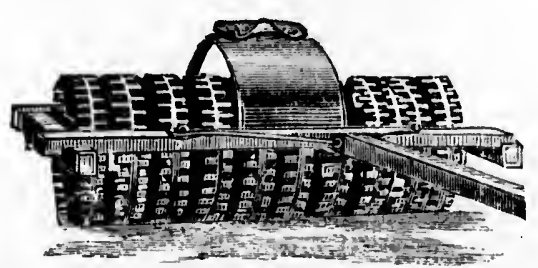

C'est un rouleau à disques mobiles, dont la circonférence est entourée de dents qui pulvérisent tout, même

Fig. 49-Rouleau brise-mottes de Deuscher 
les mottes les plus dures. Il convient par excellence aux terres glaises et compactes et permet d'ameublir parfaitement même les guérets du printemps qu'ón fait dans ces terres.

\section{\& 8-Dos cultures d'ontretien}

\section{Qu'appelez-vous cultures d'entretien?}

Ce sont des façons qu'on donne au sol ensemencé et qui comprennent le sarclage, le binage et lo buttage.

Qu'est-ce que le sarclage?

C'est une opération qui a pour but de détruire les mauvaises herbes qui poussent avec les plantes cuitivées et nuisent à leur développement.

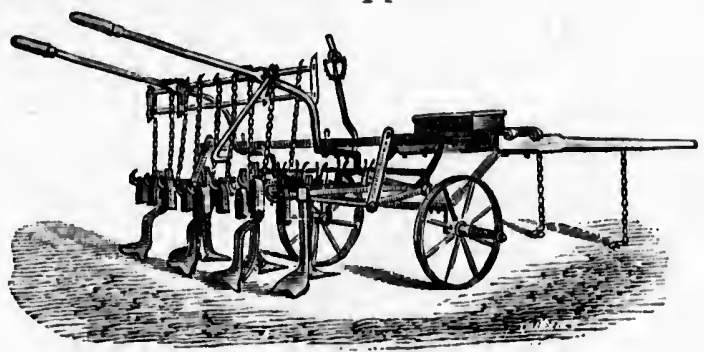

Fig 50-Houe d cueval

Qu'est-ce que le binage?

C'est une opération qui a pour but d'ameublir la surface du sol ensemencé, afin qu'il se conserve plus frais et constamment accessible à l'influence de l'air et de la rosée qui augmente sa fertilité. 
Quels sont les instruments employés pour sarcler et biner? ublir

Dans la pet i te n fait

Icé et ige.

re les cuiti-

a sur-

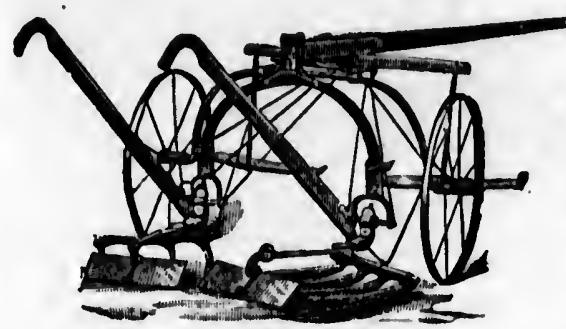

Fig. 51-Cultivateur superficiel de Tower culture, on se sert de la binette, serfouette ou gratte; dans la grande culture, on emploie la houe à cheval et les culvateurs, qui économisent beaucoup do temps.

\section{Qu'est-ce que la houe à cheval?}

C'est un appareil composé d'un cadre triangulaire muni $r$ avant d'un soc et en arrière de couteaux disposés pour fendre la terre verticalement et horizontalement, afin de couper ies racines des mauvaises herbes, de remuer la terre et de l'aérer. L'avant-train repose sur une roue qui sert à régler l'entrure, et l'arrière est armé de deux mancherons qui servent à conduire l'instrument.

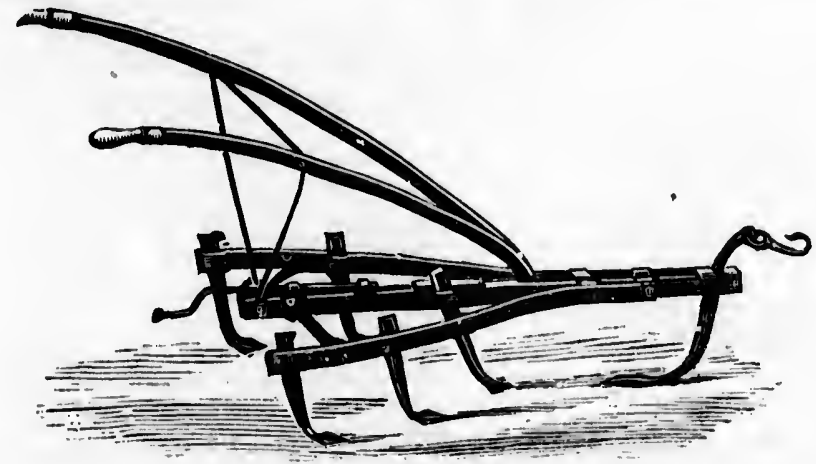

de la

Fig. 52--Houe a cheval commune 
Dans quelles cultures peut s'employs la houe d̀ cheval?

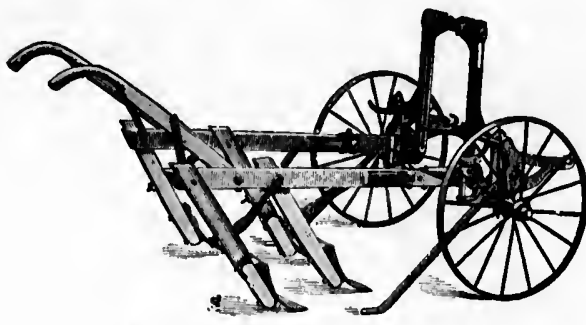

Fig. 53-Cultivateur sans timon de Bradley

Dans toutes les cultures ou les semis se font en ligne, même pour biner les céréales, quand elles sont semées au semoir et en ligne, et à cette fin les bineuses sont disposées de façon à ce que les couteaux puissent se rapprocher ou s'élnigner, pour adonner entre les rangs.

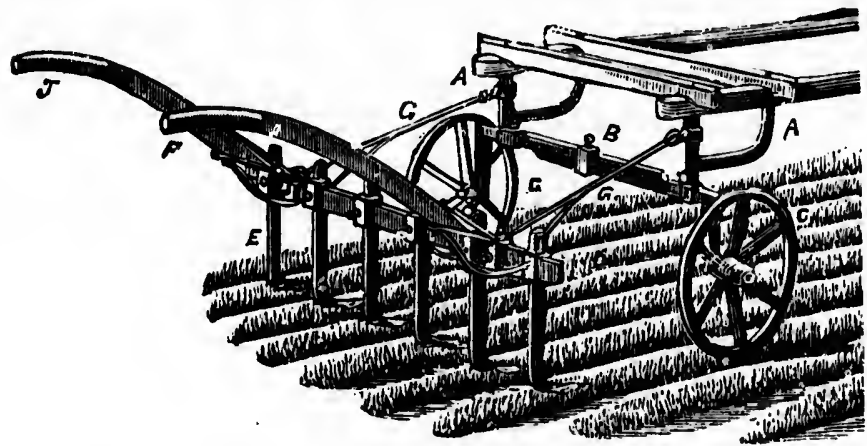

Fig. 54-Bineuse à céréales

\section{Quand faut-il opérer le binage?}

Il fant nroficter du temps où la terre commence à durcir, afin de l'empêcher de s'encroûter. L'occasion la plus propice est après une légère ondée, lorsque la surface du sol n'est pas assez mouillée pour adhérer à la couche inférieure, 
Faut-il biner plusieurs fois ?

jutes les ou les font els me pour céréales, les sont u semoir ne, et à les biont dis$t$ se rapangs.

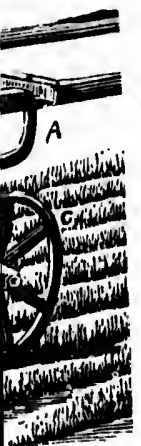

mence à occasion rsque la lhérer à

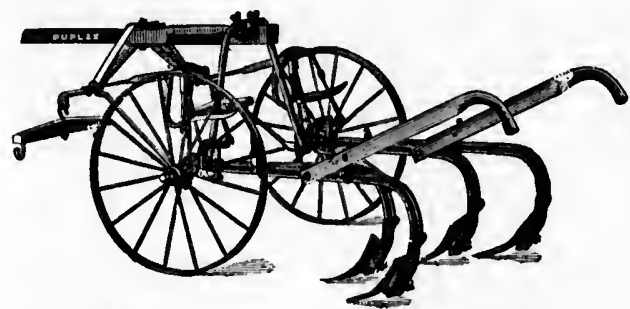

Fig. 55-Cultivateur "Duplex" de Bradley

à plusieurs pouces, mais la profondeur doit être diminuée à chaque opération.

Le binage occasionne-t-il certain travail?

Oui ; mais ce travail est beaucoup plus que compensé par l'augmentation dans le rendement de la récolte.

Qu'est-ce que le buttage?

C'est une opération qui a pour but de ramasser la terre au pied des plantes, pour enterrer la base de leurs tiges. On désigne vulgairement cette opération sous le nom de renchaussage.

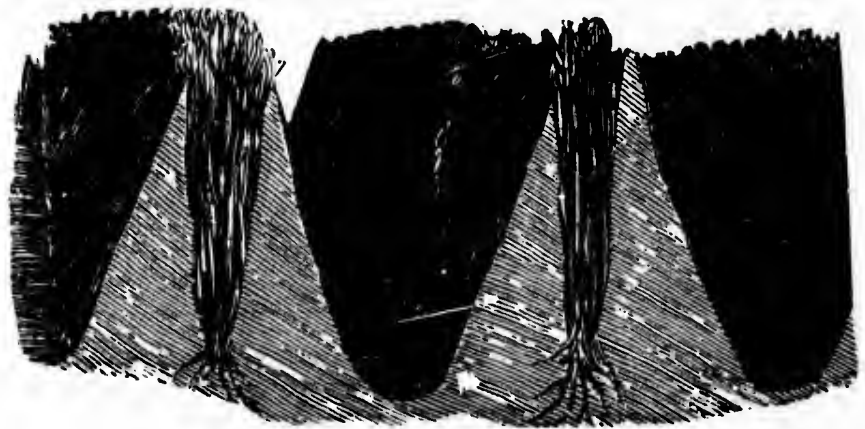

Fig. 56 - Plante buttée ou rechaussé

Autant que possible plusieurs fois, surtout dans la culture des plantes - racines. Le premier binage peut pénétrer . 
Quels sont les effets du buttage?

Le buttage détruit les mauvaises herbes, augmente la fertilité de la terre, entretient la fraîcheur autour des racines, permet à celles-ci de se développer plus facilement et protège la tige des plantes en la consolidant.

Comment se fait ie buttage?

Dans la petite culture, le buttage se fait avec la pioche ou houe à la main; dans la grande culture, avec un irstrument appelé buttoir ou butteur.

Qu'est-ce que le buttoir?

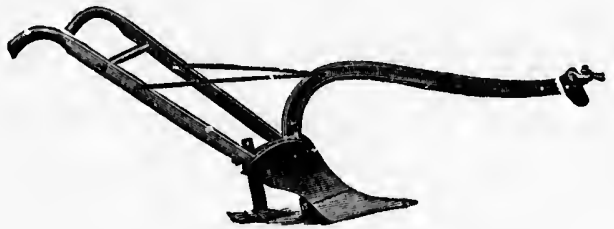

Fig. 57-Buttoir avec fouilleur de Bradley

C'est une char$r u e$ d $d e u x$ oreilles s'ecar tant et se rapprochant à volonté, sans coutre, souvent munie d'une roue servant à régler l'entrure de l'instrument.

Quelle opération doit précéder le buttage?

Pour faire produire au buttage tous les bons résultats dont il est susceptible, il faut préalablement ameublir la terre par un binage.

En quel temps doit se faire le buttage?

Le premier buttıge doit se faire quand les plantes sont au tiers de leur développement, et il est plus efficace quand on le pratique durant la rosée ou après une légère ondée. Quand on donne deux buttages, le seccial doit être moins énergique et avoir lieu une dizaine de jours après le premier. 


\section{CHAPITRE VII}

EN S E M E N CEM EN T

ne char-

d e u $x$ s'écarse rapit à voans couvent mutrument.

résultats meublir

htes sont efficace ne légère cidd doit de jours

\section{Quels travaux comprend l'ensemencement?}

L'ensemencement comprend les travaux qui se rattachent $-1^{\circ}$ à la préparation des semences; $2^{\circ}$ au semis, opération par laquelle on confie à la terre les graines ou la semence que l'on veut faire produire; $3^{\circ}$ au recouvrement de la semence.

\section{Est-il important de bien choisir la semence?}

Oui, il est de la plus grande importance de bien choisir la semence, afin de n'employer à cette fin que des graines propres, sans mélange, saines et vigoureuses.

Qu'arrive-t-il quand on emploie une mauvaise semence?

Si on emploie une semence qui n'est pas pure et bien triée, il pousse des mauvaises herbes ou d'autres plantes que celles que l'on veut récolter, ce qui diminue la qualité et la valeur de cette dernière. Si la semence n'est pas saine et vignureuse, une partie ne germe pas ou ne donne que des proủuits étiolés, ce qui diminue considérablement le rendement de la récolte. 
Est-il bon de charger la semence?

Cela n'est pas nécessaire quand on a la précaution de laisser bien mürir, de récolter en bonne condition et de nettoyer avec soin les graines destinées à la semence; mais il est avantageux de changer de semence, c'est-àdire d'acheter des graines réunissant toutes les conditions voulues, quand on n'a récolté que des grains sales, avaries ou pas suffisamment mûris.

Quelles sont les graines les plus vigoureuses et les plus aptes a germer?

Ce sont celles provenant de la récolte de l'année précédente. Plus elles sont vieilles, moirs elles possèdent de vigueur ou d'aptitude à germer promptement et énergiquement.

Comment s'assure-t-on des propriétés germinatives d'une semence?

On met quelques graines sur un linge que l'on tient constamment humecté avec de l'eau tiède. Les bonnes graines germent en peu de temps, au lieu que les autres restent intactes : on peut alors juger de la valeur de la semence par la proportion des graines qui ne germent pas.

Comment se fait le triage ou le nettoyage de la semence?

Ce triage se fait à la main pour les tubercules, comme la pomme de terre et le topinambour: pour les graines fines, telles que les céréales, il peut aussi se faire à la main; mais on emploie de préférence les procédés de de l'immersion et du triage mécanique.

En quoi consiste le triage par immersion?

A remplir une grande cuve d'eau, puis à y faire 
tomber légèrement et tranquillement la semence. Les bonnes graines vont au fond et les mauvaises surnagent à la surface. On enlève ces mauvaises graines en penchant la cuve pour faire écouler l'eau, qui entraîne avec elle tout ce qui surnage à sa surface.

Comment se fait le triage mécanique?

$\mathrm{Au}$ moyen d'un appareil appelé trieur ou séparateur de grains.

les plus

inée préossèuent ment et

ves d'une

'on tient s bonnes es autres eur de la germent

mence?

s, comme s graines faire à la cédés de

Quelles autres préparations est-il bon de donner à la semence?

Ce sont le chaulage et le pralinage.

Qu'est-ce que le chaulage?

C'est une préparation qui a pour but de prévenir certaines maladies auxquelles les plantes sont exposés, notamment la carie du blé et le charbon, puis de fournir au germe une substance qui active sa croissance.

Comment se fait le chaulage?

De trois manières: par immersion, par aspersion et par absorption.

Comment se pratique le chaulage par immersion?

On verse tranquillement la semence dans une cuve remplie de lait de chaux; on enlève les grains qui surnagent, puis au boutid'une demi-heure on retire les autres, qu'on étend pour les faire sécher et qui peuvent être semés le lendemain.

Comment se fait le chaulage par aspersion?

On répand une bouillie de chaux claire sur le grain, qu'on remue avec une pelle pour qu'il soit tout chaulé également, et le jour suivant il est prêt à employer.

y faire 
Comment se pratique le chaulage par absorption?

En lavant le grain et en le saupoudrant de poussière. de chaux vive pendant qu'il est encore humide.

$Y a-t$-il un chaulage plus efficace et en quoi consiste-t-il?

Oui : au lieu de laver le grain-surtout le blé-dans l'eau, on l'arrose avec une solution d'une demi-livre de sulfate de soude ou de sel de Glauber dans un gallon l'eau, ce qui suffit pour un minot de blé, puis on saupoudre le grain ainsi humecté avec de la poussière de chaux vive, en ayant soin de le remuer pour que tous les grains bénéficient de l'opération.

Peut-on employer autre chose que du sulfate de soude?

On peut employer une lessive de deux gallons de cendre bouillie dans deux ou trois seaux d'eau, à quoi on ajoute une couple de gallons de chaux éteinte, puis on arrose le grain avec ce mélange.

\section{Qu'appelez-vous pralinage?}

C'est une opération qui consiste à mêler la semence avec des engrais pulvérulents, tels que la poudrette, la poussière de noir animal, la cendre et autres matières semblables.

Comment se fait cette opération?

On verse de l'eau, et mieux encore de l'urine, sur la semence, pour l'humecter; on saupoudre l'engrais, puis on mélange le tout à la pelle, afin que l'engrais adhère à tous les grains.

Quel effet produit le pralinage?

En fournissant à la semence une substance nutritive 
facilement assimilable, il stimule le développement du germe et active sa croissance.

De quoi dépend la quantité de semence demployer?

ie-t-il?

Outre qu'elle varie avec les différentes espèces de semence, elle dépend dans chaque cas d'une foule de circonstances générales, telles que la préparation et la qualité du sol, la grosseur et la qualité des graines employées, la température, l'époque plus ou moins avancée des semailles et d'autres circonstances semblables.

Quelles sont les règles générales qu'il faut suivre pour dé. terminer la quantité de la semence?

Ces règles générales peuvent se résumer ainsi :

On sème clair-

1. Dans les terrains très riches, où les plantes prennent beaucoup de développement et sont exposées à taller ;

$2^{\circ}$ Dans les terrains peu profonde, ou les racines sont portées à s'entrelacer et se détruiraient, si elles étaient trop drues ;

$3^{\circ}$ Les plantes qui font des racines volumineuses, afin de ménager à ces racines l'espace voulu pour se développer completement;

$4^{\circ}$ Les plantes à tiges touffues ou feuillues, empruntant beaucoup à l'atmosphère pour se nourrir, afin de leur ménager l'espace nécessaire pour développer leur feuillage et de leur permettre de mieux profiter de l'influence de la lumière et des agents atmosphériques.

On sème dru-

utritive

$1^{\circ}$ Dans les terrains pauvres, sablonneux, où l'in- 
fertilité et le desséchement du sol empêchent une partie des graines de fructifier;

$2^{\curvearrowright}$ Dans les terrains qui sont épris de mauvaises herbes ou exposés aux ravages des insectes, qui font périr une partie de la semence ;

$3^{\circ}$ Quand la température et l'époque des semailles ne sont pas favorables à la végétation;

$4^{\circ}$ Quand on a lieu de craindre qu'une partie de la semence ne soit pas propre à germer, ou quand la semence est sale et renferme beaucoup de graines btrangères.

Qu'arrivet-il quand on sème trop dru?

Les plantes poussent trop rapprochées, les tiges et les feuilles se tassent, ce qui empêche la circulation de J'air et de la lumière; elles blanchissent, s'etiolent, manquent de rigidité et ne fructifient presque pas.

Qu'arrive t-il quand on seme trop clair?

On perd une partie du terrain, qui est envahie par les mauvaises herbes.

\section{1-Du semis}

Qu'entendez-vous par semis ou semaille?

Ce sont les opérations qui ont pour but de confier la semence à la terre? 


\section{Quel temps faut-il choisir pour semer?}

Dans un terrain humide, il faut attendre que la terre soit bien réchauffée par le soleil. Dans un terrain sec, il faut semer avant que la terre soit desséchée par la chaleur. Pour les semailles d'automne, il faut attendre que la terre ait repris un peu de fraîcheur. Enfin, il faut autant que possible ne semer que ce qui peut se herser de beau temps, car s'il survenait une pluie de durée avant le hersage, la semence se gaterait.

Dans quel état doit être le sol pour recevoir la semence?

Il doit être sec, en bonne condition pour se bien herser. Semer dans un sol humecté par la pluie ou à la veille d'une forte pluie a l'inconvénient d'exposer les graines à pourrir, car alors la terre se plaque, forme une espèce de couche dure, imperméable à l'air et à la chaleur.

Distingue.t.on plusieurs manières de semer?

Oui : il y a le semis à la volée et le semis en ligne.

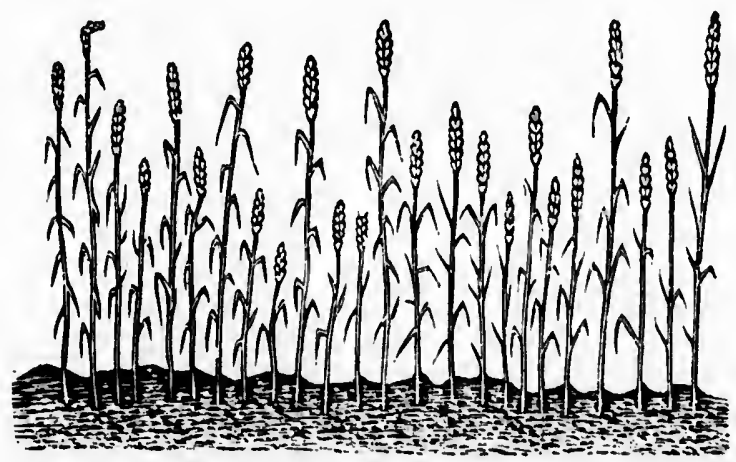

Fig. 58-Blé semé il la volée 
En quoi consiste le semis à la volée?

A repandre la semence sur toute la surface du champ, de la manière la plus égale et la plus uniforme possible.

Comment se fait le semis d la volée?

A la main ou à la machine.

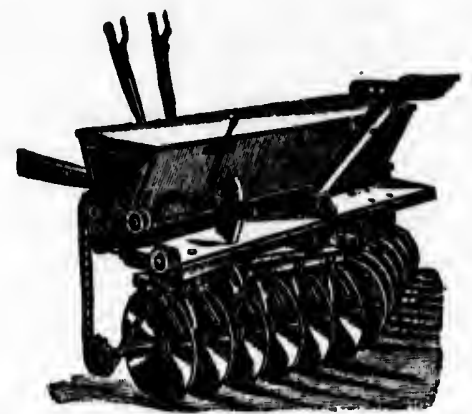

Fig. 50-Herse ì disques avee semoir

Comment procedde-t.on pour semer à la main?

Autant que possible on choisit un temps calme; mais s'il vente, on se place sous le vent, afin que celuici n'emporte pas le grain et ne l'empêche pas de se répandre également. Le semeur marche d'un pas fermo et régulier, afin que la main fasse cadence avec le pied.

Quelles sont les machines employées pour semer à la volée?

Le petit semoir à bras et le semoir à cheval, dont il y plusieur's modèles. 


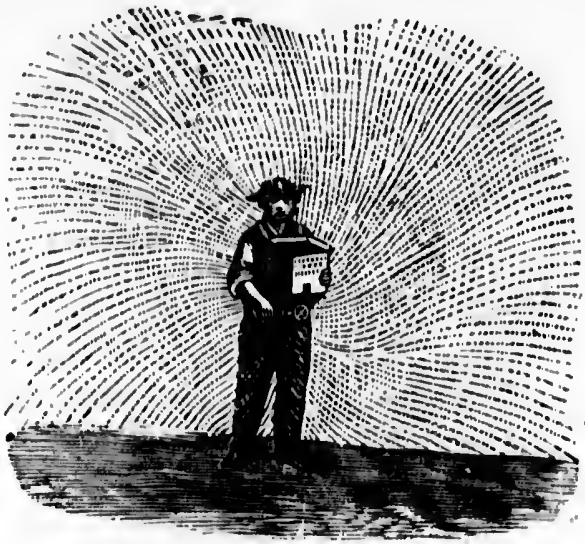

Fig. 60-Semis ì la volée, all semoir

calme ; celuise réferme avec le a volée? ont il y

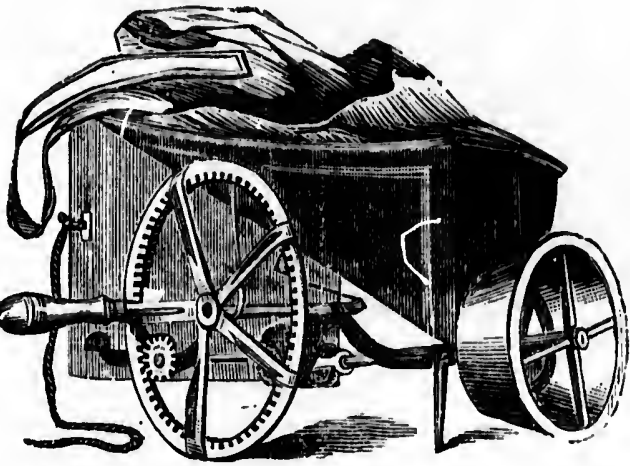

Fig. 61-Semoir ì bras, a la volèe

Comment se font les semis en lignes ?

A la main ou à la machine.

Dans quelles cultures sème t-on principalement à la main?

Dans la petite culture et surtout dans la culture de 
certaines plantes-racines, telles que la carotte, la betterave, la pomme de terre et aussi le maïs.

Quels sont les instruments en usage pour faire d la machine les semis en ligne?

Ce sont les semoirs en lignes.

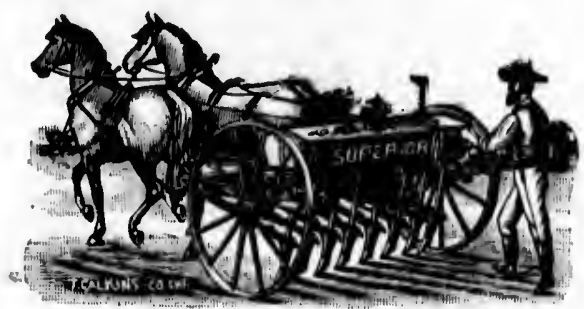

Fig. 62-Semoir en lignes "Superior."

$Y$ a-t il plusieurs types de ces semoirs?

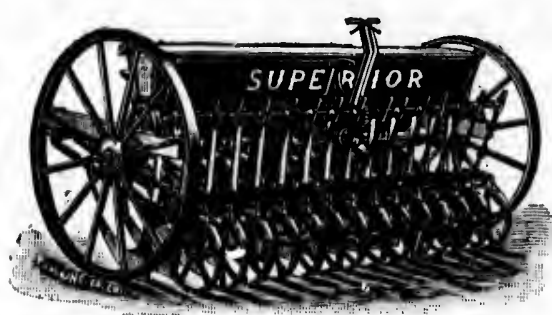

Fig. 63-Semoir en lignes, at roues recouvreuses

Oui : uns déposent « simplement la semence sur le sol; la plupart creusent de petits sillons dans lesquels tombe la semence; il yen a qui creusent les petits sillons, déposent la semence et la recouvrent. Les plus perfectionnés, outre ces opérations, scarifient la terre avant d'y déposer la semence et sont munis d'un rouleau qui la plombe à mesure que le semis est recouvert.

Ces appareils permettent-ils de régler la quantité de la semence et l'espace entre les rangs?

Oui, parfaitement. La boîte à grains est munie d'un 
bette-

appareil qui ouvre et ferme d la volonte du conducteur les orifices de décharge, méme pendant la marche de la machine. Dans quelques types de semoirs, un autre appareil permet d'écarter ou de rapprocher le rayonneur, afin de donner l'espace voulu entre les rangs. Enfin, un levier fait monter ou descendre les socs, arrêter ou marcher l'écoulement des graines, au désir du semeur, et les instruments perfectionnés sont disposés pour enterrer la semence plus ou moins, selon la profondeur désirée.

ns déimplemence a pluent de $s$ dans hbe la $y$ en a les pedépoectionnt diy qui la

té de la ie d'un

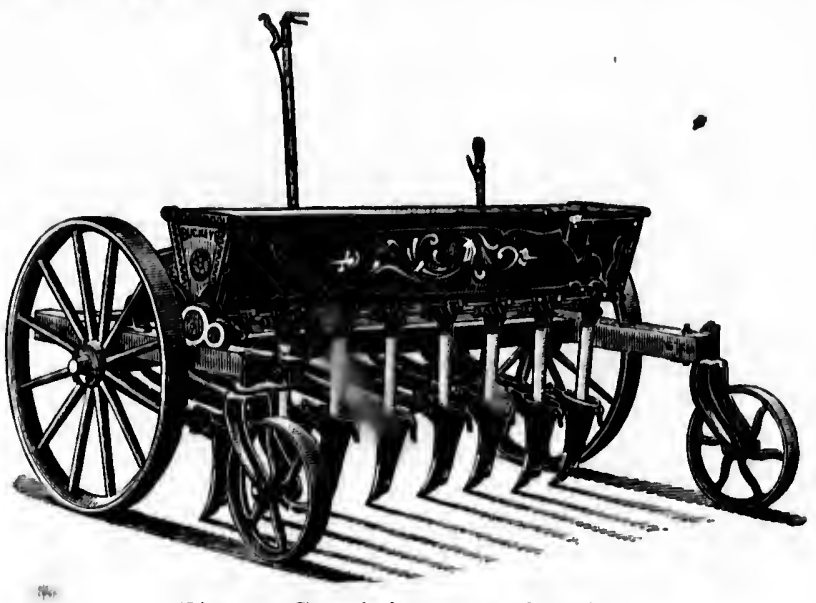

Fig. 64-Semoir à en trure ajustable

Quels sont les principaux avantages du semis à la machine?

Avec un semoir, chaque graine est placée exactement à la profondeur et à la distance désirées, sans qu'il y ait perte, de sorte que toutes les graines germent, poussent et mûrissent en même temps, ce qui donne un rendement plus beau et plus égal. Les semis en ligne, avec ces appareils, facilitent les binages et l'aération étant plus grande, les tiges ont plus de rigidité, sont 
moiñ exposées à la verse et le rendement est plus considérable. L'usage du semoir économise beaucoup de temps et de 25 à 30 pour cent sur la semence, ce qui, avec le surplus dans le rendement, paie bien vite ce que conte l'instrument.

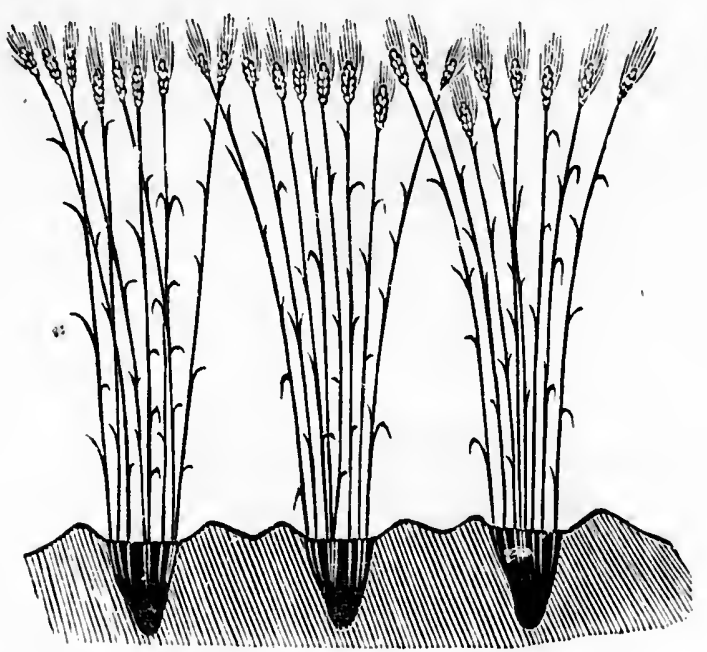

Fig 65-Blé semé au semoir en lignes

Les semiirs peuvent-ils semer toutes les graines?

Oui : ils sont ordinairement munis d'un appareil qui règle à volonté la grardeur des orifices par lesquels s'écoule la semence, ce qui permet de les employer pour semer des graines de toutes grosseurs, depuis la graine de mil jusqu'aux pois.

Peut-on employer le semoir dans les cultures où la semence dout être déposée avec l'engrais?

Oui : il y a des semoirs qui sont munis d'un distributeur qui dépose l'engrais en même temps que la semence. Pour le blé, la semence et l'engrais descendent par les 
mêmes tubes; pour les navets, les betteraves et autres graines de semblable culture, la semence descend par des tubes différents de ceux de l'engrais, ce qui permet à celui-ci d'être recouvert par la terre avant que la graine ne soit déposée.

Certains semoirs à la volée ont-ils aussi des distributeurs d'engrais?

Oui, notamment le semoir de Smith, qui se transforme aussi en simple distributeur d'engrais.

Quels sont les engrais qui se distribuent avec ces instruments?

Les engrais pulvérulents, tels que le plâtre, la chaux éteinte, la cendre, la suie, la poudrette, le noir animal, la poudre d'os, les phosphates $\epsilon$ t les guanos pulvérisés, les sels ei autres matières semblables.

Emploie t-on des semoirs spéciaux pour certaines cultures?

Oui, principalement pour les navets, la betterave et la pomme de terre.

reil qui uels s'éer pour a graine

semence

listribusemence. $t$ par les

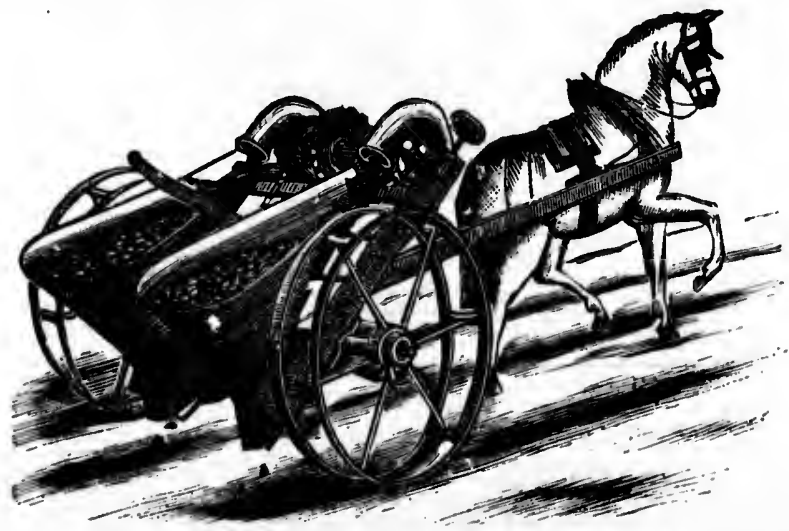
10

Fig. 66-Semoir de pommes de terre de Murray 
Comment fonctionne le semoir a betteraves avec engrais?

Ce semoir place l'engrais à une profondeur variable à volonté et le recouvre de terre, ce qui évite le contact direct de la graine avec l'engrais. D'autres socs sèment et recouvrent la graine, de manière que les premières radicelles ne viennent en contact avec l'engrais qu'au moment où elles sont assez développées pour puiser do nouvelles forces dans l'engrais. Des rouleaux, qui sont indépendants des socs, passent par-dessus l'engrais et forment les sillons, en sorte que tout se fait d'une seule opération.

Comment se sèment les pommes de terre?

On les sème généralement à la main; mais depuis quelques années on a inventé des machines pour faire cette opération. La meilleure est le scisuir Aspinwall, quị sème aussi le maïs.

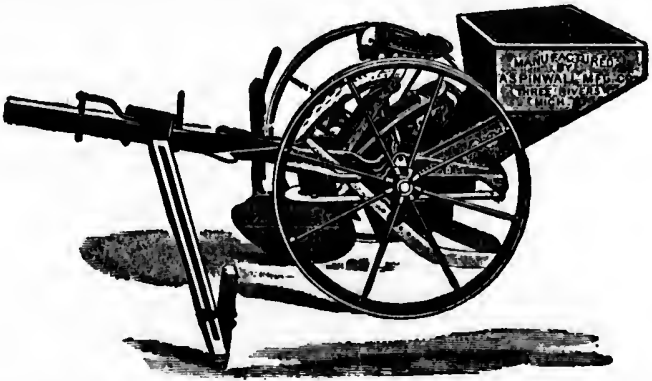

Fig. 67-Semoir i pommes de terre "Aspinwall"

Connaissez-vous d'autres espèces de semoirs ?

Oui : il y a pour la petite culture les semoirs à brouette, ou semoirs à bras, qui s'emploient pour semer les carottes, les betteraves, les oignons et autres graines fines. 


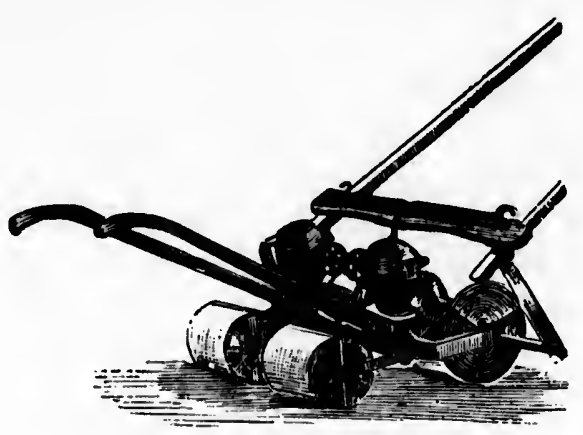

Fig. 63-Semoir à navets

Quelle préparation faut-il donner à la terre avant de lui confier la semence?

Quand la surface du guéret est rugueuse, il faut herser pour l'unir, avant de semer à la volée, pour empêcher la semence de s'accumuler dans les trous ou les creux formés par l'arête des tranches de terre soulevées par la charrue. Le hersage est pareillement nécessaire pour ameublir et préparer la surface du sol à l'action des semoirs, principalement ceux qui recouvrent la semence.

\section{\& 2-Recouvrement de la semence}

Comment recouvre-t-on généralement la semence?

emoirs à pur semer es graines
Par le hersage.

A quelle profondeur faut.il recouvrir la semence?

Cela dépend de la nature des graines, de la qualité du 
sol et de la température. Les graines fines demandent un recouvrement léger, parfois même un simple roulage, comme les graines de trèfle et de mil ; les graines plus grosses exigent un recouvrement plus épais, comme les pois, qui se sèment parfois sous raie. Quand le sol est léger et le temps très sec, on doit enterrer plus profondément la semence, afin de lui procurer l'humidité voulue pour la faire germer.

\section{Quel effet produit le roulage?}

Il comprime la terre autour de la semence, qu'il met en contact immédiat, conserve plus de frâ̂cheur, ce qui stimule encore la germination et la végétation. Enfin, le roulage est presque toujours le complément obligatoire d'un semis bien fait.

Quelles sont les herses qui conviennent aux différentes terres?

Les herses légères, telles que les herses à chaînons, les herses couleuvres et celles à dents de bois, conviennent aux sols légers, sablonneux ou très meubles; les grosses herses, à dents de fer et recourbees en avant, pour leur donner plus d'énergie, ainsi que les herses à disques, s'emploient dans les terrains durs, argileux et compactes.

\section{Comment se pratique l'ensemencement sous raie?}

On sème comme à l'ordinaire, puis on recouvre la semence au moyer d'un léger labour à la charrue ordinaire, ou encore bien mieux avec le scarificateur, le cultivateur, le polysoc ou la déchaumeuse, ce qui prend bien moins de temps. 
andent

le rougraines comme d le sol lus proumidité

u'il met $\dot{r}$, ce qui Enfin, obliga-

ifferentes haînons, convienles ; les n avant, herses à ileux et

ouvre la rue ordiateur, le ui prend

Comment se fait le recouvrement des zemis de pommes de terre et de maïs?

A la houe à la main, par un hereage en travers ou avec le buttoir.

Comment se fait le recouvrement des semis en billons?

A la main et mécaniquement, au moyen de certains semoirs à bras, munis de deux petits versoirs qui ramènent la terre sur la semence, tels que le semoir Matthews. 


\section{CHAPITRE VIII}

DE L A R C OLTE

Quels travaux comprend la récolte?

Le récolte comprend tous les travaux requis pour séparer les plantes du sol où elles ont pousse, les mettre en grange ou en cave et les préparer pour la consommation.

A quelle époque de la végétation les plantes doivent-elles être récoltées?

Toutes les plantes ne se récoltent pas à la même époque de la végétation. Les céréales se récoltent lorsque le grain est mûr ou sur le point de l'être. Les plantes cultivées pour leurs tiges ou leurs feuilles, comme le foin, la vesce et les autres plantes fourragères, se récoltent au commencement de leur floraison. Celles qu'on cultive pour leurs racines ou leurs tubercules, telles que la betterave, la carotte et les pommes de terre, se récoltent quand ces racines ou ces tubercules ont atteint leur plein développement.

Quelle faute nos cultivateurs commettent-ils généralement a l'égard de l'époque de la récolte?

Ils laissent trop mârir les céréales et le foin. 
Quel inconvénient y a-t-il d̀ cela?

Les céréales récoltées trop mâres s'égrènent sur le champ dans les manipulations de la récolte, ce qui en perd une partie. Les grains récoltés trop mârs, notamment le ble et l'avoine, donnent moins de farine et leur paille desséchée par une trop grande maturité est moirs nutritive pour les animaux. Les plantes fourragères qu'on laisse parvenir à une trop grande maturité avant de les faucher, perdent aussi une bonne partie de leurs sucs nutritifs et sont bien moins aǵréables aux animaux. Enfin, dans les régions ou le mauvais temps prend de bonne heure, en attendant trop longtemps pour faire la récolte, on s'expose à la pluie et au mauvais temps, qui rendent les récoltes très difficiles et en gâtent souvent une grande partie.

Comment les cultivateurs soigneux doivent-ils se préparer aux travaux de la récolte?

Dès qu'ils ont fini les travaux d'entretien qui suivent les semailles, ils doivent nettoyer les sranges et les fenils, mettre en ordre les instruments aratoires-ainsi que les voitures et les attelages-et s'assurer les services d'un personnel suffisant pour que tout se fasse dans le temps voulu et sans retard, une fois les travaux commencés.

Est-il avantageux de payer un peu cher pour se procurer la main d'cuvre nécessaire pour engranger la récolte en bon état?

Oui, car ces dépenses, qui peuvent paraître un peu fortes, sont bien plus que compensées par la qualité et le rendement d'une récolte engrangíse en bonne condition. 
L'usage des machines agricoles offre-t.il sous ce rapport quelques avantages?

C'est incontestable. Avec les rateaux à cheval, les faucheuses, les moissonneuses, les lieuses, les travaux se font si promptement que l'on peut presque toujours éviter le mauvais temps, ce qui compense bien vite le cout de ces machines.

Sous quels noms désigne-t on les différentes récoltes?

On appelle moisson la récolte des céréales; fenaison, celle du foin et des autres plantes fourragères, et arrachage, celles des plantes-racines.

\section{\& 1-Moisson}

préparer

i suivent les fenils, i que les ices d'un le temps mencés.

procurer lte en bon

Comment se fait la coupe des céréales?

A la faucille, à la faux, au javelier, à la faucheuse et à la moissonneuse.

Quels zont les avantages et les désavantages de la coupe d la faucille?

Elle fait une coupe régulière, permet de travailler dans les endroits difficiles, rocheux, où les autres instruments ne peuvent pas atteindre; comme elle laisse le chaume long, les javelles sont plus soulevées, ce qui fait sécher le grain plus vite et l'expose moins à germer, dans les temps pluvieux; mais la coupe à la faucille un peu ualité et est un ouvrage fatigant, long et par conséquent dispendieux, quand il faut payer la main d'œuvre; la lenteur avec laquelle elle s'opère traine la moisson en longueur et, quand on la finit trop tard, expose souvent aux pertes provenant du mauvais temps. 
Quels sont les avantages et les désavantages que présente l'usage de la faux pour la coupe des céréales?

La faux fait un travail plus rapide et un chaume plus court, ce qui augmente la quantité du fourrage ; mais elle secoue le grain en l'abattant, ce qui expose à des pertes par suite de l'egrenag. Comme il faut ensuite ramasser a la fourche et au rateau le grain qu'elle dépose en andains, ces manipulations produisent un nouvel égrenage et une perte correspondante.

Pour quelle récolte la coupe à la faux est-elle de nécessité?

Pour celle des pois, qui ne s'abattent qu'à la faux ou au crochet.

Qu'appelez-vous javelier?

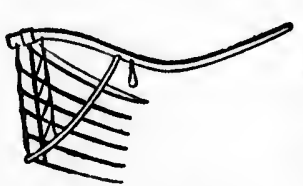

Fig. 69-Javelier

C'est une faux munie de baguettes qui ramassent le grain et permettent de le déposer en javelles régulières, comme dans la coupe à la faucille.

Quels avantages présente l'usage de cet instrument?

Il réunit les avantages de la faux et de la faucille: il fait presque autant d'ouvrage que la faux, il ramasse aussi net que la faucille, fait les javelles aussi régulièrement, mais plus minces et moins serrées, ce qui facilite d'avantage la dessiccation.

Qu'appelez-vous moissonneuse?

C'est une machine, mue par des chevaux, qui coupe le grain et le met en javelles, absolumfnt comme dans la coupe à la faucille ou au javelier. Le grain est coupé sans la moindre secousse, puis s'abat légèrement et ré- 
gulièrement sur un plateau, d'ou il est enlevé par un grand rateau qui forme les javelles et les dépose sur le sol.

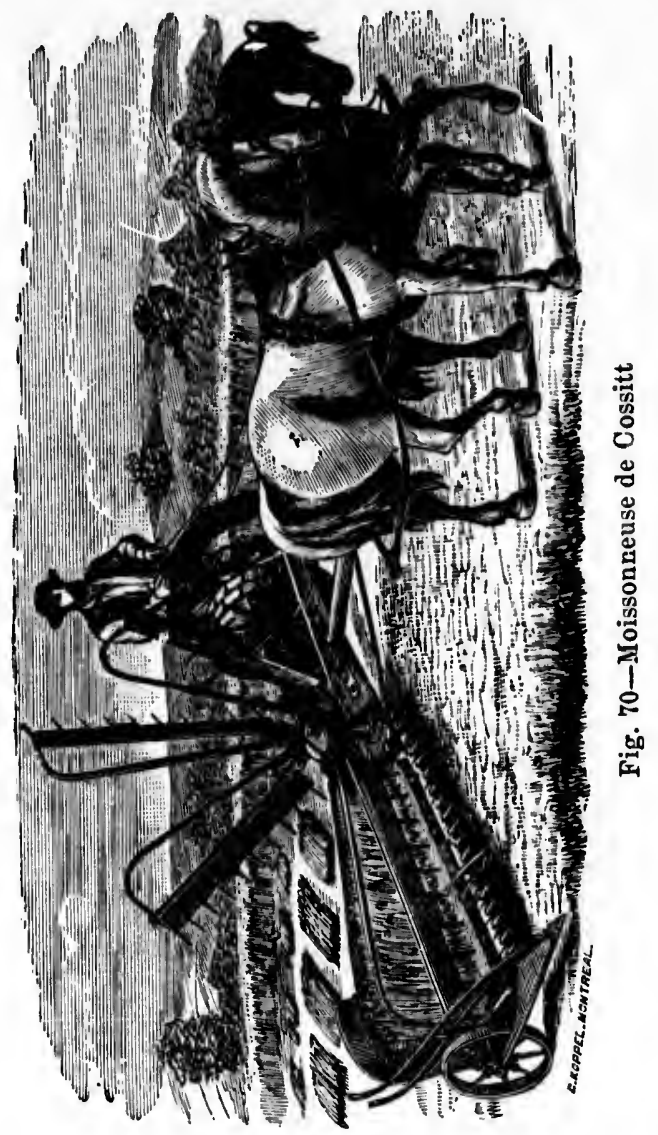

coupe e dans coupé et ré-

le baain et ivelles upe d

lle: il masse ulièreacilite

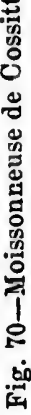

$Y$ a-t-il des moissonneuses qui font aussi l'engerbage?

Oui, les moissonneuses engerbeuses qui, d'une seule opération, coupent le grain et l'engerbent. 


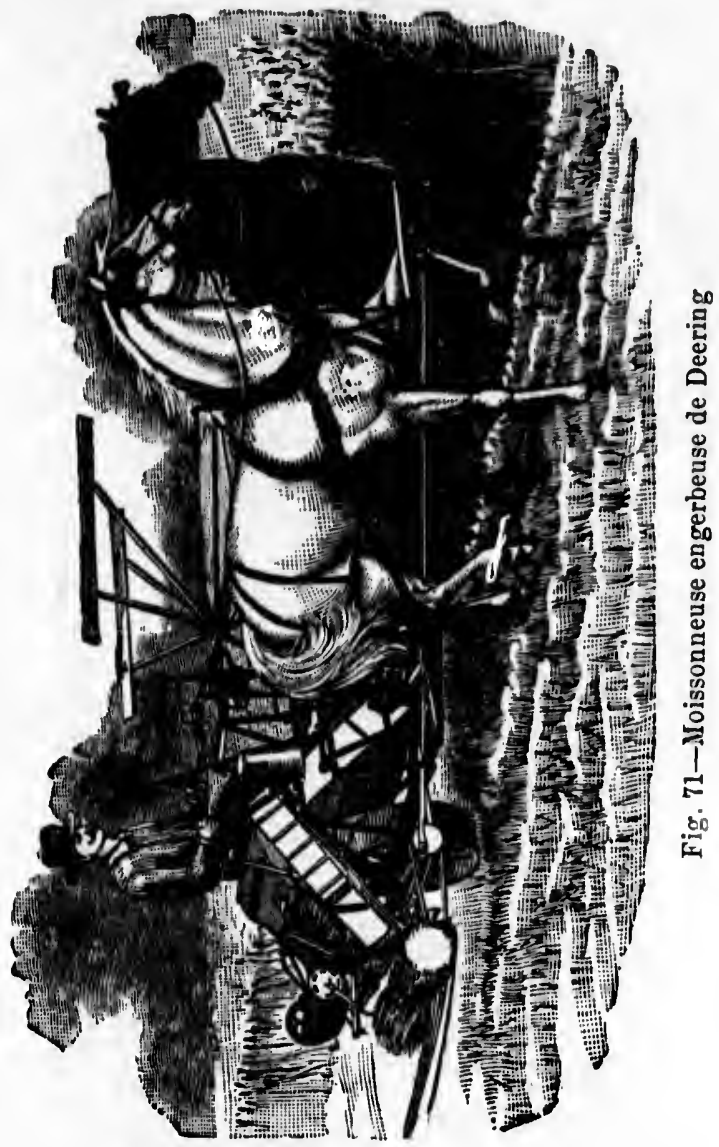

Quels avantages présente l'emploi de la moissonneuse?

Outre qu'elle fait l'ouvrage aussi bien $m$ 
coup de main d'ouvre et permet d'attendre le beau temps ou d'en profiter pour abattre la récolte dans les conditions les plus avantageuses. Enfin, au lieu d'exiger de la part de l'homme un travail fatigant et dur, comme l'ueage des instruments à bras, l'emploi de la moissonneuse n'est qu'un délassement, puisque toute la besogne $d u$ conducteur consiste a se promener confortablement assis sur un bon siège.

La moissonneuse peut-elle s'employer pour la coupe de tous les grains et dans tous les terrains?

Non : elle ne s'emploie que pour les grains qui doivent ou peuvent etre engerbés et seulement dans les terrains unis, bien préparés, divisés en planches assez larges et libres de grosses pierres ou autres obstacles semblables.

Comment engerbe-t.on le grain?

A bras ou à la machine.

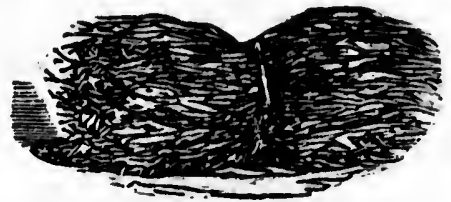

Fig. 72-Gerbe fuite à bras

Engrange-t-on les céréales immédiatement après les avoir coupées?

Non: il faut les laisser au moins trois ou quatre jours sur le champ pour leur permettre d'achever de mûrir et de sécher complètement, sans quoi elles chaufferaient et se gâteraient en grange : c'est ce qu'on appelle le javelage. 
Quel est le but du javelage?

C'est de faire sécher le grain et de lui permettre diachever de murir en puisant dans la tige les sucs qu'elle renferme encore, ce qui fait que les grains qui complètent ainsi leur maturation ne se contractent pas comme ceux qui l'achèvent sur pied. Enfin, le grain javelé, qui a subi l'influence de la rosée et du soleil, se bat et s'égrène bien plus facilement.

Que faut-il ;aire pour activer le javelage?

Il est bon de retourner les javelles ou les rangs une couple fois, afin d'exposer pareillement le dessous et le dessus à l'influence de la rosée et du soleil. Cette opération est absolument nécessaire pour empêcher le grain de se gâter et de germer, quand il reçoit de la pluie pendant qu'il est en javelles ou en rangs.

Quel est le moyen de protéger le grain coupé contre le mauvais temps, durant le javelage?

C'est de le mettre en moyettes ou quintaux.

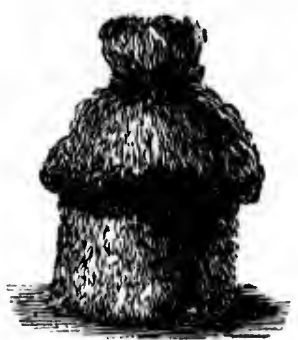

Fig. 73-Moyette

Qu'appelez-vous moyettes ou quintaux?

Ce sont des assemblages de gerbes debout, l'épis en 
haut. surmontées d'une gerbe renversée qui sert de couverture aux autres.

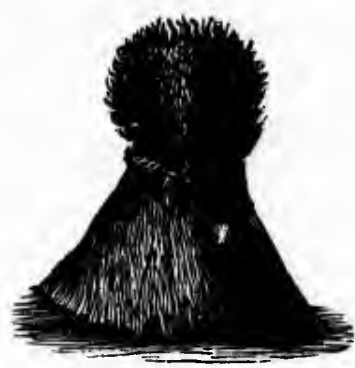

Fig 74-Moyette non coifféc

Comment se font ordinairement les moyettes?

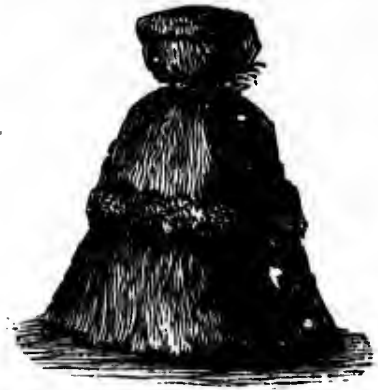

Fig. 75-Moyette coiffée
On place une gerbe debout et on l'entoure de trois ou quatrea utres, qu'on serre de la tête autant que possible et qu'on éloigne par le bas, afin de favoriser la circulation de l'air ; on place dessus une gerbe renversée, en étendant l'épis pour qu'elle embrasse les autres et les couvre complètement.

Connaissez-vous d'autres manières de faire les moyettes?

Il y en a plusieurs autres, mais la suivante est donnée

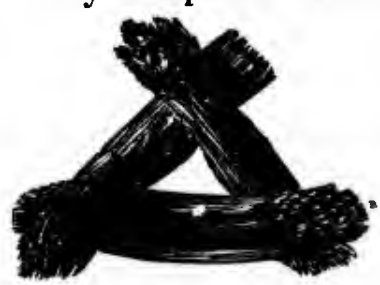

Fig. 76-Base d'une moyette comme la meilleure.-On dispose trois petites gerbes en triangle, de façon à ce que l'épis ne touche pas au sol. On place les autres gerbes en travers des trois du triangle, l'épis au centre, de manière à former un cercle. On superpose ainsi les

épis en 


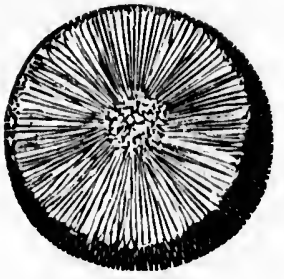

Fig. 77-Coupe d'une moyette rangs de gerbes, en les croisant de plus en plus pour diminuer le diamètre de la moyette, jusqu'à la hau. teur de trois ou quatre pieds, puis on couvre le tout par une gerbe renversée. Ces moyettes résistent bien mieux que les autres au verit et au mauvais temps.

En quel état doit être le grain engerbé pour être mis en moyettes?

Il ne faut l'engerber que lorsqu'il est absolument libre de toute humidité provenant de la rosée ou de la nluie.

Le javelage en moyettes est-il plus long que liautre?

Oui : les tiges serrées par l'engerbage sèchent bien moins vite que celles qui sont dispersées en javelles, exposées à l'air et au soleil. C'est pourquoi le javelage en moyettes doit durer de dix à quinze jours au moins, suivant l'état de la température et la verdeur du grain lors de la coupe.

Comment fait-on javeler le grain coupé à la faux?

On le ramasse en rangs immédistement après le fauchage, alors qu'il est moins enclin à s'égrener, et quand il a perdu un peu de sa verdeur, on met les rangs en veillottes, ce qui lui permet de mieux résister au mauvais temps.

Comment se fait l'engerbage à bras?

Quand plusieurs moissomeurs travaillent ensemble, un place les harts ou les liens, d'autres déposent symétriquement dessus les javelles de deux ou trois planches, et le lieur finit l'opération en attachant les harts ou les liens. 
int de le diaa hau. , puis gerbe sistent u verit mis en t libre nluie.

t bien velles, velage moins, grain

le fauquand gs en mau-

mble, métrihes, et liens.

Avec quel appareil se fait l'engerbage mécanique?

Avec la lieuse ou engerbeuse.

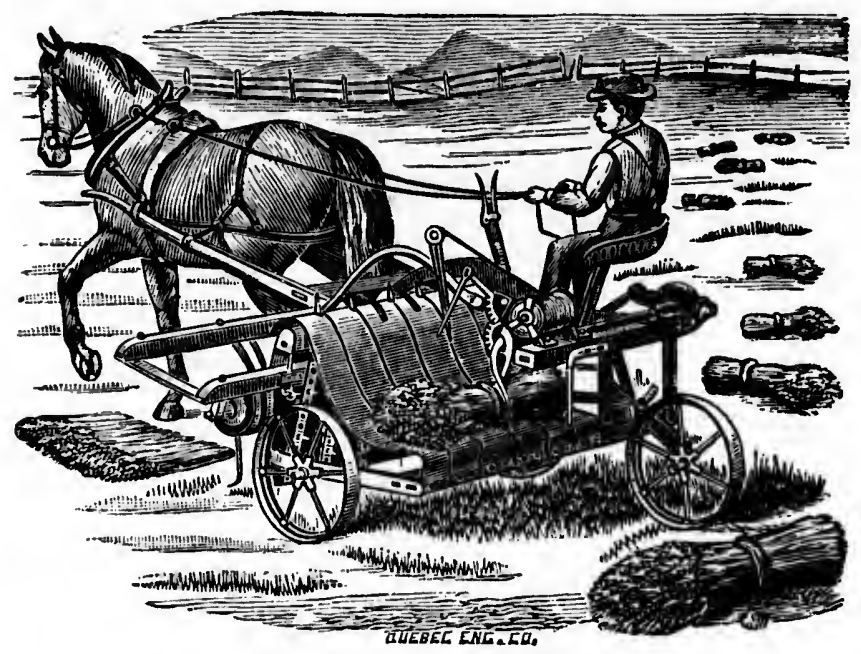

Fig. 78-Engerbeuse de Johnson

Commment fonctionne cette machine?

Elle est traînée par un cheval, auquel le conducteur fait suivre les rangs de javelles. Un appareil monte la javelle sur un demi-tambour, où un mécanisme fort simple l'enroule, la lie avec de la petite ficelle ou de la broche, puis la jette en arrière sur le sol. Avec cette machine, un enfant capable de conduire un cheval peut engerber de cinq à dix arpents par jour.

$Y$ a-t-il des machines qui coupent et engerbent en même temps?

Oui ; mais elles sont compliquées, dures à traîner, ce qui fait que généralement on préfère avoir des machines 
différentes pour faire séparément les deux opérations, surtout dans les terrains accidentés par les raies et les rigoles.

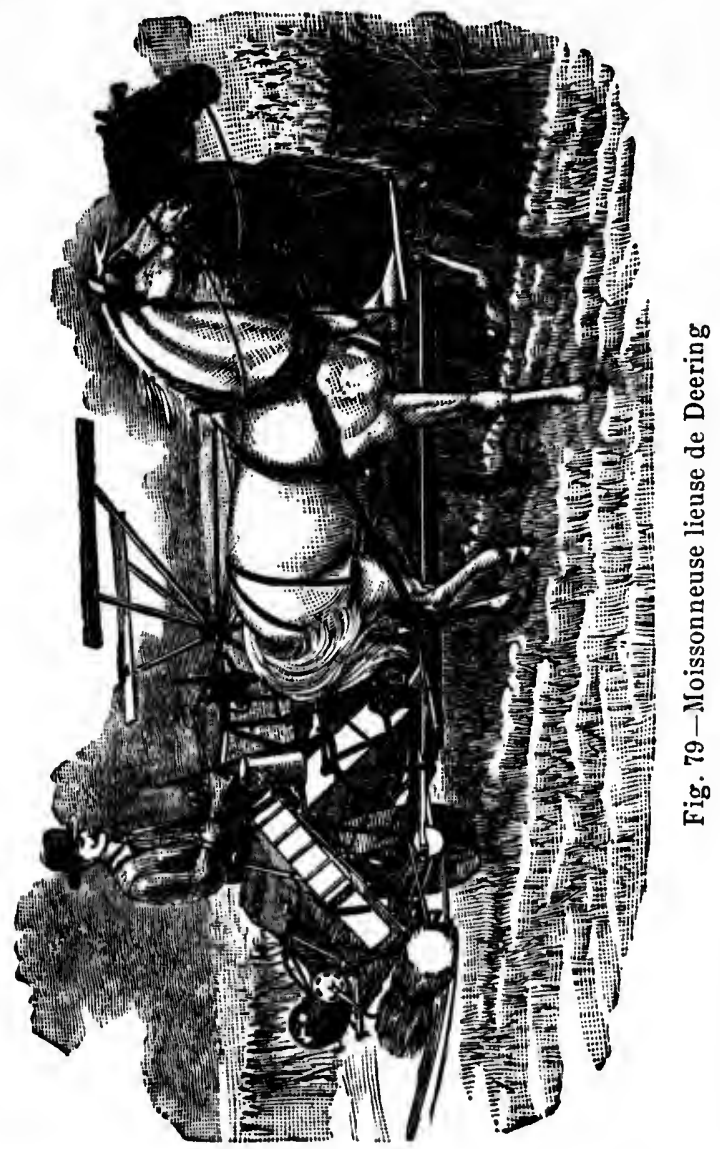

Que fa: on du grain lorsqu'il a fini de javeler et de mûrir?

On le transporte dans la grange, pour attendre le battage. 
ations, et les

mûrir? ndre le

Quellss conditions'doivent réunir les tasseries destinées d recevoir le grain?

Elles doivent être protégées contre l'humidité et le mauvais temps par une toiture et des lambris étanches, munies d'un plancher ausei bien joint que possible et élevé d'une dizaine de pouces au-dessus du sol, pour prévenir les effets de l'humidité.

Que fait-on quand le plancher est mal joint et pas assez élevé?

On le recouvre d'une couche de paille, sur laquelle on dépose ensuite le grain, qu'on étend par couches égales, quand il est en vrac ou non engerbé.

Comment dépose-t-on les gerbes dans la tasserie?

On les dispose en rangs réguliers, ayant la précaution de placer celles du rang extérieur l'épis tourné vers le centre de la tasserie et le pied vers les parois, afin d'empêcher les ravages des volailles et de la vermirie.

Comment se fait le battage des grains?

A bras ou à la machine.

Quel instrument s'emploie pour le battage à bras?

C'est le fléau, qui n'est guère en usage que pour le battage des pois, du sarrasin, du maïs et du lin, ou pour les autres grains, dans les endroits nouveaux ou les vieux établissements où l'amélioration de la culture est peu avancée.

Quels sont les appareils en usaye pour faire le battage à la machine?

On a abandonné presque partout les anciens roum 


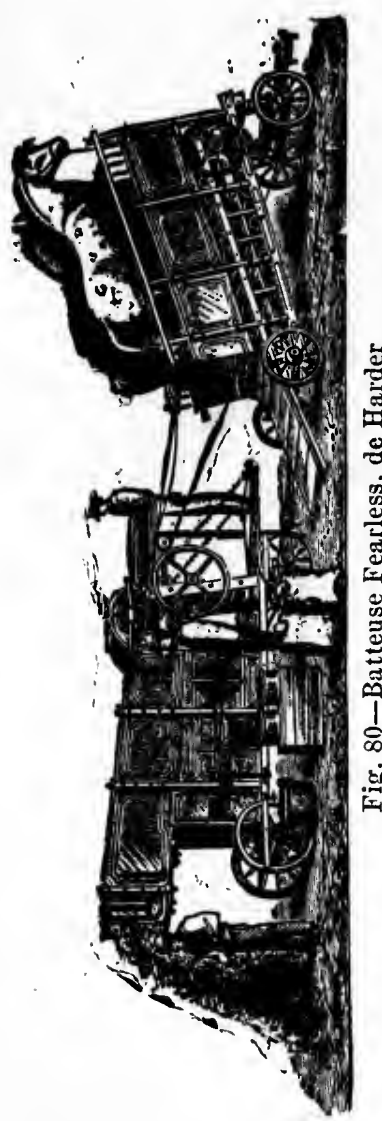

leaux à dépiquer et l'on n'emploie que les batteuses, mues par des chevaux ou des machines à vapeur.

Quelle différence y a-t-il entre lle pouvoir à cheval et le manége?

Le pouvoir à cheval, ou horse-power, est un plan incline mobile, ou le cheval n'agit que par sa pesanteur; dans le manége, le cheval n'agitque par traction sur de grands leviers qui actionnent un mécanisme commuriquant la force motrice. Il y a de ces manéges auxquels on peut atteler de six à huit chevaux.

L'usage des manéges est-il bien répandu dans certains pays?

Dans la province d'Ontario et les Etats de l'Ouest, quand un emploie les chevaux pour faire marcher les batteuses, on se sert à peu près exclusivement des manéges, parce qu'ils donnent beaucoup plus de force motrice que les horse-powers en usage dans notre province.

Comment se fait le battage a la vapeur?

Avec des batteuses ordinaires, mais plus fortes et 
et l'on atteuses, raux ou eur.

a-t-il enval et le

eval, ou plan ine cheval santeur; $\theta$ cheval on sur de actionre comrce moces maon peut uit che-

ges est-il certains

d'Ontal'Ouest, rcher les es manéorce moprovince.

fortes et actionnées par des machines à vapeur locomobiles, montées sur des roues et qui se transportent facilement avec deux chevaux.

L'usage de ces machines n'est-il pas dangereux pour le feu?

Il y en a, notamment celle dite Champion, qui sont munies d'arrête-flammèches et n'offrent aucun danger d'incendie.

Ces machines travaillent-elles rapidement?

Il y en a qui battent, vannent et nettoiènt, prêts a porter au moulin, jusqu'à dix-huit cents minots en dix heures de travail.

L'usage des batteuses d̀ vapeur est-il bien répandu?

Il est peu répandu en France, mais il l'est beaucoup dans Ontario et l'ouest des Etats-Unis, ou l'on bat généralement le grain sur le champ.

Quels sont les avantages des batteuses dे vapeur?

Ces machines étant plus fortes et plus perfectionnées que les batteuses ordinaires, elles battent plus net et permettent de battre le grain sur le champ, ce qui économise souvent les frais d'engrangement. Enfin, elles dispensent aussi de la nourriture des chevaux, qu'il faut employer avec les autres machines.

\section{Qu'appelez-vous batteuses à bras?}

Ce sont de petites batteuses mécaniques, mues à bras d'homme, passant jusqu'à 300 ou 400 gerbes par jour et qui seraient d'une grande utilité dans les endroits nouvellement défrichés, out il n'y a pas d'aires ou batteries pour séparer le grain de la paille. 
Qu'est-ce que le vannage?

C'est une opération qui a pour but de nettoyer ou de séparer de la balle et des mauvaises graines le grain battu au fléau ou à la machine.

De quels appareils se sert-on pour vanner?

Du van, qui se manie à bras, et du tarare, vulgairement appelé crible.

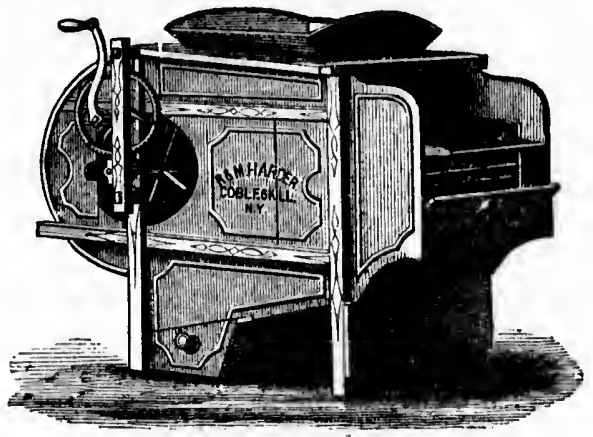

Fig. 81-Tarare de Harder

De quel appareil se sert-on pour nettoyer et séparer le grain de la manière la plus parfaite?

Du trieur qui, en épurant complètement le grain, lui donne plus de valeur pour la vente, surtout le grain de semence.

Quels soins faut-il donner au grain pour le conserver en grenier?

Il faut le déposer en couches peu épaisses, dans un lieu sec, et le remuer de temps à autre à la pelle pour prévenir l'échauffement. Quand cela ne suffit pas, on le passe au tarare pour le rafraîchir et l'aerer. 


\section{2-Arrachage}

Qu'est-ce que l'arrachage?

Ce sont les différentes opérations que nécessite la récolte des plantes-racines.

Comment se fait l'arrachage?

A la main, avec des instruments à bras ou à la machine.

De quels instruments d bras se sert-on généralement?

De la houe, de la fourche, de la bèche et surtout du crochet à deux dents, qui agit très bien dans les sols compactes.

Quelles sont les machines traînées par les chevaux, qu'on emploie pour l'arrachage?

Ce sont le buttoir, l'arracheur de pommes de terre et l'arracheur de betteraves et de carottes.

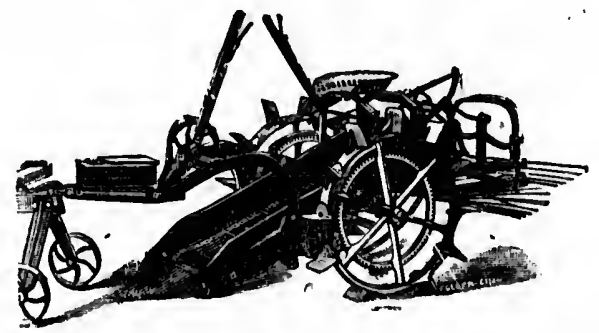

Fig. 82-Arracheur de pommes de terre de Hoover

dans un le pour pas, on

Comment se fait l'arrachage au buttoir?

On passe le buttoir dans le sillon, en piquant assez profondément pour soulever toules les pommes de terre, qui sont de suite ramassées à la main. 


\section{Comment fonctionne l'arracheur?}

Comme le buttoir, avec cette différence que la grille secoue la terre, en dégage plus efficacement les tubercules et les recouvre moins que le versoir du buttoir.

$Y$ a-til des instruments qui servent pour l'arrachage des pommes de terre et des betteraves?

Oui, notamment l'arracheur de Bajac, qui est muni d'un soc avec une grille, pour l'arrachage des pommes de terre, et qui se remplacent par deux lames, pour l'arrachage des betteraves.

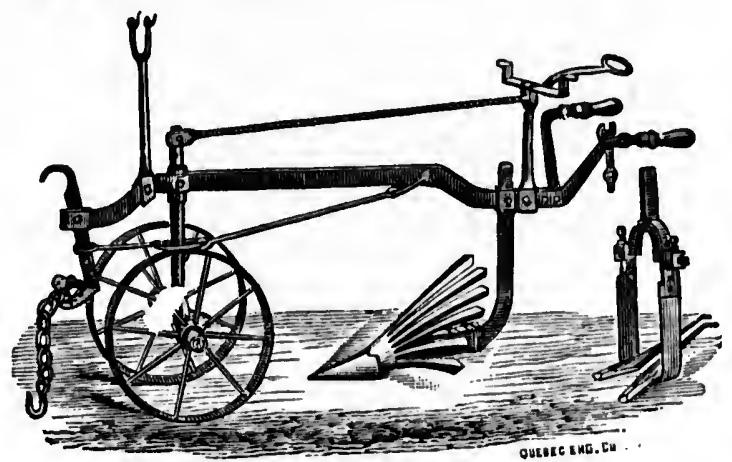

Fig. 83-Arracheur de Bajac

Que faut-il faire pour compléter l'arrachage des pommes de terre?

Après avoir ramassé toutes les pommes de terre amenées à la surface par le buttoir ou l'arracheur, on donne un hersage en travers, qui achève de mettre à découvert les tubercules restés enterrés.

Comment fonctionne l'arracheur de betteraves?

Par l'inclinaison de leur lame, les couteaux soulèvent forcément la betterave, dont l'arrachage est achevé par 
la queue de ces lamec. La betterave retombe alors grille tubertoir.

age des

muni ommes , pour dans son trou, où l'on peut la laisser sans inconvénient durant plusieurs jours.

Faut-il encaver les plantes-racines immédiatement après l'arrachage?

Il faut mettre les pommes de terre en cave aussitôt qu'elles sont sèches, vu qu'elles verdissent et prennent un mauvais goat quand on les laisse un peu longtemps sur le champ, exposées à la lumière. Les betteraves et les carottes peuvent rester bien longtemps sur le champ, pourvu qu'on ait la précaution de les amasser en tas qu'on recouvre avec les feuilles de ces plantes, qui doivent être coupées après l'arrachage.

Conment conserve-t-on les plantes-racines en cave?

On les met dans une cave sèche, par lits peu épais, afin qu'elles ne s'écrasent pas et soient moins exposées à chauffer. On recouvre le fond des lits avec de la paille ou des branches de sapin, ce qui est encore mieux, afin que ces matières absorbent l'humidité qui se produit. On les examine de temps à autre, pour enlever celles qui commencent à se gâter et feraient gâter les autres.

\section{\& 3-Fenaison}

Qu'est-ce que la fenaison?

C'est la récolte des plantes fourragères.

Quels travaux comprend la fenaison?

Le fauchage, le fanage, le ratelage et l'engrangement. 


\section{Comment se fait le fauchage?}

A la faux ou a la faucheuse

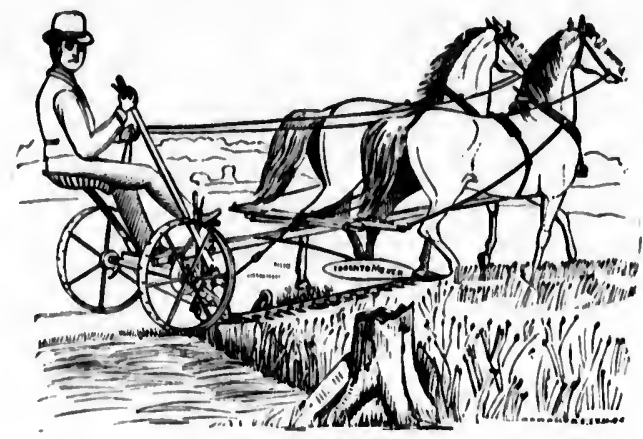

Fig. 84-Faucheuse Toronto, évitant une souche

Quelle est la condition indispensable d'un bon fauchage?

C'est que l'herbe soit coupée le plus près possible de la terre, parce que c'est près du sol qu'elle est le plus épaisse et qu'on en perdrait une partie en fauchant haut.

A quelle époque doit se faire le fauchage?

Quand les plantes sont en pleine fleur et avant que la graine commence à mârir.

Pourquoi faut-il faucher les plantes fourragères avant leur maturité?

Parce qu'en mûrissant, les tiges se dessèchent et perdent une grande partie de leurs sucs nutritifs, qui sont absorbés dans la maturation de la graine.

Quels sont les foins qu'il faut coüper en premier lieu ?

Ceux qu'on destine à l'alimentation des bêtes à cornes. 


\section{Quel temps faut-il choisir pour faucher ?}

Un beau temps sec et travailler de bonne heure le matin, afin de profiter de la rosée, qui rend l'herbe plus tendre à couper. $n_{n}$ attaque alors les parties élevées et quand le soleil est ardent, on fauche les endroits bas et frais, ou l'humidité se conserve plus longtemps.

\section{Qu'appelez-vous faucheuse?}

C'est une machine trânée généralement par deux chevaux, qui coupe le foin très près de terre et le distribue d'une manière uniforme sur le sol.

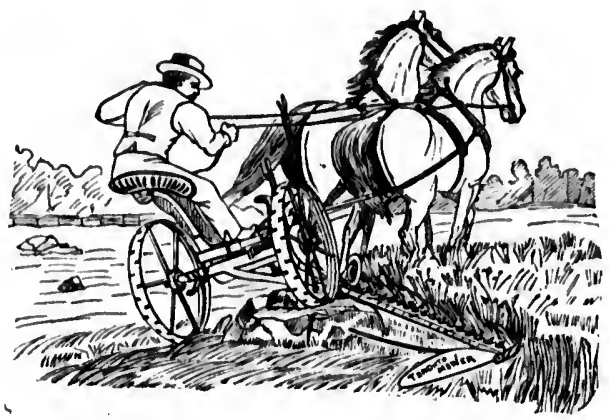

Fig. 85-Faucheuse Toronto, passant par dessus un tas de pierres

\section{Quels avantages présente l'usage de la faucheuse?}

Elle coupe plus rez terre et d'une manière plus uniforme que la faux, ce qui augmente la quantité du fourrage; elle fait beaucoup d'ouvrage en peu de temps, ce qui économise la main d'œuvre et permet de profiter du beau temps pour couper le fourrage et l'engranger dans les meilleures conditions. Enfin, elle dispense généralement du fanage. 
Quel appareil emploie-t-on pour aiguiser les couteaux des faucheuses?

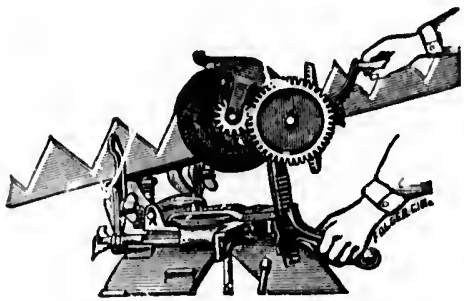

Fig. 86-Aiguiseur" Higganum"

L'aiguiseur Higganum, qui se fixe en un instant à une roue de la faucheuse, s'actionne par une manivelle, aiguise mieux et bien plus promptement que les autres appareils.

\section{Qu'est-ce que le fanage?}

C'est une opération qui a pour but d'étendre le fourrage d'une manière uniforme, après le fauchage, afin d'en accélérer la dessicuation.

\section{Comment s'opère le fanage?}

A bras, avec la fourche et le rateau, ou mécaniquement, avec une machine appelée faneuse et mue par un cheval.

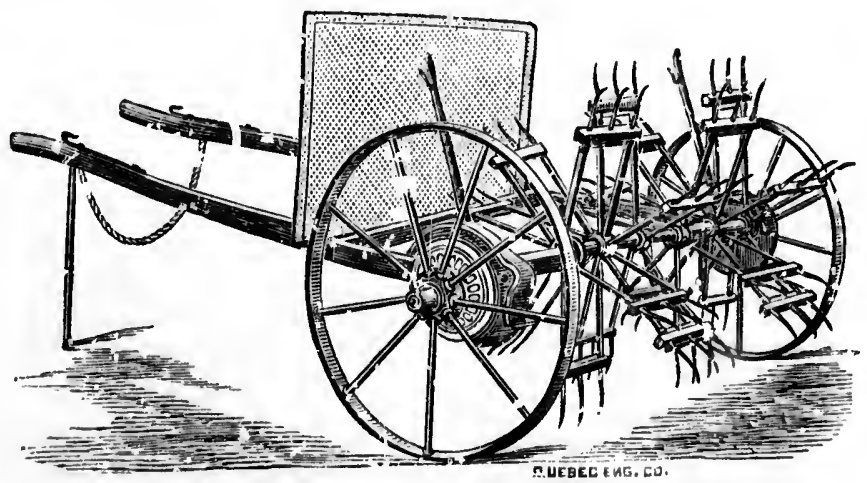

Fig. 87-Fansuse id double effet 


\section{Quand faut-il opérer le fanage?}

Si le temps est beau, i] est préférable de faner le foin aussitôt qu'il est fauché; le soir, avant la tombée de la rosée, on le ramasse pour le mettre en rangs, en veillottes ou muloches, qu'on ouvre le lendemain pour les éparpiller, après la rosée du matin. On refait les veillottes pour engranger le foin dans l'après-midi, s'il e’st assez sec ou pour le protéger encore contre la rosée, qui le noircirait et lui ferait purdre sa saveur, sauf à l'engranger la troisième ou la quatrième journée. Quand on lauche par un temps couvert ou humide, ou quand il y a apparence de mauvais temps, on laisse le foin en andains et il peut se conserver plusieurs jours dans cet état sans beaucoup souffrir. Dès que le beau temps revient, on fane et on ramasse, en suivant les précautions qui viennent d'être énumérées.

Qu'arrive-t-il si le foinn'cst pas assez sec quand on l'engrange?

Il chauffe, prend un mauvais gout et perd une partie de sa valeur, rotamment pour la vente.

Comment ramasse-t-on le fourrage fauché, pour le mcttre en rangs ou en rouleaux?

A bras, avec la fourche et le rateau ordinaire, ou avec le rateau à cheval.

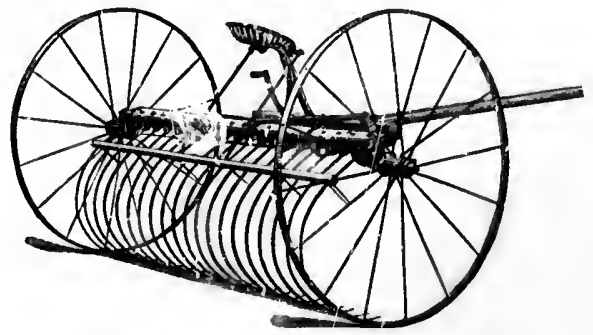

Fig. 88-Ratean Chicago, de Bradley 
Quel appareil emploie.t. on pour charger le foin à la machine?

La chargeuse, qui ratelle le foin et le monte sur la charrette ou le chariot destiné à le transporter à. la grange.

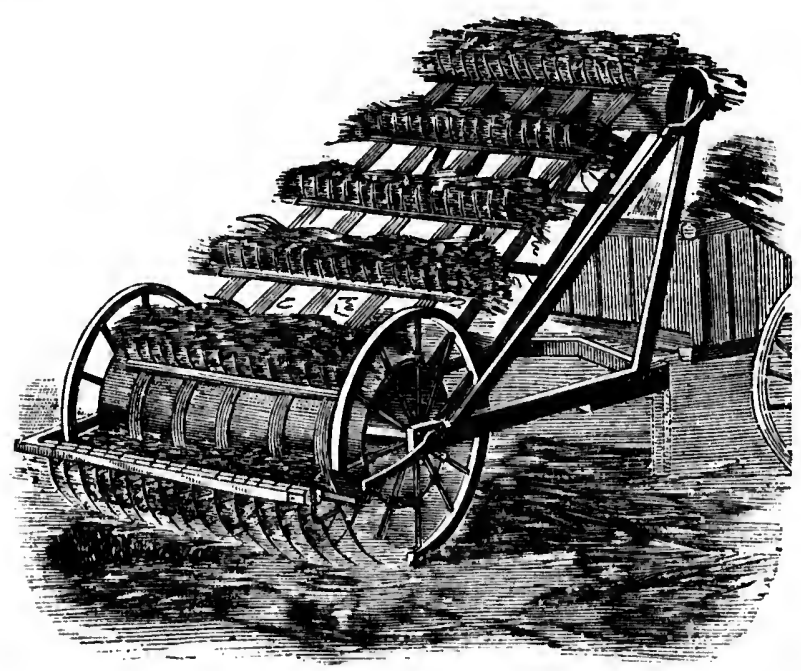

Fig. 89-Chargeuse de foin

\section{Qu'est-ce que l'appareil Acme?}

C'est un appareil employé pour ramasser le foin, le transporter et le mettre en meules. Le rateau, qui est très gra $d$, sert en même temps à transporter le foin, qu'il dépose sur une fourche, qu'un palan soulève et renverse sur la meule. Avec cet appareil, deux hommes peuvent mettre en meule vingt tonneaux de foin en une journée. 
$a m a-$

sur la

: à la

foin, le qui est e foin, lève et homle foin
Comment conserve-t-on le foin?

En fenil, en grange ou en meulon.

Quelles précautions fautil prendre pour bien mettre le foin en fenil ou en grange?

Quind le plancherdu fenil ou de la grange est exposé à l'humidité, on le recouvre de paille, pour protéger le foin contre cette humidité. $G_{11}$ dispose ensuite le foin en couches régulières, et s'il n'est pas bien sec, on le saupoudre de sel, pour prévenir l'échauffement et la moisissure, ce qui le rend d'ailleurs plus savoureux pour le bétaii.

Dans quelles circons. tances est.il ì propos de mettre le foin en meules ou meulons?

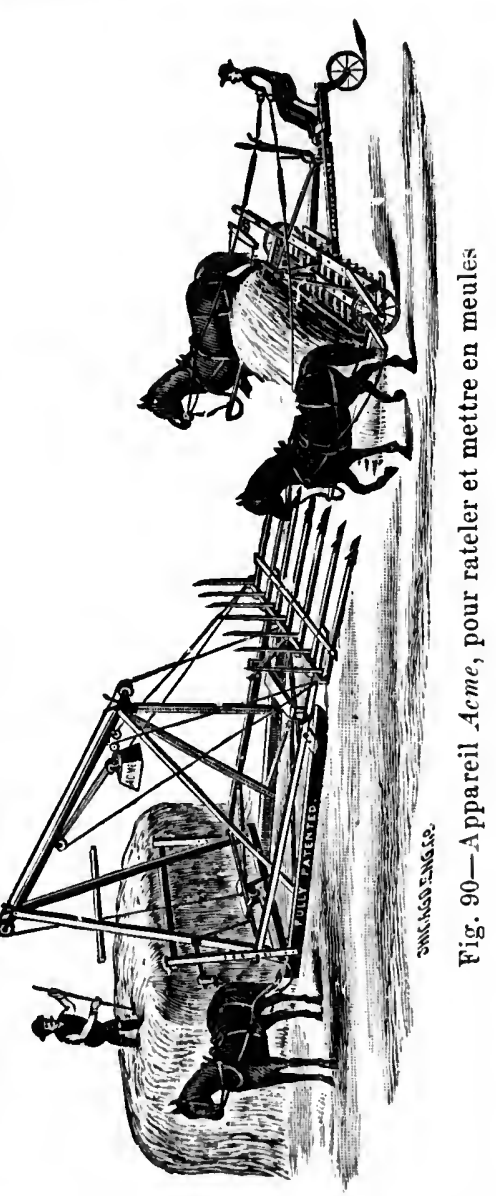

Quand il n'y a pas assez d'espace dans la grange ou dans les champs très éloignés, d'où le transport ì la grange prendrait trop de temps durant la fenaison, on met ordinairement le foin en meulons. 


\section{4-Ensilage}

\section{En quoi consiste l'ensilage?}

A conserver les fourrages verts en silos, c'est-à-dire dans des fosses creusées en terre, ou dans des constructions en bois ou en maçonnerie, de manière à soustraire compiètement ces fourrages à l'action de l'air et de l'humidité.

\section{Comment se font les silos en terre?}

On creuse dans le défaut d'une côte ou autre endroit -où l'eau et l'humidité ne sont pas à craindre-une fosse de cinq à six pieds de profondeur et en talus, afin qu'il nu se fasse pas de vide le long des parois, quand le fourrage se tasse. On dépose le fourrage dans cette fosse, de manière à ce que la partie qui excède la surface du sol soit en cône ou en demi-rond. On tasse le fcurrage autant que possible à mesure qu'on le dépose, et l'on recouvre le tout avec la terre projetée de chaque côté pour creuser la fosse.

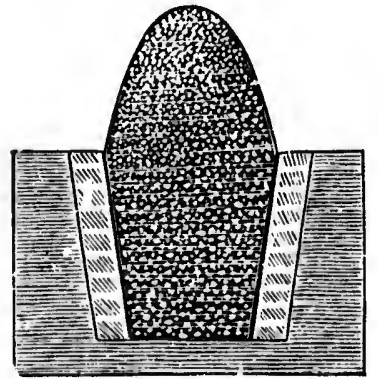

Fig. 91-Silo en terre chargé, mais non recouvert

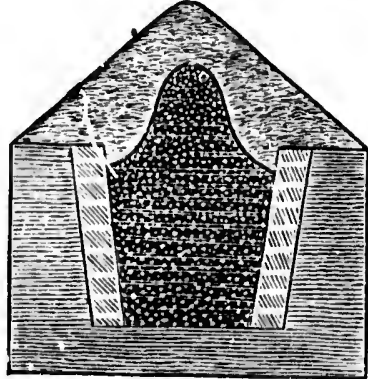

Fig,92-Silo en terre chargé et recouvert de terrs 
Dans quels pays ces silos sont-ils en usage?

-à-dire astruci sousl'air et

endroit e-une us, afiı quand ns cette la surtasse le dépose, chaque

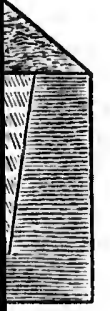

cliargé et $1 \times$
En Europe, principalement en Belgique, on France et en Allemagne.

Quels sont les silos les plus en vogue en Amérique?

Ce sont les silos en bois.

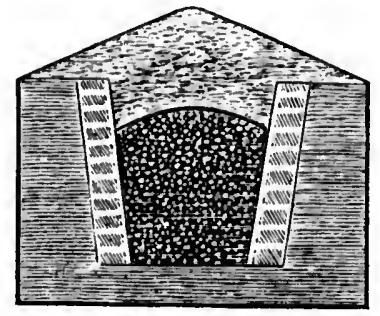

Fig. 93-Silo en terre, apres la compression du fourrage

Comment se font les silos en bois?

Tout simplement en construisant de petits bâtiments dont les parois sont imperméables.

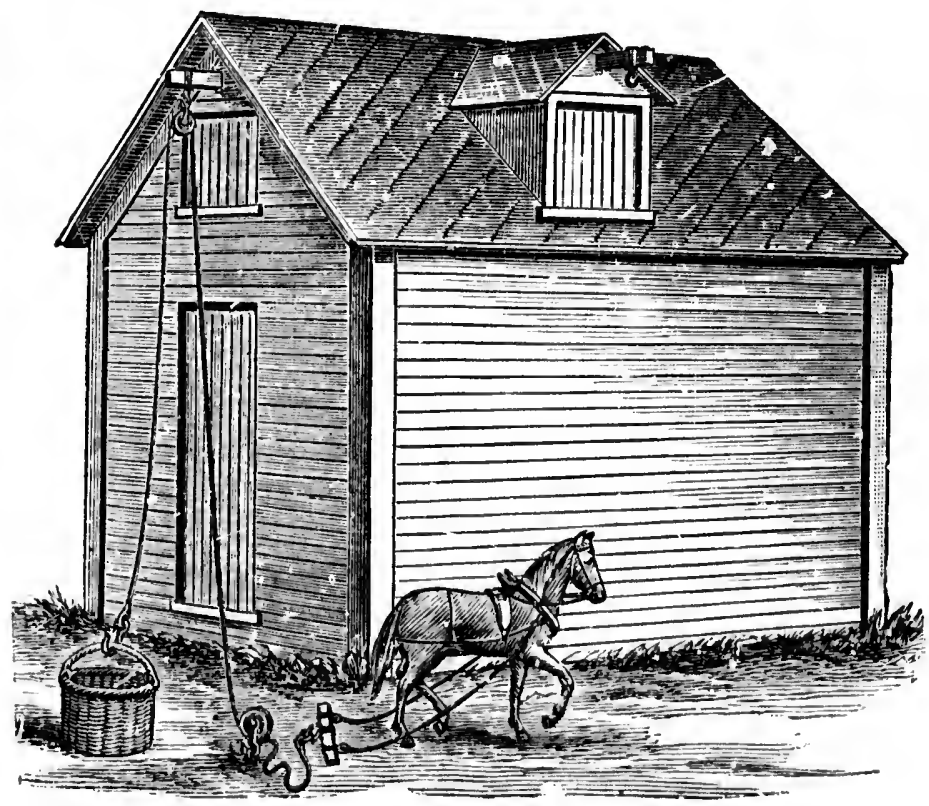

12

Fig. 94-Silo en bois 
En quoi consistent ces parois ou lambris?

En un lambris de bois bien étanche. Pour mieux réussir, on fait un lambris double à l'intérieur, en ayant soin de bien couper les joints. On arrive à la perfection en mettant un papier goudronné entre les deux lambris.

Sur quel emplacement doit être bâti le silo?

Sur un terrain sec, bien égoutté, afin que le plancher ne soit pas exposé à l'humidité, qui gâterait le fourrage. Il faut aussi instailer le silo près de l'étable, afin de n'avoir pas long à parcourir pour servir le fourrage aux animaux.

Peut-on installer le silo dans la grange même?

Oui, c'est ce que font beaucoup de cultivateurs, qui se contentent de faire un carré imperméable dans le coin d'une tasserie.

De quoi dépenderi les dimensions du silo?

De la quantité de fourrage à conserver, ou du nombre d'animaux à nourrir avec ce fourrage. Chaque animal confomme d'un pied à un pied et demi cube par jour de fourrage ensilé. Le pied cube pèse environ 40 livres. En comptant un pied cube par jour,il faudra pour chaque vache, pour six mois, ou 183 jours, 183 pieds cubes d'ensilage. Un silo de 15 pieds de largeur, 24 de longueur et 12 de hauteur, donne 4,320 pieds, ou assez pour nourrir 24 vaches durant environ six mois.

Quelles dimensions doit avoir la porte du silo?

Huit ou dix pieds de hauteur et deux ou trois pieds de largeur, c'est-à-dire juste ce qu'il faut pour permettre à un homme de passer avec deux paniers, pour char. royer le fourrage aux bêtes. 
Comment s"introduit le fourrage dans le silo?

Par le haut ou par un pignon du silo, au moyen d'un ascenseur mécanique ou tout simplement avec une grande boîte qu'on élève avec une poulie.

ncher rrage. fin de aux

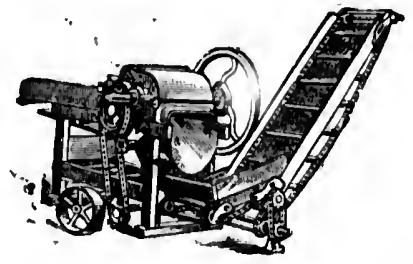

Fig. 95-Hache-fourrage avec ascenseur do Silver et Deeming

Dans quel état doit être le fourrage pour être ensilé?

A la rigueur, l'ensilage peut se faire par un temps humide, quand le fourrage est mouille; mais pour bien réussir, il faut couper le fourrage destiné au silo par un beau temps et même le laisser un peu essorer sur le champ, afin de le débarrasser autant que possible de toute humidité.

Qu'arrive-t-il quand le fourrage ensilé est trop humide?

L'humidité empêche la chaleur de s'élever à un degré euffisant pour détruire les agents de la fermentation, qui se produit alors et gâte une partie du fourrage.

Faut-il hacher le fourrage pour l'ensiler?

Cela n'est pas nécessaire pour le trèfle, l'avoine, le seigle et les autres fourrages semblables, qu'on dépose dans le silo tels qu'on les apporte du champ; mais pour bien réussir avec le blé d'inde, il faut le hacher ou le couper par sections d'un demi-pouce à un pouce 
de longueur, selon la grosseur des tiges. On hache d'autant plus court que les tiges sont plus grosses.

Pourquoi faut-il hacher le maïs?

Parce cu'en branches, il ne se tasserait pas assez pour chasser l'air et les agents de fermentation qu'il contient.

Comment dépose-t-on le fourrage dans le silo?

Par couches horizontales et uniformes de deux pieds et demi à trois pieds d'épaisseur.

Est-il nécessaire de fouler le fourrage à mesure qu'on le dépose dans le silo?

Non: il est même préférable de ne pas le fouler, excepté dans les coins et le long des parois du silo, où le tassement s'opère plus difficilement.

Peut on s'exempter de fouler même dans les coins et le long des parois?

Oui. Pour cela, quand on achève une couche d'ensilage, on forme au centre du silo un tas qui s'échauffe plus que le reste de la masse du fourrage; avant de recommencer une autre couche, on jette le fourrage ainsi échauffé dans les coins et le long des parois, où le surplus de calorique dont ce fourrage est chargé compense la perte de chaleur occasionnée par le rayonnement ou la présence de l'air froid. On recouvre immédiatement avec du fourrage vert, pour empêcher la moisissure.

Faut-il absolument emplir tout le silo sans interruption?

Non: on dépose une journée dans le silo assez de fourrage pour former une couche de deux pieds et demi à trois pieds d'epaisseur, puis on laisse l'éehauffement se produire, jusqu'à ce que la température s'élève 
hache s.

z pour ontient.

x pieds qu'on le fouler, silo, où

et le long

he d'enéchauffe ht de rege ainsi ù le surmpense ment ou atement sure.

uption?

assez de ds et dechauffee s'élève

a environ $125^{\circ}$; après un intervalle d'un ou de plusieurs jours, selon l'état du fourrage et le progrès de l'échauffement, on dépose une autre couche de la même manière et l'on continue ainsi tant que le silo n'est pas entièrement empli.

La chaleur joue-t-elle un rôle bien important dans l'ensilage?

C'est d'elle que dépend le succès de l'opération. Si le fourrage n'atteint pas une chaleur assez élevée pour détruire les agents de la fermentation, celle-ci se produit et gâte une grande partie du fourrage, qui noircit ou pourrit.

A quel degré faut-il maintenir la température du fourrage durant le chargement du silo?

Il n'y a pas d'objection à ce qu'elle s'élève à $150^{\circ}$ et même plus, durant le chargement du silo; mais une fois l'échauffement commencé, il serait dangereux de laisser tomber la température au-dessous de $120^{\circ}$, vu que ce refroidissement donnerait un regain de vie et d'activité aux agents de la fermentation.

Faut-il que la température soit uniforme dans toutela masse du fourrage?

Oui, car sans cela lee parties où la température serait trop basse seraient attaquées par la moisissure, qui gâterait le fourrage.

Quels sont les instruments qu'on emploie pour prendre la température du fourrage ensilé?

Le tube de Fry, muni d'un thermomètre à l'intérieur, ou encore une simple baguette de fer. 
Comment s'emploie cette baguette?

On l'enfonce dans le fourrage, où il faut la laisser asi $e z$ longtemps pour qu'elle prenne la température ambiante; on la retire ensuite vivement et en la touchant aux différentes parties de sa longueur, on a la température de l'ensilage aux différentes couches. Si elle est assez chaude pour qu'on ne puisse pas endurer la main dessus, la température est assez élevée; dans le cas contraire, elle est trop basse.

Comment recouvre-t-on le fourrage quand le chargement $d u$ silo est fini?

Avec une couche de paille ou de foin grossier, d'une couple de pieds d'épaisseur. La chaleur et l'humidité qui se dégagent du fourrage ensilé assouplissent cette couverture, qui s'affaisse de suite et devient imperméable en peu de temps. Dans les coins et le long des parois, on met une couche de paille plus épaisse et l'on recouvre ce rebord avec des planches, pour augmenter la pression.

Quand peut-on commencer la consommation de la conserve et comment faut-il la prendre dans le silo?

Il ne faut pas commencer la consommation de la conserve, ou du fourrage ensilé, avant trois ou quatre semaines après le chargement du silo. Pour cela, on ouvre la porte par le haut et l'on enlève le fourrage par couches horizontales, au moyen d'un rateau ou d'un racloir.

Quels sont les fourrages que l'on peut ensiler?

On peut ensiler tous les fourrages verts-trèfle, avoine, seigle, lentille, vesce, blé d'Inde-et l'on peut mêler à 
ces fourrages les courtes pailles ainsi que les balles, qui s'améliorent par leur contact avec les fourrages verts.

Quelle est la plante la plus avantageuse pour l'ensilage?

C'est le maïs ou blé d'Inde.

Quel rendement en fourrage donne le maïs?

Aux Etate-Unis,on récolte de 15 à 20 tonneaux de maïs vert par acre, et deux tonneaux de ce maïs ensile valent une tonne du meilleur foin. Les bons praticiens prétendent qu'un acre de maïs peut donner assez de conserve pour nourrir six ou huit vaches durant six mois. Dans notre province, les bons cultivateurs récoltent de 12 à 15 tonnes de maïs à l'arpent, quand il est cultivé avec un peu de soin.

Comment sème-t-on le maïs destiné à l'ensilage?

Les méthodes suivies par nos bons cultivateurs diffèrent joliment. Les uns le sèment en rangs, comme dans la culture ordinaire, et d'autres le sèment à la volée, ce qui est moins profitable.

Quelle est la méthode suivie aux Etats-Unis?

Dans l'Ouest, le pays par excellence 'du maïs, les meilleurs praticiens sèment le blé d'Inde en rangs éloignés de trois pieds les uns des autres et laissent un espace de six à dix pouces entre les tiges de chaque rang. 


\section{IMAGE EVALUATION \\ TEST TARGET (MT-3)}
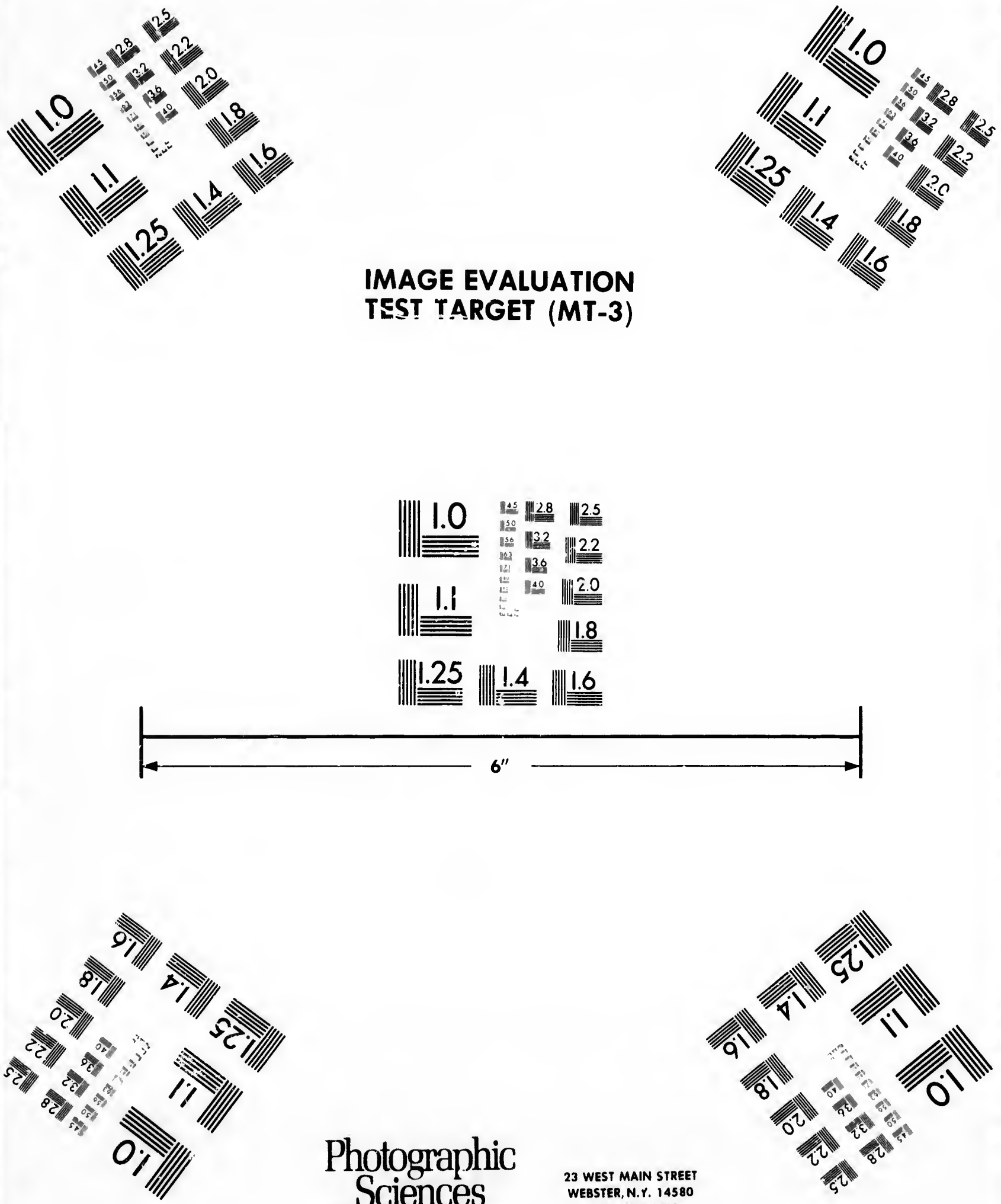

Photographic Sciences Corporation

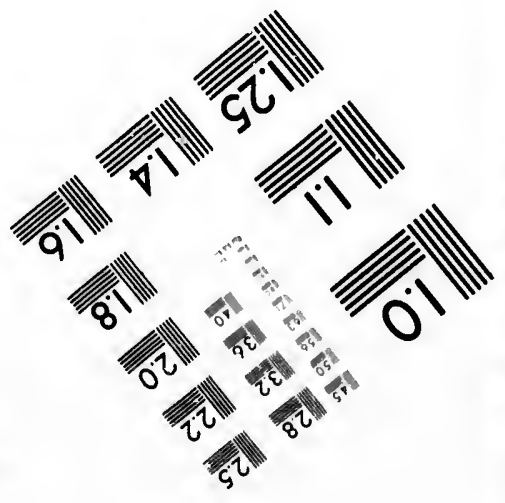





\section{CHAPITRE IX}

PRAIRIES ET PATURAGES

Qu'appellez-vous prairie?

On appelle prairie un terrain occupé par des plantes fourragères dcstincees à être converties en foin.

Combien distingue-t-on d'espèces de prairies?

Deux espèces: les prairies naturelles et les prairies artificielles.

Qu'appellez-vous prairie. no'urelle?

C'est une prairie dont l'engazounement, produit par semis ou par végétation spontance, est permanent et se perpétue de lui-même.

Qu'appellez-vous prairie artificielle?

C'est une prairie dont l'engazonnement provient du semis de certaines graines particulières et doit être renouvelé au bout de quelques années, pour faire place à d'autres cultures.

Quels sont les terrains les plus propres à la formation des prairies?

On peut former des prairies dans tous les terrains, même les moins fertiles; mais le sol qui convient le mieux est une terre de consistance moyenne, bien assainie et possédant un certain dégré d'humidité, ce qui est une condition essentielle à la bonne croissance de l'herbe. 
$Y$ a-t-il des terrains qui conviennent d'une manière particulière aux prairies naturelles?

Oui. Ce sont $1^{\circ}$ les terrains dont la surface est en pente trop rapide pour permettre une culture avantageuse; $2^{\circ}$ les bas-fonds, dans le voisinage des rivières, exposés à des inondations qui détruiraient les autres cultures; $3^{\circ}$ les sols bas et humides où les autres cultures ne réussiraient pas; $4^{\circ}$ certains terrains qui, à raison de leur composition et de leur fraîcheur naturelle, sont particulièrement aptes à la production $d u$ foin et moins à la culture des céréales.

Quelles sont les principales plantes qui exirent dans la composition des prairies artificielles?

Ce sont le mil ou fléole des prés, l'ivraie vivace, le paturin commun, le paturin des prés, lo vulpin des prés, la fétuque des prés, le fromental ou avoine elevée, l'avoine jaunâtre, le dactyle pelotonné et l'agrostis commune, parmi les graminées; le trèfle rouge, le trèfle hybride, le trèfle blanc, la luzerne, Ja minette, le sainfoin et l'anthillide ou trèfle jaune des sables, parmi les légumineuses.

Dans notre province, les prairies renferment-elles toutes ces plantes?

Non; on ne les compose généralement que de mil et de trèfle. Les autres plantes ne sont malheureusement cultivées que par les agriculteurs les plus avancés.

Le mil exige-t-il un terrain de qualité particulière?

Non, il vient dans tous les terrains, secs ou humides, pauvres ou riches; mais il produit naturellement plus dans les bonnes terres, profondément ameublies et 
fraîches, que dans les terres sèches et peu profondes, de mauvaise qualité.

\section{Quels sont les avantages du mil comme fourrage?}

C'est le plus nutritif de tous les fourrages. C'est aussi le plus facile à cultiver, vu qu'il se contente de tous les sols comme de tous les climats, et qu'à raison de la rapidité avec laquelle il sèche sur le champ, après la fauchaison, il est do be aucoup le fourrage le plus facile à récolter en bonnes conditions.

\section{Qu'est-ce que l'ivraie vivace?}

L'ivraie vivace, o' ray-grass d'Angleterre, est une plante qui donne un foin de qualité médiocre, mais qui constitue un pâturage excellent, durant jusqu'à six ou huit ans, et repousse avec une grande facilite sous la dent des bestiaux. On la sème dans une céréale, à raison d'une trentaine de livres à l'arpent, et les engrais liquiles lui vont à merveille. En Angleterre, on regarde l'ivraie vivace comme l'une des herbes les plus importantes et les plus précieuses.

\section{Qu'est-ce que le paturin commun?}

C'est une plante vivace, à la racine fibreuse, qui préfère les terrains frais et fleurit en juillet. Cette herbe est recherchée par tous les bestiaux-chevaux, bêtes à cornes, moutons-et en mélange avec d'autres espèces, elle produit en abondance de l'herbe et du foin dont les qualités nutritives sont remarquables.

\section{Qu'est-ce que le paturin des prés?}

Ce paturin, le Kentucky blue grass des Américains, est une plante vivace, dont la tige atteint jusqu'à un pied de hauteur et fournit un foin fin et delicat. Dans les 
prairies, il lui faut une couple d'années pour se déve. lopper complètement. La plupart des terrains lui conviennent, mais c'est dans les terres grasses et humides qu'il réussit le mieux.

\section{Qu'est-ce qus le vulpin des prés?}

Cette plante, qui ressemble beaucoup au mil, est précoce, donne une herbe et un foin de bonne qualité, très recherchée des animaux, principalement des chevaux et des moutons. Elle aime les sols frais et humides, un peu argileux, sans être forts. Elle peut donner deux bonnes coupes, quand la première est récoltée de bunne heure, se fane très bien et son foin conserve une très bonne odeur. En Angleterre et aux Etats-Unis, on estime que le vulpin des prés est une des meilleures herbes pour le pâturage et les prairies permanentes.

Qu'est-ce gue la fétuque des prés?

C'est une des meilleures plantes fourragères, dont la tige atteint de deux à quatre et même cinq pieds de longueur. Elle aime un terrain gras et frais, mais pas trop humide et donne en abondance de longues feuilles que les animaux broutent avec le plus grand plaisir; dans les prairies, elle produit un très bon foin, facile à sècher, qui se conserve trés bien et, ne perd que la moitié de son poids par la dessiccation. Elle croît lentement et n'est en plein rapport qu'à la troisième année, ce qui la range dans la catégorie des herbes pour les prairies ou les pâturages permanents.

Qu'est-ce que le fromental ou avoine élevée?

C'est une des plus fortes graninées qui croissent dans les prairies. Sa tige atteint jusqu'à quatre pieds et demi de hauteur dans une bonne culture. Cette plante vient dans presque tous les terrains, mais elle préfère 
les sols frais et substantiels et souffre dans ceux qui sont humides, ou exposés à la submersion. Elle réussit bien dans les coteaux qui ne sont pas trop chauds. Le fromental produit un fourrage très abondant, ne perdant que la moitié de son poids par la dessiccation et mangé avidemment $p r:$ les animaux, quand il est coupé avant la maturité de la plante. Celle-ci croît lentement, ce qui en fait une herbe pour les paturages et les prairies de longue durée.

Qu'est-ce que l'avoine jaun itre?

C'est une plante vivace, de moytnne force, qui donne un foin fin, recherché par les rnoutoi:s et les bêtes bovi. nes. Elle pousse en touffes, aime les prés secs et substantiels, situés sur des pentes peu inclinées, où l'eau ne peut pas séjourner. Elle vient bien dans les sols calcaires d'une bonne fertilité, où la fétuque. le vulpin et le mil ne réussissent pas. Dans les pâtarages, le bétail la recherche à toutes les époques de sa croissance.

\section{Qu'est-ce quo le dactyle pelotonné?}

C'est une plante forte et vigoureuse, qui donne une herbe abondante et fcurnit un gros rendement en foin. Elle est vivace et atteint de trois à cinq pieds de hauteur. Ses feuilles inférieures ont souvent deux pieds de longueur. Elle vient dans tous les terrains, mais préfère ceux qui sont frais, substantiels et ombragés. Elle pousise avec rapidité et peut donner une couple'de récoltes de foin par été. Comme sa tige et ses feuilles deviennent un peu dures en se développant, il faut la couper souvent ou la faire raser dans les pâturages, où elle fournit alors au bétail un aliment des mieux goutés et des plus nutritifs. Broutée ou fauchée en vert, elle se renouvelle très promptement, ce qui lui donne place dans tous les bons pâturages permanents. 


\section{Qu'est-ce que l'agrostis cornmune?}

I'agrostis commune, le red.top des Américains, est une plante vivace qui donne ses meilleurs rendements dans les sols frais et un yeu sableux. Aux Etats-Unis, on la cultive souvent dans des terres marécageuses, ou les autres herbes ne pousseraient pas. Dans les meilleures conditions, cette: plante n'atteint guère plus de deux pieds de hauteur et, en conséquence, elle convient moins à la prairie qu'au pâturage. Elle ne se développe complètement qu'à la troisièm $\theta$ année, entre de bonne heure en végétation, au printemps, et doit être broutée ras terre, sans quoi elle durcit et fournit une herbe moins appétissante.

\section{Distingue-t-on plusieurs espèces de trêfle?}

On en distingue cinq espèces principales : le trèfle rouge, le trèfle incarnai, le trèfle hybride ou Allsyke, le trèfle blanc et le trèfle jaune.

Quels sont les traits caractéristiques de chacune de ces especes?

Le trèfle rouge a la feuille large et une fleur rouge pourpre. Sa végétation est très rapide et il est le plus productif de tous les trèfles. Les terrains qui lui conviennent le mieux sont les sols glaiseux, mais riches en chaux, les terres un peu sableuses, mais grasses, riches et profondes, puis les sols argileux et argilo-calcaires. Il ne réussit pas dans les sols calcaires purs ou dans le suble, non plus que dans les terres aigres et les defrichements de forêts trop récents. Il est fort rustique, ne craint pas le froid et n'est endommagé par la gelée que lorsqu'il survient des dégels qui le déchaussent. 
Le trèfle incar „at, d'une croissance très rapide, réussit dans les terres sc̀ches, sableuses et produit beaucoup de fourrage vert, mais peu de fourrage sec, qui est de qualité inférieure. Ce trèfle se plaît sur les terrains calcaires perméables.

Le treffe hybride, ou Allsyke, participe des qualités du trèfle rouge et de l'incarnat et constitue, aux yeux de beaucoup de praticiens, la variété la plus facile à cultiver, vu qu'il s'accommode de presque tous les sols; c'est aussi un de ceux qui donnent le plus fort rendement, sans compter qu'il est vivace et reste productif plusieurs années.

Le trèfle blanc, qui est vivace et croît spontanemen: dans les terrains proprices, se reconnait à ses tiges rampantes, qui donnent aux prés l'apparence d'une terre couverte d'une légère couche de neige. Il se plaît surtout dans les sables et les limons humides. C'est avant tout un trèfle de paturage, vu qu'il ne vient pas assez long pour être fauché avantageusement.

Le trèfle jaune se reconnaît par ses jets étendus, aes très petites feuilles et ses fleurs jaunes. Il pousse spontanément et n'est pas cultivé, vu qu'il ne vient pas assez long pour être fauché et qu'il ne donne qu'une herbe peu recherchée par le bétail, excepté les moutons.

\section{Qu'est-ce que la luzerne?}

C'est une plante fourragère, vivace, à racine pivotante, qui produit beaucoup de petits rejetons, semblables à ceux du trèfle, avec une petite fleur bleue, et donne un fourrage supérieur au trèfle pour nourrir les vaches, parce qu'il augmente la quantité du lait, de même qu'il améliore la qualité et le gout du beụre, 
Quels sont les climats et les sols qui conviennent d la luzerne?

La luzerne aime la chaleur, redoute les hivers rigoureux et surtout les gelées tardives. Il lui faut un sol riche, bien ameubli, bien égoutté et trés profond-avec un sous-sol calcaire et perméable. Elle craint les argiles compactes et surtout les terres qui n'ont pas de profondeur, le pivot de sa racine s'enfonçant tout droit, tant qu'il n'est pas arrèté par une couche dure, jusqu'à plusieurs pieds de profondeur.

Comment doit être préparée la terre destinée à la luzerne?

Il faut lui donner un labour très profond, l'ameublir parfaitement, la nettoyer de toutes les mauvaises herbes et l'engraisser parfaitement.

Comment sème-t-on la luzerne?

Absolument comme le trèfle et dans une céréale, de préférence dans l'orge, si l'on veut avoir urie belle luzernière. Il est prudent de la semer aussi de bonne heure que possible au printemps, afin que la plante ait le temps de se développer assez pour ne pas être endommagée par les grandes chaleurs.

Quelle est la quantité du semis?

De vingt à vingt-quatre livres de graine de luzerne à l'arpent.

Quels sont les soins d'entretien à donner da la luzerne?

La première année, aussitôt après la récolte de la céréale avec laquelle la luzerne a été semée, on fait pâturer la jeune luzerne par les moutons; puis on lui applique un platrage, pour activer sa végétation et la fortifier contre les froids de l'hiver. On peut ensuite 
lui donner un demi-platrage tous les deux ans, au printemps, ou meme tous les ans, si le sol est tout-dे-fait dépourvu de calcaire. La cendre et les engrais liquides de toutes sortes son', aussi d'excellents moyens de faire produire la luzerne abondamment. Il est encore très avantageux de donner alternativement à la luzernière une légère couche de fumier consommé.

Quels sont les autres soins d'entretien?

Pour empêcher la luzerne d'être envahie par les mauvaises heries, on lui donne, au printemps, la deuxıème année, un léger hersage. Plus tard, quand elle est bien enracinée, on lui donne avec le scarificateur ou une grosse herse, deux hersages énergiques chaque année, l'un an printemps, avant qu'elle entre en végétation, et l'autre u commencement de l'automne, après la dernière coupe du fourrage.

Quand faut-il faucher la luzerne?

$\mathrm{Au}$ moment où elle commence à fleurir. Plus tôt, elle serait aqueuse, moins nourrissante et se fanerait moins facilement; plus tard, elle serait ligneuse, dure et peu recherchée par le bétail.

Quelle est la durée d'une luzernière?

Cela dépend de la richesse et de la profondeur du sol ainsi que des soins d'entretien qu'on lui donne ; mais la durée utile ne dépasse guère une douzaine d'années, dans les circonstances les plus favorables, et souvent il n'y a pas d'avantage à la conserver plus de quatre à cinq ans.

Quel rendement donne la luzernière?

Dans notre province, la luzerne bien cultivée peut 13 
donner trois récoltes par anilée, ou de quatre d liuit tonnes a l'arpent. Coupée en vert, elle fournit assez de fourrage pour nourrir trois ou quatre vaches a l'arpent. Par la dessiccation, elle peut perdre jusqu'd $75 \%$ de son poids, c'est-d-dire que 100 livres de luzerne verte ne donnent que 25 livres de foin sec.

Qu'est-ce que le sainfoin?

C'est une belle plante vivace, avec feuillage ailé, panaches de fleurs d'un violet clair, racines profondement pivotantes et qui donne un excellent fourrage.

Quels sont le climat et le sol qui conviennent au sainfoin?

Le sainfoin ne redoute ni la chaleur ni la sécheresse : c'est le fourrage par excellence des pays secs, des terrains pauvres et calcaires. Il lui faut avant tout un sol calcaire, avec sous-sol sec, et en général il ne réussit pas dans les terres où le trèfle vient bien. Il prospère dans les terres légères, sableuses et graveleuses, quand elles sont profondes et sèches.

Comment sème-t.on le sainfoin?

Comme le trèfle, sauf que la graine étant plus grosse, elle a besoin d'être mieux enterrée et surtout d'être roulée. On sème de deux à trois minots à l'arpent.

Quels soins exige le sainfoin?

Des platrages, des cendrages et des fumures, comme le trèfle.

Quelle est la durée d'une prairie de sainfoin?

Généralement de huit à dix ans. 
it tonez de rpent. le son rte ne

lé, paement

nfoin?

resse : es ter. un sol sit pas e dans d elles

plus urtout nots à

comme

\section{Quel est le rendement du sainfoin?}

De trois à quatre et même cinq tonnes a l'arpent, dans les terres les plus proprices. Il est aussi nutritif que le trèfle et plus que la luzerne.

\section{Quand fauche-t.on le sainfoin?}

Dès qu'il est en pleine fleuraison. Comme il se dessèche très vite, il ne faut pas le laisser longtemps sur le champ, après la fauchaison, sans quoi il perd une grande partie de son volume et de ses propriétés nutritives. Il fnut l'engranger assez frais pour qu'il chauffe un peu, ce qui est le seul moyen de le conserver dans toute sa bonté.

\section{Qu'est-ce que la lupuline?}

La lupuline, ou minette dorée, est une plante bisanuuelle à tiges couchées, qui croit spontanément dans les ierrains légers, calcaires ou siliceux, et se développe yarfaitement dans les terres sèches, où le trèfle ne réussit pas.

\section{Quel fourrage donne la lupuline?}

Un fourrage peu abondant, quand on le convertit en foin, mais de bonne qualite et qui devient plus productif lorsqu'on le fait pâturer, parce qu'il repousse sans cesse sous la dent du bétail. Il forme surtout un excellent pâturage pour les moutons.

Quelle culture exige la luguline?

La niême que le trèfle rouge.

Quel climat et quels sols conviennent à la lupuline?

Cette plante aime un climat tempéré, vu que l'excès 
de chaleur lui est préjudiciable. Quant au so!, elle se développe partout; mais ce qui fait son mérite, c'est qu'elle donne des produits passables dans les sables arides, ou la luzerne reste chétive, et sur les sols calcaires, trop pauvres pour nourrir convenablement le sainfoin.

Quelles sont les principales plantes qui s'emploient comme fourrage vert?

Ce sont les vesces, les lentilles, les gesses at les jargeaux?

Qu'est-ce que la vesce?

C'est une plante légumineuse-c'est-à-dire ayant une cosse comme les pois-moins importante que le trèfle, mais qui remplace avantageusement ce dernier, quand il ne réussit pas, et doune un excellent fourrage, principalement quand il est consommé en vert.

Quel sol et quelle culture conviennent d̀ la vesce?

La vesce demande un sol assez consistant et ne réussit pas dans un terrain léger, sableux et sec. Un labour suivi d'un hersage, pour l'enterrer, est toute la culture qu'elle exigo. On sème une couple de nuinots à l'arpent et l'on mêle à cette semence environ un cinquième d'avoine, de seigle ou d'orge, afin que les tiges de cette céréale servent de support à la vesce, qui se développe mieux et donne un fourrage de meilleure qualité.

Quand faut-il couper la vesce?

Dès qu'elle est en fleurs, quand on veut la faire consommer et vert, et dès que les cosses sont formées, quand on veut la convertir en foin ou fourrage sec. 
elle se it, c'est 3 sables sols calment le

$t$ comme

les jar-

rant une le trèfle, , quand , princi-

ne réusin labour a culture l'arpent inquième s de cette léveloppe lité.

faire cones, quand

\section{Quels avuntages présente la culture de la vesce?}

Sa culture est des plus faciles et comme toutes les légumineuses, elle puise une grande partie de sa rourriture dans l'air, en sorte qu'elle n'épuise pas la terre. C'est aussi une plante étouffante, qui a la propriété de détruire toutes les mauvaises herbes. Elle donne un fourrage nourissant, recherché des bestiaux et produit environ une tonne de fourrage sec à l'arpent.

Qu'avez-vous d dire des lentilles, des gesses et des jargeaux?

Ce sont des légumineuses, à peu près semblables à la vesce, qui exigent à peu près le même sol, la même culture et donnent un fourrage de même nature.

Quel est le meilleur msyen de conserver la vesce, la lentille et la gesse comme fourrage d'hiver?

C'est l'ensilage, qui conserve à ces fourrages toutes leurs propriétés nutritives, la souplesse de leurs tiges et leur bon gout. A l'ecole d'agriculture de Ste-Anne, on a pratiqué avec le plus grand succès l'ensilage de la lentille.

\section{Le blé d'Inde n'est-il pas préférable pour l'ensilage?}

Oui, parce qu'il produit beaucoup plus de fourrage. Mais le blé d'Inde demande une terre riche, bien engraissée, une culture soignée, relativement couteuse et surtout un climat chaud et sec, au lieu nue la lentille et la vesce, dont la culture est des plus simples, réussissent dans tous les sols, excepté le sable, et dans les climats humides et peu chauds, ce qui fait qu'elles sont un excellent substitut pour le blé d'Inde, dans les parties de la province où celui-ci ne pourrait pas être avantageusement cultivé. 
Peut-on faire double récolte de la lentille et de la vesce?

Oui : commo ces plantes repoussent avec vigueur quand on les coupe avant leur maturite, en semant de bonne heure, au printemps, on peut faire une première récolte au commencement de l'été, pour la consommation en vert, et avoir à l'automne une seconde récolte pour l'ensilage.

\section{Qu'est-ce que la spergule?}

La spergule, ou herbe d beurre, est une plante de la famille des œillets, qui fournit un excellent fourrage, surtout pour les vaches à lait. Elle se plaît dans les climats humides et les terres fraîches, sableuses ou sabloargileuses. Elle pousse et mûrit très vite, de sorte qu'on peut la semer jusqu'au milieu de l'été. Elle donne un fourrage abondant et d'excellente qualité.

Connaissez vous d'autres plantes qui peuvent entrer dans la composition des prairies et des pâturages?

Il y en a plusieurs, qui pourraient rendre des services considérables à notre agriculture, si les cultivateurs voulaient se donner le trouble de les utiliser.

Dans notre proi ince, emploie-t-on toutes ces plantes pour la composition des prairies?

Nor: : on n'emploie généralement que le mil et le trèfle, et un peu la lentille et la vesce. Un petit nombre de cultivateurs avancés commencent aussi à avoir des luzernières.

Serait-il arantageux de cultiver le sainfoin et la lupuline?

Oui. assurément, dans les terrains secs, sablonneux et trop calcaires, où il est impossible de faire venir le mil, le trèfle et la luzerne. 
Quelle préparation exige le sol pour être mis en prairie?

Le sol destiné à la prairie doit être profondément ameubli, ussaini, bien égoutté, nettoyé de toutes les mauvaises herbes, épierré et aplani, afin de faciliter l'emploi de la faux et de la faucheuse. C'est à ces conditions qu'on peut ubtenir une bonne prairie et facile a cultiver.

Comment sème.t-on la graine de foin?

de la urrage, ans les a sabloe qu'on nne un

rer dans

services vateurs

pour la et le trènombre roir des upuline? aneux et rle mil,

Sur le sol nu, dans une céréale ou sur une récolte déjà levée, selon les circonstances et l'époque de l'ensemencement.

Quand sème-t.on sur le sol nu?

Quand on a lieu d'appréhender ur été sec, qui nuirait à la végétation, ou quand on est autrement empêché de semer le foin au printemps, on sème la graine de foin après l'enlèvement d'une récolte hâtive et sur le sol nu, dans la dernière quinzaine d'aoat, afin que les plantes aient le temps de développer leurs racines avant l'hiver.

Comment se fait ce semis?

On fait un léger labour, suivi d'un hersage, pour. émietter parfaitement la terre, on dépose la semence, que l'on recouvre par un très léger hersage, puis on roule.

Comment se fait le semis avec céréale?

On sème la graine de foin sur le hersage du grain, puis on l'enterre au moyen d'un roulage.

Est il une autre maniere de semer la graine de fcin avec une céréale?

Oui : quand on sème du grain d'automne dans un 
terrain destiné à la prairie, on attend au printemps suivant pour semer la graine de foin, quand la céréale est déjà levée, et alors on se contente d'enterrer la graine de foin par un roulage.

Est-il plus avantageux de semer la graine de foin avec une céréale?

Oui. généralement, parce que les tiges de la céréals servent d'abri aux jeunes plantes de foin, les protègent contre la sécheresse et leur ménagent ainsi l'humiditi dont elles ont besoin pour se bien développer.

$Y$ a-t-il quelques précautions d observer en semant le grain qui accompagne la graine de foin?

Oui, il faut semer le grain plus clair qu'à l'ordinaire, sans quoi il pousserait trop fort et paralyserait en partio le développement des plantes de foin, en les soustrayant à l'influence de l'air.

Quel soin faut-il apporter au choix de la semence?

Le plus grand soin. Il faut d'abord s'assurer que la graine est nette, c'est-à-dire exempte de graines de mauvaises herbes, qui gâteraient la prairie. Il faut ensuite s'assurer que la graine de foin est bonne, c'est-à-dire propre à la germination.

Quelle est le meilleur moyen de s'assurer que la graine est bonne?

Le meilleur moyen de s'assurer de la qualité de la graine de foin, comme de celle de toutes les sortes de graines, est d'en faire germer dans une soucoupe, entre deux linges mouillés, qu'on place dans un endroit où la température est douce, près de la cheminée, sur le poêie, etc. On compte les graines qui lèvent et celles qui ne lèvent pas et l'on juge ainsi cie la qualité. 
os suiale est ine de

vec une

céréals tègent miditi

grain

linaire, partie trayant

que la le mauensuite t-à-dire

aine est

ié de la ortes de $\theta$, entre jit où la e poêie, qui ne

\section{Quelle quantité de graine faut-il mettre d l'arpent?}

Cela dépend de la nature de la semence et de plusieurs autres circonstances.

Quelle quantité faut-il des différentes graines?

Dans les circonstances les plus favorables et quand on ne sème qu'une seu'e espèce de graine de foin sur un champ, il faut semer les quantités suivantes, par arpent: mil, 30 livres ; trèfle rouge, 10 livres ; trèfle blanc, 8 livres. Quand le sol est pauvre ou mal préparé, il faut une plus grande quantité de semence.

Dans quelle proportion mélange.t-on la graine quand on sème du mil avec du trèfle rouge?

On met généralement deux livres de mil pour une de trèfle. Quand une prairie doit être transformée en pâturage, il est bon d'ajonter du trêfle blanc et alors on peut faire le mélange suivant: 8 ou 9 livres de mil, 4 de trèfle rouge et 2 de trèfle blanc.

\section{Qu'arrive-t-il quand on sème trop clair?}

Outre qu'on perd un peu de terrain et qu'on donne aux mauvaises herbes une chance de croître, le foin vient gros et long, mais donne un fourrage moins bon, parce qu'il est trop coriace.

\section{Quel avantage y a-t-il d semer dru?}

Les tiges viennent un peu moins longues, mais elles sont plus nombreuses, ce qui compense la perte de longueur. Elles scnt aussi plus fines, plus aqueuses et donnent un fourrage beaucoup plus tendre et plus recherche par le bétail. 
Quels sont les principaux soins d'entretien qu'il faut donner aux prairies?

Ce sont. le nettoyage, l'assainissement, le roulage et l'engrais,

En quoi consiste le nettoyage?

A enlever, tous les printemps, les pierrew, les buttes et autres choses susceptibles de nuire à la faux ou d̀ la fauchense, les mousses et les mauvaises herbes, qui nuisent à la croissance du foin.

Comment enlève-t-on la mousse?

Par le hersage ou en épandant sur la prairie de la cendre ou de la chaux, qui détruisent la mousse en même temps qu'elles constituent d'excellents engrais pour le mil et le trètle.

A quoi sert le roulage?

Il arrive souvent que la gelée soulève la terre et déchausse ainsi la racine de l'herbe. En roulant la prairie, on chausse l'herbe, c'est-à-dire qu'on rentre dans la terre sa racine, qui n'est plus exposée à être détruite par la chaleur. Cette opération aplanit aussi la terre, qui se prête bien mieux aux travaux de la récolte.

En quoi consiste l'assainissement?

A nettoyer chaque automne les raies, les rigoles et les fossés, pour assurer l'égouttement parfait de la prairie.

Ces travaux sont-ils bien nésessaires?

Ils sont d'une nécessité absolue, attendu que l'eau est le pire ennemi des prairies. En été, quand elle est stagnante ou en trop grande quantité dans le sol, elle 
fait pourrir la racine de l'herbe; quand elle reste dans la terre à l'automne, elle donne prise à la gelée, qui détruit encore la racine de l'herbe durant l'hiver.

Est-il avantageux de mettre de lengrais sur les prairies?

Oui, incontestablement, puisque l'engrais augmente sensiblement le rendement des prairies, même de celles qui sont déjà productives.

Quels sont les engrais qui conviennent le mieux aux prairies?

Ce sont les engrais liquides, notamment le purin, et les engrais pulvérulente, tels que les composts, le terreau, le platre, la marne, la chaux et surtout la cendre de bois, qui prcduit des effets merveilleux. On peut employer les engrais pulvérulents à l'automne; mais il est préférable de n'employer les liquides qu'au printemps, quand l'herbe entre en végétation.

et dépraians la étruite terre,

Peut-on employer le fumier d'étable?

Oui ; mais sans compter qu'il n'eet pas aussi avantageux que les autres engrais, il a souvent l'inconvénient de renfermer des graines de mauvaises herbes qui salissent les prairies, ou des pailles et autres matières on putreffaction, qui salissent le foin et lui donnent un mauvais gout.

ples et de la

Le paturage est-il un moyen d'améliorer les prairies?

Oui, pourvu qu'il se fasse dans des conditions convenables.

Quelles sont ces conditions?

D'abord, il ne faut pas faire paturer après la récolte et en automne, une prairịe qui a êté enșẹmencéce le printemps 
ni la faucher, quand même le trèfle serait très beau. En rasant ainsi une prairie neuve, on exposerait trop à la gelée les racines de l'herbe, qui ne sont pas encore assez fortes pour resister. Ensuite, on peut faire paturer une prairie d'un an, ce qui a pour effet de faire pousser l'herbe plus dru et de rendre l'engazonnement plus dense; mais il faut prendre garde que les animaux ne brisent le gazon avec leurs sabots, ce qui áetruirait une partie de l'herbe. Pour cela, on ne met sur la prairie que des animaux légers, ou qui ne marchent pas beaucoup, tels que les moutons et les vaches, et encore on ne les met que lorsque la terre est sèche, dure, ayant bien soin de les retirer quand la pluie vient amollir le sol.

Est-il avantageux pour le sol d'être mis en prairie?

Oui, c'est le moyen le plus efficace de lui conserver sa fertilité ou de le reposer, et si tant de bonnes terres s'epuisent, c'est parce qu'on ne les transforme pas assez en prairie pour les reposer.

Est-ce que la culture du foin n'épuise pas la terre comme les autres cultures?

Non : le foin, surtout le trèfle, prend presque toute sa nourriture dans l'atmosphère et enleve moins au sol qu'il ne lui donne par sa racine, qui est un excellent engrais.

Comment forme-t-on les pâturages artiflciels?

De deux manières: par semis, comme la prairie, ou bien en transformant en paturage une prairie sur laquelle on a pris deux ou trois récoltes de foin.

Qu'appelez-vous paturages naturels?

Ce.sont des terrains dont il serait difficile ou impossi- 
1. En

à la assez

: une

usser

plus

Ix ne

une

airie

jeau-

on ne

bien

sol.

erver

erres

assez

omme

te sa

u sol

llent

$\theta$, ou

ir la-

possi-

ble de tirer autrement parti et qu'on met en paturage perpétuel, à défaut d'autre culture, tels que les terrains rocheux, trop montueux, ou encore les terrains bas, exposés à des inondations.

Quelles sont les herbes qu'il faut faire entrer dans la composition d'un pdturage?

Cela varie beaucoup; mais les meilleurs praticiens conseillent pour la semence d'un arpent, le mélange suivant : trèfle blanc, 6 livres; trèfle Allsyke, 1 livre ; trèfle Rodden, 4 livres; mil, 2 livres; ivraie vivace ou d'Italie, 1 livre; Kentucky blue grass, 1 livre; Orchard grass, 1 livre.

Quelle doit être la base de tout bon pâturage?

Le trèfle blanc.

Pourquoi mélange-t-on ces différentes graines?

Il arrive souvent que certaines herbes poussent ou d'autres ne viendraient pas; en mélangeant ainsi les graines, on est sûr que si une ne réussit pas, une autre poussera et que le sol sera ainsi tout engazonné. La diversits des herbes a aussi pour effet de flatter davan. tage le goât des animaux et de rendre la dépaissance plus complete.

N'est-il pas vrai que beaucoup de cultivateurs metient des terrains en paturages sans y semer de graine d'herbe?

Oui ; mais c'est une pratique désastreuse. Outre que ces pâturages sur chaume de grain sont toujours pauvres et qu'il en faut beaucoup plus grand pour entretenir le même nombre d'animaux, ce qui est une perte de terrain, faute d'être recouverte par le gazon, la terre est bralée par le soleil, tassée par les pluies et bientôt envahie par les mauvaises herbes. 
Quels soins d'entretien faut-il donner aux paturages ?

Les mêmes qu'aux prairies.

N'y a.t-il pas aussi quelques soins particuliers?

Oui: il faut d'abord, une couple de fois par mois, épandre les crotins et les bouses, pour que le paturage soit également fertile, bon partout et qu'il ne se forme pas de ces touffes d'herbes trop fortement fumées, aux quelles le bétail ne touche pas. Il faut aussi faucher les mauvaises herbes et les talles de bonne herbe qui, en poussant en foin, deviennent dures et sont négligees par le bétail. Lnfin, dès qu'on aperçoit des espaces vides, où l'herbe s'est détériorée, il faut de suite en semer d'autre.

Quelle étendue de paturage faut-il pour chaque animal?

Cela dépend naturellement de la qualité du paturage, de l'espèce et de la taille des animaux. En général, on calcule qu'il faut environ un arpent et demi pour entretenir une vache, trois arpents pour nourrir un cheval ou un gros bœuf, et un arpent pour huit ou dix moutons.

\section{A quelle époque faut-il livrer le paturage au bétail?}

Il faut attendre, au printemps, que la terre soit assez sèche et assez raffermie pour qu'elle ne soit pas piétinée par les animaux, surtout dans un nouveau pâturage. Il faut aussi attendre 'que l'herbe soit assez poussee pour que la dépaissance n'en arrête pas la croissance; mais il ne faut pas attendre que la végetation soit trop avancée, car l'herbe est moins nutritive et comme elle est plus coriace, elle n'est pas recherchee par le bétail. 
Quel est le meilleur mode de dépaissance?

C'est de diviser le paturage en deux ou trois clos. Pendant que les animaux paissent dans l'un, l'herbe croît dans l'autre, de sorte que le bétail a toujours une herbe plus longue à brouter, se repaît plus promptement et a plus de temps pour se reposer et ruminer a l'aise.

Quand on sépare les différentes espices d'animaux, dans quel ordre faut-il leur livrer le pâturage?

Il faut d'abord introduire les vaches, ensuite les chevaux et en dernier lieu les moutons.

Est-il bon de donner de l'ombrage aux animaıs en pâturage?

Oui: quand un paturage ne renferme pas d'arbres où les animaux puissent se mettre à l'abri de l'ardeur du soleil, qui les fatigue toujours, il est très recomman. nable de leur procurer des abris artificiels, ou ils puissent trourar ce confort. Il suffit pour cela de jeter dee branches ou des planches sur des perches supportées par de longs pieux. 



\title{
CHA P TRE IX
}

\author{
ART AGRICOLE
}

Qu'est-ce que l'art agricole?

C'est l'ensemble des règles qui s'appliquent à la culture et d la récolte de chaque plante en particulier.

Comment divise-t-on les plantes au point de vue de la manière dont elles sont utilisées?

On les divise en plantes alimentaires et en plantes thdustrielles.

Qu'appellez-vous plantes alimentaires?

Celles qui sont principalement employées pour la nourriture de l'homme et des animaux.

Qu'appellez-vous plantes industrielles?

Celles qui fournissent certaines matières premières a l'industrie manufacturière, telles que le lin, le chanvre, la betterave à sucre, le tabac et le houblon.

Comment désignet-on ordinairement les plantes alimentaires?

On les divise en trois classes: $1^{\circ}$ celles qui sont cultivées pour leurs fruits; $2^{\circ}$ celles qui sont cultivées pour leurs racines; $3^{\circ}$ celles qui sont cultivées pour leurs feuilles ou leurs tiges.

14 
Quelles sont les plantes que l'on cultive généralement pour leurs fruits?

Ce sont les céréales, c'est-à-dire le blé, le seigle, l'orge, l'avoine, les pois, les fêves et le maïs.

Quelles sont les plantes qu'on cultive pour leurs racines?

Ce sont les pommes de terre, les betteraves, les carottes, les navets et les topinambours.

Quelles sont ies plantes qu'on cultive pour leurs feuilles ou leur fourrage?

Ce sont les plantes fourragères, c'est-à-dire le mil, le trè̀le, la luzerne, les lentilles, les vesces et plusieurs autres qui entrent dans la composition des prairies et des prés.

Quelles sont dans notre pays les principales plantes industrielles?

Ce sont le lin, le tabac et le houblon.

\section{1-Du ble ou froment}

Distingue-t-on plusieurs especes de blé?

Oui, on en distingue plusieurs espèces, selon qu'on se place à différents points de vue et avec ces différentes espèces, les grainetiers ont formé une couple de centaines de variétés, dont les qualités ne sont rien moins que fixes. 
D'or proviennent les différences que l'on remarque entre ces différentes variêtes?

De la manière dont le blé est cultivé. Par exemple, si vous semez de beaux blés blancs et tendres dans une glaise compactè et humide, ces blés se transformeront par cette culture en blée rouges, gris ot durs et pareillement les bles durs se transforment en bles tendres et blancs, quand ils sont cultivés dans des terrains légers. et calcaires.

Le même phénomène se produit-il dans la culture des blés barbus et des blés mutiques ou sans barbes?

Oui : il est constaté par l'expérience que par une culture soignée et améliorée, les blés barbus se transforment en blés mutiques ou sans barbes, de même que ces derniers, par une mauvaise culture, se transforment souvent en blés barbus.

Qu'entender-vous par blé d'automne et blé de printemps?

On désigne par ces appellations des blés qui se sèment à l'automne ou au printemps, respectivement.

Les blés d'automne et les blés de printemps constituent-ils des espèces fixes et distinctes?

Non: la plupart des blés désignés sous ces appellations peuvent se semer indifféremment l'automne ou le printemps, suivant les conditions climatériques dans lesquelles se fait la culture. Ainsi, pour ne donner qu'un exemple, le blé de Talavera réussit aussi bien semé à l'automne qu'au printemps.

Comment, au point de rue botanique, classe-t-on les differentes especes et variétés de ble?

On les classe, d'après la forme des épis, en blés carrés 
et en blés aplatis; d'après la disposition des épillets, en blés compactes, blés semi-compactes et blés laches; d'après la coulour, en blés blancs et en blés colorés; d'après la surface des enveloppes florales, on blés glabres ou lisses et en blés velus; d'après la présence ou l'absence de barbes, en blés barbus, en blés mutiques et en blés barbescents; d'après la consistance des grains, en blés tendres ou farineux et en blés durs ou cornés.

Quelles sont les principales variétés de blé sans barbe et les qualités qui distinguent chacune de ces variétés?

Ce sont les suivantes :

1. Le ble commun d'hiver, à grains roux et glabres, épis jaunâtre, moyennement compacte, assez souvent pourvu d'arrêtes courtes au sommet. Il est rustique et d'un volume qui varie suivant la fertilite des terrains. Il s'accommode des terres argileuses et compactes.

2. Le blé rouge d'Ecosse, à paille assez forte, épi demilâche, épillets élargis, grain rouge, variété robuste et productive.

3. Le blé blanc de Hongrie, a épi blanc, court, carré, un peu aplati et compacte : grain blanc, arrondi et tendre. Ce blé est fort estimé, mais craint les terres humides et préfère celles de consistance moyenne.

4. Le blé de Talavera, à épi long, lâche, grain blanc jaunatre, court et renflé. Ce blé est beau, productif, se sème indifféremment à l'automne ou au printemps, est précoce et marit avant presque toutes les autres variétés. Son grain opaque donne une farine très recherchée pour la patisserie.

5.
gu
uu

C'es

ada] pror

6.

clai

ble

être

froic

terr

7. lach

8.

grai des. une

9. deli proo il re 
llets, en lâches; colorés ; on blés orésence es mutiance des durs ou arbe et les

glabres, souvent stique et terrains. ctes.

pi demibuste ot.

t, carré, rondi et es terres ine.

in blanc roductif, intemps, autres très re-
5. Lo blé des haies ou de Tunstall, à épi carré, épais, régulier, couvert d'un duvet blanc et veloute; grain court, d'un blanc jaunatre, tendre et de bonne qualité. C'est une des variétés les plus précoces et des mieux adapt6es, comme ble de printemps, au climat de notre province.

6. Le blé Lamma ou blé rouge anglais, à épi d'un rouge clair ou doré; grain petit, de très bonne qualité. Oe ble est hâtif, sujet à s'égrener et doit à cause de cela étre récolté avant sa maturité. Cette rariété craint les froids, mais elle est peu exigeante sur la qualité du terrain.

7. Le ble écossais ou blé blanc de Hunter, à épi un peu lache, fin, allongé, à grain compacte et gros.

8. Le ble Chiddam, à épis serré, dressé, pyramidal, à grains blancs, un peu translucides, donnant une farine des mieux appropriées aux fins des boulangers. C'est une variété anglaise et assez productive.

9. Le ble de Saumur, à paille très blanche, assez delicat, grain grus et bien plein; il donne d'abondants produits dans les terres de consistance moyenne, mais il redoute les localites humides.

10. Le blé richelle blanche de Naples, à épi blanc, muni de quelques arrêtes très courtes; grains tendres, oblongs, d'un blanc jaunatre. C'est une excellente variété, qui demande un sol plutôt léger que compacte et craint trop les hiver rigoureux pour être semé à l'automne.

11. Le blé saumon, à épi blanc, fort et bien nourri; grain généralement blanc, oblong et tendre. C'est une des plus belles variétés et des plus productives; elle demande une terre substantielle et un peu humide ou fraîche. 
12. Le blé Pictet ou de Fellemberg ou touzelle blanche, à épi très blanc, lache, allongé, d'un blanc jaunatre; paille fragile. C'est une des meilleures variétés pour les terres un peu fortes; mais, dens notre province, ce blé ne doit être semé qu'au printemps, vu qu'il redoute les froids des hivers rigoureux, dans la culture d'automne.

13. Le blé d'Odessa, à épi un peu irrégulier, épillets inégaux, d'un rouge cuivré. Cette variete, qui est estimée, redoute les grands froids, mais résiste très bien à la sécheresse et réussit même dans les terrains à seigle.

14. Le blé de Noé on blé bleu, à paille courte et raide, grain blanc, tendre et recherché. C'est une varieté pr6coce et productive, demandant d̀ être coupée avant la maturite, mais murissant facilement en moyettes ou quintaux. Elle craint le froid et l'humidite et, dans notre province, ne devrait être semé qu'au printemps. Elle est sujette à dégénérer.

Quelles sont les principales variétés de blé barbu et les qualités qivi distinguent chaque espèce?

Ce sont les suivantes :

1. Le blé barbu de printemps, à épi blanchâtre et barbes très développées ; grain gros, renflé, demi-tendre et de couleur souvent grisâtre. Cette variété est peu exigeante sur la qualité du terrain et c'est elle que l'on cultive généralement dans notre province.

2. Le blé poulard carré ou blé de Dantzick, à épi blanc ou rougeâtre, gros et pendant à la maturité; grain gros, ovcïde, plus ou moins dur. Cette variéte est peu sensible au froid, mais lente à mûrir.

3. Le blé de Taganrok, à épi allongé, lâche, à quatre 
Blanche, à jaunâtre; tés pour vince, ce 1 redoute ure d'au-

, épillets i est estiès bien à 3 à seigle. et raide, riété preavant la yettes ou et, dans rintemps.

et les qua-

et barbes dre et de xigeante a cultive

pi blanc rain gros, peu sen-

à quatre faces et barbes de couleur variante, rousse, noire ou blanche; grain glacé et dur. Cette variété redoute le froid et ne doit être semée qu'au printemps, sous un climat comme le nôtre.

Quels sont les principaux traits caractéristiques des bles barbus?

Ces blés ont généralement une paille ferme, peu propre à la nourriture des animaux, mais qui les protège contre la verse. Leur grain a presque toujours une enveloppe plus épaisse et donne, à poids égal, moins de farine que celui des bless sans barbe; mais ils sont ordinairement très rustiques, ce qui leur donne l'avantage sur les variétés plus délicates, dans les climats froids et humides.

Comment classe-t-on les blés au point de vue de la conformation du grain?

On peut les classer : $1^{\circ}$ en blé renflé, ou celui dont le grain est court, renflé et presque arrondi, ce qui est la conformation du grain de presque tous les beaux bles blancs; $3^{\circ}$ en ble demi-gros ou moyen, ou ceux dont le grain est long, mais de grosseur moyenne, ce qui est la conformation du grain de presque tous les blés rouges, tels que le lamma, le Kessingland; $3^{\circ}$ en gros blé, ou celui dont le grain est gros et long, tel que celui du blé de Talavera.

Comment classe-t-on les blés au point de vue de la consommation?

En blés tendres et en blés durs.

Comment reconnait-on les blés tendres?

Ils sont faciles à écraser sous la dent, ont une cassure 
blanche, grenue et farineuse. Dans les bles tendres, on distingue les rouges et les blancs. Ceux-ci donnent une très belle farine; mais elle renferme moins de gluten et fait une pate plus courte que celle des blés rouges et durs.

\section{Comment reconnait-on les blés durs?}

Ils sont difficiles à écraser $\varepsilon$ sus la dent, ont une cassure grisatre, unie, cornée et presque vitreuse. Ils sont lourds et très nutritifs. Leur farine fait un pain plus gris, plus lourd et plus frais, mais plus nourrissant, et qui se durcit moins vite que celui de la farine des blés tendres.

Quelles règles faut-il suivore pour faire un bon choix dans toutes ces variêtes?

Il faut se guider sur les circonstances et choisir la variété qui s'adapte le mieux aux conditions de sol et de climat dans lesquelles doit se faire la culture.

Quelles sont les qualités générales d'un beau ble?

Le grain doit être pleis, bien formé, lisse et luisant à la surface, d'une teinte uni. forme et coulant à la main; il doit être net, c'est-à-dire c'ébarassé de graines étrangères, des vannes, de la poussière et de toutes les autres impuretés.

\section{Cholx et preparation de la semence}

Quel soin faut-il apporter dans le choix du grain destiné à la semence?

Il faut prendre bien soin de ne choisir que du blé bien 
lres, on onnent ins de es blés

ne casls sont n plus lant, et es blés

ix dans

jisir la de sol re.

isant d aain; il étran3 autres

'estiné d

lé bien

muri, au grain bien formé, plein, luisant et lourd. Il faut aussi, autant que possible, que ce soit du grain de la récolte précédente, qui possède mieux que du blé plus agé la faculté germinative.

Est-il nécessaire que le grain de semence ait le grain gros?

Non : le ble à petit grain est aussi bon que celui à gros grain, pourvu qu'il possède les autres qualités vouluss.

Connaissez-vous d'autres précautions d prendre?

Oui; il est bon de choisir pcur la semence du blé récolté dans la terre qui lui convient le mieux, ce qui est une garantie qu'il a conservé ses qualités particu. lières et distinctives.

Quelle préparation faut-il donner au blé avant de le semer?

Pour protéger le blé contre la carie ou le charbon et contre les attaques de certains insectes, il est bon d'induire la semence avec des matières propres à détruire le germe des champignons dont le grain pourrait être recouvert et à éloigner ou empoisonner certains insectes qui s'attaquent à la semence et la font périr.

Quelles sont les principales matières qu'on peut employer d cette fin?

Ce sont la chaux, les sulfates de cuivre et de zinc, le sel marin ou sel ordinaire, les carbonates de potasse et de soude, l'acide arsénieux, l'eau de mer, l'urine pourrie et le jus de fumier.

Comment s'emploient le sulfate de soude et la chaux?

Pour quatre minots de blé, on fait dissoudre une 
livre de sulfate de soude dans quatre gallons d'eau ; on met le grain sur un plancher et on le remue avec une pelle pendant qu'une autre personne verse la solution dessus. Quand le grain est bien humecte, on continue de le remuer avec la pelle et l'on saupoudre dessus quatre ou cinq livres de chaux pulvérisée et fraichement éteinte. Si le grain ainsi pıéparé ne doit pas etre semé de suite, il faut l'étendre en couches minces pour le conserver.

\section{Comment s'emploie le sulfate de cuivre ou vitriol bleu?}

On fait dissoudre un quarteron ou une demi-livre de vitriol dans une quantité d'eau suffisante pour mouiller trois minots de ble, qu'on verse dans cette solution, ou elle doit tremper de quarante à quarante-cinq minutes et on laisse égoutter ou même sécher le grain avant de le semer.

Comment s'emploient la chaux et le sel ordinaire?

On dispose quatre minots de blé en un tas de forme conique. Sur le haut du tas, on place un seau rempli d'eau bouillante, dans laquelle on jette quelques morceaux de chaux vive, ce qui produit une violente ébu. lition et forme l'eau de chaux qui déverse du seau et se répand sur le grain. Quand l'ébullition est finie, on achève de répandre sur le haut du tas l'eau de chaux qui reste, en ayant soin de ne pas verser avec l'eau la chaux déposée au fond du seau. On saupoudre ensuite le grain avec du sel, on le remue deux ou trois fois et il est prêt à semer à la volée. Quand on sème à la machine, il faut laisser sécher le grain, pour ne pas s'expo. ser à enclouer lo semoir. 
i ; on

c une lution tinue lessus aiche* it pas ainces Juiller on, ou inutes ant de

forme empli morébu. au et lie, on shaux eau la nsuite is et il a ma'expo-

\section{Climat ot nol}

Quel est le climat le plus propice d̀ la culture du blé?

Le blé s'adapte aux climats les plus variés et se cultive dans toutes les contrées ou l'homme a pu s'établir ; mais c'est dans les climats tempérés, comme celui de notre pays, qu'il réussit le mieux.

Quelle est la température qui lui est la plů favorable?

C'est celle des climats où la chaleur s'élève graduellement: si elle devient subitement très forte, la végétation se ralentit et la récolte est gravement affectée, si cet excès de chaleur n'est pas compensé par l'humidité naturelle du climat ou celle provenant des pluies.

Le blé supporte-t-il de basses températures?

Oui, lorsqu'il est cultivé dans des terres bien assainies. Ainsi le blé d'automne, qui a deux mois de végétation et qui n'est pas surpris par l'humidité avant d'être couvert par la neige, ne souffre pas des gelées d'automne et de l'hiver; il entre en végétation au printemps dès que la température atteint 40 à 50 degrés, ce qui a lieu, dans une bonne partie de notre province, vers le 20 avril.

Quel est le sol qui convient le mieux au blé?

Tardif de sa nature et d'une composition chimique assez compliquee, le blé ne réussit bien que dans les terres fertiles et assez fraîches pour maintenir longtemps la végétation en vigueur.

Qu'arrive-t-il selon que la terre est trop fraîche ou ne l'est pas assez?

Quand la terre est trop fraiche, la plante devient 
aqueuse, molle et la tige se développe au détriment de l'épi, qui porte bien moins de fruit; quand la terre ne conserve pas assez de fraícheur, la nutrition de la plante cesse et l'épi ne se forme pas.

Que suit-il de ld 8

Il suit de là que dans les régions pluvieuses, les glaises et les argiles tenaces, qui retiennent beaucoup d'humidité, sont impropres à la culture du blé, de même que dans les pays secs, les terres sableuses ou trop calcaires, qui ne retiennent pas l'humidite, sont pareillement impropres à cette culture.

Suffitil, pour que le blé réussisse bien, que la terre dans laquelle on la cultive ait la fraícheur voulue?

Non : il faut que la terre renferme en sus les eléments minéraux, surtout la chaux, qui entrent dans la composition de cette plante.

Qu'appellez-vous terre d blé

Celle qui offre les conditions voulues pour la culture du ble, c'est-d̆-dire uno terre de consistance moyenne, meuble, renfermant, dans les proportions voulues, le calcaire et la silice qui lui sont indispensables.

Place du ble dans la rotation

Quelle place doit occuper le blé dans la rotation?

Dans une bonne culture, le blé ne doit venir qu'à la suite d'une récolte sarclée, c'est-d̀-dire qu'il doit être semé dans une terre ensemencée l'année précédente en 
maïs, en pommes de terre ou autres plantes semblables, exigeant un sol profonderment ameubli, bien fumb et bien débarrassé des mauvaises herbes par les sarclages.

Peut-on semer aussi après d'autres récolles?

Oui : on peut le semer dans un friche batard, c'est-ddire dans une terre précédemment ensemencée en lentilles, en millet et, ce qui est encore bien mieux, on trèfle.

Pour quelles raisons lui assigne-ton cette place dans la rotation?

Pour se conformer aux exigences de cette céréale. Le ble veut une terre profondément ameublie, riche et exempte des mauvaises herbes, qui lui sont fatales. Les cultures sarclées ameublissent le sol, l'enrichissent par la fumure qu'elles requierent et le nettoient par les sarclages qu'elles exigent. Le trèfle enrichit aussi le sol et le débarrasse des mauvaises herbes, ce qui remplit deux des conditions que demande le ble pour bien produire.

\section{Fumure et engrails}

Sur quoi faut-il se guider pour déterminer la nature et la quantité de l'engrais qui doit être appliqué à la culture du blé?

Sur la composition chimique de cette céréale et sur celle du sol destiné a l'emblavure. 
Quels sont les principaux éléments qui entrent dans la composition du grain de ble?

D'après les expériences de Wolff et Petermann, qui font autorité en cette mutière. 1000 livres de grain de ble renferment en moyenne 20.5 livres d'azote, 8.9 d'acide phosphorique, 5.5 de potasse, 0.5 de chaux et 2.2 de magnésie. La paille renferme en sus un peu de ces elements et une grande quantite de silice.

Quels sont les engrais minéraux qui fournissent ces éléments?

Ce sont les silicates et les phosphates alcalins, notamment le superphosphate de chaux, le plus riche en acide phosphorique, et la cendre de bois, qui renferme de la potasse, de la chaux et de la magnésie.

Quels sont les engrais qui fournissent l'azote?

Ce sont les débris d'animaux, mais surtout le bon fumier de ferme, qui en renferme une grande proportion, quand on ne le laisse pas gater par l'échauffement, le lavement par la pluie ou la neige ou l'evaporation en le laissant trop longtemps étendu sur le champ avant de l'enterrer par le labour.

Comment peut-on déterminer la nature de l'engrais qu'il faut employer?

En comparant la composition du sol avec celle du ble. Si le sol, par exemple, manque d'acide phosphorique, on applique le phosphate de chaux, qui renferme cet acide ; s'il manque d'azote, il faut le plus riche fumier d'étable et de même pour les autres engrais.

Applique-t.on tous les engrais directement à la culture du blé?

Non: on applique les engrais minéraux directement ; 
mais les engrais organiques et le fumier doivent etre introduits dans le sol par la culture qui précède celle du blé, afin de détruire par cette culture les mauvaises herbes que fait surgir une fumure frafche et qui sont des plus nuisibles au ble. C'est pour cette raison que dans une bonne rotation, on met toujours le ble a la suite d'une culture sarclée.

\section{Proparation da mol}

Quelle préparation faut-il donner au sol que l'on veut en. semencer en blé ?

Pour bien réussir, le blé exige une terre propre, c'estd-dire libre de toutes mauvaises herbes, meuble et cependant bien rassise, c'est-d-dire tassée par le temps ou par le rouleau.

Pourquoi faut-il une terre propre?

Parce que le blé, à raison de la lenteur de sa végétation, it la céréale qui souffre le plus des plantes adventices ou mauvaises herbes, qui prennent facilement le dessus sur lui et l'empêchent de se développer, sans compter qu'elles enlèvent au sol une partie des substances dont le ble a besoin lui-même pour se nourrir.

Quelles fagons faut-il donner au sol pour le nettoyer?

Cela dépend de l'assolement et de la saison dans laquelle on sème.

Comment cela peut-il dépendre de l'assolement?

Il est évident que si on met le blé à la suite d'une pent; 
récolte sarclée, cette récolte a détruit toutes les mauvaises herbes et suffisamment nettoyé la terre. Il en est de même si on fait succéder le ble à une première récolte de trèfle. Mais, si on emblave un friche batard, c'est-à-dire un paturage ou une prairie, il faut prendre le moyen de iaire mourir toutes les herbes formant le gazon.

Quelles façons faut-il donner pour bien détruire l'herbe d'un friche de pré ou de prairie?

On donne d'abord un labour aussi superficiel et auss: étroit que possible, juste assez pour couper et detruire la racine de l'herbe ; on passe ensuite le scarificateur, la herse et même le rouleau, si c'est nécessaire, puis, quand l'herbe est bien morte, on fait un labour definitif, de sept à huit pouces d'épaisseur.

Ces façons s'appliquent-elles au blé d'automne ou d̀ celui du printemps?

Elles s'appliquent principalement au blé d'automne; mais elles sont aussi très utiles au blé de printemps, qui doit toujours être semé sur un labour d'automne. Dans la terre ainsi préparée en automne, l'herbe ne repousse pas le piintemps et le blé réussit à merveille, d'autant plus que la décomposition des herbes mortes, sous les sillons, forme un engrais qui profite au blé.

Quelles façons faut-il donner au sol pour l'ameublir?

Il faut d'abord un bon labour de sept ou huit pouces de profondeur, îui à l'automne, ce qui suffit pour les semailles de printemps. Pour celles d'automne, on ajoute une façon au scarificateur, dans le sens transversal des planches, et dans leur sens longitudinal, un hersage sur 'equel on depose la semence. 
Pour les semailles d'automne, peut-on semer immédiatement aprds avoir labouré?

Non: il faut donner à la terre au moins une quinzaine de jours pour se tasser et se raffermir, car le ble pousse mal dans un sol qui n'est pas assez rassis.

Un roulage fort, donné après le labour, ne raffermerait-il pas suffisamment la terre?

Peut-être, dans les sols légers ou faciles à comprimer; mais dans les terres fortes, il vaut bien mieux laisser faire le tassement du sol par le temps, qui donne un bien meilleur résultat que n'importe quel roulage.

\section{Ensemencement et quantite de semence}

Comment sème-t-on le blé?

A la volée ou au semoir.

Comment recouvre-t-on la semence?

Dans notre pays on se contente généralement d'un hersage énergique, ce qui est bien insuffisant. Le ble d'autornne doit être enterré à trois pouces ou trois pouces et demi de profondeur et le blé de printemps à deux pouces et demi ou trois pouces ; or il n'est pas de hersage, si énergique qu'il soit, qui puisse enterrer la semence à cette profondeur.

Quel est le meilleur moyen d'enterrer le blé à la profondeur voulue?

C'est de couvrir la semence da la charrue ou au cultivateur, quand on sème à la volée, ou de se servir d'un semoir enfouisseur, quand on sème au semoir. 
Comment enterre-t-on la semence d̀ la charrue?

Tout simplement par un labour superficiel de quatre pouces d'épaisseur et de neuf de largeur, ce qui est de rigueur pour les semailles d'automne.

Quand on enterre les semences d'automne d la charrue, est-il bon d'abattre ensuite la crête des sillons à la herse ou au cultivateur?

Non, parce que cela affecterait le tassement de la terre, si nécessaire aux semis d'automne, sans compter que la crête du sillon, outre qu'elle protège les jeunes tiges contre les gros vents et fixe la neige, se délite ou s'égrène au printemps et rechausse ainsi les jeunes plantes.

Quelles façons faut-il donner le printemps aux semis d'automne?

Dès que la terre est assez sèche, il faut herser et plomber, c'est-à-dire passer le rouleau. Plus le rouleau est pesant, plus la récolte réussit et les meilleurs praticiens recommandent même l'usage d'un rouleau de quatre mille livres, traîné par quatre chevaux, surtout pour les sols légers.

Comment enterret-on les semis de printemps?

A la charrue, comme les semences d'autumne, ou au cultivateur.

N'emploie-t-on pas d̀ cette fin un autre instrument?

Oui: on peut employer très avantageusement le semoir enfouisseur, qui distribue et enterre la semence, pourvu qu'il soit assez fort pour déposer et enterrer le semis à trois pouces de profondeur. 
Faut-il plomber les semis de printemps?

uatre st de

arrue, ou au

de la

npter eunes ite ou eunes

d'au-

er et uleau pratiau de ertout

ou au

ent le nence, rrer le
Oui, comme ceux d'automne.

Pourquoi faut-il enterrer la semence de blé d̀ trois ou quatre pouces de profondeur?

La tige du blé a deux séries distinctes de racines: $1^{\circ}$ des racines pivotantes, qui s'enfoncent dans le sol au-dessous du grain semé et qu'on appelle racines germinales ; $2^{\circ}$ des racines traçantes, qui servent d'appui a la tige et sortent invariablement de celle-ci à un pouce au-dessous de la surface du sol. Quand la semence n'est pas enterrée à une assez grande profondeur, les deux séries de racines se confondent, s'étouffent pour ainsi dire et n'alimentent la tige que d'une manière imparfaite.

Connaissez-vous d'autres raisons qui expliquent pourquoi le semis de blé doit être enterré d̀ une bonne profondeur?

On enterre la semence du ble à une bonne profondeur pour la protégei contre la gelée, dans les semis d'automne, et contre la sécheresse et la chaleur, dans les semis de printemps.

Quel avantage il y a-t-il d semer le blé à l'automne plutôt qu'au printemps?

D'abord, le blé semé à l'automne mûrit plus tôt que le blé semé le printemps, ce qui est un avantage considérable dans les régions où la saison agricole est courte. Ensuite, les semailles faites a l'automne sont autant d'ouvrage exempté pour le printemps, ou les travaux sont plus nombreux et plus pressants. Enfin, l'expé. rience constate qu'en moyenne le blé d'automne produit un tiers de plus que celsi de printemps, ce qui est un avantage considérable. 
La culture du blé d'automne est-elle possible dans notre province?

Notre climat, dans la partie ouest de la province, n'offre aucun obstacle à cette culture, quand elle est bien faite et quand on a soin de bien égoutter le sol.

Quille quantité de semence faut-il a l'arpent?

Cela dépend de l'etat du sol, lors des semailles, et des qualités naturelles de la terre. Les terres fortes ou mal préparées exigent plus de semence que les terres légères et bien ameublies. Enfin, il faut mettre plus de semence dans une terre pauvre que dans un sol riche, vu que le ble talle pour ainsi dire à l'infini çans une terre riche et ne talle presque pas dans un sol pauvre.

Connaissez-vous d'autres circonstances qui influent sur la quantité de la semence?

Oui : le semis à la volée demande plus de grain que celui qui se fait au semoir et il est constaté par l'expérience que le blé d'automne doit être semé moins fort que celui de printemps.

Dans une bonne terre à blé, bien préparée, quelle est la quantité de semence que l'on met à l'arpent?

Le blé d'automne semé à la volée et sous raies exige environ deux minots de semence à l'arpent, et un minot à un minot et demi, quand il est semé au semoir. Quant au blé de printemps, deux minots de semence à l'arpent suffisent quand on sème très à bonne heure; mais on met généralement deux minots et demi à trois minots, surtout pour les semis à la volée.

A quelle époque doivent se faire les semailles?

Pour le blé d'automne, vers le ler septembre; pour 
dans notre

province, d elle est le sol.

lles, et des tes ou mal res légères lus de se1 riche, vu une terre vre.

luent sur la

grain que par l'expémoins fort

est la quan-

raies exige t un minot oir. Quant e à l'arpent e; mais on ois minots,

lbre ; pour le blé de printemps, aussitôt que la terre est assez sèche pour être travaillée avantageusement. Comme le blé végète lentement, il faut toujours le semer le plus tôt possible, afin que les racines puissent prendre un développement qui leur permette de résister aux premières sécheresses et de développer des tiges plus nombreuses, plus fortes et plus fertiles.

Quels avantages résultent-ils des semailles à bonne heure?

Le blè de printemps semé à bonne heure s'enracine mieux, est plus avancé à l'arrivée des chaleurs et craint moins la sécheresse; il donne un grain plus nourri et une paille plus substantielle.

\section{Boing d'entretien}

Quelles sont les principales cultures d'entretien qu'exige le blé durant sa végétation?

La plupart des agriculteurs les négligent; mais les cultivateurs soigneix donnent au blé, durant sa végétation, les cultures suivantes : rigolage, hersage, roulage, sarclage, épamprage et nettoyage.

En quoi consiste le rigolage?

Le ble aime une terre assez humide, mais périt vite dans un sol noyé; c'est pourquoi il est indispensable, après les semailles, de bien nettoyer toutes les rigoles, afin que le surcroît d'humidité puisse s'écouler facilement et promptement. Même pour les blés d'automne, il faut retoucher les rigoles au printemps.

En quoi consiste le hersage?

Il arrive souvent que par suite de pluies ou de cha- 
leurs excessives, la terre semée en blé d'automne se masse a la surface et forme une croate qui arrête la circulation de l'air, de la chaleur et de l'humidité, qui ne peuvent pas atteindre la racine de la plante, pour en activer la végétation. Alors la plante souffre, jaunit et ne produit qu'une mauvaise récolte. Pour prévenir ce mauvais effet, on donne, aussitôt que la terre est assez sèche pour se pulvériser, un hersage qui émiette la croute, rend la surface du sol perméable et rechausse le collet des jeunes plantes, qui prennent vigueur et tallent à merveille.

\section{Faut-il que ce hersage soit énergique?}

Oui : plus il est énergique, plus la terre est ameublie, plus le résultat est efficace et plus le rendement est considérable.

Ce hersage ne détruit-il pas une partie des plantes?.

Oui, ce hersage détruit quelques plantes de ble ; mais il ne faut pas s'alarmer de cela, ni craindre, car le regain de vigueur que cette opération donne aux plantes qui restent les fait taller beaucoup plus et double la récolte.

Quel est le but du roulage ou plombage des blés d'automne?

Il arrive souvent que dans les terres légères mises en blé d'automne, la gelée soulève la terre et la boursoufle, ce qui déchausse la racine du grain et l'empêche de s'alimenter ou l'expose à la sécheresse; pour obvier à tout cela, on donne un fort roulage qui refoule le sol, enfonce les plantes et enterre leur collet.

Quel est le but du sarclage?

Le blé est de toutes les céréales celle qui est le plus 
omne se to la cir, qui ne pour en jaunit et evenir ce est assez niette la hausse le et tallent

meublie, ment est

es?.

le ; mais le regain intes qui ouble la

automne? mises en ursoufle, êche de obvier à le le sol,

endommagée par les mauvaises herbes; pour les détruire, il faut herser et, ce qui est encore bien mieux, sarcler à la houe à cheval, quand le semis a été fait à la machine et en lignes.

Le hersage et le sarclage enlèvent-ils toutes les mauvaises herbes?

Non: les plus fortes et les plus vivaces, telles que la sanve ou moutarde sauvage et les chardons résistent souvent à ces opérations et le seul moyen d'en débarrasser le grain, c'est de les arracher, car si on se contente de les couper, la racine qui reste dans la terre pousse de nouvelles tiges, qui sont plus nombreuses que les pre mières et plus nuisibles à la récolte.

\section{Qu'est-ce que la verse?}

Il arrive que par leur propre poids ou sous la poussée de la pluie et des gros vents, les tiges du blé s'affaissenet s'abattent sur le sol : c'est ce qu'on appelle la verset qui arrête en grande partie la végétation et fait manquer la récolte, en empêchant l'air et la lumière d'atteindre les plantes.

Quels moyens faut-il prendre pour empêcher la verse?

Il suffit de connaître les causes de cet accident pour le prévenir.

Quelles sont les causes les plus ordinaires de la verse?

Les causes les plus ordinaires de la verse sont:

$1^{\circ}$ Des semailles trop drues-Quand le blé est semé trop fort, il talle mal, les tiges sont trop rapprochées et restent faibles ou chétives, parce que l'air, la chaleur et la lumière ne peuvent pas assez les atteindre pour leur donner la vigueur et la rigidité nécessaires. 
$2^{\circ}$ Des fumures excessives ou trop récentes-Si le blé aime une terre riche, il n'en craint pas moins les fumures excessives ou trop récentes, qui développent les feuilles outre mesure et alourdissent la tige sans lui donner de force pour se soutenir.

$3^{\circ}$ Le retour du blé sur la même terre-La paille du blé renferme beaucoup de phosphate de chaux et de silice, qu'elle arrache à la terre pour se former. Il suffit généralement d'une récolte pour épuiser ces deux substances et si l'on en fait deux de suite, il est évident que la seconde ne trouvera pas dans le sol la quantité de silice et de phosphate nécessaire pour donner à la tige la rigidité qu'elle doit avoir pour résister à la pluie ot au vent.

$4^{\circ}$ Un labour trop superficiel-Le blé est une plante extrêmement épuisante, qui exige une terre profond ément ameublie pour puiser en quautité suffisante les substances nécessaires à sa formation. Quand le labour n'est pas assez profond, les racines ne puisent dans le sol qu'une alimentation imparfaite et laissent la tige sans force et sans vigueur.

$5^{\circ} L^{\prime}$ enterrement trop superficiel de la semence-Quand la semence du blé n'est pas enterrée à une profondeur suffisante, ses racines sont trop ramassées, ne tiennent pres. que pas dans le sol et ne donnent pas à la tige l'appui nécessaire.

Quels sont les moyens de prévenir la verse?

Ils s'indiquent d'eux-mêmes par l'exposé des causes de cet accident; il faut semer pas trop fort, fumer à l'avance et pas d'une façon excessive, ne pas faire deux récoltes alternatives de blé dans la même terre, labourer 
et enterrer la semence assez profondément, enfin donner à la terre par le roulage le tassement qu'exige blé.

Quand ces mesures préventives ont été négligées, est-il encore ur moyen d'atténuer les mauvais effets de la verse?

Oui, en saupoudrant la récolte, qui pousse avec trop de vigueur et menace de verser, avec de la chaux, de la suie ou des cendres, qui durcissent la paille, lui donnent plus de vigueur, de consistance et de rigidité.

\section{Molseon}

\section{Quand faut-il couper ou abattre le blé?}

Le blé destiné à la semence ne doit être coupé que lorsqu'il est bien mar, vu qu'il germe et lève mieux; mais celui qui doit être transformé en farine doit être coupé avant sa maturité. Le blé coupé avant la fin de sa végétation donne un grain beau, fin, lourd, à écorce mince, riche t.: farine, faisant du bon pain et offrant une teinte blonde recherchée par le commerce.

Le blé s'alimente-t-il encore par ses racines, quand il est mûr?

Il est constaté que dès que les racines sont mortes et. que la paille est en partie jaunie, le grain ne tire plus rien de la terre, mais se complète aux dépens de sa propre substance et de la matière que lui fournissent ses enveloppes florales, ce qui se fait bien mieux en gerbes que sur pieu.

Quand faut-il procéder à la récolte du blé:

Il faut procéder à la récolte du blé dès que le haut et le bas de la paille jaunissent, que les nœuds deviennent 
blanchatres et transparents, quand même une partie de la tige, les feuilles et les épis sont encore verdatres. Enfin, il faut procéder à la récolte dès que la substance du grain est solide et avant qu'elle ait assez de consistance pour résister à la pression de l'ongle. Dès qu'une partie de la paille a jauni, les grains ne reçoivent plus de nourriture de la racine et la maturité se complete bien mieux en gerbe.

Quand faut-il absolument couper le blé avant sa parfaite muturité?

Quand la récolte est affectée de la rouille. Si l'on coupe les blés rouillés pendant que la paille est verte et que le grain s'écrase sous les doigts, la rouille ne fait aucun dommage : la récolte est abondante et belle.

\section{Comment coupe-t-on le blé?}

A la faucille ou à la moissonneuse, de manière à le mettre en javelles, ce qui est indispensable dans une bonne culture.

Faut-il laisser le blé javeler longtemps?

Cela dépend du degré de maturité du grain quand on - le coupe. Le grain bien mâr sèche très vite; il peut être engerbé et engrangé une couple de jours après la coupe, quand il ne renferme pas trop de mauvaises herbes, encore vertes, qui pourraient faire chauffer le grain en tasserie. Quand le blé est coupé un peu verdatre et qu'il renferme beaucoup d'herbes adventices encore vertes, il faut laisser ja jeler jusqu'à ce que ces herbes soient bien desséchées, en ayant soin de retourner les javelles au moins tous les deux jours. Quand le grain a bien achevé sa maturation, on l'engerbe pour le mettre 
en grange, cinq ou six jours après l'avoir coupé, quand le temps est beau.

Quels sont les inconvénients du javelage sur le sol?

L'épi, en contact avec le sol humido et chaur, est exposé à germer quand il pleut et la germination est d'autant plus prompte que le grain est plus mâr. Ce blé germé perd de son poids, ne donne qu'une farine de mauvaise qualité, faisant un pain lourd et qui n'adhère pas à la croute.

Quel est le moyen de remédier aux inconvénients du javelage sur le sol?

C'est de mettre le blé en moyettes ou en quintaux immédiatement après la coupe, quand il n'est pas mouillé par la rosée ou la pluie. On évite le contact toujours dangereux des épis avec le sol et on n'a pas à retourner les javelles après la pluie.

\section{Fngrangement et bnttage du ble}

Comment procède-t-on à l'engrangement du blé ?

Quand le blé a fini de javeler, lorsqu'il est bien sec et par un 'eau temps, on l'engerbe, si on l'a laissé javeler sur champ et l'on charroie ces gerbes ou celles des moyettes à la grange, en ayant soiin de corder les gerbes sur la charette le pied en dehors et l'epi au centre. On corde les gerbes dans la grange par rangées, q ae l'on monte alternativement à une hauteur de trois ou quatre pieds, tant qu'on n'a pas couvert toute l'étendue de la tasserie. On superpose ainsi les couches de gerbes jusqu'au haut. On commence la première couche à l'endroit où les gerbes doivent ôtre jetées par celui qui 
les donne de la charette, afin de recueillir dans ces gerbes le ble qui s'égrène toujours dans ces manipulations. Le long des parois de la tasserie, on place les gerbes l'épi en dedans, afin de le protéger contre le contact de l'air et les incursions de la vermine.

\section{Comment bat-on le ble?}

Au fléau ou à la batteuse. Le fléau ne s'emploie que dans les établissements nouveaux et les petites exploitations, ou il est impossible de se procurer des batteuses qui fort l'ouvrage mieux et bien plus promptement, quand elles sont bien construites et actionnées par une force motrice suffisante.

\section{2-Du selgle}

Quels sont les traits caractéristiques du seigle?

Il est doué d'une grande rusticité et d'une puissance extraordinaire de végétation, ce qui lui permet de réussir dans les sols arides ou pauvres, de résister au froid comme à la sécheresse. Son grain donne une farine qui vient en premier lieu après celle du blé pour la panification et fournit une àes meilleures matières a la distillerie; coupé vert, avant la floraison, il donne un des fourrages les plus riches et les plus recherches par le bétail.

Distingue-t-on plusieurs variétés de seigle?

Dans notre pays, on n'en connaît généralement qu'une variet€-le seigle ordinaire ou seigle d'hiver; mais en 
Lurope on en cultive plusieurs autres variétés, notam. ment le seigle multicaule ou de la Saint-Jean, le seigle de Russie, le seigle de Vierland et le seigle de mars, qui sont toutes adaptées aux conditions climatériques de notre province.

Quelles sont les qualités respectives de ces differentes variétés ?

Le seigle multicaule donne pour ainsi dire une double récolte. Sa végétation est si énergique que semé a la fin de juin, il est assez avancé à l'automne pour donner une bonne récolte d'excellent fourrage, des mieux appropriés d l'ensilage. Cette coupe ne l'empêche pas de repousser au printemps suivant et de donner une bonne récolte de grain à l'époque ordinaire de la moisson.

Le seigle de Russie est vigoureux, forme de larges feuilles, une paille forte et de gros grains. Celui de Vierland a l'épi gros, le grair jaunatre et renflé, et le seigle de mars, à la paille fine, ‘u grain grêle, ne produit que peu lorsqu'il est semé au printemps et ne peut s'employer avantageusement que comme fourrage vert.

\section{Climat et sol}

Quel est le climat le plus propice d la culture du seigle?

Le seigle réussit dans les climats les plus rigoureux, pourvu qu'il soit cultivé dans un sol bien égoutté et qui ne se soulève pas à la gelée. Protégé par la neige, il résiste aux plus grands froids et recommence à végeter su printempe dès que la température s'élève à $45^{\circ}$ puis fleurit quand elle atteint $58^{\circ}$. Cette activité de végéta. tion lui permet de murir avant les grandes chaleurs et 
de reussir dans lez terrains sableux, auxquels il arrache sa substance avant qu'ils ne soient stérilisés par la sécheresse.

Quels sont les sols qui conviennent le mieux au ougle?

Ce sont les terres à blé, dans lesquelles il donne le meilleur rendement, excepté les argiles compactes, qui renferment trop d'humidité.

Réussit-il dans d'autres terrains?

Oui : il s'accommode des terres siliceuses et graveleuses, qu'on appelle terres a seigle, parce que celui-ci y réussit au lieu que les autres grains y périraient. Il réussit dans les sols crayeux, calcaires, argilo-calcaires, ou trop légers pour faire croître le blé; mais son produit est naturellement en proportion de la richesse du sol qu'on lui donne et de l'engrais dont on l'enrichit.

Quelle place doit-il occuper dans la rotation?

La même place que le blé. Quand il est cultivé avec soin, il réussit très bien après une récolte sarclée ou sur un brisement de jachère.

Peut-on récolter successivement dans le même terrain plusieurs récoltes de seigle?

Oui : contrairement aux autres céréales, le seigle a la faculté de se succéder plusieurs fois à lui-même dans le nuême terrain sans que son rendement diminue et l'on connaît même bien des cas où il a augmenté

\section{Le seiglc demande-til beaucoup d'engrais?}

Quand on ne vise qu'à de petites récoltes, le seigle peut se passer d'engrais et trouver tout ce qu'il lui faut dans le sol, même le plus pauvre; mais pour en obtenir des 
ache ir la ne le , qui

ravei-ci y Il iires, proe du iit.

avec u sur plue a la dans ue et ; dans ir des produits abondants, il faut Ini donner des fertilisants comme au blé, surtout des fumures contenant beaucoup de phosphates et de silicates de potasse, qui lui conviennent tout particulièrement.

Quelle préparation faut-il donner au sol destiné au seigle?

La même préparation que pour la culture du blé. Il lui faut un sol meuble, mais bien rassis.

Comment seme-t-on le seigle?

Comme le blé, à la volée ou en lignes; mais il faut le recouvrir légèrement, d'une couple de pouces de terre au plus, dans les sols légers, et d'un pouce seulement, dans les terres fortes. La quantité de semence varie d'un minot et nuart, quand le semis se fait de bonne heure, à un minot et trois quarts, quand il a lieu à une époque plus avancée.

Sème-t-on le seigle à l'automne ou au printemps?

Le seigle destiné à la production du grain se sème ordinairement dans la première quinzaine de septembre. Dans les cultures d'automne comme dans celles de printemps, il est toujours mieux de semer de bonne heure : Plus l'ensemencement est précoce, plus le produit est abondant.

Quand faut-il semer le seigle destiné d servir de fourrage en vert?

Assez tard, à l'automne ou au printemps, pour qu'il n'ait pas le temps de mûrir avant le quinze juillet, époque à laquelle on commence à l'employer pour remédier à l'insuffisance des pâturages qui se dessèchent. 
Y a-t-il une espece de seigle qui peut donner d'une seule semence du fourrage vert,et du grain?

Oui, le seigle multicaule ou de la Saint-Jean. Semé à la fin de juin, on le fauche à l'automne et il donne un excellent fourrage pour l'ensilage ; il repousse le printemps suivant et donne une bonne récolte de grain, a l'époque ordinaire de la moisson.

\section{Quelles cultures d'entretien faut-il donner au seigle?}

Les mêmes qu'au blé.

Nc faut-il pas quelquefois lui donner des soins particuliers au printemps?

Quand le seigle est cultivé dans une terre riche st bien fumée, il arrive souvent qu'au printemps la végétation se développe avec trop de vigueur; pour la ralentir, on fait passer un troupeau de moutons sur le cinamp de seigle, en ayant bien soin de choisir pour cela un temps sec.

Commerit moisonne-t-on le seigle?

De la même manière que le blé, excepté qu'il ne faut pas abattre le seigle avant qu'il soit bien mûr. Outre qu'il re s'égrène pas sur le champ, le seigle abattu avant sa parfaite maturité ne donne que des grains ridés et pauvres en farine.

Comment se font l'engrangement et le baitage du seigle?

Absolument comme ceux du blé. 


\section{\& 3--De l'orge}

Semé onne un le pringrain, à

rticuliers

riche it la végéla ralenle cinamp cela un

li ne faut Outre e abattu hins ridés seigle?

Distingue-t-on plusieurs espèces d'orge?

Oui, selon la manière dont les grains sont disposés sur l'épi, il y a l'orge à deux rangs, l'orge à quatre rangs et l'orge à six rangs; selon l'emploi, il y a l'orge pour le maltage et l'orge pour la mouture. Il y a aussi l'orge d'automne et l'orge de printemps, selon la saison à laquelle on la sème; enfin l'orge ordinaire et l'orge nue.

Quelles sont les espèces que l'on cultive dans notre province?

Ce sont principalement les orges de printemps, à quatre rangs et à six rangs.

Comment choisit-on et prépare-t-on l'orge destinée $\dot{a}$ la semence?

De la même manière que le blé.

Quel est le climat qui convient le mieux d l'orge?

Grâce à la rapidité de sa végétation, l'orge s'accommode de tous les climats habitables par l'homme. Dans les climats chauds, elle passe par les différentes phases de sa végétation assez promptement pour devancer la sécheresse, qui pourrait lui nuire; dans les climats froids, où sa végétation est encore plus rapide, elle mârit avant que la gelée puisse lui faire tort.

Quels sont les sols qui conviennent le mieux a l'orge?

L'orge s'accommode de presque tous les sols, excepté des terres humides; mais c'est dans les terrains de consistance moyenne qu'elle donne le meilleur rendement. 
Pourquoi les terrains légers et les terres compactes sont-ils moins favorables d l'orge?

Dans les terrains sablonneux, l'orge ne trouve pas en quantité suffisante les substances dont elle a besoin pour s'alimenter; dans les terres compactes et tenaces, ses racines ne peuvent pas prendre assez de développement pour fournir à la tige toute l'alimentation dont elle a besoin.

\section{Quelle place doit occuper l'orge dans la rotation?}

La même place que le blé. Comme les mauvaises herbes ou les plantes adventices lui sont plus nuisibles qu'à toutes les autres céréales, c'est après une récolte sarclée qu'elle réussit le mieux.

Quels sont les engrais qui conviennent le mieux d l'orge?

L'orge absorbe plus de substances minérales,--telles que la potasse, la chaux, la magnésie, l'acide phosphorique,-que le ble ou le seigie, et pour en obtenir le plus fort rendement, il faut enrichir la terre avec des engrais contenant ces substances, c'est-à-dire les arnendements calcaires et alcalins, les engrais riches et les fumiers bien consommés. Dans plusieurs pays européens, on eraploie les engrais liquides avec beaucoup de succès.

Quelle préparation faut-il donner au sol destiné d̀ la culture de l'orge?

Plus que les autres céréales, l'orge exige une terre riche, profonde et très ameublie pour développer ses racines fines et étendues, qui atteignent jusqu'à neuf pouces de longueur. Pour satisfaire ces exigences, il faut labourer à l'automne puis donner au printemps 
sont-ils

ve pas besoin enaces, loppen dont uvaises aisibles récolte

'orge?

-telles hosphole plus engrais lements ers bien on erncès.

a la cul-

he terre per ses 'à neuf nces, il intemps plusieurs hersages, de manière à ce que le sol, au moment où la semence lui est confiée, soit aussi meuble qu'un terreau de jardin.

Comment dépose-t-on et recouvre-t-on la semence de l'orge?

De la même manière que celle du blé ot à la même profondeur, c'est-à-dire à deux pouces et demi et même trois pouces.

Quelle quantité de semence faut-il mottre d l'arpent?

Cela dépend de la qualité du sol et de la façon dont le semis est fait. Dans une bonne terre bien préparée, on sème $2 \frac{1}{2}$ minots d'orge à deux rangs et $2 \frac{1}{4}$ minots d'orge ordinaire, quand on opère le semis avec le semoir en lignsz. Quand on sème à la volée, pour enterrer avec la herse, le cultivateur ou la charrue, il faut mettre 23 minots d'orge à deux rangs et 21 minots d'orge ordinaire. Quand la terre est mal préparée et la saison avancée, il faut mettre un demi-minot de plus.

Quels soins d'entretien faut-il donner à l'orge?

Les mêmes qu'au blé. L'orge souffre plus que les autres céréales de la présence de plantes adventices et il faut l'en débarrasser à tout prix pour avoir une bonne récolte.

Comment se fait la moisson de l'orge?

De la même manière que celle du blé, avec cette différence qu'il faut laisser mûrir complétement l'orge destinée à la brasserie. Celle que l'on récolte pour la consommation ordinaire doit être coupée dès que l'épi commence à faire le crochet et avant que la paille blaıchisse. 
Quelles précautions faut-il observer dans le battage de l'orge destinée d la brasserie?

Il faut avoir soin de baisser un peu plus le contrebatteur, pour ne pas casser le corps et surtout la pointe du grain, ce qui l'endommage pour le maltage et en diminue la valeur.

\section{\& 4-De l'avoine}

Distingue-t-on plusieurs espèces d'avoine?

Oui: il y a l'avoine blanche et l'avoine noire, qui se subdivisent en plusieurs variétés.

Quelles sont les principales variétés d'avoine blanche?

Les principales variétés d'avoine blanche sont:

1. L'avoine patate, une des plus belles variétés hâtives tant pour la qualité que pour la quantité de son produit. Elle donne un grain blanc, court et renfle, quand elle est bien cultivée. Sa paille est jaune pâle et peu volumineuss. Elle talle beaucoup quand elle n'est pas semée trop fort et ses tiges rapprochées portent de gros épis touffus. Son grain pèse de 36 à 48 livres le minot et donne plus de farine que n'importe quelle autre espèce d'avoine. Comme elle s'égrène beaucoup quand elle est mûre, il faut la couper de bonne heure;

2. L'avoine Hopetown, qui, dans une bonne terre bien cultivée réussit mieux que l'avoine patate, forme une paille plus forte et verse moins,; 
3. L'avoine de Sandy, au grain glace, compact et si dur qu'il faut l'ecraser pour le donner aux chevaux. Elle réussit bien dans les sols mous et spongieux, ne verse pas;

4. L'avoine Sheriff, écossaisse. la plus hâtive de toutes les avoines blanches, et par conséquent, la mieux appropriée aux régions où la saison agricole est courte;

5. L'avoine blanche de Tartarie, courte, talle bien, ne verse pas, produit beaucoup, mais múrit une dizaine de jours plus tard que l'avoine noire de Tartarie ;

6. L'avoine de Géorgie ou de Sibérie, vigoureuse, a grains jaunatires, gros, pesants et durs, que les vieux chevaux mangent difficilement, une des variétés les plus précoces;

7. L'avoine de Hongrie ou a grappes, tardive, mais rustique, robuste, très productive en paille et en grain, qui est maigre, léger et de qualité médiocre ;

8. L'avoine American Banner, variété nouvelle, extrêmement productive, rendant jusqu'à cent minots a l'acre, très précoce, pesant de 36 à 45 livres le minot. Le grain de cette avoine est blanc, gros et compacte; la paille est raide, peu exposée à la verse et porte un long épi symétrique;

9. L'avoine Wide awake, autre variété nòuvelle, remarquable par la qualité et la quantité de son pro. duit, qui varie de 65 à 125 minots à l'acre dans les bonnes terres ; rustique et vigoureuse, atteignant une hauteur de quatre à cinq pieds, donnant un grain renflé et bien rempli ;

10. L'avoine anglaise blanche hative ou Canadian triumph, à la paille longue et forte, portant des épis 
compactes, rempli de grains renflés, durs et courts, pesant de 48 a 50 livres le minot. Cette variete est très hative, marissant de dix à quinze jours avant les varietés ordinaires, ce qui la rend particulièrement propre aux localités où les gelées précoces sont à craindre.

Quelles sont les principales variêtés d'avoine noire?

Ce sont l'avoine noire de Hongrie et surtout celle de Tartarie, qui est bien supérieure à l'autre.

Seme-t-on beaucoup d'avoine noire dans notre province?

C'est à peu d'exceptions près la seule variété qui se cultive dans les comtés de Bonaventure et Gaspé. Le sénateur Cochrane l'a aussi introduite dans Compton ; mais ailleurs, on la cultive peu ou point, sous le prétex te que les chevaux refusent de la manger.

Ce prejugé est-il bien fondé?

Non, puisque les chevaux de la Gaspésie n'en mangent pas d'autre et que ceux de M. Cochrane, un des plus grands éleveure de l'Amérique, l'ont aussi mangée avec avidité.

L'avoine noire constitue-t-elle un bon aliment pour les chevaux?

Elle est supérieure, sous ce rapport, à l'avoine blanche ; elle est pour le moins aussi nutritive et plus excitante, ce qui la fait particulièrement rechercher en Angleterre par les meilleurs entraîneurs de chevaux de course. Dans la Gaspésie, où elle est pourtant cultivée avec peu de soin, elle pèse, en moyenne, plus de 40 livres le minot. 
courts, t́te est ant les rement crain-

elle de

ovince?

qui se pé. Le npton ; rétexte

in manun des mangée

rles che-

ne blanus excien An$\operatorname{raux}$ de cultivée as de 40

Pourquoi la cultive-t-on de préférence d̀ l'avoine blanche dans la Gaspésie?

Parce qu'on la trouve plus rustique, plus précoce et plus productive que l'avoine blanche commune.

Comment prépare-ton l'avoine pour la semence?

Comme le blé, quand on veut avoir une bonne récolte.

Quel est le climat qui convient le mieux à l'avoine?

Grâce à la rapidité de sa végétation, l'avoine peut être cultivee dans presque tous les climats, bien qu'elle soit sensible au froid ; mais elle souffre de la sécheresse et préfère un climat un peu humide, ce qui explique pourquoi elle réussit ai bien en Angleterre et pourquoi l'on dit que sa réussite dépend plus du temps que de la terre.

Quels sont les sols qui conviennent le mieux d l'avoine?

Ce sont les terrains d'alluvion qui forment les vallées des rivières. Toutes les alluvions formées de matières où la glaise n'est pas en trop grande quantité produisent invariablement d'excellentes récoltes d'avoine de toutes les variétés.

Dans quelles conditions l'avoine réussit-elle le mieux dans les terrains glaiseux?

Quand on la sème sur un relevé de trèfle ou d'autres herbes fourragères. En ouvrant la terre et la rendant plus friable, les racines du trè̀le et des autres herbes l'empêchent de se durcir, ce qui favorise le dévoloppe. ment des tendres radicelles de l'avoine.

L'avoine réussit-elle dans les sables légers ou les sols trop calcaires?

Non: ce sont les terres qui lui conviennent le moins. 
L'avoine cultivée dans un sable sec a la balle dure et sèche, ne donne qu'un grain peu farineux; dans un terrain calcaire et pauvre, son grain est pus farineux, mais plus petit.

\section{L'avoine pousse-t-elle dans les sols iurbeux?}

Oui, pourvu que le sous-sol ne soit pas formé par ce composé de glaise, de sable et d'oxide de fer que les $\mathrm{An}$. glais appellent hard-pan et que l'on désigne en français sous le nom de tuf.

\section{Quelle place faut-il donner à l'avoine dans la rotation?}

L'avoine peut succéder à toutes les récoltes, venir au commencement ou à la fin d'une rotation; mais c'est ordinairement sur un defrichement de paturage ou de prairie qu'elle donne le meilleur produit. Quand elle vient a la fin de la rotation, elle ne prospère qu'en proportion de l'engrais laissé dans la terre par les récoltes précédentes. Quand elle vient après le blé ou l'orge, qui ont favorise la multiplication des plantes adventices, elle ne donne souvent que de faibles récoltes.

Quels sont les engrais qui conviennent le mieux a l'avoine?

Ceux qui contiennent beaucoup de silice, de chaux, de potasse et de phosphore, ce qui explique pourquoi elle réussit si bien dans les terres neuves ou récemment déboisées.

Quelle préparation faut-il donner au sol destiné à l'avoine?

Pour avoir une bonne récolte d'avoine, il faut préparer la terre avec autant de soin que pour la culture du blé, l'assainir, l'ameublir aussi profondément que possible et détruire toutes les mauvaises herbes. 
ure et un termais

par ce les $A n$ rançais

tion?

enir au is c'est ou de nd elle en prorécoltes l'orge, dventi8.

avoine? chaux, jurquoi mment

avoine? prépature du e possi.
Prend.on généralement toutes ces précautions pour cultiver l'avoine?

Non, ce qui explique pourquoi on n'obtient que de chétives récoltes, de vingt à trente minots à l'arpent, quand avec un peu plus de soin il serait facile de doubler et même de tripler ces chiffres.

Comment sème-t-on l'avoine?

Comme les autres céréales-à la volée, ou en lignes avec le semoir, ce qui est infiniment preférable, attendu que le grain vient bien plus beau et murit bien plus également.

Est.il bien important d'enterrer profondément les semis d'avoine?

Cela est de la plus grande importance pour protéger l'avoine contre la sécheresse, qui lui est particulièrement nuisible. Quand on n'emploie pas le semoir en lignes, déposant la semence à la profondeur voulue, la meilleure méthode est de bien ameublir la terre par le hersage, de semer sur ce hersage et d'enterrer la semence avec le cultivateur. Quand le sol est bien meuble, comme dans les terres sablonneuses ou de savane, on peut semer sous raie, c'est-à-dire enterrer la semence avec la charrue. Dans tous les cas, on finit l'opération par un roulage.

A quelle époque faut-il semer l'avoine?

Invariablement aussitôt que possible et jamais après la mi-juin, pour avoir une bonne récolte.

Quelle quantité de semence faut-il mettre à l'arpent?

Deux minots et demi ou trois minots, quand on sème de bonne heure, et quatre minots ou plus quand on 
sdme tard, vu que dans ce cas, la sécheresse empeche l'avoine de taller autant. En Ecosse, ou la culture de l'avoine réussit à perfection, on sème jusqu'd six et sept minots d l'acre.

Quels soins d'entretien faut-il donner d l'avoine $\$$

Dans la bonne culture, on lui donne les memes soins qu'au ble.

Comment se fait la moisson de l'avoine?

On opère généralement d'une façon bien différente; mais pour bien faire, il faut moissonner l'avcine de la même manière que le ble, pour ne pas perdre une partie de la récolte, qui autrement s'egrène sur le champ.

Quelle précaution faut-il prendre pour ramasser l'avoine quand on la coupe d la faux ou d̀ la faucheuse?

Il faut éviter l'usage du râteau à cheval, qui l'égrènerait beaucoup, et la ramasser d la fourche, en ayant la précaution de la secouer le moins possible. Il est bon d'observer les mêmes précautions pour la mettre dans la charrette, lors de l'engrangement.

Faut-il attendre que l'avoine soit bien mûr pour la cons per?

Au contraire, il faut la couper quand elle est encore verdâtre, sans quoi il s'en égrènerait une bonne partie dans les manipulations de la moisson. On ne laisse mârir complètement que l'avoine destinée à fair grain de semence. 


\section{5-Du sarrasin}

\section{Connait-on plusicurs variétés de sarrasin?}

Il n'y en a que deux variétés: le sarrasin noir, ou sarrasin ordinaire, et le sarrasin de Tartarie, vulgairement appelé petit sarrasin, sarrasin jaune ou sarrasin sauvage.

Quels sont les traits caractéristiques du sarrasin jaune?

Ses graines sont rugueuses, munies de dents sur leurs angles, moins lisses, plus dures et plus petites que celles du sarrasin noir. Au lieu d'être blanches, comme celles de l'autre espèce, les fleurs du sarrasin jaune sont verdatres, les tiges sont moins rouges et plus ramifiées. Ses graines, quand elles sont mâres, se détachent encore plus facilement que celles du sarrasin noir.

Quels sont, comparativement d̀ l'espèce noire, les qualités et les défauts du sarrasin jaune?

Le sarrasin jaune est plus rustique, plus vigoureux, plus précoce et plus productif que le noir; il réussit dans des conditions où le sarrasin noir serait arrêté ou tué par le froid; mais il s'egrène plus que l'autre, donne un produit moins estimé, un grain plus dur, plus difficile a moudre, une farine plus brune, plus amère et qui fermente moins bien.

Faut-il apporter quelques précautions particulières dans le choix et la préparation de la semence du sarrasin?

Aucune. Le sarrasin n'étant exposé à aucune maladie provenant de sa graine, il suffit de choisir pour la semence du grain bien mûr et bien formé.

Quel est le climat qui convient au sarrasin?

Le sarrasin est très sensible aux influences atmosphé. 
riques; la sécheresse, la chaleur excessive, les vents froids, les gelées blanches lui sont nuisibles et même fatales; mais la rapidité de sa végétation lui fait surmonter presque tout cela et permet de le cultiver partout où les autres céréales réussissent, même dans les endroits dont elles sont exclues par les basses températures du printemps et de l'automne.

Quel est le sol qui con: vierst au sarrasin?

Pourvu qu'ils soient meubles, bien égouttés et pas trop riches en engrais, le sarrasin s'accommode de tous les sols, même des sables légers et granitiques, ainsi que des terrains calcaires. Ce sont les terres argileuses et humides qui lui conviennent le moins.

Quelle place faut-il assigner au sarrasin dans la rotaticn?

Le sarrasin n'a pas de place particulière dans la rotation; dans la bonne culture, il est surtout employé comme plante intercalaire, nettoyante ou améliorante. Quand on s'aperçoit qu'une autre céréale va manquer, on laboure ce terrain et on l'ensemence en sarrasin qui, grâce à sı rapidiť́ de végétation, a encore chance de mûrir. On sème aussi le sarrasin, qui est une plante étouffante, pour débarrasser des mauvaises herbes un terrain qui en est infesté. Enfin, on sème souvent le sarrasin pour l'enfouir en vert comme engrais.

Quels sont les engrais qui convionnent au sarrasin?

Le grain et la paille du sarrasin contiennent une bonne proportion de chaux, de magnésie, de potasse et d'acide phosphorique; quand la terre dans laquelle on le cultive ne renferme pas de ces substances en assez grarcie quantité, il faut, pour obtenir le plus fort rendement, y remédier au moyen des engrais. 
8 vents même ait surrer parans les impéra-

et pas de tous 3, ainsi rileuses

taticn? ans la nployé orante. anquer, in qui, nce de plante bes un vent le

ae bonasse et elle on a assez rende-

\section{Quel effet produit l'excès d'engrais?}

Dans le terrain ensemencé en sarrasin, l'excès de fumier rend la plante feuillée, vigoureuse, retarde la maturité et compromet ainsi la récolte.

Quelle préparation exige le sol destiné au sarrasin?

Un ameublissement parfait, ce qui est la condition essentielle du plein succès de cette culture.

Comment sème-t.un le sarrasin?

On le sème généralement à la volée et l'on recouvre la semence d'un coup de herse.

Quelle quantité de semence faut-il mettre d l'arpent?

Quand on cultive le sarrasin pour la récolte du grain, on sème un demi-minot à l'arjent. Comme cette plante se ramifie beaucoup et qu'il lui faut beancoup d'air pour mûrir, on compromet la récolte eri semant trop dru. Quand on cultive pour le fourrage ou l'enfouissage en vert, il faut semer plus fort.

A quelle époque faut-il semer le sarrasin?

Au printemps, dès que $\mathrm{J}_{\mathbf{a}}$ terre est bien sèche. On peut attendre jusqu'à la fin de juin et même plus tard quand on n'a pas à craindre les gelées hâtives.

Quels soins d'entretien faut-il donner au sarrasin?

Aucurn : la rapidité de sa croissance le protège contre les mauvaises herbes. qu'il étouffe, ce qui fait qu'on le cultive souvent pour nettoyer un terrain infesté de plantes adventices.

A quelle époque faut-il récolter le sarrasin?

Comme il est très sujet à s'égrener, le sarrasin doit 
être récolte avant la maturité complète, dès que les graines inférieures sont mares, sans quoi il se produit indéfiniment sur la mê:ne tige de nouvelles fleurs et de nouvelles graines, lorsque le temps est favorable. Les grains de la tête, qui sont encore verts, finissent de márir après la moisson.

Comment coupe-t-on le sarrasin?

A la faucille, à la faux ou à la moissonneuse.

Quelle est la meilleure de ces trois méthodes?

C'est la coupe ì la faucille; mais comme cette opération est longue et fatiguante, on peut, sans inconvénient, la remplacer par la coupe à la moissonneuse.

La coupe à la faux présente-t-elle quelques inconvénients?

Oui : la secousse que lá faux imprime à la tige fait tomber une partie des graines et il s'en perd encore plus dans les manipulations qu'il faut opérer pour ramasser la récolte ainsi coupée.

Quel temps faut-il choisir pour abattre le sarrasin?

Le matin, à la rosée, ou après un orage, lorsque les capsules qui renferment le grain sont fermées par l'humidité, ce qui empêche l'égrenage.

Laisse-t-on le sarrasin en javelles sur le champ?

Non, car cela l'exposerait à chauffer plutôt qu'à sécher. Dès qu'il est abattu, on le met en petites gerbes que l'on dispose en faisceaux, la graine en haut, en les réunissant par douze ou quinze et les écartant du pied, pour faciliter la circulation de l'air. On laisse ainsi ces gerbes sur le champ une quinzaine de jours pour que le grain achève de marir. 
ue les roduit $s$ et de Les le mú-

opéraénient,

iients? ge fait encore pour

ue les r l'hu-

t qu'à es gerıut, en int $d u$ laisse jours

La pluie ne peut-elle pas endommager le sarrasin ainsi laissé sur le champ?

Au contraire, elle ne peut que lui faire du bien, en hatant la maturation du grain.

Quelles précautions prennent les cultivateurs soigneux pour charroyer le sarrasin?

Ils couvrent le fond de la voiture de toile ou de vieux draps, pour empêcher de se perdre les graines qui se détachent des tiges.

Est-il prudent de laisser le sarrasin en tasserie?

Non: il est à peu près impossible de dessécher complètement les tiges de sarrasin, qui conservent toujours de l'humidité, capable de causer dans la masse du fourrage une fermentation susceptible de tout gâter. Pour prévenir ce danger, on bat le sarrasin au moment même de l'engrangement ou peu de temps après.

Comment bat-on le sarrasin?

Au fléau ou à la batteuse, qu'il faut avoir soin de desserrer, pour ne pas casser ou ecraser les graines entre les dents.

Le sarrasin est-il un grain bien utile?

Il sert à la nourriture de l'homme et plusieurs agronomes le recommandent pour les chevaux, en mélange avec l'avoine. Il est bon pour engraisser certains animaux, surtout les porcs, et excellent pour nourrir les poules, qu'il fait pondre de bonne heure.

Quel est le meilleur emploi de la paille de sarrasin?

En litière, vu qu'elle est très absorbante et très fertilisante. 
Est-il prudent de faire consommer le sarrasin en vert?

Non, car il a le grave inconvénient de produire souvent un gonflement de la tête chez les animaux qui s'en nourrissent. La peau se gonfle, les oreilles, les paupières, les joues deviennent œdémateuses ou remplies de tumeurs molles et blanchatres; les yeux sont presque fermés et les oreilles pendantes. Ces accidents, rarement graves, disparaissent dès qu'on change la nourriture des animaux.

\section{6-Des pois}

Distingue-t-on plusieurs especces de pois?

On en distingue deux espèces: le pois cuitivé ou pois des jardins et le pois gris, ou pois des champs, qui est l'objet de la culture en grand. Dans cette dernière espèce, il y a des variétés hâtives et d'autres tardives.

Le choix des pois de semence exige-t-il quelque soin particulier?

Il y a beaucoup de pois qui sont percés d'un petit trou, causé par la larve d'un insecte, ce qui leur fait perdre la faculté de germer; il faut naturellement les mettre de côté. Quant, au reste, les pois conservent leur faculté germinative durant plusieurs années, et l'on peut sans inconvénient choisir pour la semence des pois récoltés depi i une couple d'années.

Quel climat demandent les pois?

Ils aiment un climat tempéré, plutôt sec qu'humide et ils réussissent dans toutes les parties de notre pays, quand ils sont bien cultivés. 


\section{Quels sont les sols qui conviennent aux pois?}

ouvent ui s'en es paumplies it prescidents, inge la

ou pois qui est dernière tardives. in partiun petit eur fait nent les hservent nées, et ence des

humide re pays,

Les terres à blé et surtout les sols de consistance moyenne et un peu argileux, de préférence aux terres légères.

\section{Quelle place doivent occuper les pois dans la rotation?}

Ils peuvent succéder à toutes les autres plantes, excepté à eux-mêmes; le même terrain ne doit êtro ensemencé en pois qu'à de longs intervalles, huit ou dix ans. Quand on les sème en lignes, comme en Angleterre, ils peuvent prendre la place d'une culture sarclée, pour nettoyer la terre, et venir avant une céréale.

Quels sont les engrais qui convienneni aux pois?

Ce sont les fumiers consumés et, parmi les substances minérales, la marne et la chaux, qui sont indispensables à la réussite des pois et qu'il faut ajouter, quand la terre n'en renferme pas assez. Quand on emploie du fumier long et pailleux, il vaut mieux le mettre en couverture, ce qui protège aussi les jeunes plantes contre les premières sécheresses, qui leur sont très nuisibles.

Quelle préparation faut-il donner au sol?

Les pois demandent un sol profondément ameubli, mais bien rassi, ce qu'on leur procure au moyen d'un fort labour d'automne, surtout dans les terres compactes. Dans une terre trop compacte, ils ne fleurissent presque pas; dans les terres humides, il se forme beaucoup de fleurs, mais elles tombent sans former de gousses; dans les terres trop grasses, enriçhies avec du fumier frais, les tiges viennent longues et grosses, mais ne produisent presque pas de fleurs et de grain. 
Comment sèmet-on les pois?

A la volée ou en lignes. Ce dernier mode est de rigueur pour le pois cultivé ou des jardins.

Comment se font les semis en ligne?

On herse le guéret pour empêcher la semence de s'éparpiller entre les crêtes des tranches de terre; on dépose la semence avec un semoir à maïs, en laissant un espace d'un pied ou d'un pied et demi entre les rangs, puis on refend les raies à la charrue pour recouvirir la semence et une dizaine de jours après, on donne un hersage en travers, afin d'unir le terrain pour le binage.

Comment enterre-t-on les semis d la volée?

A la herse, quand on sème sur labour, au cultivateur ou à la charrue, quand on cultive sous raie, ce qui est la meilleure méthode. Pour bien réussir, il faut que la semence soit enterrée à trois ou quatre pouces de profondeur.

Quelle quantité de semence faut-il mettre d̀ l'arpent?

Un minot au plus, dans les semis en lignes et un minot et quart à deux minots, quand on sème à la volée. Quand les pois sont semés trop dur, le bas des tiges ne forme pas de gousses.

A quelle époque faut-il semer les pois?

Aussi de bonne heure que possible, afin qu'ils puissent entrer en pleine végétation avant la sécheresse, qui leur est très nuisible.

Quels soins d'entretien exigent les pois?

Dans les semis en lignes, il faut donner plusieurs 
binages à la houe à cheval, pour empêcher le durcissement du sol et la croissance des mauvaises herbes. Dans les semis à la volée, il suffit de donner un coup de herse quand les germes commencent à sortir de terre.

Comment moissonne-t-on les pois?

ance de

rre; on laissant ntre les r recoua donne ar le bi-

tivateur qui est at que la de pro-

\section{nt?}

t un mia volée. tiges ne

ils puisresse, qui

plusieurs

On les arrache, ou ce qui est bien mieux, on les coupe à la faux, en prenant bien soin de les secouer le moins possible et de les enrouler en petites veillotes. On les laisse ainsi sécher au soleil, on les ramasse en tas pour les engranger, en ayant soin, dans toutes ces manipulations, de les égrener le moins possible.

Quand faut-il couper les pois?

$\mathrm{Au}$ moment où les gousses du bas des tiges sont mures, sans s'occuper qu'il y ait encore des fleurs ou des gousses un peu vertes dans la tête.

Comment bat-on les pois?

Au fléau. On fait quelquefois cette opération à la batteuse, ce qui a pour inconvénient de casser une partie des grains et de diminuer la valeur de la récolte.

\section{\& 7-Des fèves}

La fève est-elle une plante bien utile?

C'est une des plantes les plus utiles en agriculture. Elle donne des fourrages salubres et abondants, n'épuise pas le sol, le nettoie des mauvaises herbes, par les sarclages qu'elle exige si on la sème en lignes, et par 
l'ombre qu'elle produit, quand elle est semée à la volée. Toniques et même fortifiantes, les fèves donnent de la vigueur aux animaux; pour les chevaux, elles sont plus nourrissantes que l'avoine et c'est à elles que le pur-sang anglais doit beaucoup de sa force musculaire. Chez les bêtes à l'engrais, notamment les bœufs et les moutons, elles produisent des chairs fermes, savoureuses et de la bonne graisse.

$Y$ a-t-il plusieurs espèces de fêves?

Il y en a une foule de variétés, qui se divisent en deux groupes principaux: la féverole ou fève d cheval, la grosse fève ou fève des marais, moins rustique et moins productive que l'autre espèce.

Quel est le sol qui convient aux fèves?

Tous les sols moyens conviennent aux fèves; mais cette plante aime les terres frâ̂ches, surtout la fève des marais. Elles réussissent bien dans les terres à blé et donnent d'excellents produits dans les terrains argileux, compactes, qu'elles ameublissent.

Quelle place doivent occuper les fèves dans la rotation?

Elles précèdent les céréales et réussissent très bien sur un guéret de prairie ou de pâturage, qu'elles préparent admirablement à la culture du blé et de l'orge. Les fèves peuvent se succérer, sans inconvénient, dans le même sol, quand on lui donne l'engrais voulu, et la culture de la féverole est considérée comme améliorante, à raison des composés azotés qu'elle puise dans l'atmosphère et qu'elle assimile.

Quels sont les meilleurs engrais pour les fèves?

Ce sont les engrais pulvérulents, riches en phosphates 
a volée. t de la es sont que le culaire. is et les savou-

sent en heval, la $t$ moins

s ; mais fève des à blé et argileux,

tion?

rès bien es prépaprge. Les dans le et la culliorante, l'atmos- et potasse, notamment la superphosphate de chaux, le noir animalise, les cendres et le fumier d'étable.

Quelle préparation faut-il donner au sol?

Pour bien réussir dans la culture des fèves, il faut donner deux labours au sol qu'on leur destine-un labour profond à l'automne et un autre au printemps, au moment de semer. On peut cependant se contenter d'un seul guéret quand on sème sur un gazon rompu et dans une terre pas trop compacte.

Comment sème-t-on les fèves?

A la volée et encore bien mieux en lignes, comme les pois, sous raie ou sur labour, mais en ayant bien soin d'enterrer les semis à trois ou quatre pouces, ce qui est essentiel au succès.

A quelle époque faut-il semer les tèves?

Aussi de bonne heure que possible, sans quoi elles seraient exposés a être détruites par la sécheresse.

Quelle quantité de semence faut-il employer?

En Angleterre, où l'on donne un soin particulier à cette culture, on met de deux à deux minots et demi à l'acre.

Quels soins d'entretien faut-il donner aux fèves?

Les mêmes qu'aux pois. Des hersages, huit ou dix jours après l'ensemencement, détruisent les mauvaises herbes, aèrent le sol et favorisent l'accroissement de la jeune plante, qui ne souffre pas de ce hersage. Plus tard, on donne dans le même but des façons à la houe à cheval et en dernier lieu, on pratique l'écimage. 


\section{Qu'est-ce que l'écimage?}

Après que les cosses ont commencé à se former sur la partie inférieure des tiges de fève,il se produit au sommet de nouvelles fleurs qui, n'ayant pas eu le temps de marir, ne font que nuire aux autres, qu'elles privent d'une partio de l'alimentation fournie par la tige, en meme temps qu'elles servent de réceptacle aux puceróns, les pires ennemis de la féverole. Pour prévenir tous ces inconvénients, on coupe le sommet des tiges et cette operation s'appelle écimage.

Comment moissonne-t-on les fèves?

On les coupe à la faux, quand elles sont semées a la volée, et a la faucille, quand le semis a éte fait en lignes. Quand on coupe a la faux, on laisse durant quelques jours les tiges en andair , après quoi on les met en javelles pour achever la dessiccation puis on les engerbe pour les entrer. Quand on les coupe a la faucille, on laisse aussi javeler quelques jours et l'on forme ensuite des petites gerbes qu'on laisse debout sur le champ, pour achever la dessiccation.

Comment bat-on les fèves?

Au fléau, comme les pois.

\section{8-De la lentille ct de la vesce}

Comment cultive-t-on la lentille et la vesce?

Comme les pois. On sème à la volée, avec un simple labour et l'on enterre à la herse. Ces légumineuses 
demandent le même sol et les mêmes erigrais que les pois, sauf les vesces, qui exigent une terre plus consistante et plus fraîche.

\section{9-Du mais ou ble d'Inde}

$Y$ a-ti-il plusieurs espèces de maïs?

Non, il n'y en a qu'une espèce; mais par la culture et la sélection, on en a formé un nombre infini de va. riétés.

Quelles sont les variétés les mieux adaptées à notre pays?

Ce sont le maïs jaune et le maïs blanc du Canada, qui sont hâtifs, rustiques et s'accommodent bien de notre climat.

Faut-il observer quelques précautions dans le choix de la semence?

Il faut choisir des grains bien mniris et bien formés. Certains praticiens préfèrent les grains des extrémités de l'êpi, d'autres préfèrent ceux du milieu.

Est-il bon de faire subir quelque préparation à la semence?

Il est bon de la mettre dans de l'eau tiède, que l'on tient exposée aux rayons du soleil, ce qui amollit l'écorce du grain et hâte la germination. Pour empêcher les oiseaux, surtout les corneilles, de manger le semis, on le fait tremper une douzaine d'heures dans de l'eau goudronnée, puis on le saupoudre de plattre, de chaux et de cendre.

n simple nineuses 
Quel est le climat qui convient au maïs?

Le maïs est une plante tropicale et qui a besoin d'une grande chaleur pour accomplir sa végétation. Cependant elle réussit dans les régions du norả, même par un été frais et pluvieux, pourvu qu'elle ait une couple de semaines de chaleur en juin et au commencement de juillet, puis un automne tardif, avec du temps chaud a l'époque de la maturation.

Les changements de température sont.ils nuisibles au maïs?

Durant sa période de croissance, le maïs ne peut pas supporter une température moyenne au-dessous de $65^{\circ}$; mais, du moment que l'excès de chaleur du haut du jour donne cette moyenne, peu importe que la température soit plus basse le soir et le matin.

Quels sont les sols qui conviennent au maïs?

Le maïs pousse dans tous les sols, pourvu qu'ils ne soient pas mouillés, et il réussit dans les terres fortes comme dans les terrains légers; mais il préfère un sol de consistance moyenne, fertile, profond, ameubli et bien assaini. Il réussit admirablement dans les terraine drainés.

Quelle place occupe le maïs dans la rotation?

Par les façons et les fumures qu'il exige, le maïs entre dans la catégorie des cultures sarclées et a sa place au début de la rotation, pour préparer la terre pour le blé et les autres céréales. Il succède aussi, sans inconvénient, à la plupart des autres récoltes, au blé, à l'orge et même aux pois. 
Quels sont les engrais qui conviennent le mieux au maïs?

nd'une Cepenpar un uple de uent de haud a

ibles au

eut pas de $65^{\circ}$; laut du mpéra-

u'ils ne fortes e un sol eubli et terraing

le maïs sa place pour le s inconà l'orge

Le maïs contient beaucoup de chaux, de magnésie, de silice, de potasse et de soude, qu'il faut lui fournir au moyen des silicates et les sulfates alcalins, des cen. dres de bois et du fumier, quand la terre manque de ces substances.

Quelle précaution faut-il observer dans l'emploi du fumier de ferme?

Il faut éviter s'emploi des fumiers verts et longs, surtout dans les terrains légers, et n'employer que des fumiers bien décomposés.

Pourquoi faut-il éviter les fumiers verts et longs?

Parce qu'en désagrégeant la terre, ces fumiers neutralisent l'action de la capillarite, empêchent l'humidité de remonter à la surface du sol, qui est trop chauffée par le soleil, c'est-à-dire la partie du sol où le maïs puise tous les aliments nécessaires à sa vegétation.

Est-il une circonstance oì l'on peut avantageusement employer le fumier vert et long pour engraisser la terre d̀ maïs?

Oui, quand on sème le blé d'Inde sur un relevé de prairie ou de pâturage, dans un sol glaiseux et compacte, que le fumier long désagrège et rend moins compacte. On enterre ce fumier par un labour d'automne. En se décomposant dans le sol, le fumier ouvre celui-ci, le réchauffe, le rend plus friable et plus meuble.

Comment s'emploient les récoltes enfouies?

De la même façon que les fumiers longs, en les enterrant par un labour d'automne. 
Les récoltes dérobées ou enfouies en vert sont-elles bien employées pour fumer les terrains à maïs?

Oui, surtout aux Etats-Unis, où l'on emploie à cette fin le trèfle, le saigle, le sarrasin et le millet ou mohu de Hongrie.

\section{Quels avantages présente le millet?}

Comine cette plante, qui est riche en azote, parcourt toutes les phases de sa végétation en huit semaines, on peut la semer vers la fin d'aont, après une récolte hâtive de pcmmes de terre ou de grain et l'enfouir vers la fin d'octobre, précisément dans le temps où le millet sera dans les meilleures conditions pour fournir un excellent engrais.

Comment faut-ii préparer la terre pour la culture $d u$ maïs?

Le blé d'Inde ne réussit bien que dans un terrain rassis, mais parfaitement ameubli, ce qui s'obtient, dans les terres fories, par un labour d'artomne et des hersages énergiques au printemps suivant. Les herses à disqücss sont les mieu:: appropriées à cẹtte fin. Dans les terres légères, ou df consistanc? moyenne, on pent labourer au printemps, mais il faut lierser le guéret i mestis a qu'il est fait, pour empêcher la formation des mottas.

$Y$ a-t-il des instruments spécialement adaptées à la préparation de la terre destinée au maïs?

Oui, nctamment le pulvérisnteur de Tower (fig. 44, pago 124). Cet appareil a l'avant nuni d'une série de lames qui émiettent la terre, d'une pièce transversale qui l'écrase et l'unit. et il a à l'arrière une espèce do peigne 
qui achève de pulvériser le sol et lui donne l'apparence d'un véritable terroir.

Est-il important que la, surface du sol soit bien unie?

C'est absolument nécessaire au succès de la récolte, pour régulariser l'action des agents atmosphériques et les façons d'entretien, qui sont indispensables.

Comment sème-t-on ie maïs ?

A la volee, en fosses ou en lignes.

Comment se fait le semis a la volée?

Abeolument comme celui des céréales et l'on enterre la semence par un hersage.

Cette méthode est-elle recommandable?

$\mathrm{Au}$ contraire, elle eft condamnable à tous les points de vue, notamment parce qu'elle rend impossible les soins d'entretien, principalement les binages, qui sont absoiument nécessaires au blé d'Inde. Même qrand on cultive le maïs pour lo fourrage, il produit beaucoup plus lorsqu'on le sème à la fosse ou en lignes.

Comment se fait le semis d la fosse ou en poquets?

On ouvre des sillons avec le buttoir ou la charrue dans le sens longitudinal is terrain, en ayant soin d'espacer ces sillons de trois picus ou trois pieds et demi, selen l'espace qu'on veut laisser entre les rangs; on ouvre ensuite d'autres sillons transversalement aux premiers et pareillement espacés, ce qui divise le champ en carrés, comme un damier; à tcus les points d'intersection des lignes, on dépose quatre ou cinq grains de semence, que l'on recouvre en passant sur le terrain une herse renversée.

fig. 44 , ŕrie de ale qui peigne 
$Y$ a-t-il des appareils spéciaux pour faire les semis en poquets?

Oui, notamment ceux de Haworth, de Deuscher et de plusieurs autres fabricants américains. Ces instruments, qui sèment deux rangs à la fois, creusent le sillon, déposent la semence à des intervalles absolument réguliers et la recouvrent du même coup. Avec cet appareil, traîné par deux chevaux, un homme peut ensemencer cinq ou six arpents par jour.

Comment se fait le semis en lignes et quels appareils emploie-t-on à cetite fin?

Comme celui du blé et des autres céréales. On emploie à cette fin des semoirs qui ne déposent qu'un seul grain à la fois et se règlent de façon à laisser entre les grains, dans un même rang, l'espace désiré. Ces appareils ereusent le sillon, déposent et recouvrent la semence d'une seule opération. Quelques-uns, tels que l'Aspinuall, sont organisés pour déposer des engrais pulvérulents avec le semis.

Quel espace faut-il laisser entre les rangs et entre les grains de semis?

Pour les petites variétés ou les petits maïs, on espace les rangs de trois pieds à trois pieds et demi et les grains d'un même rang de cinq à six pouces, quand on sème en lignes; pour les g ands maïs, on laisse de trois pieds et demi à quatre pieds entre les rangs et de huit à dix pouces entre les grains d'une même ligne.

Quel appareil emploie-t-on pour marquer l'espacement des rangs?

Les semoirs bien faits sont nunis d'un rayonneur, qui marque la trace du prochain sillon ou de la pro. 
ret de ments, sillon, tégu; appaenseils em-

On emin seul tre les appaent la els que ngrais

grains

espace grains ime en ieds et à dix

ent des

nneur, a pro- chaine ligne. Quand le semoir n'est pas muni de cet appareil, on se sert du rayonneur, c'est-à-dire d'un madrier auquel on fixe des limons, pour le faire traîner par un cheval, et des chevilles ou dents qui font sur le sol des traces indiquant la place des sillons ou des lignes.

\section{Est-il mieux de semer en poquets ou en lignes?}

Cela dépend de la nature du terrain. Dans les terrains plans, bien assainis, bien nettoyés, bien préparés, oit les mauvaises herbes ne sont pas à craindre, le semis en ligne est préférable, et des bons praticiens prétendent qu'il donne un meilleur rendement en grain ; mais lans les terrairs mal assainis, exposés à l'humidité, à surface rugueuse, où les mauvaises herbes sont à craindre, il faut adopter de préférence le semis en poquets, qui permet de donner des binages plus énergiques et de combattre plus efficacement l'envahissement des mauvaises herbes.

Quelle quantité de semience faut-il mettre à l'arpent?

Eliviron an gallon. Il faut un peu plus quand les grains sont gros et la terre riche.

A quelle profondeur faut-il enterrer la semence?

A trois pouces, au plus. Quand on sème de bonne heure, avant que le sol soit parfaitement réchauffé, ou dans une terre un peu humide, il est même prudent de ne pas semer à plus d'un pouce et demi de profondeur, sans quoi on exposerait la semence à pourrir en terre.

A quel temps faut-il semer le maïs?

Le tempz le plus propice est ordinairement la fin de mai ou le commencement de juin; cela dépend de 
l'allure de la saison et de la précocité de la variété qu'on sème. Il faut attendre que la terre soit bien réchauffee et qu'il n'y a plus à craindre la gelée. Quand on sème dans une terre encore froide ou humide, la germination retarde ou la semence pourrit. Si on sème trop tôt et qu'il survienne une gelée après que la semence est sortie de terre, il y a danger de perdre la récolte.

\section{Quels soins d'entretien faut-il donner au mais?}

Comme le blé d'Inde souffre beaucoup de la présence des mauvaises herbes ou des plantes adventices et comme il a absolument besoin d'une terre friable et perméable à la surface, pour développer ses longues racines traçantes, ii faut de toute nécessité lui donner des hersages et des binages répétés.

Quand faut-il lui donner les premières faşons?

Quatre ou cinq jours après les semailles, ou même plus tôt, si on s'aperçoit qu'elles commencent à pousser, on donne un hersage pour détruire les mauvaises herbes puis on répète le hersage quand le maïs commence à sortir de terre.

Ce hersage ne nuit-il pas aux jeunes plantes?

Sur le coup, lis jeunes plantes paraissent endommagées; mais il n'en est rien et au bout d'une couple de jours, elles reprennent vigueur et se portent à merveille.

Quels instruments empioie-t-on pour donner ces premières façons?

Une herse 'égère, comme la herse sarcleuse de Thomas, ou encore mieux la herse de Tower, qui est l'instrument par excellence pour cette opers.tion. Quand on 
emploie le pulvérisateur, on le passe diagonalement sur le champ et les rangs de semis.

Quels insiruments faut-il employer pour les façons ultérieures?

Quand le blé d'Inde a atteint trois ou quatre pouces de hauteur, il serait endommagé par la herse ou le pulvérisateur; on opère alors les binages avec la houe à cheval et les cultivateurs à lames horizontales, tels que ceux de Bradley et le cultivateur superficiel de Tower, qui est l'instrument le mieux approprié à ces binages.

Quiel inconvénient présentent les cultivateurs ordinaires?

Le maïs projette un grand nombre de racines très longues, mais traçantes et qui s'enfoncent rarement à plus de quatre ou cinq pouces dans la terre. Si les socs des instruments employés pour faire le binage pénétrent jusqu'à cette profondeur, comme c'est le cas pour la plupart des cultivateurs ordinaires, ine partie des racines est détruite par ces instruments, la tige ne s'alimente qu'imparfaitement et la récolte est compromise ou diminuse d'autant.

Les cultivateurs a lames de Bradley et de Tower ne présent-ils pas le même inconvienient?

Non. Les lames de ces instrumonts, disnosées et coupant horizontalement, rasent la terre à l'instar du rasoir sur la figure, n'ont ni socs, ni pointes qui puissent atteindre la racine; et comme leur entrure se règle automatiquoment, on peut varier l'épaisseur du binage par demi-pouces et raser extrêmement près des plantes sans toucher aucunement aux tiges.

de Thost l'insuand on

uple de à mer-

oremières 


\section{Quelle profondeur faut-il donner aux binages?}

Un pouce ou deux en commençant et augmenter jusqu'à trois pouces dans les dernières façons, alors que les racines sont plus enfoncées; mais il faut se garder a vec soin d'aller plus loin que la profondeur à laquelle le semis a été enterré.

\section{Faut-il répéter les binages bien souvent?}

Aussi souvent que les mauvaises herbes se montrent à la surface du sol. On continue ainsi tant que les tiges du ble d'Inde n'ont pas atteint quinze ou dix-huit pouces de hauteur, alors qu'elles donnent assez d'ombrage pour empêcher la croissance des mauvaises herbes et conserver au sol la fraîcheur voulue.

Comment les binages superficiels conservent.ils la fraîcheur au sol?

En ce que la terre remuée par ces binages forme une couverture absolumerit comme une couche de paille, qui ombrage le sol sous.jacent, dans lequel s'opère l'alimentation des racines, le protège contre l'ardeur $\mathrm{d} u$ soleil, sans en exclure l'air, qui y circule librement.

En quoi pêchent les binages profonds ?

Outre qu'ils détruisent une partie des racines, ils ont aussi l'inconvénient de laisser autour de celles qui ne sont pas lacérées une masse de terre égrenée qui se dessèche et nuit considérablement à la croissance de la plante.

Est-il bon de butter on rechausser le blé d'Inde?

Beaucoup de cultivateurs de notre pays suivent cette pratique, qui est universellement condamnée par les meilleurs praticiens des Etats de l'Ouest, où la culture du maïs se fait à la perfection et avec le plus grand succès. 
Que fait-on lorsqu'on s'aperçoit qu'il y a des vides dans les lignes de semis?

Quand on s'aperçoit qu'il y a des vides dars les rangs de semis, provenant ou de ce que la graine n'a pas germé ou de ce que les tigelles ont été détruites par un hersage trop énergique, on remplit ces vi ${ }^{\prime}$ os en y semant des graines d'espèce plus hative, capables d'arriver a maturité en même temps que les autres.

Comment se pratique l'écimage du mä̈s ?

Quand les soies qui se forment au bout des épis sont flétries ou fanées, on enlève les panicules des fleurs males et l'on coupe la tige au-dessus de l'épi le plus haut ainsi que les épis surabondants, s'il y en a. On coupe aussi les feuilles qui se développent à la partio inférieure de la tige et l'on donne tous ces rebuts au bétail, qui les inange avec avidité.

Quel est l'effet de l'écimage?

On prètend qu'il augmente la quantité et la qualité du grain ; mais, comme il diminue la quantité du fourrage, on ne pratique cette opération que sur le maïs destiné à la récolte du grain et non sur celui qui doit étre engilé.

Quand faut-il couper le maïs?

Il faut couper le maïs destiné a l'ensilage, au moment où le grain est en lait et se laisse difficilement rayer par l'ongle, époque a laquelle il renferme le plus de substances nutritives.

Comment coupe-t-on le mä̈s d'ensilage?

A la faucille, à la faux ou à la faucheuse et en pre18 
nant soin de ne faire cette opération que quand la plante n'est humectée ni par la rosée ni par la pluie.

Comment dispose-t on le maïs sur le chainp après l'avoir coupé?

On le met en javelles ou en fagots, à bras ou avec un grand râteau adapté à cette fin.

Combien de temps peut-on laisser le maïs d'ensilage sur le champ?

Une journée ou deux, quand le temps est sec, et le soleil peu ardent; mais quand il y a lieu de craindre le mauvais temıps ou une chaleur excessive, il est mieux de couper l'avant-midi et d'ensiler l'après-midi du même jour.

Quelle est la voiture la plus commode pour transporter le blé d'Inde au silo?

Un wagon ou chariot à roues basses, muni à l'arrière d'un madrier, sur lequel sont clouées des tringles transversales, qui forme un plan incliné permettant aux ouvriers de monter facilement avec les brassées de maïs pour les déposer sur la charge.

Quand faut-il récolter le blé d'Inde cultivé pour la récolte du grain?

Lorsque le grain est bien mûr, c'est-à-dire quand les spathes ou les feuilles qui recouvrent l'épi sont blanches, s'entrouvrent et laissent voir le grain, qui est alors dur et donne une cassure cornée, quand on l'écrase sous la dent.

Comment se fait la récolte du maïs cultivé pour le grain?

On le coupe à la faucille ou à la faux puis on le met en bottes d'environ un pied de diamètre, qu'on réunit 
quand la pluie.

rès l'avoir

d avec un

lage sur le

sec, et le craindre est mieux midi du

nsporter le

à l'arrière gles transttant aux s de maïs

la récolte

quand les ont blanii est alors crase sous

- le grain? on le met 'on réunit quatre par quatre, debout, et qu'on attache serré par la tête, puis on le laisse javeler ou sécher. Quand la des. siccation est assez avancée, on défait ces moyettes pour détacher les épis des tiges et l'on transporte le tout aux bâtiments.

\section{Peut-on suivre un autre procédé?}

Oui : on peut détacher les épis des tiges sur le champ même-ce qu'on appelle vulgairement casser le blé d'Inde-transporter les épis aux bâtiments, puis couper les tiges et les mettre en quintaux, comme le maïs coupé avec les épis.

Comment détache-t-on les épis de la tige?

Ordinairement, cette opération se fait à la main, ce qui est très long; mais depuis une couple d'années on se sert aux Etats-Unis de machines spéciales qui, d'une seule opération, séparent les épis, hachent ou écharpent les tiges, comme fait la batteuse ordinaire pour la paille des céréales. Les tiges ainsi écharpées se dessèchent mieux et prennent moitié moins d'espace dans la grange.

\section{Comment fonctionne, cette machine?}

Une première paire de rouleaux séparent les épis des tiges; les épis tombent alors entre d'autres rouleaux qui les épluchent, c'est-à-dire enlèvent les feuilles et les soies, après quoi les épis sont entraînés par un ascenseur qui les dépose dans une voiture, pour les transporter à l'endroit voulu. I.es feuilles et les tiges sont coupées par un hache-fourrage et entraînées du côté opposé par un autre ascenseur qui dépose le fourrage haché dans une autre voiture. 
Que fait-on des épis après les avoir séparés des tiges?

On les dépose dans un endroit sec, bien aéré et bien ventilé, pour les faire sécher complètement. Quand on a lieu de craindre l'humidite, on les dépouille de leurs feuilles, ce qui facilite la dessiccation. Lorsque la récolte est peu considérable, on retrousse les feuilles sans les détacher de l'épi, on les tresse et l'on suspend ces tresses aux entraits ou gur des perches, aans un grenier, ce qui est le meilleur moyen d'obtenir une dessiccation parfaite et de ne pas exposer le grain a chauffer ou moisir.

Comment égrène-t-on le maïs ?

Dans la petite culture, on l'égrène en raclant les épis sur les aretes d'une barre de fer, ou bien on le bat au fléau, en ayant soin de mettre les rangs d'épis suffisam. ment épais pour que la batte ne casse pas les grains; dans la culture plus avancée, l'égrenage se fait avec une machine spéciale, l'égreneur de maïs, ce qui est de beaucoup la meilleure méthode.

Est-il avantageux de ramasser les tiges du maïs récolté pour le grain?

Oui: ces tiges, récoltées et conservées avec le soin voulu, sont un des meilleurs fourrages qu'on puisse donner aux bêtes bovines, qui le préfèrent souvent au foin de qualité ordinaire.

Comment se fait la récolte des tiges ${ }^{\circ}$

Quand on casse le maïs sur le champ, on coupe ensuite les tiges, on les met en bottes et en quiutaux, on les laisse sécher cemplètement, puis on les met en grange ou en meulons. 
Comment fait-on pour les rendre plus faciles d engranger?

On les passe a la batteuse, ce qui les rend plus faciles à sécher et réduit leur volume au quart de l'espace qu'elles occupent quand elles sont en branches. Un local de $32 \times 12$ pieds et de 8 pieds de hauteur peut contenir le fourrage de douze acres de maïs, ainsi passé à la batteuse.

les 6 pis bat au iffisam. grains ; vec une lo beau-

olté pour

\section{10-Des pommes de terro}

Distingue-t-on plusiours varietés de pommes de terre?

Le nombre en est presque infini; mais on peut les réduire à deux divisions principales: les variétés hâtives et les variétés tardives.

Quel est le climat qui convient le mieux à la pomme de terre?

Cette plante s'accommode pour ainsi dire de tous les climats et on peut la cultiver bien loin vers le nord; mais pour donner son meilleur produit, elle prefère un climat plutôt frais et tempéré que chaud, plutôt humide que sec, ce qui explique pourquoi elle réussit si bien en Irlande.

Quelles sont les parties de notre province où l'on trouve le mieux ces conditions climatériques?

Ce sont la Gaspésie et la contrée contigüe aux deux rives du Saint-Laurent, en aval de Québec. 


\section{IMAGE EVALUATION TEST TARGET (MT-3)}
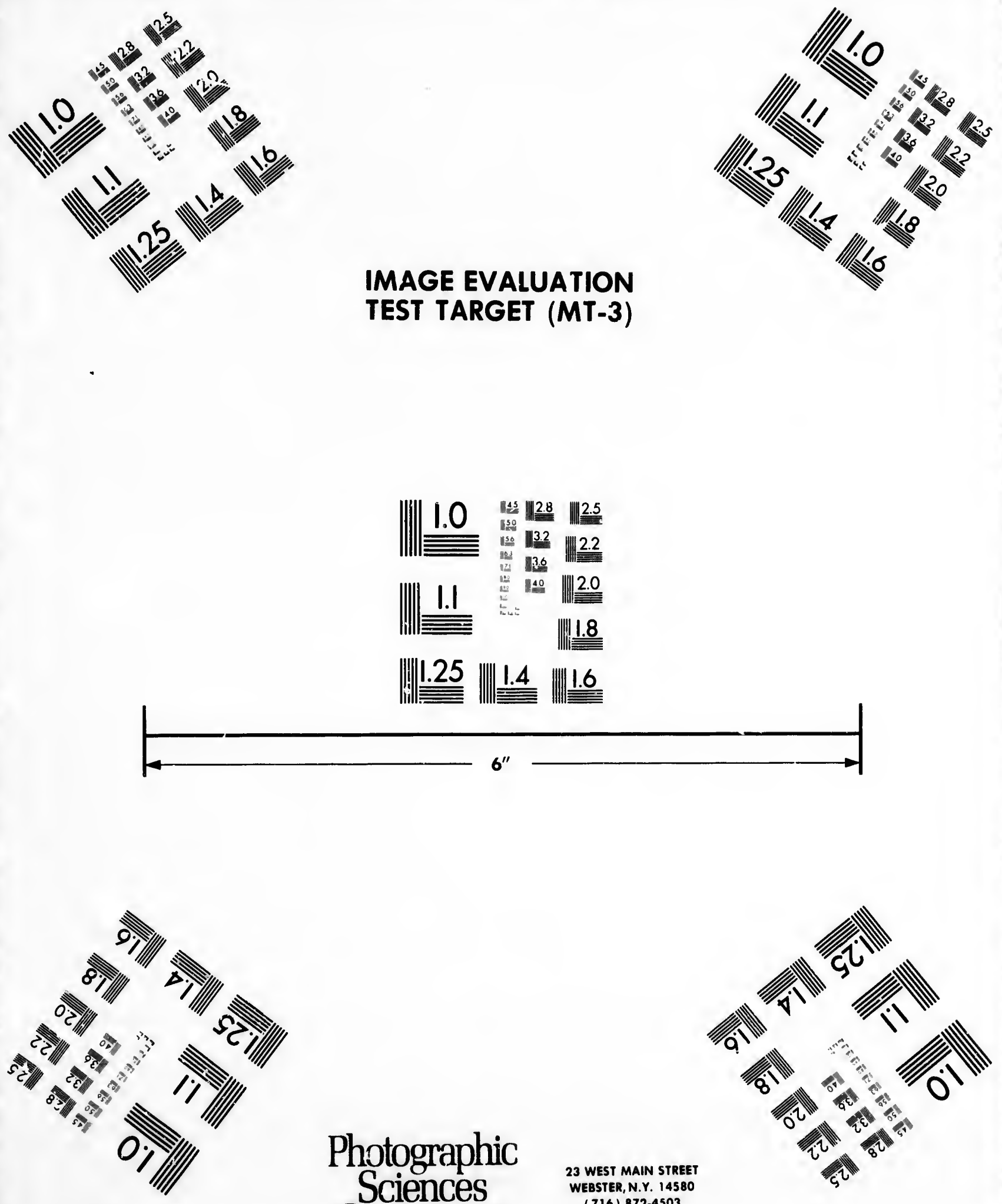

Photographic Sciences

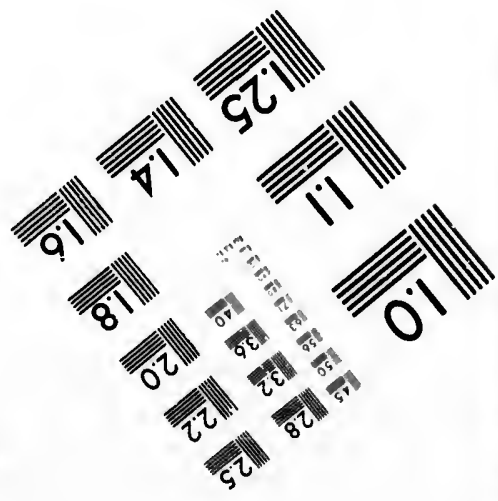
Corporation 


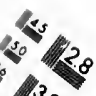

$3^{3}$

$1 / 3$

8 
Quels sont les sols qui conviennent le mieux à la pomme de terre?

Ce sont les terres de consistance moyenne, un peu sableuses, profondes et bien assainies, reposant sur un sous-sol poreux. Les terrains vierges, nouvellement déboisés, meubles et friables, lui conviennent admirablement et dans ces terrains, les tubercules ont toujours un gout exquis.

La qualivé des pommes de terre est-elle affectée par la qualité du sol dans lequel on la cultive?

Oui, considérablement. Les pommes de terre cultivées dars les sols sableux ou graveleux contiennent plus de fécule et moins d'eau que celles cultivées dans une terre glaiseuse, mouillee ou froide. Les sols tourbeux ou les savanes qui ont été bien égouttés produisent les meilleures pommes de terre; elles sont riches, farineuses, très riches en fécule, dont elles contiennent de 18 à 22 pour cent. Celles qui ont le goat le plus exquis sont celles qu'on plante, sans autre engrais, dans un relevé de trèfle, parfaitement pulvérisé, ameubli et aussi friable qu'un terreau de jardin.

Quels sont les fumiers et les engrais qui conviennent le mieux a la pomme de terre?

Ce sont les fumiers de bêtes bovines, décomposés, et les engrais minéraux renfermant beaucoup de potasse, notamment les cendres de bois, qui constituent l'engrais par excellence de la pomme de terre, ce qui explique pourquoi cette plante réussit si bien dans les terres neuves et les brâlis.

Peut-on aussi employer les fumiers vists et longs?

Oui; mais il faut avoir le soin de les enfouir a 
mme de

an peu sur un lement idmiraoujours

la qua-

ce cultiiennent es dans Is tourduisent es, farinent de exquis ans un et aussi

nnent le osés, et potasse, 'engrais $x p l i c u e$ res neu- l'automne par un labour profond. C'est dans les terres fortes que ce fumier est le mieux approprie, vu qu'il contribue à désagréger le sol, à le rendre plus friable et plus meuble.

Quand on dépose le fumier dans les sillons, comment faut-il l'employer?

Dans les terres fortes, on met genéralement le fumier au fond du sillon, puis on le recouvre d'une mince couche de terre, sur laquelle on dépose les germes ou le semis ; dans les terres sableuses ou graveleuses, on met le fumier sur le semis, ce qui lui conserve vins d'humité et le protège mieux contre les atteintes de 1 w. écheresse.

Peut-on employer les récoltes enfouies pour fumer la pomme de terre?

Oui, notamment le trèfle, qui est un des meilleurs engrais qu'on puisse employer pour cette culture. On le sème, au printemps, dans une céréale, on l'enterre à i'automne par un labuur, sur lequel on sème les pommes de terre le printemps suivant. Les tubercules récoltés dans ces conditions sont farineuses, ont un goat exquis et sont de beaucoup les meilleurs pour la table.

Quelle préparation faut-il donner au sol destiné à la porrme de terre?

Pour développer ses longues et profondes racines, la pomme de terre a besoin d'un sol friable, profondément ameubli et parfaitement nettoyé des mauvaises herbes. On lui procure tout cela par un labour d'automne, d'au moins huit pouces de profondeur, et au printemps, par un autre labour, des façons au cultivateur et des hersa- 
ges. Dans les sols légers et très sableux, on peut se limiter au labour du printemps, suivi des façons au cultivateur et des hersages.

Comment seme-t-on les pommes de terre?

A la butte, en poquets ou en ligne dans les sillons.

Dans quelles circonstances et de quello façon se fait le semis a la butte?

Dans les terres nouvellement déboisées, où les souches et les racines rendent impossible l'usage de la charrue et des autres instruments aratoires. On forme, avec la terre ramassée à la pioche et dans laquelle on mêle autant de cendre de bralis qu'or peut en trouver, de grosses buttes dans lesquelles on sème plusieurs germes que l'on recouvre de quatre o'l cinq pouces de terre bien meuble.

Comment se fait le semis en sillons?

On ouvre les sillons a la charrue ou au butoir; on y dépose le fumier, quand on l'emploie de cette façon, on donne un coup de herse pour le recouvrir d'une mince couche de terre, on dépose le semis a la main, puis on le recouvre à la herse ou au buttoir.

Quelle distance faut-il laisser entre les sillons et les germes dans les sillons?

On dépose les germes à sept ou huit pouces les uns des autres daus le sillon et l'on espace les sillons d'une trentaine de pouces. On indique cet espacement au moyen du rayonneur, qu'on fixe à la charrue ou au buttoir dont on se sert pour faire les sillons.

Comment se fait le semis en poquets?

On fait deux séries de sillons, l'une longitudina- 
peut so façons au

sillons.

xit le semis

souches a charrue e, avec la mêle auouver, de rs germes terre bien oir; on $y$ façon, on ine mince , puis on

les germes

Is les uns ons d'une ement au uo ou au gitudina- lement et l'autre transversalement, qu'on espace d'une trentaine de pouces dans chaque sens. Dans les fosses que forme l'intersection des sillons, on dépose cinq ou six germes, qu'on enterse de la meme manière que dans le semis on sillons.

A quelle profondeur faut-il enterrer le semis?

A une couple de pouces, dans les terres humides et où la secheresse n'est pas à craindre; a trois ou quatre pouces, dans les sols légers et qui se dessèchent facilement.

Quelle quantité de semis faut-il mettre d l'arpent?

Une dizaine de minots.

Seme-t-on les pommes de terre entières ou coupées par germes?

On peut les semer entières, ou rondes, quand elles sont petites; mais les meilleures praticiens les coupent par morceaux contenant un ou deux germes, ce qui donne le meilleur semis.

A quel temps faut-il semer la pomme de terre?

Aussi de bonne heure que possible, dès que le sol est assez sec et assez chaud pour permettre à la végétation de se produire.

Peut-on semer les pommes de terrè à la machine?

Oui, et bien mieux qu'on ne saurait le faire à bras, ou avec la charrue ou le buttoir, ainsi que cela se pratique ordinairement.

1 Quel est le meilleur semoir de pommes de terre?

C'est l'Aspinwall (fig. 67, page 146), fabriqué par la compagnie Aspinwall, de .Trois-Rivières, dans le Michi- 
gan. Cet appareil, d'une seule operation, fait le sillon, dépcse le semis et les engrais pulvérents, quand on veut en mettre, puis lez recourre bien mieux qu'on ne pourrait le faire à la herse ou à la charrue. Avec cette machine, traînée par deux chevaux, un homme sème cinq ou six arpents de pommes de terre par jour.

Quels soins d'entretien faut-il donner à la pomme de terre?

Des hersages, des binages et des buttages, pour empêcher la croiseance des mauvaises herbes et maintenir la fraîcheur dans le sol. On donne un coup de herse quand les feuilles coramencent à prindre ou à sortir do terre et ensuite des façons avec le cultivateur entre les rangy. Le cultivateur Planet est des mieux appropriés à cette opération. On répète cette façon au cultivateur quand la surface du sol s'encroate ou menace de s'éprendre en mauvaises herbes. Quand les plantes ont atteint une douzaine de pouces de hauteur, on donne un premier buttage, ou rechaussage, puis un deuxième une quinzaine de jours après, ce qui achève les cultures d'entretien.

\section{Comment se donne ce buttage?}

A la charrue ou au buttoir, en passant alternativement le long de chacun des deux côtés de chaque rang.

\section{Est-il bon d'écimer les pommes de terre?}

Beaucoup de praticiens d'expérience prétendent qu'en coupant les fleurs des pommes de terre, pour empêcher la graine de se former, on augmente considérablement la quantité et la qualité du produit.

Quand faut-il arracher les pommes de terre?

Quand elles sont mûres, c'est-à-dire quand les tiges se 
iillon, 1 veut pourcette sème

terre? ir emntenir herse tir do tre les opriés vateur ce de lantes n don. euxièes culrnatihaque qu'en pêcher ement

flétrissent et se dessèchent et quand la pelure ne se détache pas du tubercule, lorsqu'on la presse avec le pouce.

Comment se jait l'arrachage des pommes de terre?

A bras, avec une houe ou une fourche à trois dents, à la charrue ou d̀ la machine.

Quels sont les meilleurs arracheurs de pommes de terre?

Ce sont les machines de Hoover (fig. 82, page 167), et

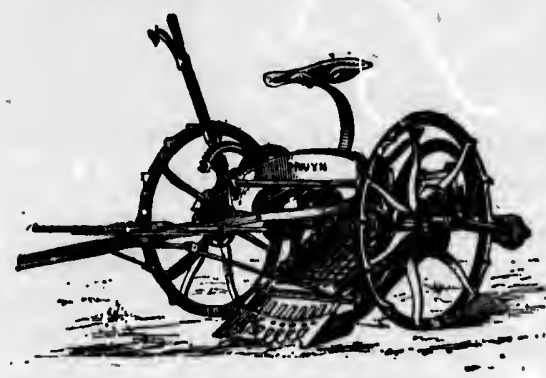

Fig. 36-Arracheur de pommes de terre de Pruyn. de Pruyn, qui fonctionnent à merveille, netíoient parfaitement les tubercules et peuvent en arracher plusieurs arpents par jour. Aux Etats-Unis, la machine de Pruyn est preférée aux autres.

Est-il prudent de laisser les pommes de terre longtemps sur le champ, avant de les encaver?

Non: il ne faut les laisser sur le champ que juste le temps nécessaire pour leur permettre de sécher un peu et les encaver sans retard; autrement, les tubercules ainsi exposés à la lumière prennent une couleur verdâtre et un mauvais goât. Quand, pour une raison quelconque, on est forcé deles laisser un peu longtemps sur le champ, il faut les recouvrir avec des fanes ou de la paille, pour prévenir le mauvais effet de l'action du soleil et de la lumière. 
Quels sont les principales conditions que doivent réunir les caves ou les caveaux dans lesquels on conserve les pommes cie terre?

C'est d'être inaccessibles a la lumière et a la chaleur, qui gatent le goat des pommes de terre, les font germer et leur enlèvent par là une partie de leur féculo, c'est-àdire de leur principal element nutritif.

Quel est le meilleur moyen de conserver les pommes de terre destinées da la semence?

On creuse dans ur endroit sec et bien egoutté une fosse de cinq pieds de profondeur, de la longueur et de la largeur voulues pour contenir la quantité à conserver. Dès que les tubercules sont bien essorés, après les avoir arrachés, on les dépose dans cette fosse, en une couche de trois pieds d'épaisseur, puis on aciève de remplir la fosse avec une couverture de paille, que l'on recouvre d'une couche de terre de trois ou quatre pouces d'épaisseur, arrondie au milieu, pour empêcher l'eau de pluie de pénétrer dans la fosise. Aux premiers froids, on met une autre couche de paille et de terre. Pour favoriser la ventilation, on laisse dans cette couverture de paille et de terre deux orifices que l'on bouche ensuite avec des bottes de paille. On n'ouvre ensuite la fosse qu'au printemps, au moment où l'on a besoin des tubercules pour les planter.

Quels sont les avantages de cette méthode?

Les pommes de terre ainsi conservées à l'obscurit6 complète et sous une température approchant du point de congélation ne germent pas, sont bien plus vigoureuses, poussent bien plus rapidement et donnent de bien plus beaux produits. 


\section{1-De la betterave}

\section{La betterave est-elle une planto bien utile?}

shaleur, germer c'est-à-

de terre

tt6 une

ur et de nserver. les avoir couche mplir la :ecouvre d'épaisde pluie , on met avoriser le paille ite avec se qu'au bercules

bscurit6 du point as vigounnent de

C'est une des plantes les plus utiles et les plus précieuses. En France, en Belgique et en Allemagne, elle a rendu des services signalés à l'agriculture, qu'elle a transformée et enrichie plus que n'importe quelle autre plante. Dans ces pays, la betterave joue le double rôle de plante fourragère et de plante industrielle, en ce sens qu'elle fournit la nourriture au bétail et la matière première à la sucrerie et à la distillerie.

\section{Distingue-t-on plusieurs especes de betteraves?}

Il y en a un grand nombre de variétér qui so divisent d'une manière générale en betteraves fourrcgères et en betteraves $d$ sucre.

Est-ce que toutes les betteraves peuvent servir a la nourriture du bétail et à faire du sucre?

Oui ; mais les unes sont plus propres à la nourriture du bétail, au lieu que d'autres conviennent mieux à la fabrication du sucre, ce qui explique pourquoi on les a respectivement classéts en betteraves fourragères et en betteraves à sucre.

Quelles sont les principales variétés de betteraves fourragères?

En France, le pays où cette plante est lo mieux cultivée, les principales variétés sont la betterave champêtre ou racine de disette, lo mangold wurtzel des Anglais, la betterave rouge globe, la betterave jaune, la jaune globe, la jaune d'Allemagne et d'autres variétés, qui sont charnues, pivotantes, deviennent très grosses et poussent en grande partie hors de terre. 
Quelles sont les principales variétés de betteraves d sucre?

Elles se réduisent à deux catégories principales: la betterave blanche d collet vert et la blanche da collet rose.

Quelles sont les principales qualités de la betterave d sucre?

Cette betterave doit untrer profondément en terre, ne pousser que très peu en dehors, être très lisse, conique et dépourvue de chevelu.

Quels sont le climat et le sol qui conviennent le mieux à la betterave?

Cette plante vient dans tous les climats, dans le sud comme dans le nord; mais la sécheresse retarde ou arrête sa croissance et ce sont les régions à pluies d'été qui lui conviennent le mieux. Eile donne ses meilleurs rendements sous un climat humide et chaud. Quant au sol, la betterave vient dans toutes les terres ou ne se trouvent pas des eaux stagnantes; mais elle préfère les terres un peu fortes à celles qui sont trop légères et c'est dans les terres à blé, les bonnes terres franches, qu'elle donne le plus de produits. Il lui faut toujours un sol profond, bien ameubli et bien assaini.

Quelle préparation faut-il donner au sol destiné à la betteraye?

Comme toutes les plantes à racines pivotantes, la betterave exige un sol profondément meubli. Après de nombreuses expériences répétées durant plusieurs années dans certaines staticns expérimentales des EtatsUnis, on est arrivé à la conclusion que pour donner les meilleurs produits sous le double rapport de la quantité et de la qualité, la betterave à sucre exige un labour d'une profondeur mojenne de douze à quinze pouces. Ces labours profonds empechent la betterave de produire 
dsucre?

ales: la -ose.

ds sucre?

erre, ne conique

ieux da la

- le sud arde ou ies d'été reilleurs

Quant où ne se éfère les égères et ranches, toujours

iné à la

intes, la Après de eurs anes Etatsnner les quantité a labour pouces. produire

plusieurs racines et la portent à se développer dans la terre, au lieu de sortir du sol, ce qui est toujours un inconvénient pour la betterave à sucre qui, dans la partie bors de terre, se décolore et rend la clarification du sucre plus difficile. Pour les betteraves fourragères qui se développent naturellement hors du sol, telles que la champêtre et la grosse jaune, on peut se contenter d'un labour moins profond.

Faut-il labourer en automne ou au printemps?

Il est infiniment mieux de labourer a l'automne, surtout dans les terres un peu fortes. En s'effleurissant à la gelée, les arêtes du guéret d'automne forment une masse friable qui absorbe l'humidité et se rassied mieux.

Quelle autre préparation faut-il donner au sol le printemps, immédiatement avant de semer?

Il faut éviter de labourer le sol ou de le remuer profondément, ce qui lui ferait perùre l'humidité absorbée durant l'hiver ou le printemps, et se contenter de l'ameublir parfaitement à la surface avec le cultivateurs la herse et le rouleau, ce qui est de nécessité absolue.

Quels sont les engrais les mieux appropriés à la betterave?

Ce sont les fumiers d'étable bien décomposés et les engrais artificiels ou du commerce, renfermant beau. coup de potasse, notamment pour la betterave à sucre.

Quel inconvénient présentent les fumiers longs ou pailleux?

Ils ameublissent trop le sol, l'allegent outre mesure, ce qui l'expose à la sécheresse en rendant impossible l'action de la capillarité. 
Comment peut.on atténuer le mauvais effet des fumiers pailleux

En mélangeant ces fumiers, en petite quantite, avec des engrais pulverulents, tels que la poudrette, les composts, la cendre et d'autres matières sembiables.

Quel inconvénient présente l'emploi du purin, de l'urine, de l'engrais flamand et des chlorures que fournissent les usines d gaz?

Ces matières peuvent s'employer avantageusement dans la culture de la betterave fourragère; mais il faut en Eviter l'emploi dans la culture de la betterave à sucre, vu qu'elles empêchent le semis de cristalliser et donnent une couleur jaune au jus de betterave.

Quelle quantité de fumier faut-il mettre d i'arpent

Pour la betterave a sucre, surtout, il ne faut pas excéder quinze tonneaux, ou de vingt-cinq a trente voitures à l'arpent. Une fumure excessive diminue lo percentage du sucre, en développant trop la végetation et empechant la plante de mârir à temps.

Quand faut-il mettre le fumier sur la terre réservée d la culture de la betterave?

A l'automne et l'enterrer de suite par un labour.

Quelle préparation recommande-t-on de donner à la graine de betterave avant de la semer ?

On recommande de faire tremper la graine de betterave durant vingt-quatre leures au plus dans de l'eau tiède, ce qui a pour effet de séparer la bonne graine de la mauvaise et de hater considérablement la germination. Pour la rendre plus facile d mancuvrer, surtout quand on sème au semoir, on saupoudre la graine avec 
du platre, de la cendre, de ia chaux ou de la terre pulvérisée, ce qui la dessèche assez pour la rendre facile a semer.

Quelle quantité de graine faut-il mettre d l'arpent?

Desix à dix livres, selon qu'on sème plus ou moins dru.

Comment sème-t-on la graine de betterave?

Sur billons, quand on opere dans un terrain humide, et à plat, quand on sème dans un terrain où l'humidité n'est pas à craindre.

\section{Comment forme-t-on les billons?}

En tirant avec le buttoir ou la charrue des sillons que l'on renverse l'un contre l'autre, par un labour en adossant ou à hue, et entre lesquels on laisse l'espacement voulu, c'est-à-dire une vingtaine de pouces. On passe ensuite le rouleau sur ces billons pour en aplanir la surface et raffermir la terre.

Comment dépose-t-on la graine dans ies billons?

A la main ou au semoir. Quand on sème à la main, une personne creuse les trous à la distance vouicie avec le plantoir et une autre personne dépose la graine dans ces trous et la couvre, à une profondeur d'un pouce. Quand on emploie le semoir, l'appareil fait lui-même les trous et y dépose la graine, qu'on recouvre ensuite à la main. On finit l'opération, dans l'un ou l'autre cas, en passant une seconde fois le rouleau, qui achève d'enterrer la graine et donne à la terre le tassement voulu pour l'empêcher de se dessécher trop.

Comment se fait le semis à plat?

Quand la terre a été hersée, roulée et bien préparée, 
on passe le rayonneur, qui trace les petits sillons à un pouce de profondeur. On dépose ensuite la graine dans ces sillons d la main ou au semoir. On enterre la semence avec une herse l6gère ou une houe à cheval. On finit l'operation par un roulage qui consolide la terre et lui conserve plus d'humidité.

Quel espacement faut-il laisser entre les rangs et les plantes. dans chaque rang?

Pour la betterave fourragère, on peut espacer les rangs de vingt-quatre à trente pouces et les plantes dans chaque rang de huit pouces; mais pour le betterave a sucre, il est mieux de n'espacer les rangs que d'une quinzaine de pouces et de ne laisser que six pouces entre les plantes de chaque rang.

Pourquoi faut-il moins espacer la betterave d̀ sucre que les betteraves fuurragères?

Parce qu'il est constaté par l'expérience que les petites betteraves-ainsi qu'elles poussent quand elles sont plus rapprochees-contiennent un bien plus fort percentage de sucre que les grosses. Le percentage est en raison inverse du volume de la betterave et moins celle-ci est grosse, plus elle est riche on sucre et meilleure est sa qualité.

Quels soins d'entretien faut-il clonner aux betteraves?

Des sarclages eí des binages pour empêcher la croissance des mauvaises herbes et maintenir à la surface du sol une couche mince de terre meuble qui conserve l'humidite au sol, facilite l'action des agents atmospheriques et agit comme une couverture de paille ou de fumier. 
lons à un aine dans enterre ne houe dlage qui dité.

les plantes. pacer les ntes dans etterave à ue d'une dces entre

sucre que

que les tand elles plus fort ntage est et moins meilleure

\section{aves?}

c la croisurface du conserve tmosphélle ou de

Quel est le but de l'éclaircissage et comment le pratique-i-on?

On sème généralement deux ou trois graines ensemble, pour être sûr qu'une au moins poussera. Il arrive souvent que toutes les graines poussent, ce qui produirait un encombrement capable de nuire considerablement au développement des plantes. Pour empêcher cet encombrement,on ne laisse qu'une plante dans chaque trou at l'on enlève les autres ; c'est ce qu'on appelle l'éclaircissage. On pratique cette opération quand la terre est humide et ne s'enlève pas avec les plantes à détruire, ce qui pourrait endommager celles restant. On arrache les plantes qui doivent disparaître ou encore on les coupe au collet, quand on craint de trop remuer la terre en les arrachant.

Comment arrache-t-on les betteraves?

A la bèche, à la fourche-trident, à la charrue ou avec l'arrache-betteraves, qui est le meilleur outil pour cette opération.

\section{Quel temps faut-il choisir pour faire l'arrachage?}

Autant que possible un temps sec. Il arrive souvent que des betteraves arrachées à la pluie et encavées quand elles sont encore mouillées se conservent; mais il est mieux de les arracher par un beau temps et de les laisser essorer avant de les mettre en cave.

\section{Qu'appellez-vous décolletage?}

Après que les betteraves sont arrachées, il faut les débarrasser de leurs feuilles avant do les encaver. On coupe les feuilles au collet en ayant bien soin de ne pas attaquer la partie charnue de la plante; c'est ce qu'on appelle le décolletage. 
Coupe-t-on aussi les petites racines et l'extrémité de la betterave?

Non; il faut bien s'en garder, car cela ferait promptement pourrir la betterave ainsi lacérée.

Quelles précautions faut-il observer dans l'emmagasinage des betteraves?

Il faut les emmagasiner dans un endroit frais, un peu humide et les déposer par couches d'au plus quatre pieds d'épaisseur. Quand la cave est trop èche, il est bon de recouvrir les betteraves d'une couche de terre humide, pour les empêcher de se dessécher.

Peut-on conserver les betteraves en silo?

Oui et c'est même une pratique assez commune dans plusieurs pays.

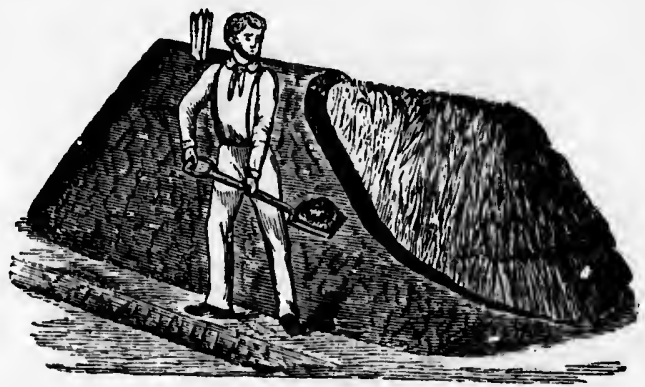

Fig. 97-Silo à betterave

Comment se font ces silos?

Dans un endroit sec et bien égoutté, on creuse une fosse de douze à quinze pouces de profondeur, de la largeur et de la longueur requises pour loger la quantité de plantes à conserver. On couvre le fond de la fosse de branches ou de paille, sur laquelle on dépose les 
betteraves, qu'on accumule en un tas ayant la forme conique. La hauteur du tas doit excéder sa largeur du tiers. Sur les betteraves ainsi entassées, on jette une couche de terre assez épaisse pour protéger les betteraves contre la gelée. Pour faciliter l'aération et empêcher l'échauffement, à tous les cinq ou six pieds delongueur on met un cloisonnage en branches excédant le dessus du tas. Ces branches servent de ventilateurs, ménagent une issue d l'air chaud et pour empêcher le froid de pénétrer dans le silo, il suffit de jeter quelques pelletées de terre sur le bout des branches, quand arrivent les grands froids. Les betteraves ainsi ensilées se conservent parfaitement.

\section{12-De la carotte}

\section{La carotte est-elle une plante bien utile?}

C'est une des plantes les plus précieuses pour la nourriture du bétail. Elle fournit une bonne nourriture aux bêtes à l'engrais, aux animau' de travail et aux vaches laitières. C'est un des fourrages-racines qui engraissent le plus rapidement le bétail ; on le donne aux porcs et à la volaille comme aux herbivores. Elle forme pour le cheval une nourriture avidement recherchée; elle le tient en très bon état, lui donne de la. force, de la vigueur, lui rend la peau scuple et le poil brillant. Elle est très salutaire aux poulains ; ceux qui en mangent prennent une bonne constitution et grandissent rapidement. Elle est parfaitement approprice au tempérament du mouton, qui s'en engraisse. Elle 
donne aux vaches beaucoup de lait, qui produit un beurre excellent.

Distingue-ton plusieurs variétés de carottes?

Les catalogues des grainetiers en contiennent de longues nomenclatures; mais pour la grande culture, on n'emploie que les longues et les demi-longues.

Quelles sont les variêtés les plus recommandables?

Ce sont la carotte blanche comte de Steel, la Surrey, la grosse blanche de Belgique, l'Orthe blanche à collet vert, la grosse blanche courte des Vosges, la demi-longue écarlate $h A$ tive et l'écarlate d'Altringham, variéte anglaise qui est excellente pour les fins culinaires.

Quels sont le climat et le sol qui conviennent d la carotte?

La carotte s'accommode de presque tous les climats, mais elle donne ses plus forts rendements dans les contrées oil l'atmosphère est humide; la sécheresse arrête sa végétation. Quant au sol, elle demande une terre profonde, riche, parfaitement meuble. C'est dans les terrains substantiels et un pen sableux qu'elle réussit le mieux.

Quelle préparation faut-il donner au sol destiné d la carntte?

Lente à lever et faible dans sa jeunesse, la carotte ne doit être semée que dans une terre profondément ameublie, bien fumée avec du fumier décomposé, parfaitement nettoýe et libre de mauvaises herbes, absolument comme pour la betterave.

Comment sème-t-on la carotte?

Comme la betterave, dans des petits sillons tracés au 
coduit un

nt de lonalture, on

Surrey, la llet vert, la écarlate $h \hat{A}$ ise qui est

la carotte?

les climats, uns les con. esse arrête une terre st dans les le réussit le

destiné à la

a carotte ne ment ameué, parfaiteabsolument ns tracés au’ rayonneur, à un pouce de profondeur, éloignés d'une quinzaine de pouces, avec espacement de cinq ou six pouces entre les plantes de chaque rang.

Quelles sont les cultures d'entretien?

L'éclaircissage, des sarclages et des binages, absolument comme pour la betterave.

Quelle précaution faut-il observer dans le choix de la graine de semerce?

Il faut avoir bien soin de choisir de la graine de l'année précédente, attendu que celle qui est plus vieille ne germe pas. Pour rendre cette graine plus facile à mancuvrer, on la mélange avec un peu de sable. Il faut deux ou trois livres de graines à l'acre.

Comment fait-on pour hater la germination de la graine?

On trempe la graine durant huit ou dix heures dans de l'eau tiede, puis on l'étend en couche épaisse sur un plancher, jusqu'à ce qu'elle commence à germer, ce qui. prend de six à huit jours; on la mélange alors avec du plâtre noulu et on la sème.

Comment arrache-t-on et emmagasine-t-on la carotte?

Comme la betterave, aussi tard que possible dans l'automne; mais, dans la cave, il faut mettre les couches moins épaisses que celles de betteraves, attendu que la carotte est plus sujette à s'échauffer en cave.

\section{\& 13-Des navets}

Le navet est-il une plante bien importante en agriculture? C'est une des plantes les plus importantes. C'est a 
la culture du navet que l'Angleterre doit en grande partie l'amélioration de son agriculture et c'est aussi en grande partie au navet que les éleveurs anglais doivent la formation de ces magnifiques races de bêtes à cornes et de moutons que les agriculteurs de tous les autres pays recherchent pour améliorer leur bétail.

Distingue-t-on plusieurs variétés de navets ?

Oui; mais les plus anciens et les mieux connus sont le globe commun, le navet a collet pourpre, l'hybride, le navet de Suede ou rutabaga, dont le Carter et le Rennie sont des meilleurs variêtés.

Quel est le climat qui convient le mieux au navet?

Un climat humide et brumeux, ce qui explique pourquoi cette plante réussit si bien en Angleterre et en Ecosse, où elle donne des rendements merveilleux.

Quels sont les sols qui conviennent le mieux au navet?

Ce sont les terres jaunes, ou loams, légères, friables, meubles, profondes et bien pulvérisées. Cependant le rutabaga, ou navet de Suède, réussit bien dans les terres fortes, glaiseuses, renfermant beaucoup d'alumine, pourvu que ces terres soient bien ameublies.

Quelle préparation faut-il donner au sol qu'on veut semer en navets?

Comme toutes les plantes-racines, le navet exige un sol profondément et parfaitement ameubli. Pour satisfaire à cette exigence, on donne à l'automne un labour profond et au printemps suivant, deux ou trois labours moins forts, qu'on fait suivre de hersages et autres cultures pour pulvériser parfaitement la terre. 
nde par-

tussi en doivent ornes et :es pays

us sont bride, le $\rightarrow$ Rennie

de pour$\theta$ ot en ux.

vet? friables, dant le 35 terres lumine,

ut semer

xige un ur satislabour labours cultu.

Quels sont les engrais qui conviennent le mieux au navet?

Les engrais riches en phosphate, notamment les os pulvérisés et le superphosphate de chaux, les fumiers d'étable, les cendres et les récoltes enfouies.

Combien faut-il defumier a l'acre et comment l'emploie-t-on?

On met à l'acre de vingt-cinq à trente voitures de fumier d'etable, à l'automne, et on l'enterre de suite par un labour profond.

Comment s'emploient le phosphate et les autres engrais pulvérulents?

On met ces engrais près de la surface du sol ou dans les petits sillons destinés à recevoir les semis.

Qu'arrive-t-il quand l'engrais est trop riche en matières azotées et trop pauvre en phosphate?

Les feuilies se développent outre mesure au détriment de la racine, qui reste chétive et ne donne qu'une maigre récolte.

Comment sème-t-on la graine de navet?

A la volée, en lignes sur billons ou en lignes à plat, ce qui est de beaucoup la meilleure méthode.

Quelles sont les variétés de navets qui peuvent se semer a la volée?

Toutes les variétés, excepté le rutabaga, qu'il faut nécessairement semer en lignes.

Comment enterre-t-on les semis à la volée?

Avec une herse de branche, au rouleau ou, ce qui est bien mieux, avec un madrier trainé en travers par un cheval. 
De quel instrument se sert-on pour faire les semis en lignes?

$\mathrm{Du}$ semoir à navets, qui est un appareil spécial et fait l'operation d'un seul coup. (fig. 68 page 147)

Comment se font les semis sur billons?

De la méme manière que ceux de la betterave et de la carotte.

Quel espace faut-il laisser entre les lignes?

De vingt à vingt-sept pouces entre les lignes et oinq ou six pouces entre les plantes dans chaque ligne.

A quelle époque faut-il semer les navets?

Il n'est pas prudent de semer le rutabaga plus tard que le commencement de juillet; mais on peut attendre jusqu'à la fin de ce mois pour semer les autres variétés, notamment le jaune d'Aberdeen, le collet vert, lo Greystone et le globe de Norfolk, qui réussissent bien mieux que le rutabaga dans les sols légers.

Quelle quantité de semence fautil mettre à l'arpent?

Deux ou trois livres, selon la richesse du sol.

Quels soins d'entretien faut-il donner aux navets?

Les mêmes qu'à la betterave et à la carotte,-des hersages, des binages et des éclaircissages.

\section{Quand faut-il récolter les navets?}

On peut les laisser en terre jusqu'aux premières grosses gelées; alors on les arrache et on les décollette pour les mettre en cave ou en silo, ce qui est bien mieux. 


\section{Comment se font ces silos ?}

Dans un endroit sec, pas exposé à l'humidite, on creuse une fosse d'une couple de pieds de profondeur et cinq ou six pieds de largeur, dans laquelle on dépose les navets, pour faire un tas de forme prismatique. On recouvre les navets d'une couche de paille, sur laquelle on superpose des couches de terre, d'une epaisseur suffisante pour mettre les plantes à l'abri de la gelée. Quand tout est fini, on creuse autour du silo un petit fossé destiné à en bloigner l'eau 'et l'humidité.

et oinq

ne.

lus tard attendre variétés, Treystone eux que

-des herres grostte pour ieux:

\section{14-Du lin}

\section{Le lin est-il une plante bien utile?}

Oui: sa tige donne la filasse, aves laquelle on fabrique la toile; sa graine fournit au bétail un des aliments les plus riches et à l'industrie, l'huile avec laquelle on delaie les peintures.

Quel est le climat qui convient le mieux au lin?

Cette plante pousse sous tous les climats habitables ; mais c'est sous un climat doux et un peu humide qu'elle réusssit le mieux, ce qui explique pourquoi elle vient si bien en Angleterre, en Irlande, dans le nord de la Belgique et de l'Allemagne ainsi que dans la région avoisinant la mer Baltique, en Russie.

Quel est le sol le plus propice au lin?

Le lin vient dans toutes les terres qui produisent de bonnes récoltes de céréales; mais pour donner ses meil- 
leurs produits en filasse et en graine, il lui faut une terre franche ou un loam profond, fertile, très meuble et pas trop humide. J'humidité lui est préjudiciable et il ne donne qu'une chétive récolte dans les terres fortes, glaiseuses, qui sont bien assainies, bien ameublies et bien engraissées.

Quelle préparation faut-il donner au sol qui doit être ensemencé en lin?

Il n'y a pas d'autre plante qui exige un sol aussi bien préparé que le lin et qui récompense aussi bien des cultures et des engrais donnés à la terre qui lui est destinée. Il faut absolument débarrasser le sol des mauvaises herbes et l'ameublir comme un terreau de jardin.

Quelles façons faut-il donner au sol pour satisfaire $d$ toutes ces exigences?

Dans les terres un peu fortes, on laboure a l'automne et l'on nettoie les rigoles, pour assurer un égouttement aussi parfait que poesible. Dans les terres noires, les sols poreux, sablonneux ou graveleux ainsi que dans les terrains d'alluvion, il faut labourer en aout ou septembre, afin de détruire par le hersage les mauvaises herbes qui surgissent. Le printemps suivant, dès que la terre est rassise et assez sèche, il faut donner un second labour, aussi profond que le premier, herser doux fois et rouler immédiatement avant de semer, s'il y a des mottes que la herse n'a pas pulvérisées.

Quel est le but de ces hersages et de ce roulage?

C'est de rendre la surface du sol aussi neuble et aussi uni que possible, afin que la graine lève et que la plante pousse d'une manière absolument uniforme. Dans un sol ainsi préparé et bien engraissé, le lin atteint souvent une longueur de trois ou quatre pieds. 
je ter-

ble et ble et fortes, ies ot

e ense-

i bien $38 \mathrm{cul}$. tinée. vaises

toutes

omne ment is, les dans at ou vaises is que un erser r, s'il

aussi de la rme. tteint lin 8

Quels sont les engrais qui conviennent de préférence au

Le lin contient une très forte proportion d'acide phosphorique, d'acide sulfurique, de chlore, de potasse, de chaux et de magnésie; les engrais qui peuvent lui fournir ces matières sont naturellement les phosphates et les silicates alcalins, tels que le superphosphate de chaux, les os pulvérisés, les cendres de hois, la chaux et le sel marin. Les fumiei's de vache et de mouton bien fermentés, le noir animalisé et le noir des raffineries et particulièrement les tourteaux de lin lui sont aussi fort appropriés.

Peut-on employer le fumier vert dans la culture du lin?

Non: le lin, comme le blé, veut un fumier bien décomposé. Quand on lui donne un fumier vert, qui n'a pas fermenté, on obtient peu de graine, et la tige, qui est volumineuse et sujette a la rouille, ne donne qu'une filasse grossière, de peu de valeur.

Quand on applique l'engrais directement au lin, comment faut-il l'employer?

On enterre le fumier d'étable par le labour d'automne et les engrais pulvérulents le priritemps suivant, par les façons qui précèdent le semis.

Quelle place doit occuper le lin dans la rotation?

Comme cette plante est munie de racines longues et pivotantes, qui vont chercher leur nourriture à une grande profondeur dans la terre, il faut la faire venir après des récoltes qui ont accumulé une quantité suffisante de principes fertilisants dans les couches inferieures du sol. Comme les mauvaises herbes sont des plus nuisibles dans cette culture, il faut autant que 
possible mettre le lin d̀ la suite d'une récolte sarclée, qui a débarrasé́ la terre des mauvaises harbes et l'a profondément amoublie.

Peut-on mettre le lin sur un défrichement ou un relevé de trèfle ou de prairie?

Oui : un relevé de trèfle ou de prairie bien ameubli est une des meilleures terres qu'on puisse donner au lin, qui va puiser dans les couches inférieures du sol l'engrais formé par la décomposition des racines du trèfle.

Comment sème-t-on la graine de lin?

Comme la graine de foin et sur la terre fraichement remuée, pour procurer a la graine la fraicheur dont elle a besoin pour germer promptement.

Comment fait-on pour assurer l'uniformité dans la distribution de la semence?

Pour rendre la graine moins coulante, on la trempe dans de l'eau tiède deux ou trois heures, puis on la mélangè avec du platre moulu, ce qui la rend plus facile à manipuler. Pour être sâr de semer également partout, on divise le terrain en lisières de quinze à dix-huit pieds de large, qu'on marque en trainant une petite chaine sur le hersage. On sème en faisant le tour de ces lisières. Pour obtenir plus d'uniformité, certains praticiens sèment la moitié de la graine dans le sens longitudinal et l'autre moitié dans le sens transversal.

Qu'arrive-t-il quand le semis n'est pas uniforme?

Dans les endroits ou il y a trop de semence, le lin pousse fin, ne donne que peu de graine et marit plus tard; dans les endroits ou le semis est plus clair, les tiges viennent grosses, donnent beaucoup de graine, mais une filasse plus grossière. 
ee, qui rofon-

elevé de

meubli au lin, l'entrèfle.

lement ont elle distri-

trempe la mé. facile a artout, it pieds chaine de ces ins prans lonsal.

le lin rit plus lair, les graine,

\section{Quand faut-il semer la graine de lin}

Quand la terre est bien rassise, parfaitement réchauffée et qu'il n'y a plus à craindre la moindre gelée, qui est fatale au jeune lin.

Est-il mieux de semer avant ou après un orage?

Quand on sème avant un orage, il arrive souvent que la pluie détruit une partie de la graine, qui ne germe pas; au contraire, en semant après un orage, aussitôt que la terre ne colle plus aux instruments, les petites mottes s'emiettent uu moindre toucher, le sol est très friable, la graine s'enterre admirablement et lève avec une vigueur et une uniformité remarquables et le lin prend de suite le dessus sur les mauvaises herbes.

\section{Quelle quantité de semence faut-il mettre d l'acre?}

Cela dépend de l'objet qu'on a en vue. Quand on sème spécialement dans le but d'obtenir de la filasse, il faut semer plus dru et alors on peut mettre un minot et demi ou deux minots a l'acre. Quand on a particulièrement en vue la récolte de la graine, il ne faut pas semer plus d'un minot à l'acre et beaucoup même sèment moins. Pour avoir une bonne récolte de graine et de filasse, les meilleurs praticiens sèment un minot et demi à l'acre.

\section{Qu'arrive-t-il selon qu'on sème dru ou clair?}

Quand on sème dru, le lin ne forme pas de branches, pousse fin, long, et donne plus de filasse, qui est de qualite supérieure; quand on sème clair, le lin forme des branches, donne une filasse plus grossière et moins égale, mais produit beaucoup de graine d'excellente qualité. 
Comment recouvre-t-on le semis de lin?

On le recouvre généralement avec une herse très légère et, ce qui est encore mieux, avec un cadre muni de branches.

Ce procédé offret-il quelques inconvénients?

Oui : les pieds des chevaux, qu'on emploie généralement pour traîner ces instruments, creusent des trous où la graine, enterrée trop profondément, lève vien plus tard, ce qui gâte considérablement l'uniformité de la récolte, tant de la graine que de la filasse.

Peut-on remédier à cet inconvénient?

Oui, très facilement. Au lieu de faire le hersage avec les chevaux, on emploie une herse en branches traîné par un homme, qui fait autant d'ouvrage qu'un cheval et peut ainsi herser quatre ou cinq acres par jour.

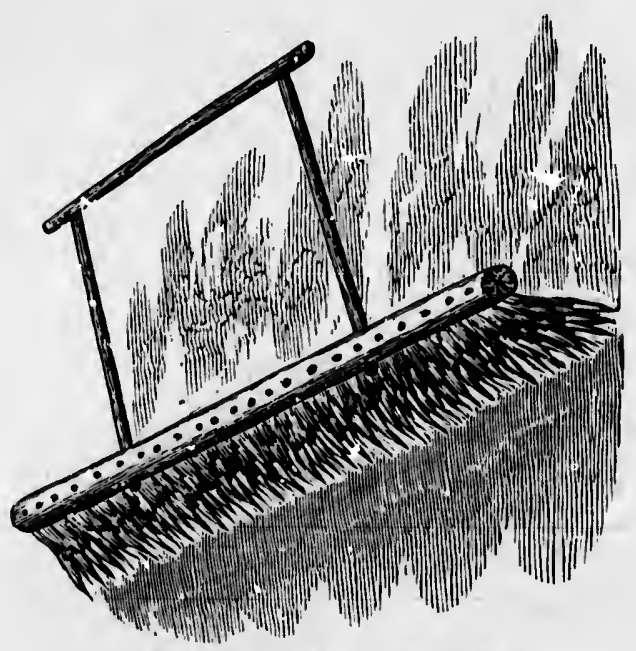

Fig. 98-Ierse en branches 
Commeni se font ces herses en branches?

rse très

re muni

énérale-

s trous

ien plus

té de la

ige avec traînée cheval ir.

On forme le dos avec un morceau de bois de quatre ou cinq pieds de longueur et de trois ou quatre pouces carrés ou avec une perche ronde. Dans les trous percés dans ce dos, on fixe des branches d'une couple de pieds de longueur et l'on finit l'appareil en y adaptant un brancard sur lequel l'homme tire pour traîner la herse. Quand celle-ci n'est pas assez pesante, on attache sur le dos quelques pièces de bois.

A quelle profondeur faut-il enterrer la graine de lin?

Un demi-pouce suffit amplement, quand la terre est bien préparée.

Est-il bon de rouler la terre après le semis?

Cette pratique est suivie par beaucoup de cultivateurs, mais les meilleurs praticiens l'évitent avec soin, vu que ce roulage forme solivent une croate qui empêche une partie des tigelles de sortir, sans compter que le piétinement des chevaux forme des trous qui détruisent l'uniformité de la récolte.

Quels soins d'entretien faut-il donner au lin?

Il faut le débarrasser soigneusement des chardons, de la sanve ou moutarde sauvage ainsi que de toutes les autres mauvaises herbes de cette nature, qui rendent les manipulations subséquentes plus difficiles, gatent la qualite de la filasse et de la graine.

Faut-il arracher ou couper ces mauvaises herbes?

Il faut les couper ras de terre; en les arrachant on s'exposerait à arracher en même temps ou à déraciner des tiges de lin.

20 
A quelle époque faut-il arracher ou couper le lin?

Quand les capsules qui renferment la graine ont pris une couleur brune et quand les feuilles sont mortes sur la partie inférieure de la tige, jusqu'au quart ou au tiers et quand la tige elle-même, de vert foncé qu'elle était, a pris une couleur jaunatre clair, c'est le temps propice pour arracher le lin et en obtenir la plus belle filasse.

Comment récolle-t-on le lin?

On l'arrache à la main et même, dans certains pays, on le coupe à la faucille ou au javelier.

Comment se fait l'arrachage dे la main?

Chaq'ue ouvrier prend une largeur d'environ quatre pieds, saisit la plante juste au-dessus de la tête, par poignées, en ayant soin de ne pas mêler les tiges, puis, d'un coup vif, l'arrache de terre, puis l'étend régulièrement sur le sol, en rangs épais d'un pouce. Après avoir laissé ce rang exposé au soleil une demi-journée, quand le temps est bien beau, on le retourne pour faire sécher pareillement l'autre côté. Quand les tiges sont fanées et bien sèches, on en forme des bottillons de cinq ou six pouces de diamètre; qu'on attache avec les tiges éparses qui restent sur le champ ou avec des harts et l'on met ces bottillons en moyettes longues pour achever la dessiccation des capsules et préparer le battage de la graine.

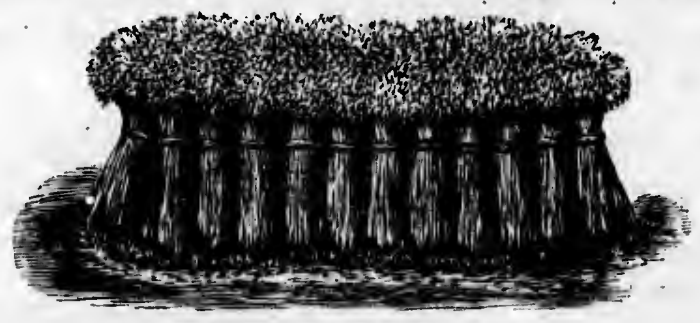

Fig. 99-Lin en moyette 
Peut-on mettre le lin en bottillons et en moyjettes immédiatement après l'arrachage?

Oui, et il est même parfois nécessaire de le faire. Quand le temps est humide ou menace de tourner à la pluie, il est mieux de mettre le lin en petites bottes et en moyettes en l'arrachant. On fait ces moyettes courant du nord au sud, afin qu'elles soient mieux exposćes à l'action du soleil.

tains pays,

iron quatre la tête, par tiges, puis, d régulièreAprès avoir rnée, quànd faire sécher sont fanées cinq ou six tiges éparses s et l'on met ver la dessicde la graine.

(n)

Quelles précautions faut-il observer en faisant les bottillors?

Il faut d'abord frapper le pied $d \iota$ bottillon sur la jambe ou sur le sol, pour faire tomber toute la terre qui adhère à la racine de la plante et l'on frappe verticalement le pied du bottillon sur le sol, pour le bien égaliser.

Combien de temps faut-il laisser le lin sur le champ après l'avoir engerbé?

Le lin qu'on laisse étendu sur le sol pour sécher peut s'engranger ou se mettre en meules immédiatement après l'engerbage; mais celui qu'on engerbe en l'arrachant doit rester en moyettes, sur le chainp, au moins huit ou dix jours.

\section{Comment sépare-t-on la graine des tiges?}

En battant le lin au fléau, ou sur un caillou ou une charrue renversée ou. encore à la machine à battre le grain.

Comment dispose-ton ls batteur de la machine pour battre le lin?

Avec les batteuses dont la sole ou le contre-batteur est mobile, on le lève ou on le baisse, selon le cas, de manière à ce que l'extrémité des dents se croise à peine; 
quand le contre-batteur est fixe, on enlève la moití des dents. La batteuse ainsi préparée, on lui présente la tête des bottillons, en les retenant fermement, de façon à ce que les dents de la machine n'atteignent que la partie de la tige où se trouve la graine.

Quelle est la meilleure de ces trois méthodes?

C'est le battage contre un caillou, qui n'affecte aucunement la fibre du lin et do.ane une bien plus belle filasse.

N'y a-t-il pas un autre moyen de séparer la graine des tiges du lin?

Oui, il y a la méthode de la drége.

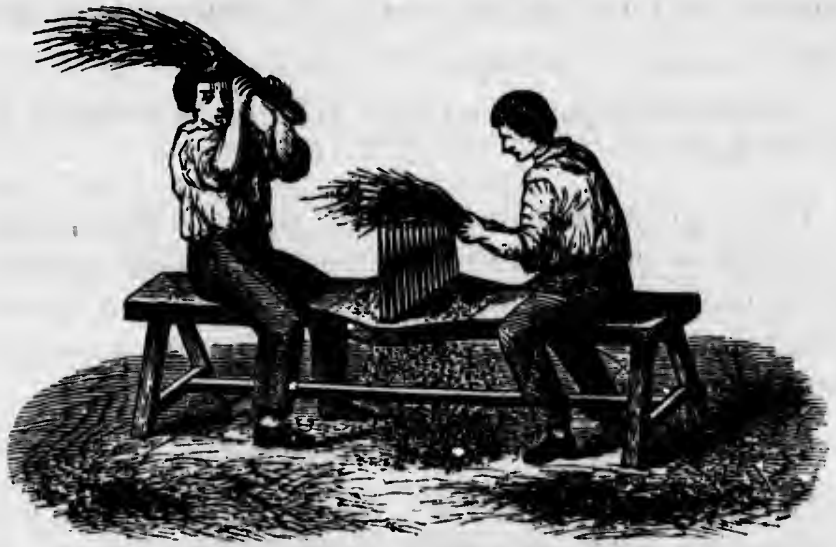

Fig. 100-Ouvriers égrenant à la drége.

En quoi consiste cette méthode?

La drége, ou grand peigne à une ou deux rangees de dents. se fixe sur un chevalet solide. L'ouvrier saisit les poignées de lin par la racine et frappe la tête sur le peigne en tirant à lui. Les capsules, ne pouvant passer entre les dents, tombent sur une toile placée sous le 
noitié des résento la de façon ont que la

ecte aucuplus belle graine des

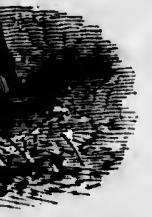

rangées de vrier saisit tête sur le vant passer cée sous le chevalet. On étend ensuite les capsules sur un plancher et quand elles sont bien sèches, on les bat au fléau pour en faire sortir la graine.

\section{Comment se font ces dreges?}

La drège est tout simplement un peigne dont les dents sont formées avec des baguettes de fer, carré ou rond, d'un demi-pouce, espacées d'une ligne et demie les unes des autres, de dix-huit pouces de longueur, appointies jusqu'à trois pouces de l'extrémité supérieure et taraudées dans un bout de madrier d'orme de trois ou quatre pouces d'epaisseur.

Quelle opération doit subir le lin après l'enlevement de la graine?

Le rouissage, qui se fait sur terre ou dans l'eau.

Quel est le but de cette opération?

C'est de décomposer les matières mucilagineuses ou la gomme qui retient les filaments ou la partie exífrieure de la tige, a la chènevote ou partie intérieure, qui est dure et ligneuse.

Commeni se fait le rouissage sur terre?

En étendant le lin en couche très mince sur l'herbe d'un pré et l'y laissant tant que, sous l'action de la rosée et du soleil, la filasse ne se détache pas de la chènevotte. Pour que le rouissage soit bien régulier, on retourne le lin quand le dessus est bien roui, ce qui prend trois ou quatre semaines, afin d'exposer pareillement le dessous à l'action de la rosée et du soleil. On le met ensuite en moyettes pour le faire achever de sécher et on l'engrange dans un endroit bien sec, en attendant le broyage. 
Comment se fait le rouissage dans l'eau?

En plaçant debout les bottillons de lin dans l'eau d'un étang ou d'une rivière, de façon à ce que l'eau les recou. vre complètement, ce qui donne une bien plus belle filasse que le rouissage en terre. Au bout de sept ou huit jours d'immersion, suivant les circonstances, on retire le lin de l'eau pour l'etendre, le faire bien sècher et l'engranger en attendant le broyage.

Quel est le but du broyage?

C'est d'ecraser ou de triturer la chènevote ou partie ligneuse du lin pour la détacher de la filasse.

Quelle opération doit subir le lin pour se bien broyer?

Le hallage ou la dessiccation dans un four ou sur un fourneau à cette fin, afin de rendre la chènevote aussi cassante et aussi friable que possible.

Comment se fait le broyage?

A bras, avec la broye ordinaire, ou à la machine, c'està-dire en passant le lin entre deux rouleaux cannelés, actionnés par un manège à cheval.

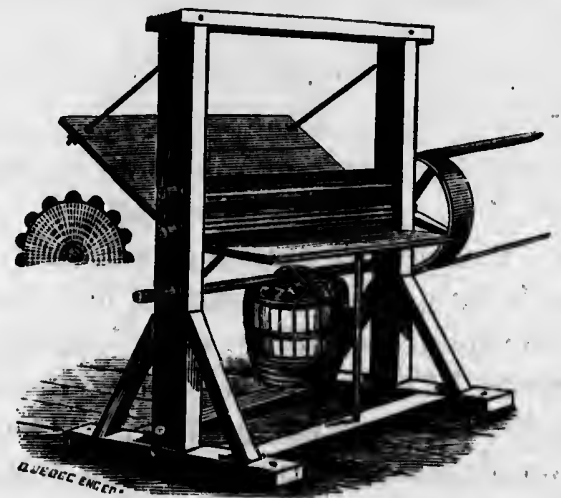

Fig. 101-Nachine à broyer. 
Comment enlève-t-on la chènevote du lin broyé ?

l'eau d'un i les recouplus bolle de sept ou nces, on rein sècher et

ou partie broyer? $r$ ou sur un. evote aussi ıchine, c'est'-, ix cannelés,
Par l'écanguage ou l'écochage, comme on dit dans notre pays.
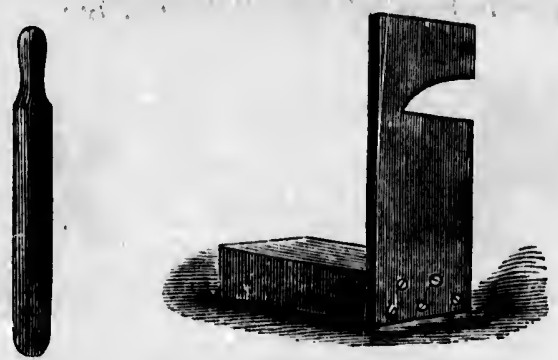

Fig. 102-Couteau et planche d écocher

Comment se fait l'écanguage?

A bras, en battant le lin avec un gros couteau en bois le long d'une planche à écocher ou à la machine, avec un appareil à cette fin.

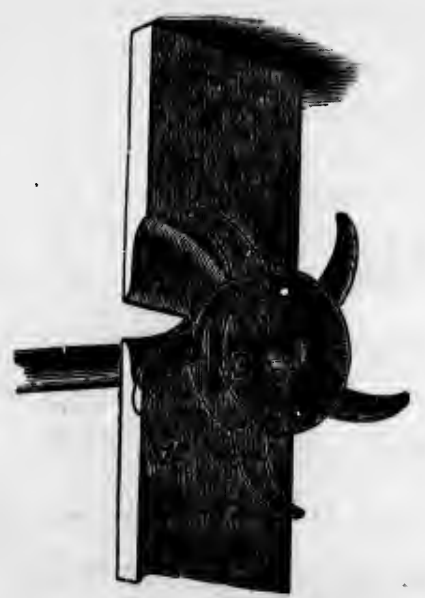

Fig. 103-Machine d̀ écocher 
Cominent achève-t-on de nettoyer la filasse?

En la passant dans un gros peigne qui démèle les fils, les refend et les débarrasse de toutes saletés. C'est ce qu'on appelle le peignage ou sérançage.

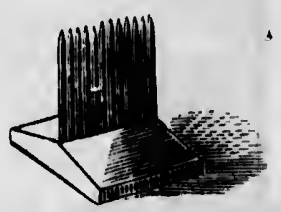

Fig. 104-Peigne \& filasse

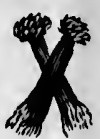

Fig. 105-Poignées de filasse 


\section{CHA PIT R X X}

\section{ASSOLEMENT OU ROTATION DES RÉCOLTES}

Qu'entendez-vous par assolement ou rolation des récoltes?

On entend l'ordre dans lequel les différentes plantes doivent se succéder dans une terre durant un certain nombre d'années, pour ne pas l'epuiser et en obtenir le plus de produits possible.

Sur quoi est fondée la théorie des assolements?

Sur les faits observés dans la pratique et sur les données fournies par la science, notamment la chimie.

Quels sont les faits, observés dans la pratique, qui font voir la nécessité des assolements?

Il est bien connu que lorsqu'on cultive une plante dans un même terrain durant plusieurs années consécutives, la végétation perd de sa force d'année en année, la récolte diminue et finit même par ne pas être suffisante pour indemniser des frais de culture.

Comment expliquez-vous ce phénomène?

Chaque plante puise dans la terre, pour se nourrir et se former, une certaine proportion d'éléments minéraux; mais cette proportion varie avec les différentes plantes, qui, n'ayant pas les mêmes exigences, peuvent se succéder avantageusement dans le même terrain. Ainsi le trèfle, la pomme de terre absorbent comparativement beaucoup de chaux, de potasse et d'autres 
alcalis, au lieu que le blé recherche de préférence les phosphates. Si vous cultivez durant plusieurs annees la pomme de terre dans un terrain, elle lui enlève presque tous les alculis qu'il renferme, mais elle laiseera le phosphate à peu près intact; si vous semez du blé dans ce terrain qui ne donne plus qu'une chétive récolte de pommes de terre, vous aurez une bonne récolte de ble, qui recueillera le phosphate laissé presque intact par la pomme de terre. Il suffit de jeter un coup d'œil sur les tableaux faisant voir la composition chimique des différentes plantes, pour se convaincre de la nécessité de la rotation des récoltes.

$Y$ a-t-il d'autres raisons quii expliquent la nécessité de la rotation des récoltes?

Oui, notamment la manière dont les plantes se nourrissent, se forment et se récoltent. Certaines plantes, telles que les céréales, ne développent leurs racines qu'à la surface du sol et n'épuisent, pour se nourrir, que la couche supérieure de la terre; d'autres plantes, telles que le trèfle, la luzerne, forment de longues racines qui pénètrent avant dans le sous-sol, où elles vont chercher leur nourriture; et n'enlèvent rien à la couche supé. rieure. Il est évident qu'en mettant après le trèfle, qui n'enlève rien à la couche supérieure, une céréale, qui ne forme que des racines superficielles, cette céréale profitera de toute la richesse que la croissance du trèfle aura laissé accumuler à la surface. De la même manière, le trèfle qui viendra après. la céréale bénéficiera de tout l'engrais que la croissance de la céréale aura laissé accumuler dans le sous-8ol. Enfin la racine et le bas de la tige du trèfle, qui restent dans lo sol après la fauchaison, constituent un engrais dont bénéficient les plantes qui viennent après. 
unce les années ve presseera le du ble récolte colte de $\theta$ intact up d'œil imique a néces-

té de la

se nourplantes, nes qu'à , que la is, telles ines qui shercher se supé. le trèfle, céréale, s, cotte oissance De la céréale $\theta$ de la Enfin ent dans ais dont

La nature même des cultures joue-t-elle aussi un certain rôle dans la rotation?

Oui. Il y a des cultures qui nettoient le sol et le préparent admirablement pour d'autres réco'tes. C'est ainsi que la culture des plantes sarclées, telles que le maïs, la pomme de terre et la betterave, débarrasse la terre des mauvaises herbes et la prépare admirablement pour le blé et les auires céréales, auxquelles les plantes adventices sont très nuisibles.

\section{Quel est le but de la rotation des récoltes?}

C'est de donner à la terre le plus haut degré de fécondité possible et de conserver cette fécondité, tout en tirant de la terre le plus de produits possible.

$Y$ a-t-il des formules, fixes pour les assolements ou les rotations de culture?

Non : il faut se guider sur les circonstances et certaines règles générales qu'un cultivateur sensé peut facilement appliquer à son exploitation.

Quelles sont ces règles générales?

On peut les résumer ainsi :

1. Alterner les récoltes fertilisantes et les récoltes épuisantes;

2. Alterner les cultures d'après la longueur de la racine des plantes, c'est-à-dire alterner les plantes à racines courtes et celles à racines longues;

3. Alterner les plantes selon les substances qu'elles absorbent pour se nourrir et se former;

4. Etendre autant que possible la culture des plantes fourragères. 
La rotation des cultures est-elle bien importante en agricullure?

C'est d'elle que depend le succès et même quand les différentes pratiques culturales sont un pou négligées dans les détails, un cultivateur réussit bien, amasse do l'argent et conserve sa terre en bon 6tat, s'il guide ses opérations sur un système de rotation raisonné et bien appliqué aux circonstances dans lesquelles il se trouve. 


\section{TABLE DE8 MATIERE8}

PAGES

AVERTIBSEMENT

3

Chapitre I

Notions préliminaires

5

Chapitre II

Notions générales sur la végétation

Chapitre JII

Du sol et des différentes espèces de terre

Chapitre IV

Qualités et défauts des différents sols-plantes qui leur conviennent

\section{- Chapitre V}

Amendements et engrais

8 1-Amendements 32

8 2-Des engrais

I. Engrais animaux............................... 44

II. Engrais liquides................................ 48

III. Matières fécales ................................ 50

Iv. Colombine ...................................... 53

v. Engrais végétaux............................. 54

vI. Engrais minéraux ............................... 58

vir. Engrais mixtes................................ 69 


\section{TABLE DES MATIÈRES}

PAGES

Chapitre VI .

Mise en culture 'u sol........................................ 87

\& 1-Déboisement .......................................... 87

\& 2-Epierrement........................................ 91

8 3-Assqinissement..................................... 92

\& 4-Des labour's ......................................... 100

\& 5-Du déchaumage..................................... 119

8 6-Du hereage .............................................. 122

8 7-Du roulage .......................................... 125

8 8-Des cultures d'entretien........................... 128

Chapitre VII

Ensemencement ................................................ 133

\& 1-Du semis................................................... 138

\& 2-Recouvrement de la semence................... 147

Chapitre VIII

De la récolte ................................................. 151

\& 1-Moisson ............................................. 153

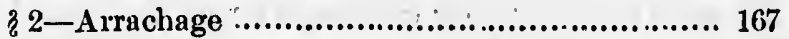

\& 3-Fenaison............................................ 169

\& 4-Ensilage.......................................... 176

Cha PITRE IX

Prairies et paturages.......................................... 185

Cirafitre X

Art agricole.................................................. 209

\& $\mathrm{i} .-\mathrm{Du}$ ble ou froment.................................. 210

Choix et préparation de la semence.............. 216

Ciimat et sol........................................... 219

Place du blé dans la rotation...... ............... 220

Fumure et engrais................................... 221

Préparation du sol..................................... 223

Ensemencement et quantite de semence........ 225

Soins d'entretien ..................................... 229 


\section{TABLE DES MATIERES}

PAGES
PAGES

Moisson 233

Engrungement et battage du blê.

? 2-Du seigle

Climat et sol 235

\& 3-De l'orge 236

8 4-De l'avoine 237

5-Du sarrasin. 241

\& 6-Des pois

7-Des fèves

\& 8-De lu lentille et de la vesce

8 9-Du maìs ou ble d'Inde.

10-Des pommes de terre

\& 11-De la betterave.

8 12-De la carotte

8 13-Des navets $2+4$

8 14-Du lin 251 256 259 262 263 277 285 293 295 299

\section{Chapitre XI}

Assolement ou rotation des récoltes. 313 


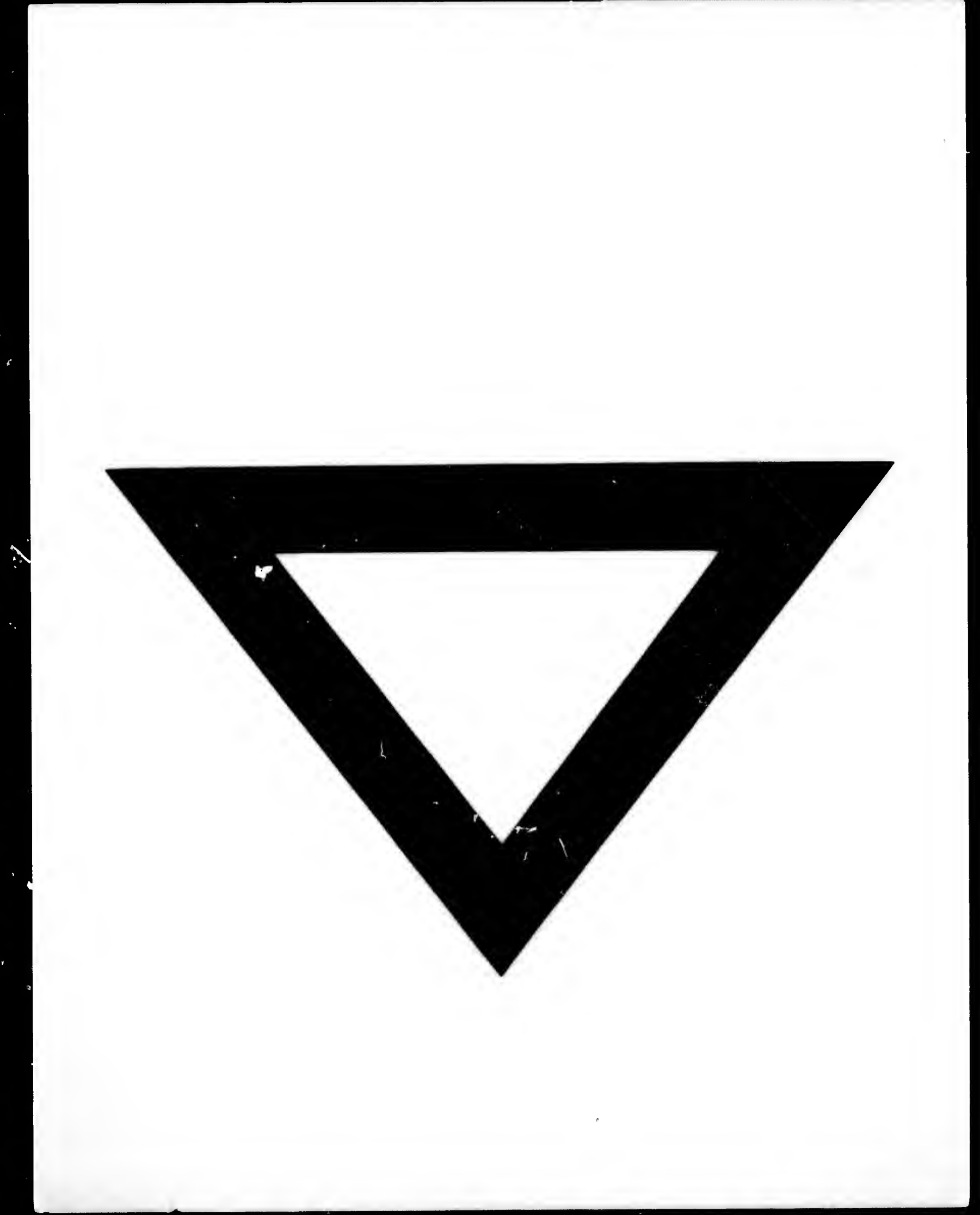

